\title{
Handbook of Recommendea Practices for the Determination of Liquid Monopropellant Rocket Engine Performance
}

\author{
JET PROPULSION LABORATORY \\ CALIFORNIA INSTITUTE OF TECHNOLOGY \\ PASADENA, CALIFORNIA 91103 \\ AUTHORS: R. A. BUORKLUND \\ R. S. ROGERO \\ R. K. BAERWALD \\ JUNE 1979
}

Approved for Public Release;

Distribution unlimited

\begin{abstract}
PREPARED FOR:
AIR FORCE ROCKET PROPULSION LABORATORY DIRECTOR OF SCIENCE \& TECHNOLOGY

AIR FORCE SYSTEMS COMMAND

NATIONAL AERONAUTICS \& SPACE ADMINISTRATION WASHINGTON, D.C.

EDWARDS AFB, CALIFORNIA 93523
\end{abstract}

EProDucel aY

NATIONAL TECHNICAL

INFORMATION SERVICE

US. DEPARIMEMT OF COUHERCE SPRinefito, VA. zis! 
NOTICES

When U.S. Government drawings, spectfications, or other data are used for any purpose other than a definitely related government procurement operation, the Government thereby incurs no responsibility nor any obligation whatsoever, and the fact that the Government may have formulated, furnished, or In any way supplied the sald drawings, specifications or other data, is not to be regarded by implication or otherwise, or in any manner licensing the holder or any other person or corporation; or conveying any rights or permission to manufacture, use, or sell any patented invention that may in any way be related thereto.

FOREWORD

The work was prepared by the Control and Energy Conversion Division, Jet Propulsion Laboratory, California Institute of Technology, and was fointly sponsored by the Air Force Rocket Propulsion Laboratory, Edwards AFB, California, through a MIPR F0-4611-76-X-0053 with NASA and by the National Aeronautics and Space Administration under Contract NAS7-100.

Th1s report has been reviewed by the information office/XOJ and is releaseable to the National Technical Information Service (NTIS). At NTIS it will be available to the general public, Including foreign nations. This technical report has been reviewed and is approved for publication; it is unclassified and suitable for general public release.

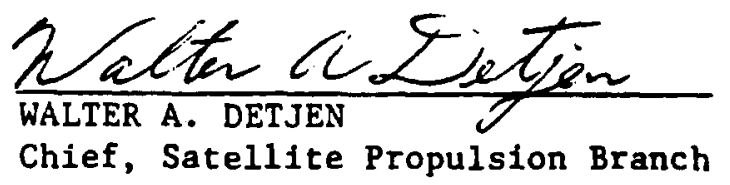

FOR THE COMMANDER

Elavard E Stion

EDWARD E. STEIN, Deputy Chief,

Liqu1d Rocket Div1sion 


\section{GENERAL DISCLAIMER}

This document may have problems that one or more of the following disclaimer statements refer to:

- This document has been reproduced from the best copy furnished by the sponsoring agency. It is being released in the interest of making available as much information as possible.

- This document may contain data which exceeds the sheet parameters. It was furnished in this condition by the sponsoring agency and is the best copy available.

- This document may contain tone-on-tone or color graphs, charts and/or pictures which have been reproduced in black and white.

- The document is paginated as submitted by the original source.

- Portions of this document are not fully legible due to the historical nature of some of the material. However, it is the best reproduction available from the original submission. 
SECURITYCLASSIFICATION OF THIS PAGE (When Date Eniorod)

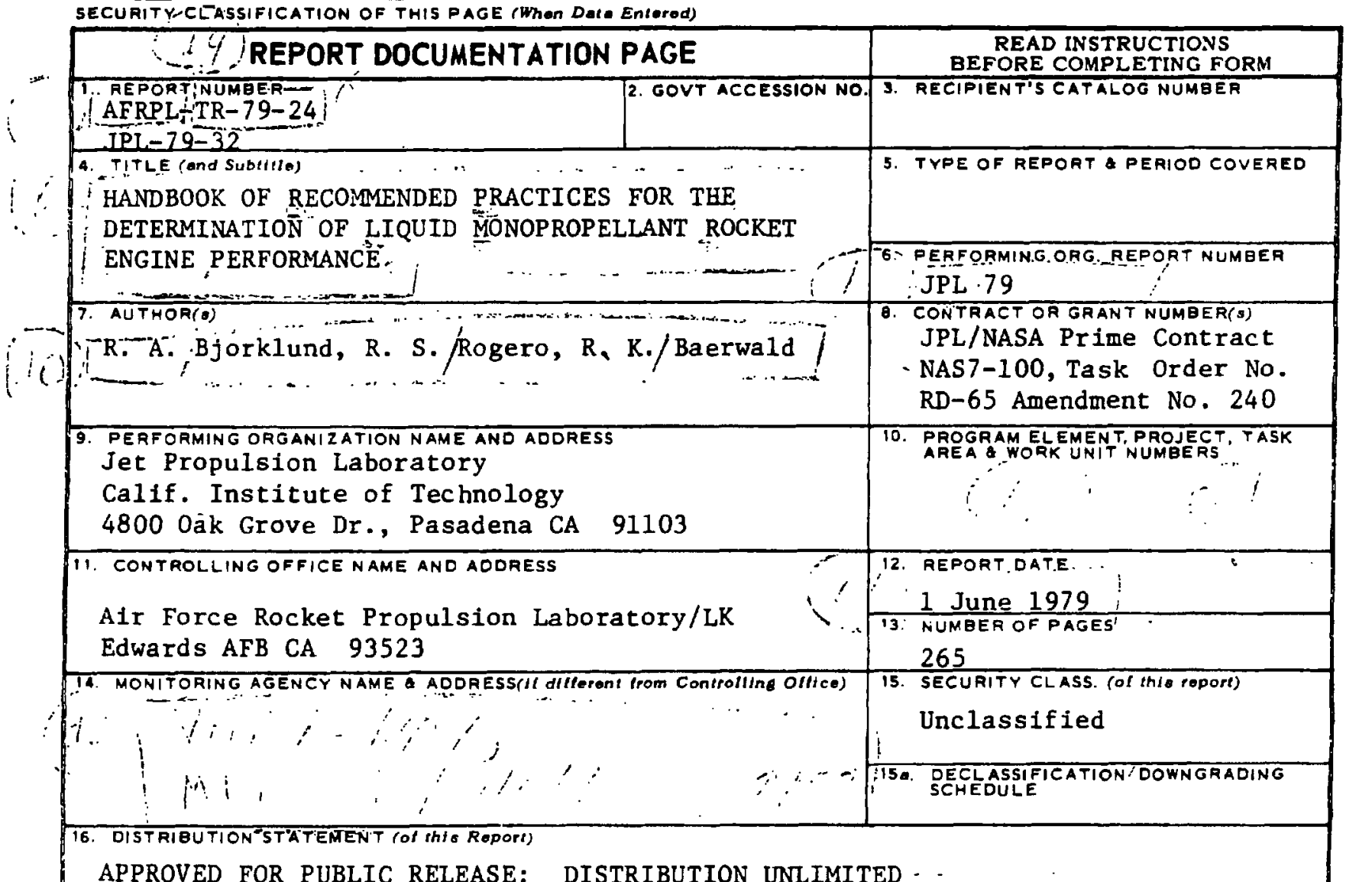

APPROVED FOR PUBLIC RELEASE: DISTRIBUTION UNLIMITED -

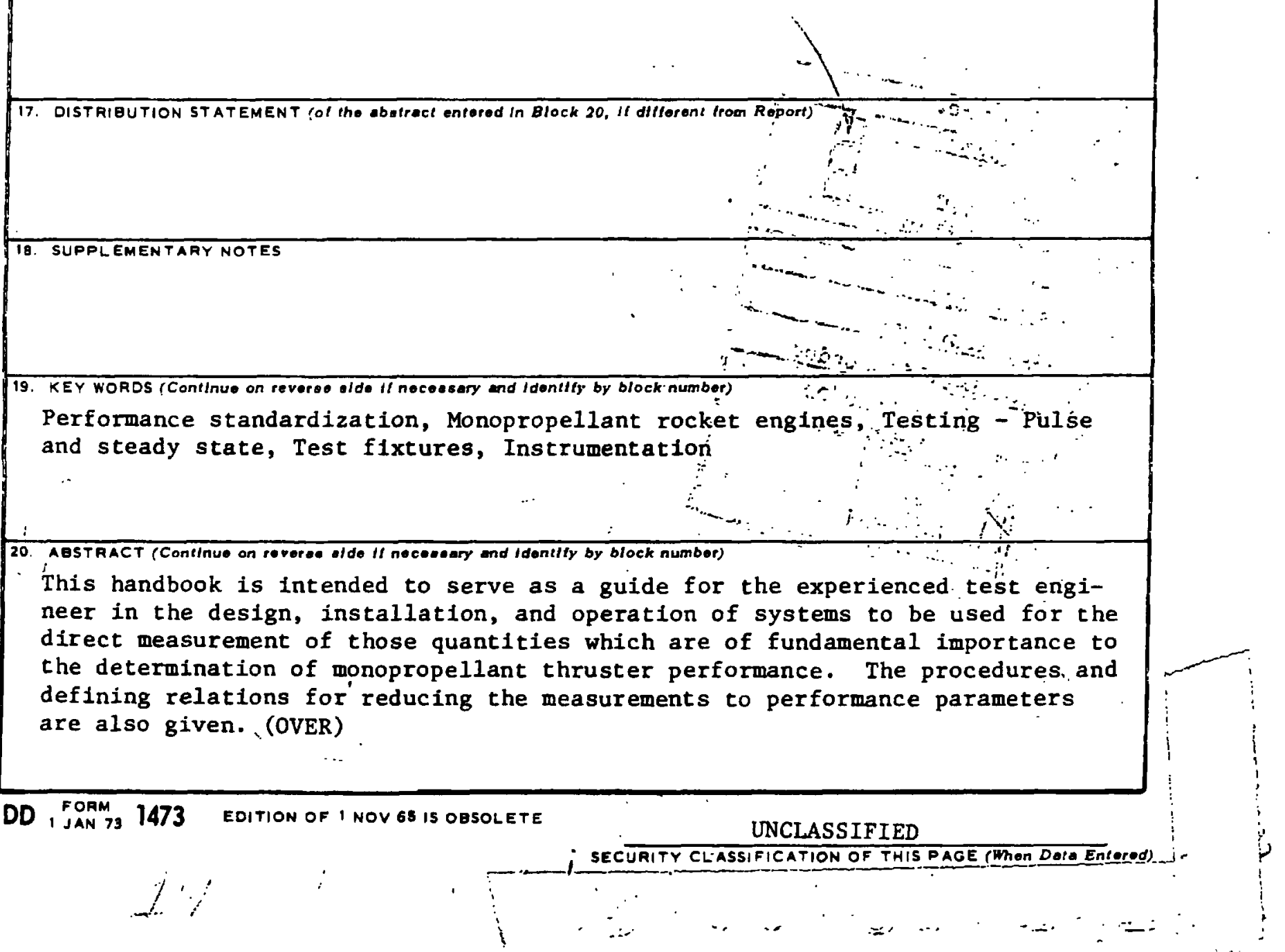


This handbook is composed of six discrete sectlons pertaining to force and Impulse measurement, propellant mass usage and flow measurement, pressure measurement, temperature measurement, exhaust gas composition measurement, and data reduction and performance determination. References, appendixes, and glossarles are included with each section as necessary.

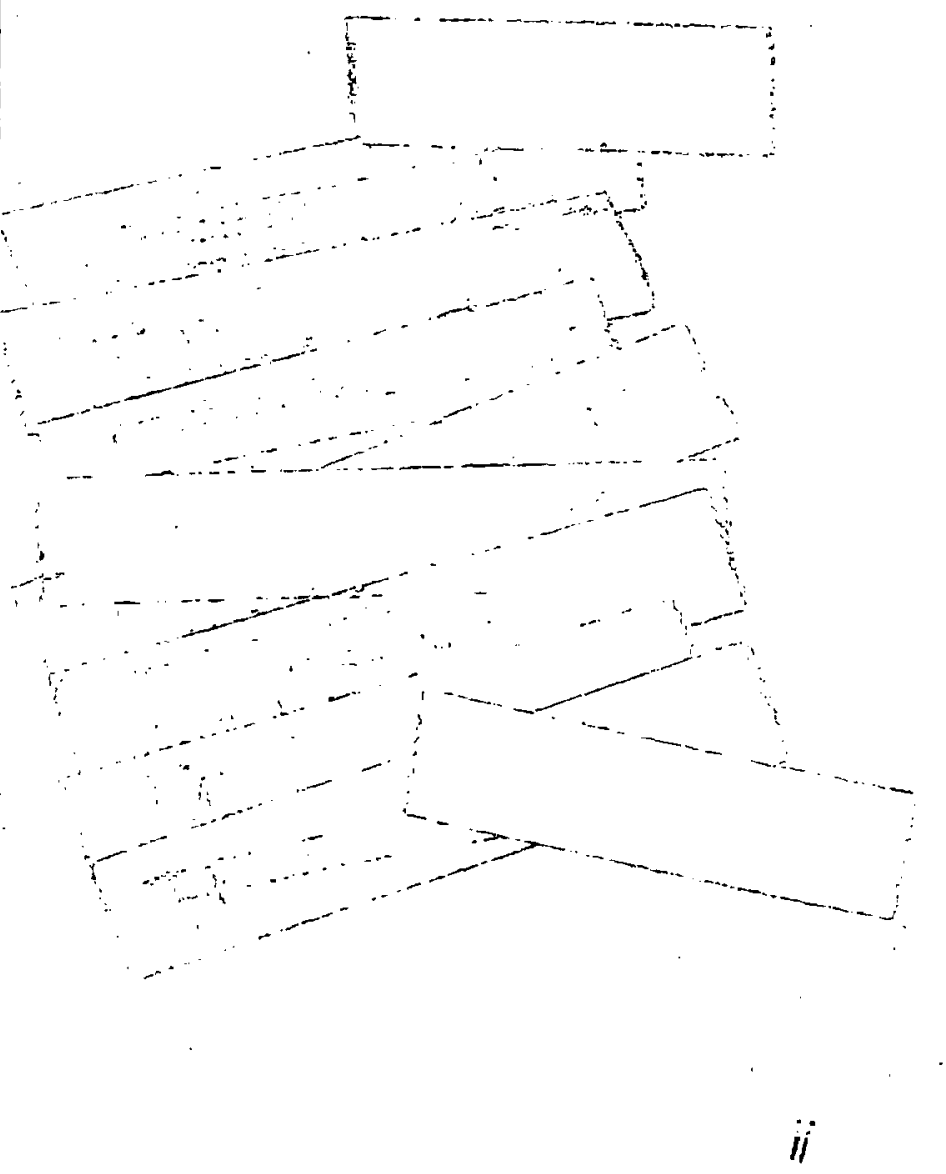


This Handbook of Recommended Practices for the Determination of Liquid Monopropellant Rocket Engine Performance has the objective of promoting a uniformity of methodology throughout the monopropellant community as regards to pulse mode and steady state thruster testing and data reduction. The program was conceived within a Joint Army-NavyNASA-Air Force (JANNAF) monopropellant working group, consisting also of representatives from industry and academia, to fill what was felt to be a universal need for such standardization of practices among the manufacturers and users of monopropellant rocket engines.

The JANNAF Rocket Engine Performance Working Group has devoted considerable effort toward the development of a consistent methodology for determining rocket engine performance. However, the publications of the JANNAF Rocket Engine Performance Working Group are directed primarily toward bipropellant engines operating at steady state conditions and are, therefore, not directly applicable to the performance determination of monopropellant engines which may operate primarily in the pulse mode. However, the Handbook of Recommended Practices of Measurement of Liquid Propellant Rocket Engine Parameters, Chemical Propulsion Information Agency (CPIA) Publication No. 179, and Rocket Engine Performance Test Data Acquisition and Interpretation Manual, CPIA Publication No. 245, both published by the JANNAF Rocket Engine Performance working Group, have served as excellent guides for the development of the current document.

This handbook is intended to serve the experienced test engineer in the design, installation, and operation of systems which include the determination, by direct measurement, of rocket engine thrust and impulse, propellant mass flow, pressure, temperature, and exhaust gas composition. The algorithms and defining relations for reducing these measurements to performance parameters are also given. This document is not intended to serve as a primer for the inexperienced engineer, as the depth required for such a publication is clearly beyond the scope of this or any other single document. Specific design guidelines are, however, offered for the critical components of each system.

This handbook is divided into six relatively discrete sections. These sections are presented in the following order:

- Force and Impulse Measurement

- Propellant Mass Usage and Flow Measurement

- Pressure Measurement

- Temperature Measurement

- Exhaust Gas Composition Measurement

- Data Reduction and Performance Determination 
Each of the sections includes a table of contents, glossary, references, and appendixes as necessary.

To achieve the uniformity of data acquisition and interpretation which is the goal of the handbook, it is recommended that the procedures and practices outlined herein be required for all RFQ's and contracts. This recommendation implicitly includes also adherence to CPIA Publication No. 180 , ICRPG Handbook for Estimating the Uncertainty in Measurements Made With Liquid Propellant Rocket Engine Systems. Deviations from these procedures should be specifically negotiated.

This handbook has been formatted for reprint as a CPIA publication. It is probable that its use by the monopropellant community will result in recommendations for additions or revisions. These comments are welcomed and may be addressed to the authors at JPL, the program sponsors at AFRPL and NASA/OAST, or, in the case of the CPIA version, to:

\author{
Chemical Propulsion Information Agency \\ Johns Hopkins University \\ Applied Physics Laboratory \\ 8621 Georgia Avenue \\ Silver Springs, Maryland 20910
}


This handbook was produced under the joint sponsorship of the U.S. Air Force Rocket Propulsion Laboratory (AFRPL) and the National Aeronautics and Space Administration, Office of Aeronautics and Space Technology (NASA/OAST). Program managers at AFRPL included Mr. Paul Erickson, Lt. Vince Broderick, and Capt. Dennis Gorman. Mr. Frank Stephenson was the program manager at NASA/OAST.

The development of this handbook involved the efforts of almost the entire monopropellant community. A considerable expenditure of time and energy was contributed by those organizations which supplied materials or comments in response to the comprehensive survey questionnaire which was distributed throughout the monopropellant and bipropellant community. The following individuals and organizations deserve much credit for their efforts in this regard (listed alphabetically):

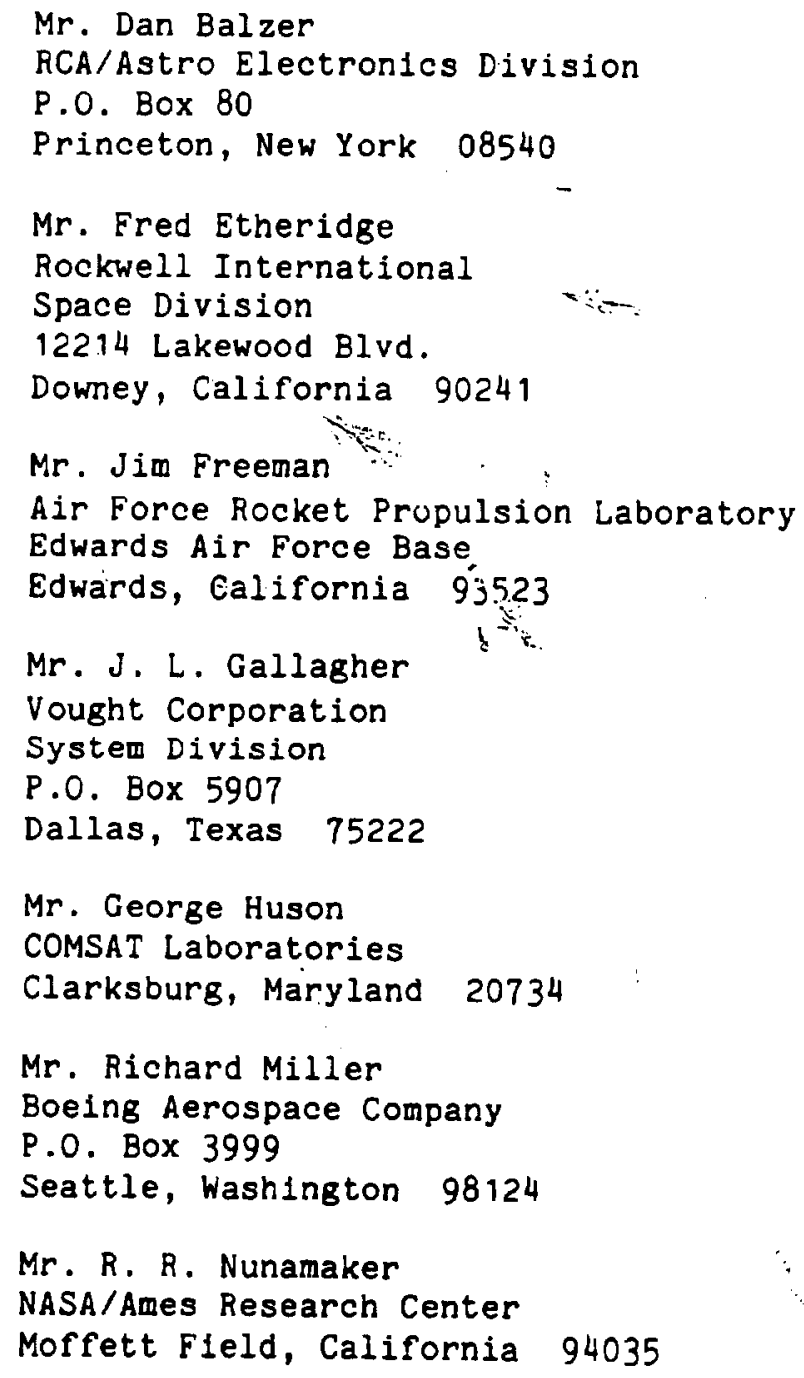


Mr. R. David Steel

Martin Marietta Corporation

P.O. Box 179

Denver, Colorado 80201

Mr. Norm Stern

Aeroneutronic Ford Corporation

One Ford Road

Newport Beach, California 92663

Mr. Thomas E. Williams

NASA/Goddard Space Flight Center

Greenbelt, Maryland 20771

By far the most comprehensive responses were supplied by the rocket engine manufacturers themselves. This seems to be due not only to the fact that the manufacturers have the most sophisticated and complete rocket engine test facilities, but also to a genuine interest on the part of the manufacturers in the production of this handbook. Excellent responses were received from the following (alphabetically):

Mr. T. E. Hudson

The Marquardt Company

16555 Saticoy Street

Van Nuys, California 91409

Mr. Milt Marcus

Hamilton Standard

Bradley Field Road

bindsor Locks, Connecticut 06096

Mr. V. A. Moseley

Bell Aerospace Company

P.0. Box One

Buffalo, New York 14240

Mr. Robert Sackheim

TRW Systems Group

One Space Park

Redondo Beach, California 92078

Mr. Bruce Schmitz

Rocket Research Corporation

York Center

Redmond, Washington 98052

Mr. Walter Schubert

Pratt \& Whitney Aircraft

Florida Research and Development Center

P.0. Box 2691

West Palm Beach, Florida 33902

In addition to the written responses, much additional information was obtained from visits to select organizations. This provided 
the authors with the opportunity to see firsthand the test facilities involved and to have explained the rationale behind the various measurement philosophies and data reduction procedures.

The following organizations were gracious enough to give of their time in this manner (alphabetically):

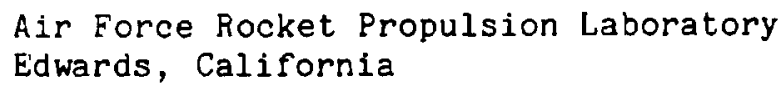

The authors would like to take this opportunity to express their appreciation for the cordial way in which they were received and for the hospitality extended to them by the above organizations.

Following acquisition of the information which was gathered in the manner described above, a draft of the six handbook sections was produced and distributed to over 32 members of the monopropellant community. Several months were allowed for a review and critique of the proposed recommended practices.

In addition to those members and organizations of the monopropellant thruster community, gratitude is expressed to the following individuals for taking the time to review and comment in detail upon various sections of the draft document: Mr. Phil Bliss, Intersociety Director, Instrument Society of America; Mr. Pierre F. Fuselier (retired), 
Lawrence Livermore Laboratory; Mr. Jon Inskeep, Jet Propulsion Laboratory; Mr. Frederick Williams, Eastern Standards Laboratory, Dept. of the Navy; $\mathrm{Mr}$. Philiip Scott, the Foxboro Company; and Mr. Donald Eond, Jet Propulsion Laboratory.

It must be pointed out that not all comments received from the various reviewers were incorporated into the final document and the acknowledgments given here do. not imply the unqualified endorsement of the handbook by any individual or organization. Some of the changes suggested by the reviewers would have caused an increase in the scope of the task and would have resulted in unacceptable publication delays and fiscal complications. Some reviewers contradicted one another rather strongly and, in other cases, the authors disagreed with the comments offered. It is felt, however, that none of the required compromises have worked to the detriment of the usefulness or accuracy of the document. 
CONTENTS

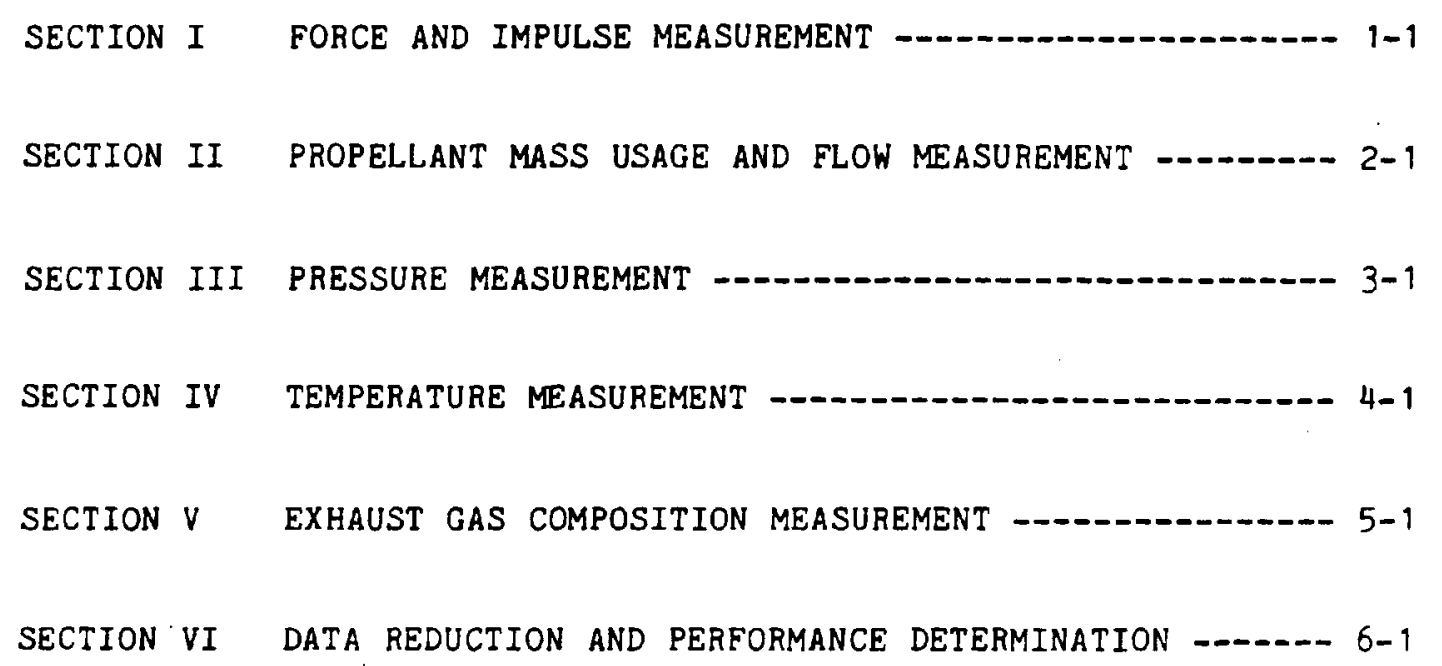




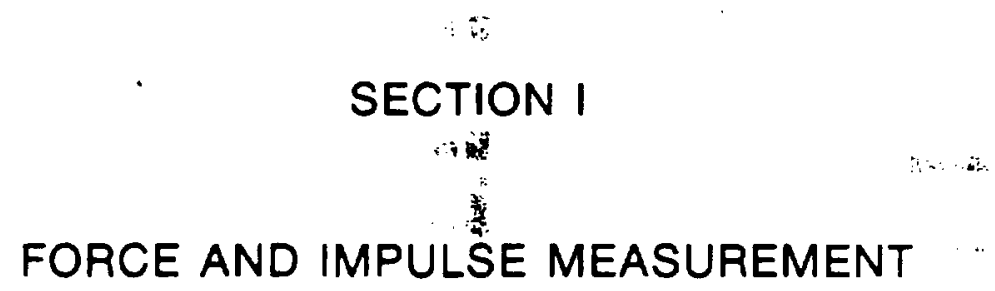

1.1 
SECTION I

FORCE AND IMPULSE MEASUREMENT

CONTENTS

1.0

INTRODUCTION -

2.0

SCOPE

$1-1$

2.1

OBJECTIVE

$1-1$

2.2

LIMITATIONS

$1-2$

3.0

DESIGN CONSIDERATIONS

$1-2$

3.1

MECHANICAL COMPONENTS

$1-2$

3.1 .1

Thrust Stand

$1-4$

3.1 .2

Measurement Force Transducer

$1-6$

$3 \cdot 1 \cdot 3$

Calibration Equipment

$-12$

3.2

ELECTRICAL AND ELECTRONIC COMPONENTS

3.2 .1

Signal Conditioning Equipment

$-15$

3.2 .2

Electrical Calibration Equipment

$-18$

3.2 .3

Recording Equipment

$-18$

3.2 .4

Visual Display Equipment

$-18$

3.2 .5

Data Processing Equipment

$1-19$

4.0

INSTALLATION AND CHECKOUT PROCEDURES -

4.1

COMPONENT CERTIFICATION

4.1 .1

Force Transducer

$1-19$

4.1 .2

Calibrator Dead Weights

$1-25$

4.1 .3

Thrust Stand Flexures and Restraints

$1-25$

4.1 .4

Dynamic Force Calibrator

$1-25$

$$
1-i a)
$$



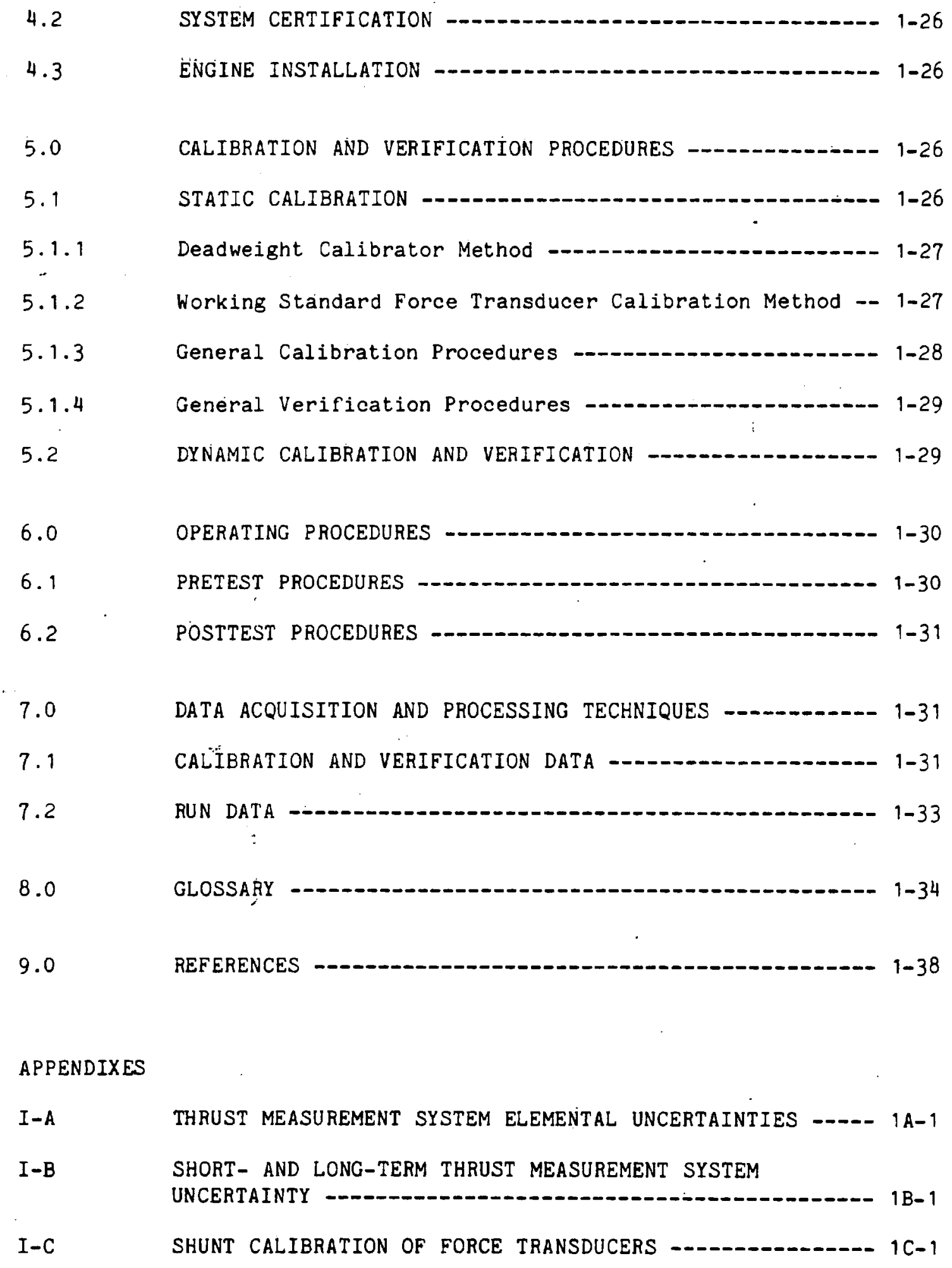


\section{Eigures}

1-1 Mechanical Components of a Vertical Single Element Axial Thrust Measurement Stand _._._. 1-3

Conventional 6-Wire Strain Gage Bridge Transducer -..-- 1-9

$1-3$

Thrust Measurement System Block Diagram

$1-4$

Abnormal Loading Effect, Test Installation -...-.-.-. 1-24

$1-B-1$

Example of Control Data for

Uncertainty Checks _...... 1B-3

1-B-2 Block Diagram of Short- and Long-Term

Uncertainty Checks -

1-C-1 Shunt Calibration Circuit Configuration $\ldots \ldots \ldots \ldots . . .-1 C-2$ 
SECTION I

FORCE AND IMPULSE MEASUREMENT

\subsection{INTRODUCTION}

Recommended practices are outlined for the design, installation, checkout, calibration, and operation of a thrust measurement system to be used during tests of a liquid monopropellant rocket engine. Three appendixes are included: I-A, Thrust Measurement System Elemental Uncertainties; I-B, Short- and Long-Term Thrust Measurement System Uncertainty; and I-C, Shunt Calibration of Force Transducers.

\subsection{SCOPE}

This section has been written to serve as a guide for the experienced engineer in the design, installation, and operation of a measurement system for measuring the thrust and impulse produced by a liquid monopropeliant rocket engine. No attempt has been made to specify the detailed configuration for any portion of the measurement system, but rather specific design guidelines are provided for the critical components of each portion of the system. These guidelines, used in conjuction with current, state-of-the-art, commercially available equipment and good engineering practices, will provide a measurement system which meets the performance criteria specified.

\section{$2.1 \quad$ OBJECTIVE}

The thrust to be measured is derived from the catalytic decomposition of monopropellant hydrazine in the reaction chamber of a rocket engine at pressures ranging from 69 to $3450 \mathrm{kN} / \mathrm{m}^{2}$ ( 10 to 500 psia). These engine tests are normally conducted in a vacuum chamber where simulated altitudes of $30 \mathrm{~km}(100,000 \mathrm{ft})$ or higher can be maintained. The recommended practices contained in this section are directed specifically to measurements of thrust and impulse having the following uncertainties.

\begin{tabular}{|c|c|c|c|}
\hline Thrust Range & Mode of Operation & Uncertainty & in Measurement \\
\hline \multirow{2}{*}{$\begin{array}{l}0.044 \text { to } 44 \mathrm{~N} \\
(0.01 \text { to } 101 \mathrm{br})\end{array}$} & Steady state & $\pm 0.5 \%$ & Thrust \\
\hline & $\begin{array}{l}\text { Pulsed mode, } 5 \mathrm{~ms} \\
\text { min. on time }\end{array}$ & \pm 5.08 & Impulse \\
\hline \multirow{2}{*}{$\begin{array}{l}44 \text { to } 4400 \mathrm{~N} \\
(10 \text { to } 1000 \text { lbf })\end{array}$} & Steady state & $\pm 0.25 \%$ & Thrust \\
\hline & $\begin{array}{l}\text { Pulse mode, } 50 \mathrm{~ms} \\
\text { min. on time }\end{array}$ & $\pm 2.0 \%$ & Impulse \\
\hline
\end{tabular}


The recommended practices in this section are limited to thrust measurements of a single monopropellant hydrazine rocket engine. There is no fundamental reason why these practices would not be applicable to other types of monopropellant thrusters or even bipropellant rocket engines if certain environmental factors peculiar to the specified propellant(s) are accommodated. Additional limitations are listed below:

(1) Only those thrust systems that infer a force from a bonded metallic strain gage transducer are considered in this section. Specialized applications requiring higher transducer electrical output, extended highfrequency response, miniature size and/or weight or some combination of these characteristics may necessitate other transduction techniques. For the vast majority of force measurements related to monopropellant rocket engines, however, the bonded metallic strain gage transduction element is the recommended choice.

(2) Test cell simulated altitude pressure should be maintained at a level which assures design exhaust nozzle flow characteristics.

(3) Temperature conditioning should be limited to a practical operating range as determined for the specified spacecraft environment designed to use monopropellant hydrazine.

(4) The minimum pulsed thrust duration is limited by the propellant control valve operating time. For low thrust, below $44 \mathrm{~N}$ ( $10 \mathrm{lbf})$, this could be as short as $5 \mathrm{~ms}$; however, at higher thrust, above $44 \mathrm{~N}$ (10 lbf), a more practical limit is about $50 \mathrm{~ms}$.

\subsection{DESIGN CONSIDERATIONS}

The design of a thrust measuring system requires consideration of certain key mechanical, electrical, and electronic components which must be incorporated. Mechanical components include the thrust stand, a measurement force transducer and the force calibration equipment. Electrical and electronic components include electrical calibration, signal conditioning, recording, visual display and data processing equipment.

\subsection{MECHANICAL COMPONENTS}

A typical arrangement of the major mechanical components in a vertical, single element, axial thrust measuring stand is shown in Figure 1-1. These components are identified as follows:

\section{(1) Thrust frame into which the rocket engine assembly} is mounted. 


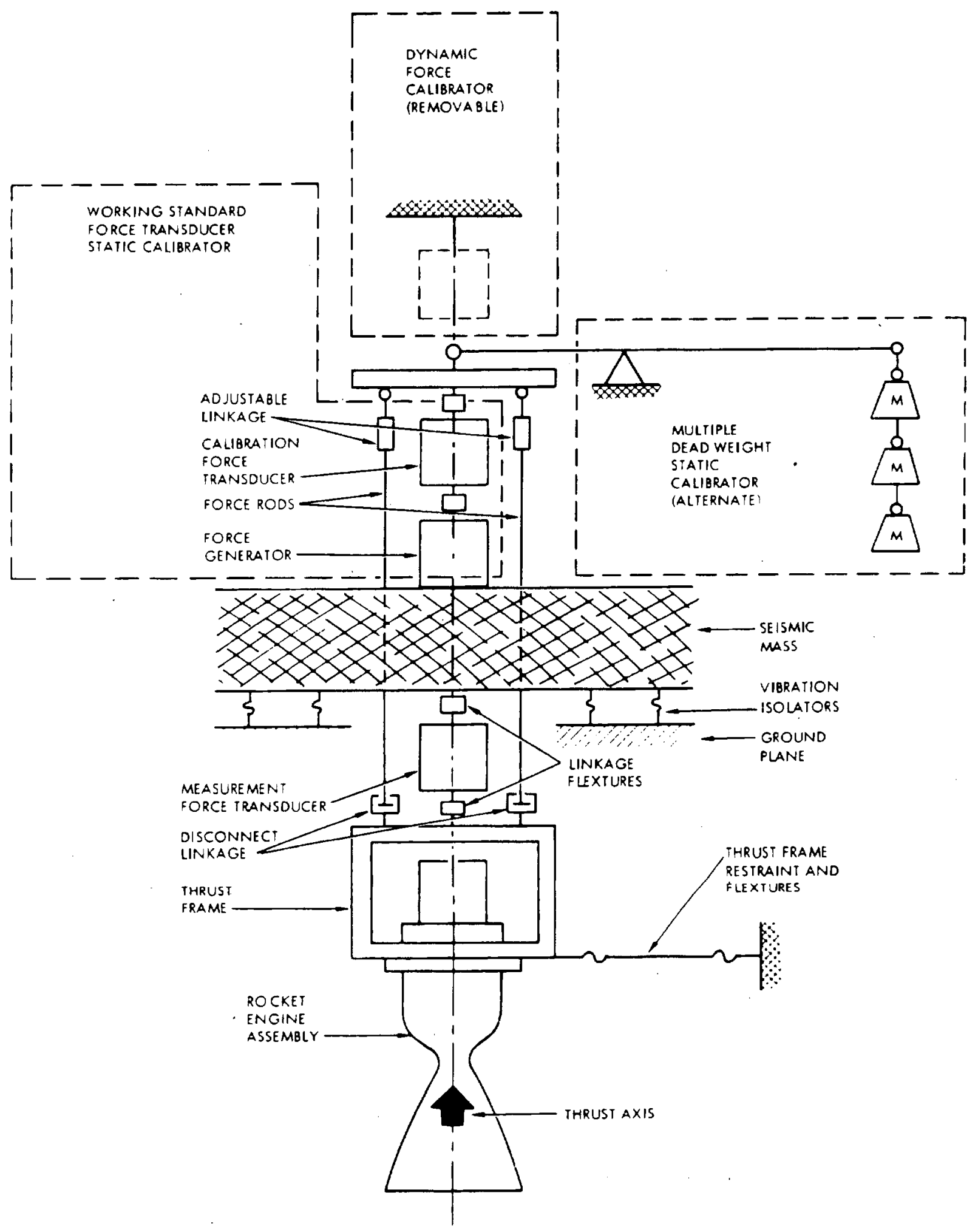

Figure 1-1. Mechanical Components of a Vertical Single Element Axial Thrust Measurement Stand 
(2) Measurement force transducer with mechanical Iinkages and flexures.

(3) Seismic mass with vibration isolators attached to the ground plane.

(4) Thrust frame restraints and flexures attached to the seismic mass.

(5) In-place static force calibrator of either the multiple dead weight type or the working standard force transducer with force generator type.

(6) Dynamic force calibrator which is normally removed during engine testing.

A horizontally orlented thrust measuring stand will have the same basic components. Additional flexural supports would normally be required for the thrust frame.

As shown in Figure 1-1, the measurement force transducer is normally linked mechanically between the thrust frame and the seismic mass with flexures. An alternate method for the optimum high-response pulsed thrust stand would be to eliminate the flexures and use hard mounting on both ends of a ruggedized force measurement transducer. The rocket engine thrust frame assembly is restrained by struts containing pairs of flexures so that movement along only the thrust axis is permitted. The geometric centerline of the axisymetrical engine is show to coincide with the thrust measurement axis. Forces applied by the static calibrator should also coincide with the thrust measurement axis. The interaction of the thrust system components that takes place during engine testing should be faithfully duplicated by in-place calibration techniques.

3.1 .1

Thrust Stand

The following considerations are of primary interest in the design of a thrust measuring stand:

(1) The thrust stand should be designed to have a large seismic mass to engine-thrust frame mass ratio $\left(\mathrm{m}_{s} / \mathrm{m}_{e}\right)$. Experience has indicated that this ratio should be greater than 20:1 with values around 500:1 desirable.

(2) The seismic mass should be well isolated from vibration by the test chamber and ground plane.

(3) Transverse restraints used to counteract forces and moments generated by the engine should be designed to limit their axial restraint to less than $0.15 \%$ of the axial force applied.

(4) Transverse restraints should be installed perpendicular to the main axis of thrust. 
(5) Transverse restraints should be designed to withstand at least $20 \%$ of the axial force because forces of this magnitude may be developed during the start transients or during engine failures.

(6) Transverse restraints should be attached between the thrust frame and the selsmic mass so that engine changes can be made without disturbing the thrust stand alignment.

(7) Propellant and purge lines should be installed so that they serve as elastic pivots.

(8) Propellant and purge lines should be installed nominally perpendicular to the main thrust axis to balance forces and moments, and to minimize the effect of fluid flow, temperature, and pressure variations on thrust measurements. Flexible propellant lines should be avoided unless it can be demonstrated, through calibration procedures, that the effects of system pressurization are negligible.

(9) The thrust frame structure should be designed to deflection limits rather than stress limits. A very stiff lightweight structure will have a natural frequency high enough to ensure accurate response to pulsed thrust inputs and oscillations that will not influence steady state thrust measurement. A natural frequency in excess of 200 $\mathrm{Hz}$ is attainable. Environmental changes which may affect the alignment and restraint should be thoroughly evaluated.

(10) Safety stops should be used to limit engine motion if a thrust frame member fails during a test because of fatigue, overload, or other hardware failures.

(11) Safety stops should be set for a clearance of at least 4 times the rated deflection.

(12) The measurement force transducer must be protected from inadvertent overloads during installation and removal of the test engine assembly by suitable mechanical stops. If this is not practical the force transducer should be removed during these operations.

(13) Lost motion in the axial load column should be eliminated.

(14) Clearance must exist between fixed and movable parts of the thrust frame over the range of interest of system deflection.

(15) Targeis should be installed for allgnment purposes.

(16) Locating jigs and indexes should be built into the stand to facilitate proper alignment. 
(17) Thermal load on the thrust stand should be minimized through the use of radiation shields, conductive insulators, or thermal compensating elements.

3.1 .2

Meàsurement Force Transducer

These recomended practices are limited to thrust systems that measure force with a bonded metaliic strain gage force transducer, commonly referred to as a load cell. The load-carrying structure of the force transducer is normally machined from a single piece of heattreated metal. The elastic deformation of this structure" is sensed by attached strain gage elements. These strain gages are electrically connected in a wheatstone bridge circuit which can be balanced at no load. The application of a force to the load structure produces resistance changes in the strain gages, thus unbalancing the bridge circuit. The resultant output signal is directly proportional to the applied force and the excitation voltage. Standard design specifications for straln gage force transducers are given in ISA-S 37.8, Reference 1-i. The following is a sumary of these basic design considerations as they apply to a thrust stand force transducer.

\subsubsection{Mechanical Design}

(1) The type of force transducer is determined by the direction of the applied load as tension, compression, or universal, combining both tension and compression. The universal type would normally be used in thrust stands. Where preloading is used a compression type could be employed.

(2) The physical dimensions, type of mounting, mounting dimensions, and type of force connection will vary with manufacturer, but all transducers can generally be adapted for thrust stand installation.

(3) The load-line linkage from the thrust frame to the force transducer should be designed such that only axial loads are transmitted. When using a directly connected load line, flexural linkages are normally used on both ends of the transducer. Preloaded installations use a hard mount on the fixed end and point contact on the active end to eliminate off-axis loads.

(4) A series installation of force transducèrs for redundant thrust measurement is not recommended.

(5) A parallel installation of force transducers is not recommended for single-component axial thrust measurement. This arrangement reduces the output signal sensitivity and compounds inaccuracies and nonreliability. 
(6) The electrical connections can be either multipin standard connectors mounted on the transducer outer case or a flexible cable providing the required conductors and shielding for each bridge circuit.

(7) Load range selection should be made such that the transducer is normally operating over the 75 to $90 \%$ portion of its full scale range. An overload of 150\% of full scale range should produce no degradation in specifications. The ultimate rating for structural failure should be $300 \%$ of capacity or greater.

(8) Derated (downranged) force transducers are used to increase overload capability, increase thrust system stiffness and therefore dynamic measurement response, or extend the static force measurement range to lower values. If derated by a factor of $10: 1$ or more, the force transducer will probably have to be specially selected and thermally compensated to obtain the desired accuracy.

(9) Deflection of the force transducer's strain element must be minimized to keep the thrust stand total deflection low and dynamic response high. Total deflection over the full scale load of 0.044 to $4400 \mathrm{~N}$ (10 to 1000 lbf $)$ varies from 0.0013 to $0.013 \mathrm{~cm}(0.0005$ to 0.005 in.) depending on the type of strain element used.

(10) The natural frequency of the transducer should be several times greater than the thrust stand resonant frequency; a value of $1000 \mathrm{~Hz}$ or higher is recommended.

(11) A safe operating temperature range that is compatible with the test cell environment and that will not cause permanent calibration shift or permanent change in any of its characteristics should be specified for the force transducer. Normal compensated temperature range should be around $0^{\circ}$ to $66^{\circ} \mathrm{C}\left(32^{\circ}\right.$ to $\left.150^{\circ} \mathrm{F}\right)$. Maximum operating and storage temperature range should be around $-54^{\circ}$ to $+93^{\circ} \mathrm{C}\left(-65^{\circ}\right.$ to $\left.+200^{\circ} \mathrm{F}\right)$. Extended temperature ranges are possible with special design provisions. Due to the highly transient nature of the operating temperature that can exist in a test cell, it is recommended that an independent temperature controlled environment be provided for the force transducer. Experience has shown that thermal drift can prove to be the highest single source of error in thrust measurements.

(12) Barometric pressure decrease from ambient to complete test cell vacuum should not cause any change in transducer characteristics. 
(13) Material selection for all transducer components should acknowledge possible contact with hydrazine decomposition products. Metal parts which experience temperatures above $93^{\circ} \mathrm{C}\left(200^{\circ} \mathrm{F}\right)$ while exposed to ammonia may be nitrided (Reference 1-2). Also, stress corrosion cracking is accelerated under these conditions. An inert gas purge of the transducer case or the surrounding environment will prevent these effects.

(14) Vibration and acceleration along the load axis resulting from rough engine operations should be considered separately from the static overload requirements. The strain gage mounting and electrical connections are the transducer elements which are most susceptible to these effects. Bonded strain gages with well-designed terminal pads and supported lead wires are recommended.

\section{1 .2 .2}

Electrical Design

(1) The type of strain gage should be bonded metallic foil.

(2) The number of active strain gage bridge arms should be four for a single bridge and eight for a double bridge. A double bridge is recommended for load ranges of $222 \mathrm{~N}$ ( $50 \mathrm{lbf}$ ) and above.

(3) Recommended excitation should be a regulated voltage of 5 to $28 \mathrm{~V}$ dc. Maximum excitation voltage which will not permanently damage the transducer should be $20 \%$ or greater than the rated voltage.

(4) Input and output resistance for dc excitation is specified in ohms at a specific temperature in ${ }^{\circ} \mathrm{C}\left({ }^{\circ} \mathrm{F}\right)$. Normal. values range from 120 to 350 ohms.

(5) Electrical connections for each bridge circuit, should conform to pin designation shown in the wiring schematic diagram (Figure 1-2). The output polarities indicated on the wiring diagram apply when an increasing force is applied to the transducer.

(6) Insulation resistance is specified in megaohms at a specific voltage and temperature between all terminals or leads connected in parallel and the transducer case. A value of 5000 megohms or greater is recormended.

(7) Shunt calibration resistance should be specified in ohms for a nominal percentage of full scale output at a specific temperature. The terminal across which the resistor is to be placed shall be specified. 


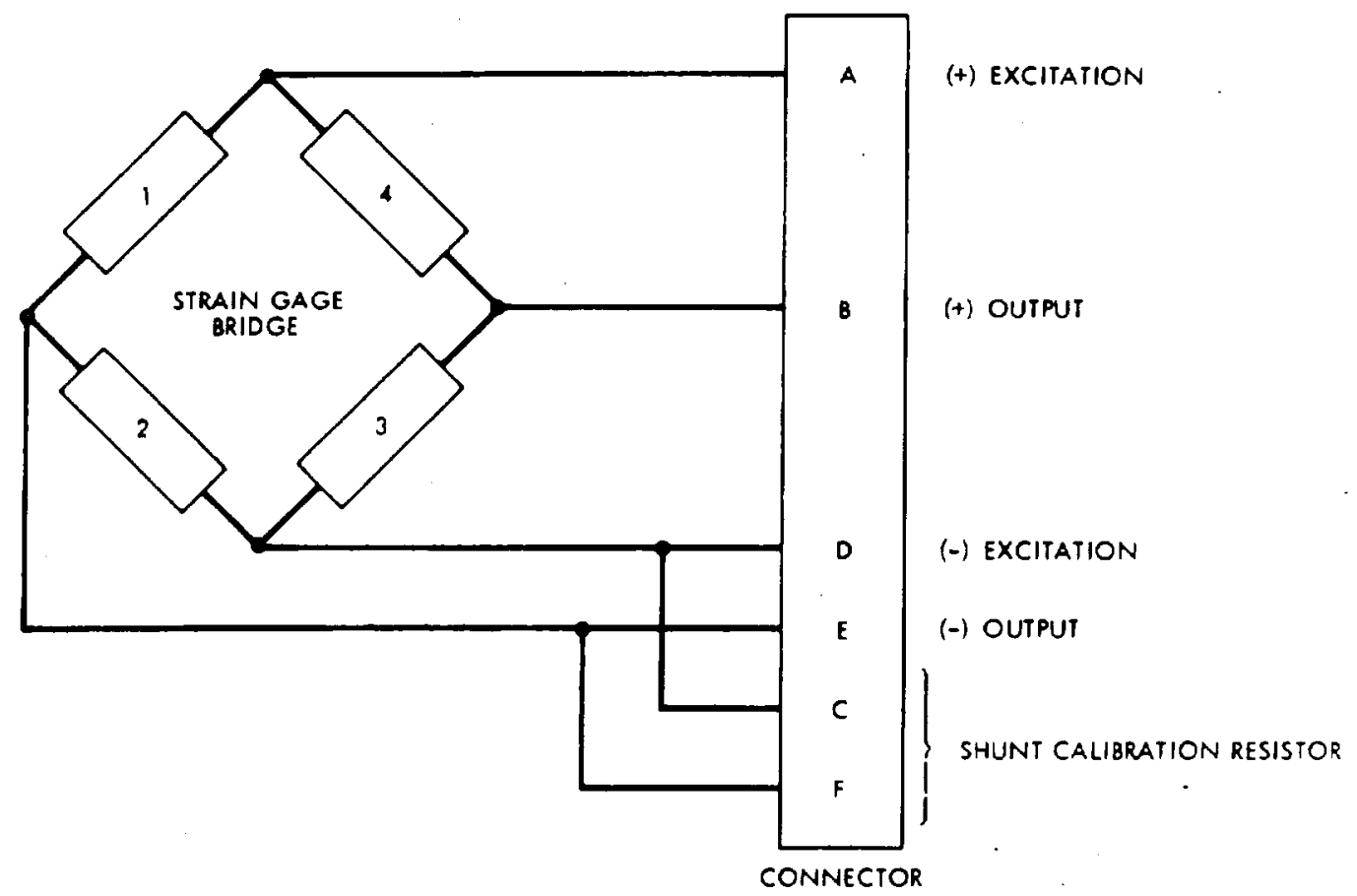

NOTES:

1. THE OUTPUT POLARITIES INDICATED ON THE WIRING DIAGRAM APPLY WHEN AN INCREASING ABSOLUTE PRESSURE IS APPLIED TO THE PRESSURE PORT (SENSING END) OF AN ABSOLUTE PRESSURE TRANSDUCER. FOR DIFFERENTIAL AND GAGE PRESSURE TRANSOUCERS, THE INDICATED POLARITIES APPLY WHEN THE ABSOLUTE PRESSURE AT MEASURAND PORT IS GREATER THAN THE ABSOLUTE PRESSURE AT THE REFERENCE PRESSURE PORT.

2. THE BRIDGE ELEMENTS SHALL BE ARRANGED SO THAT FUNCTIONS PRODUCING POSITIVE OUTPUT WILL CAUSE INCREASING RESISTANCE IN ARMS I AND 3 OF THE BRIDGE.

3. POSITION OF ANY INTERNAL COMPENSATION NETWORK SHOULD BE INDICATED. SEE APPENDIX III-C.

Figure 1-2. Conventional 6-hire Strain Gage Bridge Transducer

3.1.2.3 Performance Characteristics. The basic performance parameters of measurement force transducers are listed below. Unless otherwise specified, they apply at the following ambient conditions: temperature $23 \pm 2^{\circ} \mathrm{C}\left(73.4 \pm 3.6^{\circ} \mathrm{F}\right)$; relative humidity $90 \%$ maximum; barometric pressure $98 \pm 10 \mathrm{kN} / \mathrm{m}^{2}(29 \pm 3 \mathrm{in}$. $\mathrm{Hg})$.

(1) Range is usually expressed in newton (pounds force) compression or tension or both.

(2) Eind points are expressed as millivolts per volt of excitation or millivolts at specified volts of excitation. 
(3) Full scale output (FSO) is expressed as millivolts per volt excitation or miliivolts at specified volts of excitation.

(4) Zero-measured output is expressed as percent of full scale output at full rated excitation and no applied load force.

(5) Stability refers to the ability of a transducer to retain its performance throughout its specified operating and storage life.

(6) Linearity is expressed as percent of full scale output in direction(s) of applied loading.

(7) Hysteresis is expressed as percent of full scale output upon application of ascending and descending applied forces including rated force.

(8) Combined hysteresis and linearity are expressed as percent of full scale output upon application of ascending and descending forces including rated force.

(9) Repeatability is expressed as percent of full scale output over a specified time period with a specified number of cycles of load application.

(10) Static error band is the combined linearity, hysteresis and repeatability expressed as percent of full scale output as referred to a defined type of straight line.

(11) Creep at load is expressed as percent of full scale output with the transducer subjected to rated force for a specified time period.

(12) Creep recovery is expressed as percent of full scale output measured at no load and over a specified time period immediately following removal of rated force, that force having been applied for the same period of time as specified above.

(13) Warm-up period is that time period, starting with the application of excitation, required to assure that subsequent shifts in sensitivity and zero will not exceed the specified percent of full scale output.

(14) Static spring constant is expressed in newtons per meter (pounds force per inch) as determined experimentally or analytically from the dynamic response of a simplified spring mass system representing the force transducer.

(15) Equivalent dynamic masses are expressed in kilograms (pounds mass) for both ends of the transducer in the system described above. 
(16) Internal mechanical damping is expressed in newtons per meter/second relative velocity (pounds force per inch/ second relative velocity) between ends at a specified frequency in hertz and a specified dynamic load in newtons (pounds force).

(17) Safe overload rating is expressed as an applied force in newtons (pounds force) for a specified time period in minutes which will not cause permanent changes in transducer performance beyond specified static error band.

(18) Rated force of the transducer is the maximum designed axial force in newtons (pounds force). The rated force may be in compression, tension, or both.

(19) Thermal sensitivity shift is expressed as percent of sensitivity per specified ${ }^{\circ} \mathrm{C}\left({ }^{\circ} \mathrm{F}\right)$ temperature change over the compensated temperature range in ${ }^{\circ} \mathrm{C}\left({ }^{\circ} \mathrm{F}\right)$.

(20) Thermal zero shift is expressed as percent of full scale output per specified ${ }^{\circ} \mathrm{C}\left({ }^{\circ} \mathrm{F}\right)$ temperature change over the compensated temperature range in ${ }^{\circ} \mathrm{C}\left({ }^{\circ} \mathrm{F}\right)$.

(21) Temperature error band is expressed as output values within a specified percent of full scale output from the straight line establishing the static error band over the compensated temperature range in ${ }^{\circ} \mathrm{C}\left({ }^{\circ} \mathrm{F}\right)$.

(22) Temperature gradient error is expressed as less than a specified percent of full scale output while at zero load and subjected to a step function temperature change over a specified range in ${ }^{\circ} \mathrm{C}\left({ }^{\circ} F\right)$ lasting for a specific time period in minutes and applied to a specific part of the transducer.

(23) Cycling life is expressed as a number of full scale cycles over which the transducer shall operate without change in characteristics beyond its specified tolerance.

(24) Other environmental conditions which should not change transducer performance beyond specified limits should be listed, such as:

(a) Shock, triaxial

(b) High-level acoustic excitation

(c) Humidity

(d) Corrosive spray

(e) Corrosive gases 


\section{(f) Electromagnetic fields \\ (B) Magnetic fields}

(25) Storage life is expressed as a specific time period (days, months, years) the transducer can be stored in a spectfied environment without changing specific performance characteristics beyond their specified tolerances.

(26) Concentric angular load effect is expressed as percent of full scale output difference from true output (axially loaded output multiplied by cosine of angle) resulting from a load applied concentric with the primary axis at the point of application and at a specifled angle in degrees with respect to the primary axis.

(27) Eccentric angular load effect is expressed as percent of full scale output difference from true output (axially loaded output multiplied by cosine of angle) resulting from a load applied eccentric with the primary axis and at a specified angle in degrees with respect to the primary axis.

(28) Eccentric load effect is expressed as percent of full scale output to difference from axially loaded output resulting from a load parallel to but displaced a specific distance in millimeters (inches) from concentricity with the primary axis.

(29) Ambient pressure effects are expressed as the change in sensitivity and the change in zero measurand output due to subjecting the transducer to a specified ambient pressure change above or below atmospheric.

\subsubsection{Calibration Equipment}

Calibration equipment for the thrust measuring system is separated into three types. The in-place static calibrator and the dynamic calibrator are used on the thrust stand in the test cell. A third type involves the laboratory calibration of the force transducer.

3.1.3.1 In-olace Static Calibrator. It is essential that the thrust measuring system be provided with in-place static calibration equipment that can produce the same axial deflection on all critical restraints as will be present during the actual engine test. This equipment should be capable of remote operation within the test cell under both pretest and posttest conditions of simulated altitude (vacuum) and temperature and in the presence of all contributing forces including mechanical line and flexure effects, pressurized propellant supply lines, and the dynamic influence of all supporting systems. 
The following ltems should be included in the design of the in-place static calibrator:

(1) The calibrator should be either a multipoint dead weight type or a working standard force transducer with a variable force generator.

(2) The calibration range should be from 0 to $120 \%$ of the highest anticipated normal load with values established at three or more intermediate steps.

(3) The application of the calibration loads should be in both ascending and descending steps that are repeatable in either a preprogrammed or selective manner, so that the transition from one force to the next is accomplished without creating a hysteresis error in the measurement due to overshoot.

(4) The maximum inaccuracy of the force calibrator should not be more than one half the permissible tolerance of the measurement force transducer.

(5) Traceability (not more than twice removed) to the National Bureau of Standards should be established for the force calibrator.

(6) The calibration force should be applied coincident with the thrust axis of the test engine and in the same direction as the deflection produced by engine operation.

(7) The calibrator support structure should be independently mounted on the seismic mass, separate from the fixed structure of the measurement force transducer.

(8) The calibrator force linkage should include a disconnect coupling that will isolate the calibrator from the thrust frame when not in use.

(9) Provisions for adjustment, alignment and verification of the calibration force must be given the same emphasis as the measurement force.

(10). Protection against damage from shock, vibration, radiation or corrosion caused by the test cell environment should be provided for the calibrator.

3.1.3.2 Dynamic Calibrator. The dynamic response of a thrust stand depends on the stiffness and mass distribution throughout the entire active system. The response characteristic can best be determined by experimentally applying a suitable time-varying force to the complete system and measuring the output versus time response of the measurement force transducer. The time-varying force can be supplied by an electromagnetic forcing coil capable of producing sinusoidal forces or step function forces. A simpler method is 
to use a single instantaneous force change of sufficient magnitude to cause the thrust stand to ring. In elther case, data can be developed which provide a measure of thrust stand sensitivity, resonant frequency, and damping factor. The dynamic calibrator should be capable of remote operation with the thrust stand and test cell at simulated engine operating conditions.

The following items should be included in the design of the dynamic force calibrator:

(1) The dynamic force should be applied to the thrust frame coincident with the measurement thrust axis and in the same direction as the deflection produced by engine operation.

(2) The dynamic force calibrator should be independent of the static force calibrator so as not to cause any damage to the sensitive equipment.

(3) Due to the added weight and complexity, the dynamic calibrator should be disconnected from the active mass of the thrust frame. It may even be removed from the thrust stand completely and only installed when required.

(4) Magnetic forcing coils should be thoroughly characterized using simulated engine and thrust frame mass before being employed on the thrust stand. The generated force input should be tailored to match the anticipated operating characteristics of test engine thrust pulse whenever possible.

(5) The application of an instantaneous force change using falling weights, swinging hammer, frangible preloaded linkage, electrlc solenoid hamer (pinger), etc., should be thoroughly evaluated for causing possible shock overloads to the test engine assembly or the measurement force transducer.

3.1.3.3 Laboratory Calibration. Acceptance and qualification tests should be performed on the strain gage force transducer in a calibration laboratory before the transducer is installed into the thrust stand. The basic equipment consists of a force calibrator, a source of electrica? excitation for the strain gage, and a device which measures, the electrical output of the transducer. The error or uncertainties of the laboratory calibration system should be less than one third of the permissible tolerance of the measurement force transducer. Traceability (not wore than twice removed) to the National Bureau of Standards should be established for the laboratory equipment.

The following is a sumary of the design considerations for a laboratory force calibration system as given in Reference 1-1: 
(1) The force calibrator should have a maximum uncertainty of no more than one fifth of that permissible for the measurement force transducer. Typical values for three types of force calibrators in either tension or compression are:

(a) Dead weight: maximum error $\pm 0.01 \%$ test load

(b) Proving ring: maximum error $\pm 0.1 \%$ full scale

(c) Reference standard force transducer: maximum error $\pm 0.1 \%$ full scale.

(2) The range of the instrument supplying or monitoring the calibration force should provide the necessary accuracy to $125 \%$ of full scale range of the transducer.

(3) A stable source of electrical excitation of accurately known amplitude is required for the strain gage bridge circuit. DC excitation is normally provided by electronically regulated power supplies utilizing line power. The maximum uncertainty for these excitation power sources should be $\pm 0.02 \%$ of reading or better.

(4) A digital electronic voltmeter with preamplifier is normally used to measure the electrical cutput signal of the force transducer. The maximum uncertainty for this type of instrument is (a) for 0 to $10 \mathrm{mV}$ range with $1 \mu \mathrm{V}$ sensitivity maximum error $\pm 0.02 \%$ of reading or $\pm 2 \mu \mathrm{V}$, whichever is greater or (b) 0 to $100 \mathrm{mV}$ with $10 \mu \mathrm{V}$ sensitivity maximum error $\pm 0.01 \%$ of reading or $\pm 10 \mu \mathrm{V}$, whichever is greater.

\subsection{ELECTRICAL AND ELECTRONIC COMPONENTS}

The major electrical and electronic components to be considered in the design of a thrust measurement system include (1) signal conditioning equipment, (2) electrical calibration equipment, (3) recording equipment, (4) visual display equipment, and (5) data processing equipment. These components are shown in the thrust measurement system block diagram, Figure 1-3. In general all of these components are comercially available, off-the-shelf items. Most of the items are available from more than one manufacturer. The major concern in the selection of these comporients must be the evaluation of the various manufacturers' zeneral specifications in relation to the specialized force measurement requirement. A subsequent verification that the equipment finally selected conforms to the manufacturers' specifications is essential.

\subsubsection{Signal Conditioning Equiprent}

Signal conditioning equipment includes the following functional devices: power supplies, amplifiers, electrical cabling, shielding, signal distribution and switching network, and filters. The regulation and stability 


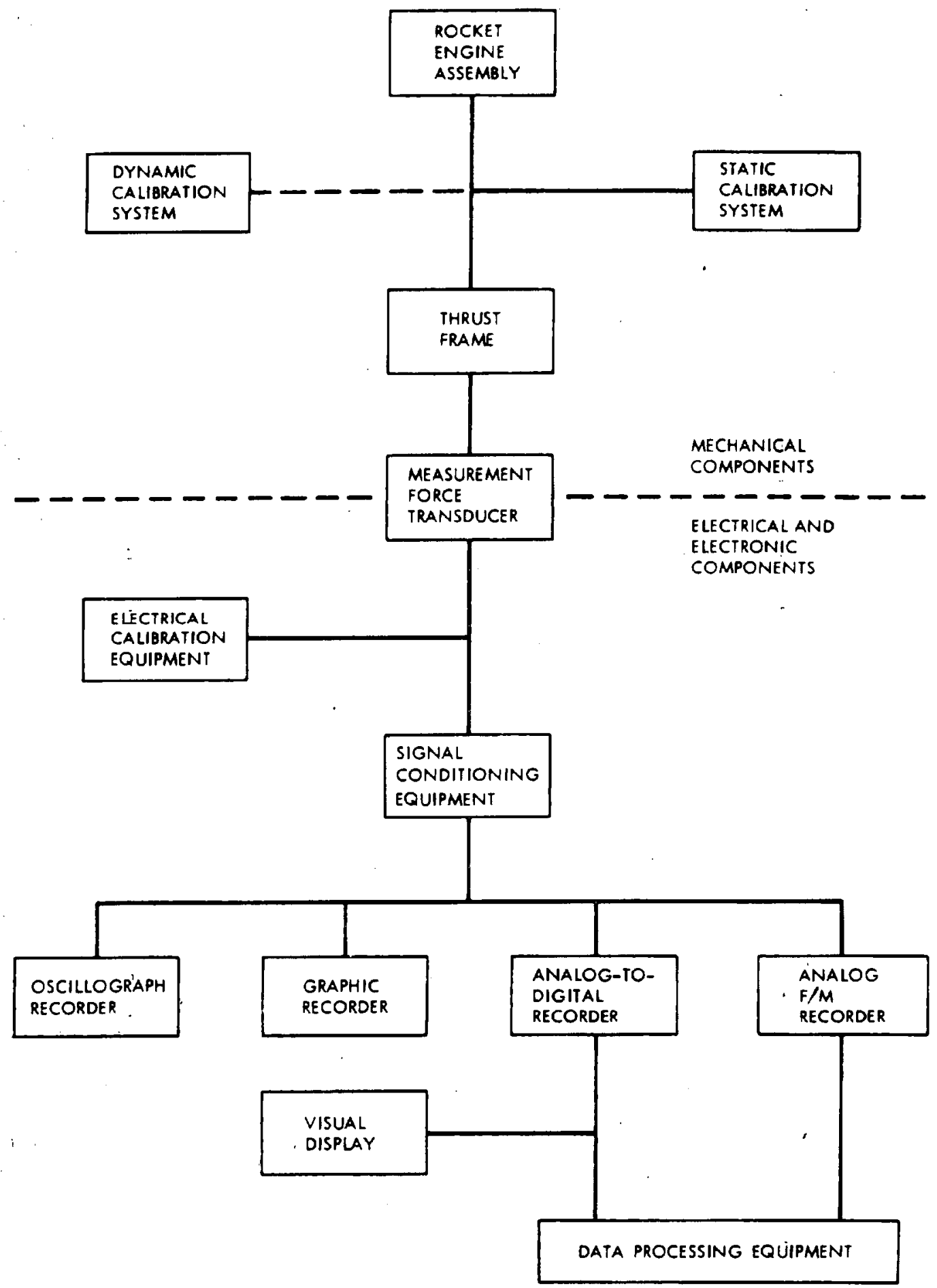

Figure 1-3. Thrust Measurement System Block Diagram

i 
of this equipment should be $\pm 0.05 \%$ or better, wherever applicable. The design of these devices varies widely depending on system philosophy and economics; however, certain design principles are universally recomended as follows:

(1) Power supplies. Constant voltage excitation is the primary type used with high-accuracy thrust measurement systems. Power supplies can be individually rack-mounted units or miniature (several in one card) devices integral with other signal conditioning equipment. Generally, there are provisions for voltage adjustments, less of ten for zero balance. Ripple should be less than $100 \mu \mathrm{V}$ peak to peak.

(2) Amplifiers. The use of high-quality differential amplifiers is now almost universal. With a transducer full scale output of 20 to $40 \mathrm{mV}$, an amplifier gain of 50 to 500 is sufficient for most conventional analog-todigital conversion and recording systems. It should be verified that peak common mode voltages do not exceed the rejection limits of the amplifier.

(3) Electrical Cabling and Shielding. Electrical noise can be minimized by the use of proper shielding and grounding techniques (Reference 1-3). Transmission cables between the transducer and the recording system usually consist of multiple pairs of twisted, shielded, splice-free conductors. A total of 6 conductors should be used for each transducer.

The wire gage and corresponding resistance of the excitation and calibration leads should be taken into account when developing calibration techniques and other system design considerations.

Each transducer cable should be individually shielded, with continuity of shield to the operational amplifier. The shield grounding connection should be in accordance with the amplifier manufacturer's recommendations. Multichannel cables consisting of inner cable shielding, and overall shielding of the large cable are recommended for long transmission runs. The outer shield of the multiconductor cable should also be terminated at a single point ground. The outer shield and ail inner shields should be insulated from each other.

(4) Other signal conditioning equipment includes such items as filters, distribution and switching units, and impedance matching devices. The design of these and related devices varies depending on system philosophy, but should in all cases be high-quality equipment providing stability (both with time and temperature), line vcltage regulation, and linearity. Thermally induced errors should be minimized in all circuits. 


\subsubsection{Electrical Calibration Equipment}

Some form of electrical simulation of the transducer response to force should be provided. This simulation should track any change in the system sensitivity that is caused by changes in the environmental conditions. The two most commonly used electrical calibration systems that are readily adaptable to automated periodic tests are discussed below. The first of these techniques includes the transducer in the calibration and is thus quasi end to end. The other involves only the electrical and electronic equipment. The advantages (convenience, technical, or economic) of each system will largely depend upon the user's existing transducers, signal conditioning equipment, cabling, etc.

(1) Shunt calibration with a constant voltage system requires a 6-wire system to the transducer if an external signal shunt resistor is used: 2 wires are used for excitation, 2 for output, and 2 for shunt simulation. The technigue for using a 6-wire shunt resistor calibration method is presented in Appendix III-C.

(2) Voltage substitution techniques can be used to calibrate the electronics system (amplifier, recorder, etc.) in addition to, or in lieu of, any transducer electrical or end-to-end calibration. This method requires that the transducer be electrically disconnected (usually by a switching network) and a known voltage substituted. Such a calibration technique will not necessarily provide any information about changes in ambient output nor will it even reveal if the transducer has been disconnected. It should therefore not be the only type of electrical calibration employed.

\subsection{3 "Recording Equipment}

The four commonly used recording systems for recording thrust measurement, data are (1) digital system, (2) graphic recorders, (3) oscillograph and (4) analog magnetic tape recorders. Two or more of these systems may: be combined to provide high accuracy, high-frequency response, and quick readout.

\subsubsection{Visual Display Equipment}

A visual display of real time measured data in engineering units along with other critical operating parameters is required for both pretest and posttest calibrations and for monitoring during the engine test. This alphanumeric data can be presented in either hard copy (printed) or non-hard-copy (no record) form or both. The non-hard-copy is usually displayed on some type of cathode ray tube (CRT) device through a selective preprogrammed format. 


\subsubsection{Data Processing Equipment}

The data processing equipment is not generally dedicated exclusively to the thrust measurement system, but is used to process many other parameters also. This equipment should be chosen and used with care so that the uncertainty of the data is not increased during processing.

\subsection{INSTALLATION AND CHECKOUT PROCEDURES}

4.1

COMPONENT CERTIFICATION

All the critical components of the thrust measurement system should be certified for compliance with design specifications before installation. This is best accomplished by precision inspection plus standard laboratory test and evaluation. Components so certified should include the following items:

(1) Thrust measurement force transducer

(2) Calibrator working-standard force transducer

(3) Calibrator dead weights

(4) Thrust stand flexures

(5) Thrust stand restraints

(6) Dynamic force calibrator

\subsubsection{Force Transducer}

The thrust measurement force transducer and the calibrator working-standard force transducer, if one is to be used, should be certified by performing the acceptance and qualification tests and recording all data as given in ISA-S37.8, Reference 1-1. (Where the quantity of transducers used makes justification of qualification testing difficult, such tests may be waived provided the manufacturer is able to certify compliance from previous testing on similar units.) The working-standard force transducer should be certifled to an uncertainty of not more than one half the permissible tolerance of the measurement force transducer.

4.1.1.1 Acceptance Test. Individual acceptance tests are performed to evaluate those characteristics which are a function of transducer piece parts, assembly, or adjustment, and might vary considerably from one unit to the next.

The acceptance tests for the force transducer from Reference 1- 1 are sumarized as follows: 
(1) Inspect the transducer for mechanical defects, poor finish and improper identification markings.

(2) Install the transducer into the force calibrator with axial alignment as specified by the manufacturer. Connect the excitation source and readout instrumentation to the transducer and turn on for the specified warm-up period. Prior to calibration, it is desirable to exercise the force transducer by applying rated load and returning to zero load for several cycles.

(3) Conduct two or more calibration cycles in succession, including five to eleven points in both ascending and descending directions while monitoring excitation amplitude and recording output signal. From the data obtained in these tests the following transducer characteristics should be determined:

(a) End points

(b) Full scale output

(c) Zero unbalance

(d) Linearity

(e) Hysteresis

(f) Hysteresis and linearity combined

(B) Repeatability

(h) Static error band

(4) Repeat the calibration cycles over a specified period of time after warm-up. This data establishes the following characteristics for that period of time:

(a) Zero drift

(b) Sensitivity drift

(5) Apply the rated force to the transducer during a specified short period of time. The measurement of changes in output at constant excitation during the time period should establish:

Creep at load

(6) At zero load, measure output and sensitivity over a period of time, up to one hour, starting with the application of excitation to the transducer. The observed time to stabilize should determine the following characteristic: 
Warm-up period

(7) Apply the specifled rated overload for the specifled number of times in the specified direction of tension or compression, followed by one complete calibration cycle to establish that the transducer performance characteristics are still within specification. This should verify:

\section{Safe overload rating}

(8) Measure the insulation resistance between all terminals, or leads connected in parallel, and the case of the transducer with a megohm-meter using a potential of $50 \mathrm{~V}$, unless otherwise specified, at room temperature. This should establish:

Insulation resistance

(9) A Wheatstone bridge (for dc) or an impedance bridge (for ac) should be used to measure and establish the following:

\section{(a) Input impedance \\ (b) Output impedance}

4.1.1.2 Qualification Test. Qualification tests are performed to evaluate those characteristics which are a function of transducer design. They thus would not be expected to vary appreciably from one unit to another for a particular transducer model. The performance of a representative sample of units should represent the performance of an entire lot.

The qualification tests for the force transducer (Reference 1-1) are summarized as follows:

(1) The force transducer, while still installed in the force calibrator, should be placed in a suitable temperaturecontrolled chamber. After stabilizing the chamber and transducer at a specified temperature, one or more calibration cycles should be performed within the chamber. The procedure should be repeated at an adequate number of selected temperatures within the specified operating range of the transducer, and finally after return to room temperature and stabilization. From these tests the following characteristics should be determined:
(a) Thermal sensitivity shift
(b) Thermal zero shift
(c) Temperature error band 
(2) With the force transducer at room temperature within the controlled chamber, and with no applied load, it should be subjected to a specified thermal transient above or below room temperature. The observed output over a specified period of time establishes:

Temperature transient error

(3) Install the force transducer into a suitable test fixture with the axial alignment as specified. Attach an electromagnetic forcing coil which is capable of producing an axial load which is $20 \%$ of the force transducer rated load or higher. Connect the excitation source, readout instrumentation, and recórder and turn on for the specified warm-up period. Apply a sinusoidal force at a specified load and sweep the frequency from zero until the first resonant peak output is reached. This should establish transducer:

(a) Natural resonant frequency

(b) Frequency response

Apply a step function force at a specified load and time period. The recorded output should establish:

(a) Natural resonant frequency

(b) Static spring constant

(c) Damping factor

(d) Equivalent dynamic masses

After completion of the above test, remove the transducer from the test fixture and reinstall it into the force calibrator. Perform one complete calibration cycle to verify the ability of the transducer to perform satisfactorily.

(4) Install the force transducer into a suitable vacuum chamber with the axial alignment as specified. Connect the excitation source and readout instrumentation to the transducer and turn on for the specified warm-up period. With the transducer at room temperature and no applied load, reduce the barometric pressure within the test chamber in a controlled manner to a specified level below atmospheric and hold. Observe the output over a specified time period to establish:

Ambient pressure effects

After completion of two or more cycles of the above test, remove the trinsoucer from the vacuum chamber 
and reinstall into the force calibrator. Perform one complete calibration cycle to verify ability of the transducer to perform satisfactorily.

(5) Install the force transducer into a suitable test fixture with the axial alignment as specified. Mount this test assembly onto a vibration and/or shock test machine in the axial loading direction as specified. Connect the excitation source and readout instrumentation to the transducer and turn on for a specified warm-up period. With the transducer at room temperature and zero initial applied load, subject the transducer to a specified series of vibration and/or shock tests at prescribed frequency and $g$ loading. Observe the output during each of the specification tests to establish:

Vibration and/or shock effects

After completion of the above test, remove the transducer from the test fixture and reinstall into the force calibrator. Ferform one complete calibration cycle to verify ability of the transducer to perform satisfactorily.

(6) To determine the effects of concentric angular loading (and side loading), insert wedge blocks above and below the force transducer installed in the force calibrator as shown in Figure 1-4a. The angle subtended by the two larger surface areas (b) of each block should be equivalent to the specified angle of interest and should result in the specified side load. Apply rated load and as soon as stabilized, read output and remove the load. A comparison of pretest and posttest zero measurand should establish:

$$
\text { Concentric angular loading efrects }{ }^{1}
$$

(7) To determine the effects of eccentric angular loading, remove the upper wedge block as shown in Figure $1-4 b$. Apply rated load and as soon as stabilized, read output and remove the load. A comparison of pretest and posttest zero measurand should establish:

$$
\text { Eccentric angular loading efiects }{ }^{1}
$$

(8) To determine the effect of eccentric loading, remove both wedge blocks, install a flat load button into the transducer,

The effects of the various types of loading related to axial loading conditions can be determined in accordance with the expressions included in Figure 1-4. 


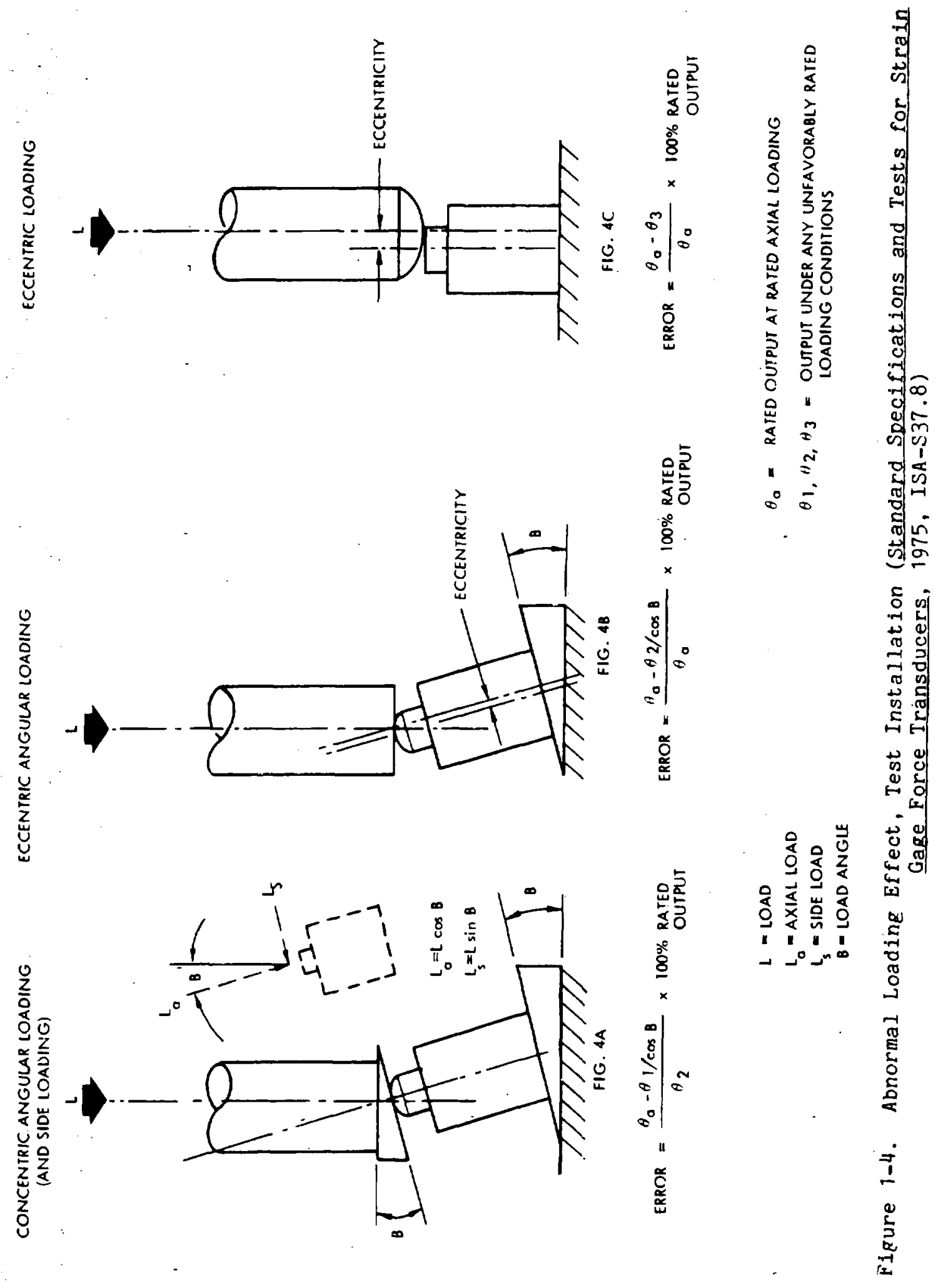


and adjust eccentricity specified through placement of the force transducer under the convex loading ram surface, Figure $1-4 \mathrm{c}$. Apply rated load and, as soon as stabilized, read the output and remove the load. A comparison of the measured pretest and postitest zero should establish:

\section{Eccentric loading effects ${ }^{2}$}

(9) Application of force to the transducer for the specified minimum number of cycles, over the specified range of force, will establish:

Cycling life

(10) The transducer should be subjected to a final complete individual acceptance test to verify that qualification testing has not caused the transducer to exceed specified tolerances.

4.1.2 Calibrator Dead Weights

For a thrust stand using a dead weight calibrator, the actual value of weights should be certified by a standard laboratory weighing which is traceable to the National Bureau of Standards. Correction factors for determining actual weight at the test site should include local gravity and air buoyancy.

4.1.3 Thrust Stand Flexures and Restraints

The thrust stand flexures and restraints should be certified by laboratory test for elastic deformation at 1.5 times design load capability. Cyclic tests at rated loads should be performed whenever work hardening or fatigue are principal xodes of failure.

4.1.4 Dynamic Force Calibrator

The dynamic force calibrator should be certified by laboratory test to verify input versus output characteristics. Electromagnetic forcing coils should be certified using the same power supplies and waveform generators specified for the test cell operations.

2 The effects of the various types of loading related to axial loading conditions can be determined in accordance with the expressions included in Figure $1-4$. 
The total thrust measurement system, including the'thrust frame containing a simulated engine mass, the force measurement system, and the static and the dynamic calibration equipment, must be certified for conformance to design specifications upon completion of construction. In addition, the linearity, hysteresis, deflection, and response characteristics must be determined and certified to be within design specifications. This certification should be performed after any major stand modification, after any significant engine malfunction, or after replacement of the measurement force transducer. Systematic, although less comprehensive, checks should be performed after any change in the thrust stand hardware.

\subsection{ENGINE INSTALLATION}

After the initial installation of an engine in the thrust system and with all plumbing attached, the following checks must be made at arbient test condition:

(1) Confirm coincidence of centerline of rocket engine exhaust nozzle with centerline of thrust measurement system.

(2) Confirm coincidence of calibration force vector with expected rocket engine thrust vector.

(3) Confirm that the maximum limits specified for nonlinearity and hysteresis have not been exceeded. Static thrust system calibration data should be used in this initial evaluation to check for changes in system characteristics.

(4) Confirm that the specifications for dynamic response, natural frequency, and damping factor have been satisfied.

- Dynamic thrust system calibration data should be

used in this initial evaluation to check for changes

in system characteristics.

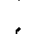

5.1 STATIC CALIBRATION

Because of the stringent accuracy requirement for thrust measurement, maximum care and attention to detail musi be provided both in preparation and implementation of the calibration and verification procedures. Particular considerations for the two recommended static calibration nethods and some general procedures are summarized as follows and apply to both the calibration and verification of the thrist measurement system. 
5.1.1 Deadweight Calibrator Method

(1) Inspect weights before each calibration to establish conformance to design and cleanliness requirements.

(2) Confirm freedom of movement of force transmission and decoupling system.

(3) Determine that weights are suspended and floating at each loading step.

(4) If multiplier leverage systems are used, calibrate in place at regular intervals. Use a reference standard force transducer directly traceable (not more than twice removed) to the National Bureau of Standards in place of the normal measurement force transducer. This calibration should be repeated with and without a simulated engine mass on the thrust frame to establish the effects of varying engine mass.

5.1.2 Working Standard Force Transducer Calibration Method

(1) The working standard force transducer system should be selected so that its uncertainty is less than one half the uncertainty required of the measurement force transducer system. Because it is decoupled from the thrust frame during engine testing, it may be designed to be less rugged and have greater deflection which results in higher output signal level.

(2) Calibrate the working standard force transducer and its associated excitation source and readout equipment so as to be directly traceable (not more than twice removed) to the National Bureau of Standards per Reference $1-1$ and as summarized in Section 4.1.1.

(3) With the thrust frame and the measurement force transducer decoupled or removed and replaced by a solid load bearing member, use the in-place rorce generator to document the linearity, hysteresis, repeatability and stability of the working standard force transducer system.

(4) With the thrust frame and measurement force transducer system reinstalled, complete one or more calibration cycles with and without a simulated engine mass on the thrust frame. Record the outputs of the calibration and measurement force systems simultaneously to documerit the characteristics of these combined systams and corfigurations. This data may be used to define the thrust frame characterisics and for diagnostic purposes. 
(1) Inspect the connections of all thrust system components (Figures 1-1 and 1-3) for conformity to the configuration that will be used for test data acquisition.

(2) Inspect the points of connection of all engine system components, propellant and purge lines, and attached instrumentation.

(3) Verify that all required test facility systems are ready for full simulation of actual test conditions.

(4) Verify that instmumentation and data recording systems are ready for thrust stand calibration.

(5) Activate facility systems to obtain desired test conditions and allow time for stabilization.

(6) Verify that test cell pressure and temperature conditions are stable.

(7) Verify that propellant feed system pressure and temperature conditions up to the engine valve are stable.

(8) Impose on the thrust stand during calibration and verification any additional forces which will be present during operation.

(9) Calibrate the thrust measurement system without removing or otherwise disturbing the measurement force transducer, flexures, linkages, or other components that could affect the calibration.

(10) Record electrical calibration signals to determine scaling factors for data reduction and to check ranges of recording equipment. These electrical simulation signals should be of the same magnitude as the electrical signals produced by the callbration forces.

(11) Exercise the mechanical and electrical systems to at least $120 \%$ of anticipated operating level.

(12) Apply calibration loads carefully without overshoot in increasing steps from 0 to at least $120 \%$ of anticipated operating level and in decreasing steps to 0 .

(13) Visually verify, record ard reduce all calibration data using the same systems that will be employed during the actual rocket engine test.

(14) Calibrate the thrust measurement system in place prior to each test. Verification should be $p \in r$ formed prior to and after each rur. This procedure should 
be followed until sufficient data are acquired to justify statistically that calibrations are not required at this frequency.

\subsubsection{General Verification Procedures}

After completing the pretest thrust calibration tests summarized above perform the following verification tests just prior to engine hot firing and immediately after engine shutdown:

(1) Apply, by means of the force calibration system, a known force equal to the nominal expected for the actual engine test.

(2) Record the data at a sampling rate and for a period which is normal for steady state engine conditions. Also record the applied force as indicated by the working standard if one is used.

(3) Repeat the applied nominal load test 10 or more times.

(4) Visually verify, record and reduce all verification data using the same systems that will be employed during the actual engine test.

(5) Record an electrical calibration signal of the same magnitude as that produced by the applied load from the force calibration system.

(6) Ensure that the mechanical portion of the calibration system is decoupled from the thrust measurement system following these verification tests and before any actual engine tests.

\subsection{DYNAMIC CALIBRATION AND VERIFICATION}

The dynamic calibration and verification of the thrust stand requires the same care and attention to details as the static calibration and verification. Both can be performed in sequence at the same test assembly providing the dynamic calibration system does not reduce the accuracy of the static calibration system. The same procecural steps may be performed up to the decoupling of the static force system and application of the dynamic force system. Sowe of the reconmended general procedures for dynamic force calibratior: and verification for both fretest and postiest are as follows:

(1) Verify the operation of any special high-response instrumentation and recorders used to obtain transient data.

(2) Apply dynamic calibration force in increasing steps from 0 to $120 \%$ of anticipated operating level and in decreasing steps to 0 . 
(3) Visually verify, record, and reduce dynamic calibration data using the same systems that will be employed during actual engine test.

(4) In-place dynamic calibration of the thrust measurement system should be performed prior to the first test of an engine assembly and need not be repeated unless there is a major modification to the engine assembly, thrust measurement system, or replacement of the measurement force transducer.

(5) Dynamic verification of the thrust measurement system is accomplished by applying a dynamic force equal to the nominal expected for the actual engine test.

(6) Dynamic verification test is repeated 10 or more times.

(7) Visually verify, record, and reduce dynamic verification data using the same system that will be employed during the actual engine test.

(8) Dynamic verification tests shouid be performed just prior to engine hot firing and immediately after engine shutdown.

(9) Ensure that the mechanical portion of the dynamic calibration system is decoupled from the thrust measurement system before any actual engine tests.

\subsection{OPERATING PROCEDURES}

To ensure that maximum quality thrust measurement data are produced during each test run, certain inspections and verifications must be made. Some of the recommended procedures are shown below for both the pretest and the posttest periods.

\subsection{PRETEST PROCEDURES}

(1) Visually inspect the thrust stand for binding, misalignment, etc.

(2) Set up and verify the data acquisition system.

(3) Close up the test cell and establish the desired pressure and teinperature test conditions.

(4) Record verification and/or electrical simulation data, and check these data for conformance with predicted standards for the measurement systeri.

(5) Establish the run zero reference, and record this value. 


\subsection{POSTTEST PROCEDURES}

(1) Record the zero reference.

(2) Record verification and/or electrical simulation data, and check these data for conformance with predicted standards.

(3) Back fill the test cell and establish a safe ambient environment inside before opening and allowing access.

(4) Visually inspect the thrust stand for binding, misalignment, etc.

\subsection{DATA ACQUISITION AND PROCESSING TECHNIQUES}

Many generalized standard techniques must be applied in the acquisition and processing of the calibration, verification, and run data even though a wide range of equipment types and handling techniques will be used for handling these thrust measurement data. Certainly no attempt is made in this handbook to specify the detailed techniques which are appropriate to the various items of equipment supplied by different manufacturers.

\subsection{CALIBRATION AND VERIFICATION DATA}

Recommended practices for the acquisition and processing of calibration and verification thrust measurement data are as follows:

(1) Calibration and verification data should be recorded on the same equipment as run data.

(2) Initial system calibration data must be used to determine whether the thrust system design requirements (e.g., limits on deflection, hysteresis, and nonlinearity, if applicable) have been met. Several sets of data should be obtained and plotted.

(3) After the initial calibration of the thrust system, the system should be verified a number of times to determine the short-term uncertainty. For each verification, a factor for use in determining uncertainty should be calculated. This factor will be a function of the applied force (approximately equal to the nominal force prcduced by the engine at the test operating conditions), the net electrical output from the force transducer produced by this force, and the net output of the electrical sinula. tion signal. A discussion of a method of short- and longterm uncertainty analysis is found in Appendix I-B.

(4) Verification data are used to compute the measurement uncertainty of the systen, to compute a period of predicted satisfactury performance, and to check the system for trends and excursions. 
(5) If the calculated uncertainty of the system exceeds the allowable limit, the system should be improved until such time as the allowable limit is not exceeded. The total uncertainty of the thrust measurements produced by a system designed in accordance with the practices outlined in this handbook is obtained by combining all the elemental uncertainties (Appendix I-A). The accepted method for the calculation of total uncertainty is presented in Reference 1-4.

(6) Posttest verifications should be carefully examined for any deviation from pretest calibrations and/or verifications. If such deviations are outside acceptable limits, corrective action should be taken immediately and the validity of the test data should be questioned.

(7) A periodic (e.g., at least once a month or before each test, whichever is longer) reevaluation, consisting of verification of the thrust measurement system and computation of system uncertainty, must be made as long as the thrust stand is in use.

(8) Calibration and verification records should contain at least the following data:

(a) Test stand identification

(b) Parameter identification

(c) Recording system identification

(d) Date, time, and ambient temperature

(e) Identification of the force standard used

(f) Identification of the measurement force transducer

(g) Range of the force transducer

(h) Calibration range of the system

(i) Run number (where applicable)

(j) Propellant conditioned temperature

(k) Test cell conditioned temperature

(1) Test cell ambient pressure (altitude simuiation level)

(m) Test engine identification

(n) Identification of the operators. 
7.2 RUN DATA

Recommended practices for the acquisition and processing of run thrust measurement data are as follows:

(1) Engine test data should be accumulated with this thrust measurement system only after the uncertainty requirements have been met.

(2) Data reduction for each run should be based on the average factor as determined from the pretest and posttest verifications.

(3) Run data should be examined to identify gross malfunctions such as failure to record, intermittent connections, dropouts, and other equipment malfunctions.

(4) The period of observation for data reduction must be chosen such that the syster meets the requirements for the specifled test conditions.

(5) Data reduction using a predetermined procedure should be done as quickly as possible after completion of a test so that, in the event of data discrepancy, troubleshooting will be expedited.

(6) Final reduced data should be tabulated for convenient comparison with user specifications.

(7) All calibration, verification, calculated uncertainty, and engine test data should be retained until a data release is dictated by the program requirements. In general, this includes all information related to the interpretation of the measured thrust.

(8) In the event of equipment malfunction, all data associated with that equipment should be examined for validity. This process will be simplified if all equipment used is appropriately identifled and the identification is made a part of the permanent test records. 


\subsection{GLOSSARY}

Accuracy. The closeness or agreement between a measured value and a standard or true value.

Ambient conditions. The conditions (pressure, temperature, etc.) of the medium surrounding the case of the transducer.

Axial Thrust. The single component of the total thrust vector that acts along the geometrical centerline of an axisymetric engine.

Best Straight Line. A line midway between two parallel straight lines closest together and enclosing the calibration curve.

Bonded. Permanently attached over the length and width of the active element.

Calibration. A test during which known values of measurand are applied to the transducer and corresponding output readings are recorded under specified conditions. (Only during a calibration may adjustments be made so that a relationship convenient for data reduction purposes can be established.)

Calibration Traceability. The relation of a transducer calibration, through a specified step-by-step process, to an accepted national standard, usually maintained by the National Bureau of Standards.

Creep. A change in output occurring over a specific time period while the force and all environmental conditions are held constant.

Damping. The energy dissipating characteristic which, together with natural frequency, determines the upper limit of frequency response and the response-time characteristics of a transducer.

Drift. An undesired change in output over a period of time, which is not a function of force.

End Points. The outputs at the specified upper and lower limits of the force change.

Error. The indicated value minus the true or ideal value.

Error Band. The band of maximum deviations of output values from a specified reference line or curve due to those causes attributable to the transducer, as measured over two consecutive calibration cycles unless otherwise speciried.

Excitation. The external electrical voltage and/or current applied to a transducer for its proper operation.

Freouency Response (Ampiitude). The change with, frequency of the output/input amplitude railo (and of the phase difference between output and input), for a sinusoioally varying forse applied to the transducer. 
Eull Scale Qutput (FSO). The algebraic difference between the outputs at the end points.

Hysteresis. The maximum difference in output, at any force within the specified range, when the value is approached first with increasing and then with decreasing force.

Input Impedance. The impedance (presented to the excitation source) measured across the excitation terminals of a transducer.

Life cycling. The specified minimum number of full range excursions or specified partial range excursions over which a transducer will operate without changing its performance beyond specified tolerances.

Linearity. The closeness of a calibration curve to a specified straight line (such as the line between end points). (Nonlinearity is expressed as the maximum deviation of any calibration point from the specified straight line, during any one calibration cycle. It is expressed as "less than $\pm \ldots$ of full scale output.")

Measurand. A physical quantity, property or condition which is measured (such as force).

Qutput. The electrical quantity which is produced by the transducer as a function of the applied force.

Qutput Impedance. The impedance across the output terminals of a transducer presented by the transducer to the associated external circuitry.

Pulse Mode Qperation. For the purpose of this section, pulse mode operation is defined as occurring whenever (a) the thruster valve is commanded closed prior to the attainment of $95 \%$ of the steady state catalyst bed temperature as measured at the outer wall surface, or (b) the performance of the thruster is to be monitcred over a time period which includes both the start-up and shut-down transients, and during which time the transient portions of any measurement are significant with respect to any steady state measurements.

Reference Standard. An instrument which is calibrated in a laboratory against an interlab standard and is used as a standard in calibrating a working standard.

Repeatability. The ability of a transducer to reproduce output readings when the same force is applied to it repeatedly, under the same conditions, and in the same direction. (Nonrepeatability is expressed as the maximum differerce between output readings; it is expressed as "less than _. of full scale output.")

Reseiution. The least discernible output change wrich reflects a change in force (expressed in of FSO).

Besonant Frequency. The, frequency at which a transdlicer responds with maximum output ampiitide. 
Response IIme. The length of time required for the output of a transducer to rise to a specified percentage of its final value as a result of a step change of force.

Rise Tlme. The length of time for the output of a transducer to rise from a small specified percentage of its final value to a large specified percentage of its final value.

Sensing Element. That part of the transducer which responds directly to force.

Sensitivity. The ratio of the change in transducer output to a change in the force.

Stability. The ability of a transducer to retain its performance throughout its specified operating 11 fe and storage life.

Static Calibration. A calibration performed under stated environmental conditions by application of the weasurand to the transducer in discrete amplitude intervals, in the absence of any vibration, shock, or acceleration:

Steady State Operation. For the purpose of this section, steady state operation is defined as that portion of a test after which the temperature at the outer surface of the catalyst bed wall has achieved 95\% of its equable asymptotic value, but prior to the time at which the propellant valve is commanded closed. Steady state measurements should be made only after the attainment of this condition.

Strain. The mechanical deflection of a structural element in the context used in Hooke's law which states that the modulus of elasticity is equal to the stress divided by the strain.

Temperature compensation. Provision of a supplemental device, circuit, or special materials to counteract known sources of temperature errors.

Temperature Range, Compensated. The range of ambient temperatures, given by their extremes, within which the transducer is intended to operate within specified tolerances; within this range of ambient temperature error band, temperature gradieat error, thermal zero shift and thermal sensicivity shift are applicable.

Temperature Range, Operating. The temperature range in which a transducer may be operated without damage.

Thermal Sensitivity Shift. The sensitivity shift due to changes of the ambient temperature within the compensated temperature range.

Thermal Zere Shift. The change in output at zero applied force, when the transducer is subjected to changes of ambient temperature withir the compensated temperature range.

Threshold. The smallest change in force that will result in a measurabie change in transducer ou'sput. 
Total Error Band. The band of maximum deviations of calibration output values from a specified reference line or curve due to those causes attributable to the transducer.

Iransducer. A device which provides a usable output in response to a specified measurand.

Unbonded. Stretched and unsupported between ends (usually refers to strain-sensitive wire).

Uncertainty. Measurement. The collective term meaning the difference between the true value and the measured value. Includes both bias and random error. Implies small measurement error and small uncertainty. (See Reference 1-4.)

Verification. A verification confirms an established relationship to a standard. (Confirmation implies that no adjustments have been made since the last calibration because an adjustment might void the statistical history of the system.) Verification data are also used to compute the measurement uncertainty of the system, to compute a period of predicted satisfactory performance and to check the system for trends and excursions.

Vibration and Acceleration Error. The maximum change in output, at any force within the specified range, while vibration or acceleration levels of specified amplitude and range of frequencies are applied to the transducer along a specified axis at room conditions.

Working Standard. An instrument which is callbrated in a laboratory against an interlab or reference standard and is used as a standard in calibrating measuring instruments in place on the test stand.

Zero Shift. Any change in output at zero applied force.

NOTE: Definitions and nomenclature used in the glossary and throughout this handbook conform to the Instrument Society of America Standard for Electrical Transducer Nomenclature and Technology (Refererice 1-5) wherever applicable. 


\subsection{REFERENCES}

1-1. Standard Specifications and Test for Strain Gage Force Transducers, ISA-S37.8, Instrumentation Society of America, 1975.

1-2. Hydrazine Compatibility Design and Handling Criteria - Design Handbook, AFRPL-TR-75-6, TRW Systems Group, Redondo Beach, California, December 1975.

1-3. Morrison, R., Grounding and Shielding Techniques in Instrumentation, Second Edition, John Wiley \& Sons, New York, 1977.

1-4. ICRPG Handbook for Estimating the Uncertainty in Measurements Made With Liquid Propellant Rocket Engine Systems, CPIA Publication No. 180, ICRPG Performance Standardization Working Group, April 1969 .

1-5. Electrical Transducer Nomenclature and Terminology, ISA-S37.1, Instrument Society of America, 1969. 
APPENDIX I-A

THRUST MEASUREMENT SYSTEM ELEMENTAL UNCERTAINTIES

The following identifiable elemental uncertainties must be quantified in order to ascertain the overall uncertainty in the reported thrust measurement. The reference document for the calculation of this uncertainty is the ICRPG Handbook for Estimating the Uncertainty in Measurements Made With Liquid Propellant Rocket Engine Systems, Reference $1-4$.

I.

STANDARDS CALIBRATION SYSTEM

A. National Bureau of Standards

Overall uncertainty, including bias and precision.

B. Interlat Standard

Overall uncertainty, including bias and precision.

C. Reference Standards

Overall uncertainty, including bias and precision.

D. Working Standards

1. Residual bias from curve fit.

2. Variance of the data about the data curve.

II. THRUST STAND

A. Stand Calibrator

1. Residual bias from curve fit.

2. Variance of the data abolit the data curve.

B. Thrust Frame

1. Residual bias from thrust stand restraints.

2. Bias caused by propellant line pressure change.

3. Bias caused by propellant line temperature change.

4. Bias caused b; propellant finw.

5. Bias caused by engine weight change.

C. Measurenent Force Transducer

1. Residual bias from curve fit.

2. Variance of the data about the data curve.

3. Bias caused by pressure change. 


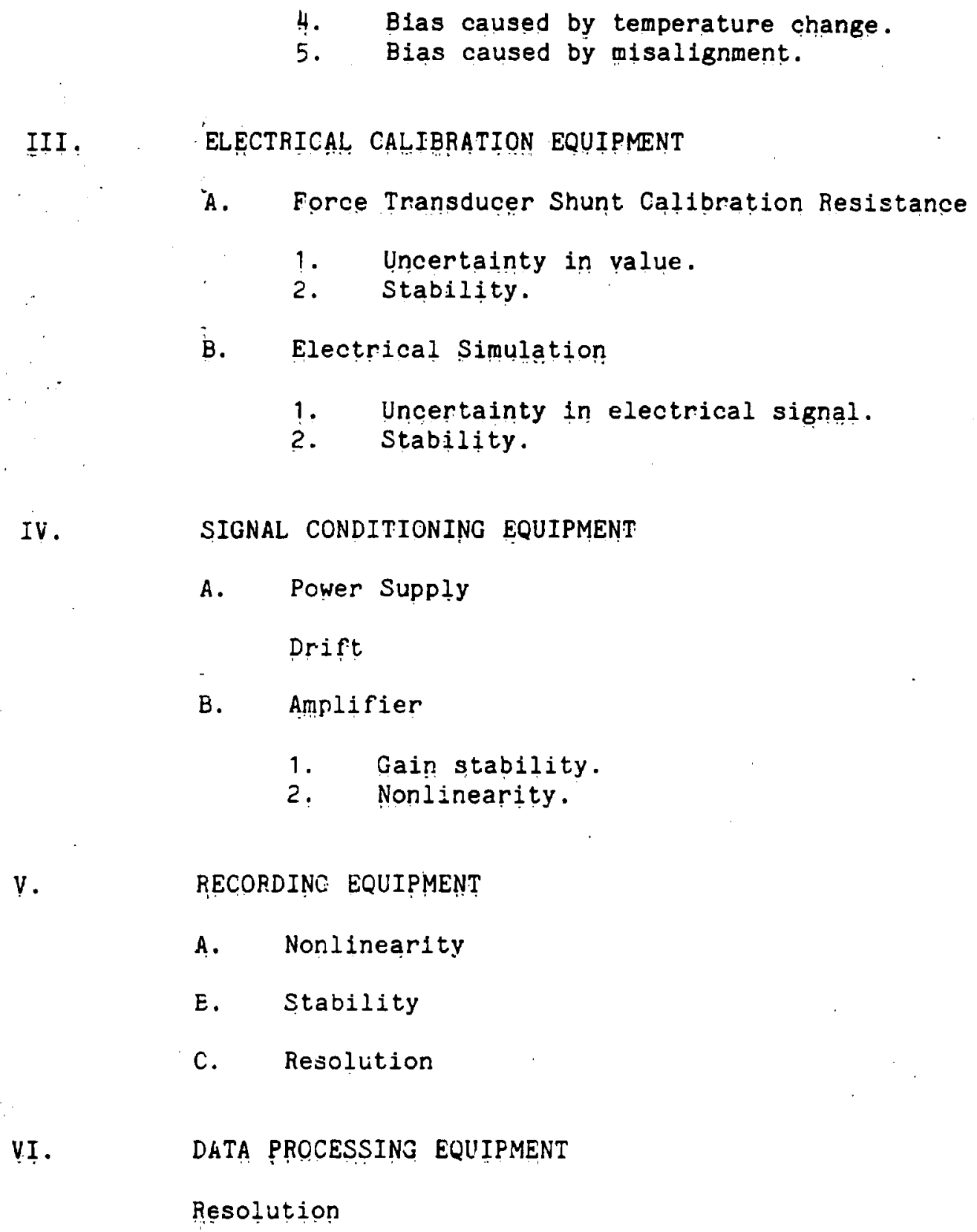
A. Nonlinearity
E. Stability
c. Resolution

VI. DATA PROCESSING EQUIPMENT

Resolution 


\title{
APPENDIX I-B
}

\author{
SHORT- AND LONG-TERM THRUST MEASUREMENT SYSTEM UNCERTAINTY
}

Short-term thrust measurement system uncertainty is determined from verification data taken at frequent intervals. The elapsed time between these verifications must be at least equal to the anticipated elapsed time between the pretest and posttest verifications. Long-term uncertainty uses data from verifications taken at least 48 hours apart. The data must be analyzed to determine the thrust measurement system uncertainty. If the required uncertainty limits are met using the data from the long-term verifications, the test data are to be reduced based on the long-term average data reducing factor. If the limits. cannot be met, then the test data may be reduced based on the shortterm average data reduction factor.

New verifications are added to the statistical history of the system on a periodic basis. Ideally, this period should be a function of the ratio of the maximum allowable uncertainty to the observed uncertainty, the average time elapsed between verifications, and the rumber of verifications being used in the current evaluation. After each addition is made, the system should be analyzed to check for compliance to the uncertainty limits, and a new average data reduction factor is generated. Testing should be allowed to continue as long as the uncertainty limit is not exceeded. Once the uncertainty limit is exceeded, engine testing should be stopped, and the system should be improved. Subsequent to the improvement, a rew statistical history should be started.

The following additional requirements should be piaced on the verification data used in the analysis of the thrust measurement system.

(1) Only veriflcations made since the latest calibration should be used.

(2) Only the most recent verifications shodld be used. (It is recommended that this be limited to the last ten samples. A sample size of 10 is large enough to obtain a good statistical average for tine data reduction factor but 3 mall enough.so that trends can be detected.)

(3) Verifications resulting from arroneous procedures or failty verification equipment should be exclucied after proper documentation.

(4) All valid verifications meeting these requirements are to be included in the statistical history of the system.

It is also recomriended that a chart be kept for each verification showing: (1) the simulated data level (in newto:.s or pounds 
force), (2) the level of the simulation signal (in millivolts), (3) the system sensitivity or data reduction factor (in newtons per millivolts or pounds force per millivolts), (4) the system unbalance at zero load (in millivolts). With this chart, potential system problems can be spotted. The successive simulated data levels and system unbalances should remain constant, whereas the values of simulation signal and system sensitivity may vary in opposite directions as shown in Figure I-B-1.

The relationship between calibration and verification data as well as the relationship between short-term and long-term uncertainty is shown in the block diagram in Figure I-B-2. The typical paths for corrective action that can be taken when the system requirements are not met are also shown in Figure I-B-2. 

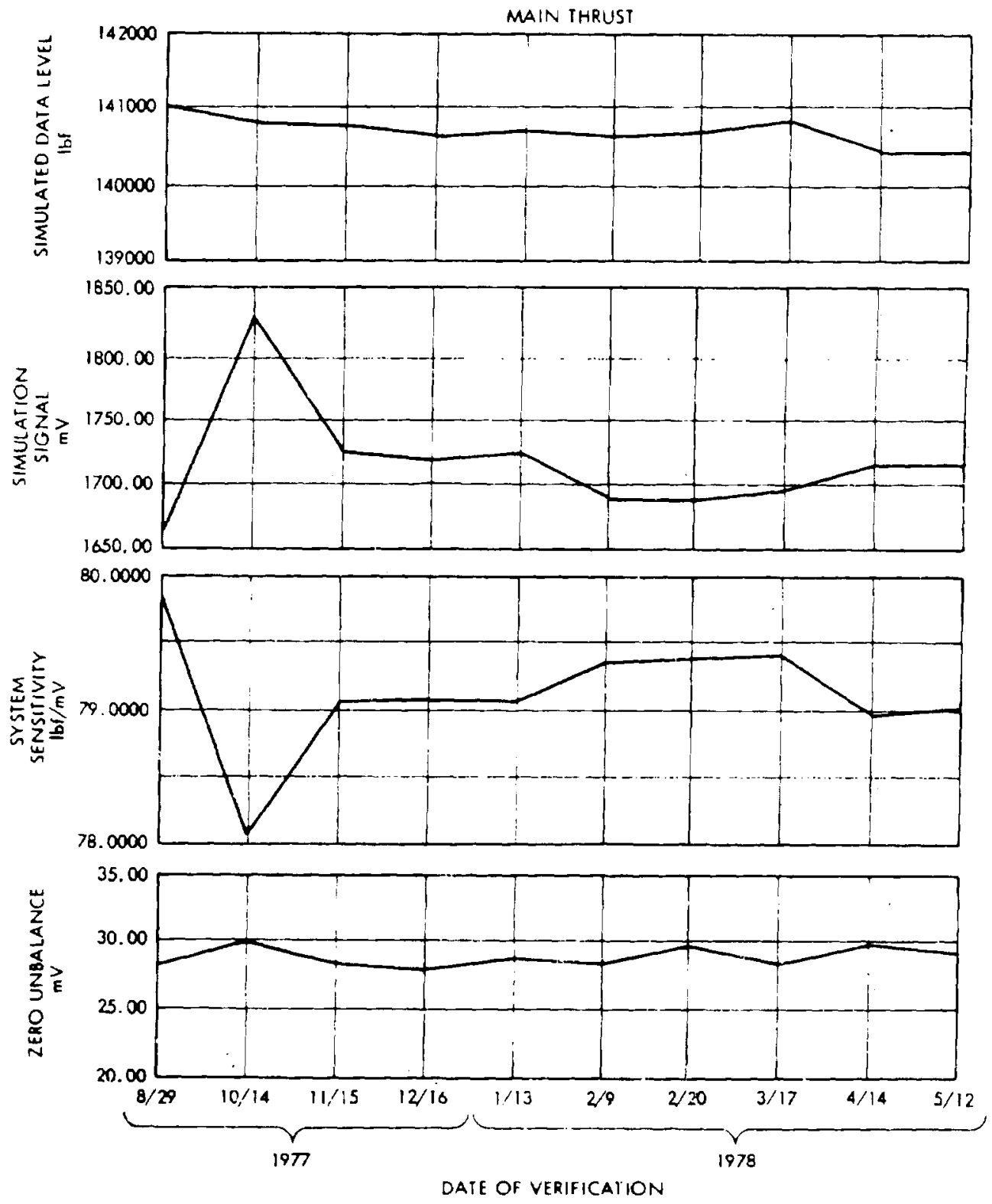

Figure I-B-1. Example of Control Data for Uncertainty Checks 


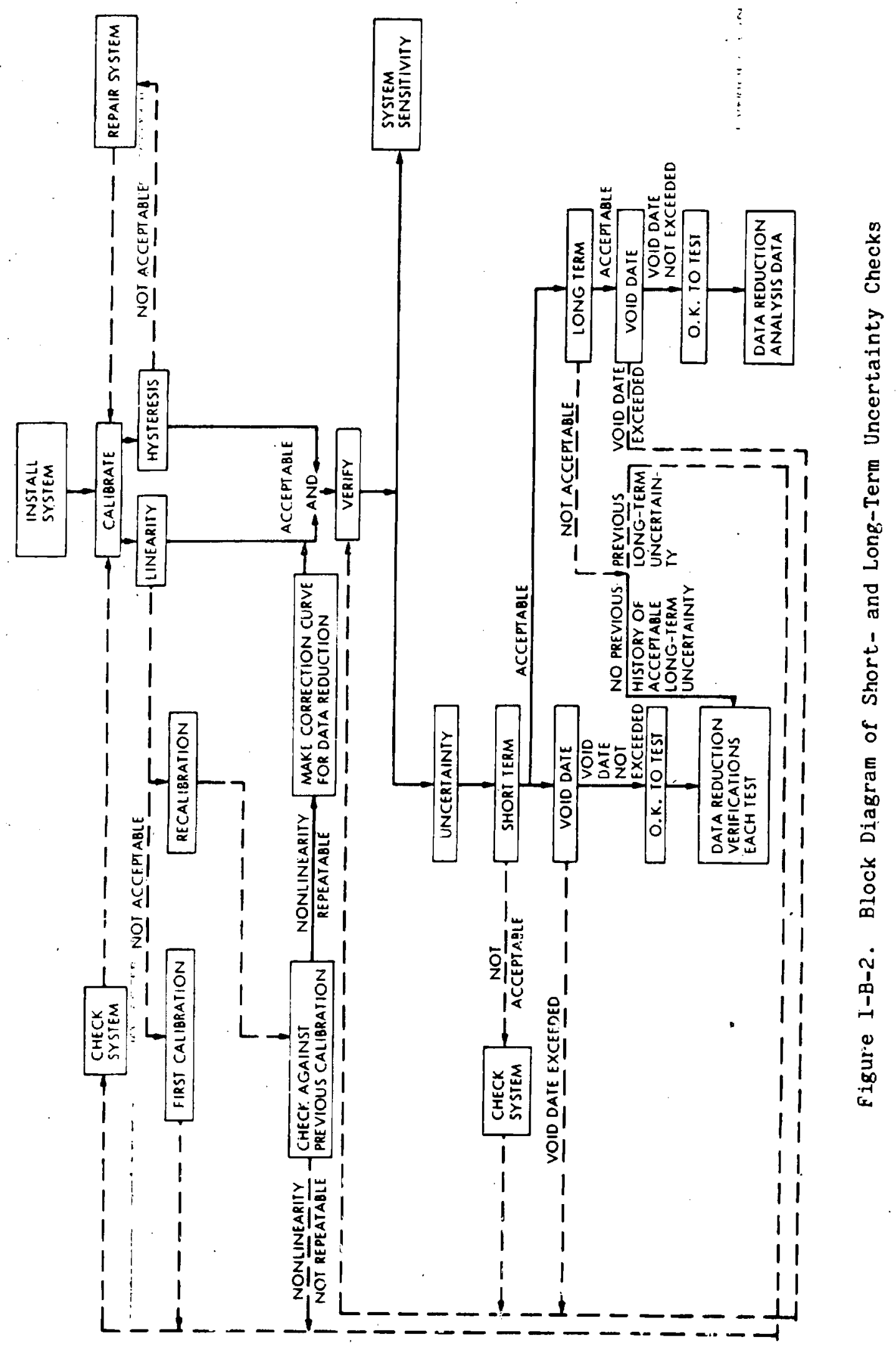


It is beyond the scope of this document to provide an indepth mathematical analysis of all possible configurations, techniques and sources of error associated with shunt calibration. Instead, discussion will be confined to a 6-wire measurement system and a single method of applying the calibration resistor. For a discussion of the effects and possible sources of error from several circuit and procedure variables, see Section III - Pressure Measurement, Reference 3-9, A Guide for the Static Calibration of Pressure Transducers.

\section{CIRCUIT CONFIGURATION}

Figure I-C-1 shows a 4-arm bridge circuit with balancing network and shunt calibration resistor. The 6 wires that make up the transmission lines are of equal size and thus have approximately equal resistance ( $R$ line). The values of the balance and limiter resistors are typical for this corfiguration. The shunt calibration resistor shown in Figure $\mathrm{I}-\mathrm{C}-1$ produces a positive signal output when the calibration switch is closed.

\section{DETERMINATION OF CALIBRATION RESISTANCE VALUE}

The values of the calibrating resistors $\left(R_{c}\right)$ used will vary according to the preferences of the user. In some instances standard values of $R_{c}$ are chosen to fairly close tolerance and the shunt-to-force correlation vaiues are allowed to vary from iransducer to transducer. This results in uneven correlation values, a situation of no consequence so long as the precise values for the individual transducens are used. In ocher applications the preference is to trim the bridge resistance and transducer sensitivity so that a constent value of $R_{c}$ will produce the same percent of flill scale output in all similar transjucers. Ej.ther technique will work so long as a consistent procedure is followed and the measurement techniques are understood by those involved.

The sensitivity adjustment resistor $R_{S}$ is normally split equaliy between the two excitation leads. In this case $\beta=0.5$. Also, under this condition the effects of ali other resistances excepi $R$, the bridge resistance itself, or $R_{\text {ealibrate }}\left(R_{c}\right)$ are zero or negligible. $R_{c}$ can be determined by:

$$
R_{c}=\frac{R}{4 K S}-\frac{R}{2}
$$

where $R_{c}$ is the calibration resistance value, $R$ the bridge resistance, $K$ the percentage of full scale output, desired $(10,25,50 \%$, etc.: and $S$ the full scaie sensitivity of th.e transducer in volts cutput/volts excitation ( $C .002,0.003$, etc.) For a transducer with a 350-ohm bridge and $3 \mathrm{mV} / \mathrm{V}$ sensitivity, the following $R_{c}$ valutes and percent of full scale output values correspond: 


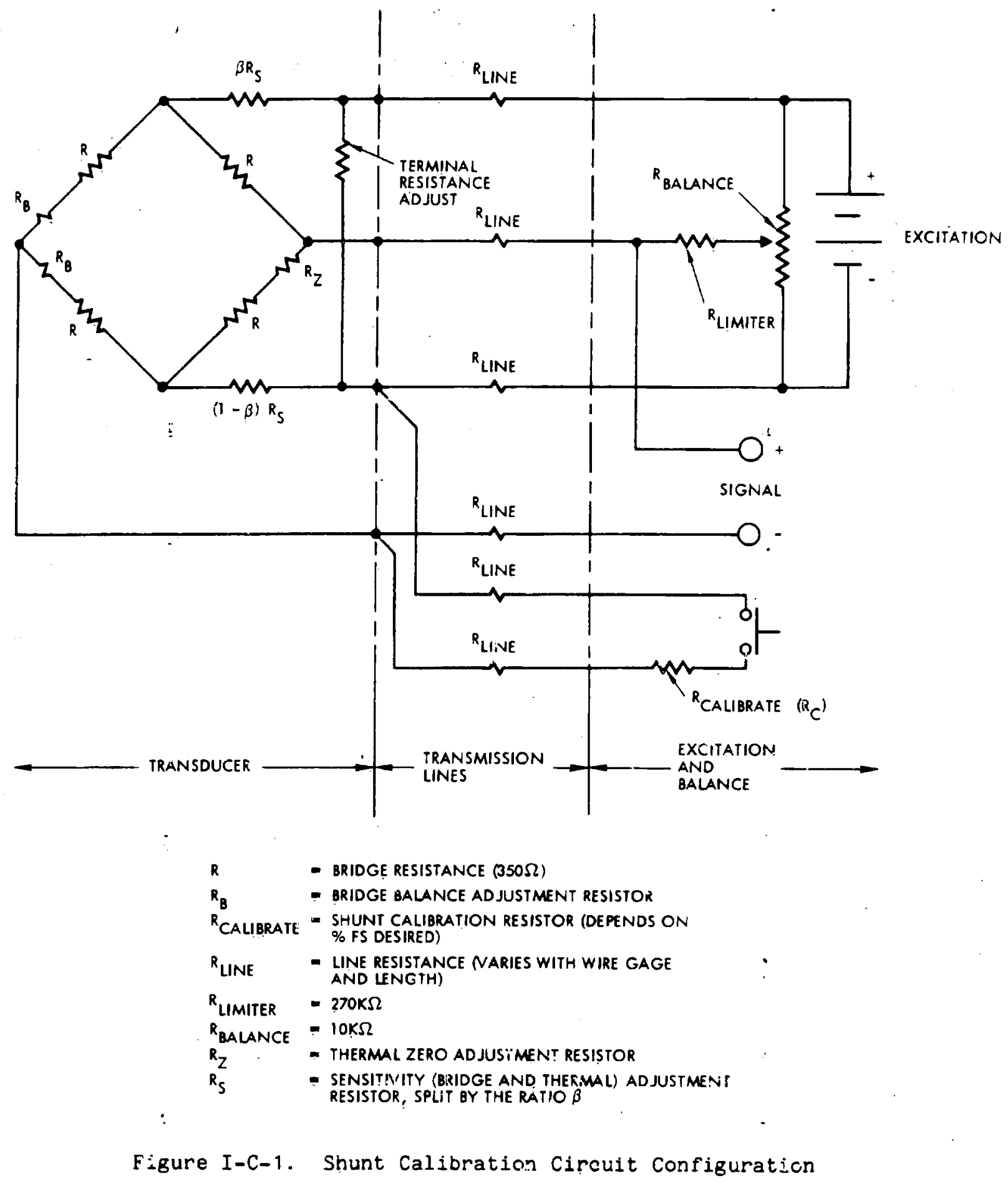




\begin{tabular}{rr}
\multicolumn{1}{c}{ FS } & $\mathrm{R}_{\mathrm{c}}$ (ohms) \\
\cline { 2 - 2 } 10 & $291.5 \mathrm{~K}$ \\
25 & $116.5 \mathrm{~K}$ \\
50 & $58.2 \mathrm{~K}$ \\
80 & $36.3 \mathrm{~K}$ \\
100 & $29.0 \mathrm{~K}$
\end{tabular}

In the foregoing example, bridge resistance and sensitivity are nominal values and will vary from one transducer to another. Sensitivity can be standardized with adjustment of $A_{S}$. Variations in bridge resistance will result in changes in $K$ for a given $R_{C}$. Transducers are sometimes standardized for output due to shunt calibration by varying $\beta$, the ratio of the split in $R_{S}$ between the two excitation leads. The computation however becomes more complex:

$$
R_{c}=\frac{R\left(R+2 \beta R_{S}\right)-R K S\left(2 R+3 R_{S}\right)-4 \beta K S(1-\beta) R_{S}^{2}}{4 K S\left(R+R_{S}\right)}
$$

The third term in the numerator has negligible ef fect on the result, so that a simplified expression for $\beta$, when $R_{c}$ and $S$ are standardized, becomes:

$$
\beta=\frac{4 R_{s} K S\left(R+R_{S}\right)+R K S\left(2 R+3 R_{S}\right)-R^{2}}{2 R R_{S}}
$$

Standardizaticn of output due to shurt calibration adds complexity and cost to the measurement process and has no advantage in modern automated data reduction. It is therefore no: recommended. Standard $R_{c}$ values should be used and the resultant $K, q F S$, allowed the small variations from one transducer to anotrer. $R_{S}$ should be split equally in each excitation lead.

\section{MEASURING AND CONPUTING SHLNT-TO-FORCE CORRELATION}

Shunt-to-force correlations are usually determined under laboratory conditions as part of the routine transducer calibration. When such is the case the transducer outputs at various loads are recorded and upon return to zero load the desirec calibration resistor(s) are applied and the correspondirg output(s) recorded. Data taken in this manner has the advantage of containing little, if any, time dependent variations.

To calculate the shunt-to-force correiation in engineering units for a particular $R_{C}$, the "ollowing formula mey be used:

$$
R_{c} \text { (equivalent) }=\frac{E_{r}}{E_{f}} \times F
$$


where $E_{r}$ is the output produced by application of $R_{c}$, and $E_{f}$ is the output produced by a particular force $F$. For instance, where $E_{r}=15.535$ and $E_{f}=15.123$ at $500.000 \mathrm{~N}$ the shunt-to-force correlation or equivalent value of $R_{c}$ would be $513.622 \mathrm{~N}$.

Then, in a measurement application, if the same value $R_{c}$ produces an output of 14.926 and the measurand produces an output of 16.204 the value of the measurand $(M)$ can be determined by:

$$
\begin{aligned}
M(N) & =\frac{E_{m}}{E_{r}} \times R_{c} \text { (equivalent) } \\
& =\frac{16.204}{14.926} \times 513.622 \\
\text { Measurarid } & =557.600 \mathrm{~N}
\end{aligned}
$$

Generally, if there is a choice of more than one $R_{c}$ to use during a test, the one nearest the expected value of the measurand will provide data with the minimum of uncertainty. 
SECTION II

PROPELLANT MASS USAGE AND FLOW MEASUREMENT

$2-i$ 
SECTION II

PROPELLANT MASS USAGE AND FLOW MEASUREMENT

CONTENTS

1.0

INTRODUCTION -

2.0

SCOPE -

2. 1 OBJECTIVE - $2-1$

2.2

LIMITATIONS

$2-1$

3.0

DESIGN CONSIDEFATIONS -

3.1

MECHANICAL COMPONENTS -

3.1 .1

Piping System -

3.1.2 Turbine Flowmeter -

3.1.3 Positive Displacement Flowmeter

3.1.4 Calibration System

3.2 ELECTRONIC AND ELECTRICAL SUBSYSTEMS -

3.2.1 Signal Detection and Transmission -

3.2.2 Signal Corditioning -

3.2.3 Recording - R $2-12$

4.0 INSTALLATION AND CHECROUT PROCEDURES -

4.1 COMPONENT CERTIFICATION -1

4.1.i Measurement Flowmeters, General

4.1.2 Turbine Flowmeter -

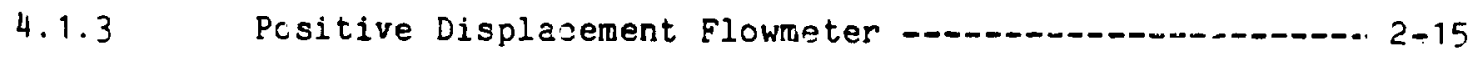

4.1.4 Working Standard Flowmeter

4.1.5 Ir.-place Measuring Vessel

4.2 FLOW SYSTEM $-1.10-17$ 
5.0

5.1

5.2

5.3

5.4

5.5

6.0

6.1

6.2

7.0

7. 1

7.2

8.0

9.0

A PPENDIX

II-A

\section{Eigures}

$2-1$

$2-2$

$2-3$

$I I-A-1$
CALIBRATION AND VERIFICATION PROCEDURES -

IN -PLACE CALIBRATION

LABORATORY CALIBRATION -

TURBINE FLOWMETER -

POSITIVE DISPLACEMENT FLOWMETER

VERIFICATION PROCEDURES.

OPERATING PROCEDURES

$2-23$

PRETEST PROCEDURES

$2-23$

POSTTEST PROCEDURES

DATA ACQUISITION A.ND PROCESSING TECHNIQUES -

CALIBRATION AND VERIFICATION DATA

RUN DATA

$2-25$

GLOSSARY -

REFERENCES -

i

FLOWMETER MEASLREMENT ELEMENTAL UNCERTAINTIES _....

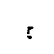

Flow Measurement System Scrematic Diagram -

Typical Flow Straightentr

Test Flow Measurement System Blnck Diagram _.

Flowreter Measurement Eiemenial Uncertainties - - .....-- 2A-2

$\checkmark$

-

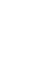




\title{
SECTION II
}

\author{
PROPELLANT MASS USAGE AND FLOW MEASUREMENT
}

\subsection{INTRODUCTION}

Recommended practices are outlined for the design, installation, checkout, calibration, and operation of a flow measuring system to be used during tests of a liquid monopropellant rocket engine. One appendix is included: Appendix II-A, Flow Measurement System Elemental Uncertainties.

\subsection{SCOPE}

This section has been written to serve as a guide for the experienced engineer in the design, installation, and operation of a flow measurement system for measuring propellant flow in a liquid monopropeliant rocket engine. Design guidelines rather than detailed specifications are provided for the sritical components of each portion of the system. These guidelines, used in conjunction with current state-of-the-art, comercially available equipment and good engineering practices, will provide a flow measurement system which meets the performance criteria specified.

2.1

\section{OBJECTIVE}

Measurements of propellant flow are extremely important in datermining performance of a rocket engine since these measurements are used directly ir. tise calculation of engine specinic impulse and characteristic velocity. The recommendations in this section are directed toward measurement uncertainty goals as follows:

\section{Elok Range}

$2.3 \times 10^{-5}$ to $2.3 \times 10^{-2} \mathrm{~kg} / \mathrm{s}$

$\left(5 \times 10^{-5}\right.$ tc $\left.5 \times 10^{-2} 1 \mathrm{bm} / \mathrm{s}\right)$

$2.3 \times 10^{-2}$ to $2.3 \mathrm{~kg} / \mathrm{s}$
Mode of Operaticn

Steady state

Pulse mode ( $5 \pi \mathrm{s} \mathrm{min}$.

Steady istate

Pulse mide ( $50 \mathrm{~ms}$ min.)
Uncertainty

in Measurement

$\pm 0.50 \%$

$\pm 2.0 \%$

$\pm 0.25 \%$

$\pm 1.00 \%$

\subsection{LIMITATIONS}

Normally, propullant mass flow determinations are made by use of individual measurements of volumetrj.c fl.ow, propeilant temperature and pressure. The latter two measuremerts are used to obtain the propellant density in order to convert the volumetric slow to a masis flcw. Recommended pactices for propellant pressure and temperature measurements are covered in Sections III and IV. Inis section is limited to recommendec p:actices for the measurerient of rolumetric propeliant flow by the use 
of turbine flowteters for steady state test operations and positive displacement flowmeters for pulse mode or short steady state operations. Although most of this information was developed from experience with monopropellant hydrazine, it is equally applicable to other liquid monopropellants such as hydrogen peroxide.

\subsection{DESIGN CONSIDERATIONS}

The design of the flow measuring systems requires consideration of the type of flowmeters, the piping system, the measured fluid, and the support measurements (temperature and pressure). Because of the unknown effects of the piping system, it is recommended that measurement systems be designed with in-place calibration capability so that these effects are essentially calibrated out. This is not always possible, however, and many systems include calibration of the flowgeter off site on similar piping configurations using a substitute liquid such as water. Since both in-place and laboratory calibrations are in prevalent use, the following recommendations are categorized into the two groups as applicable.

\subsection{MECHANICAL COMPONENTS}

In designing the flow measuring system, the following mechanical components are of primary importance:

3.1.1 Piping System (see Figure 2-1)

(1) The system should be designed to include an in-place flowmeter calibration and verification system.

(2) Return flow and tanking should be accomplished through plumbing other than that containing flowmeters being calibrated.

(3) Materials selected for the tankage, piping, and related components should be selected to be compatible with the monopropellant over a long exposure time at the maximum temperature and pressure specified for normal test operations. (Hydrazine compatibility design and handling criteria are given in Peference 2-1.)

(4) The system should be designed for long-term thermal

: conditioning $\left(0^{\circ}\right.$ to $80^{\circ} \mathrm{C}$, or $32^{\circ}$ to $175^{\circ} \mathrm{F}$, for hydrazine) from the propellant supply tank to the test engine interface.

(5) The piping system should provide for two or more turbine flowmeters in series. These should be insialled per the recommended practices given in ISA-RP31.1, Feference 2-2. 


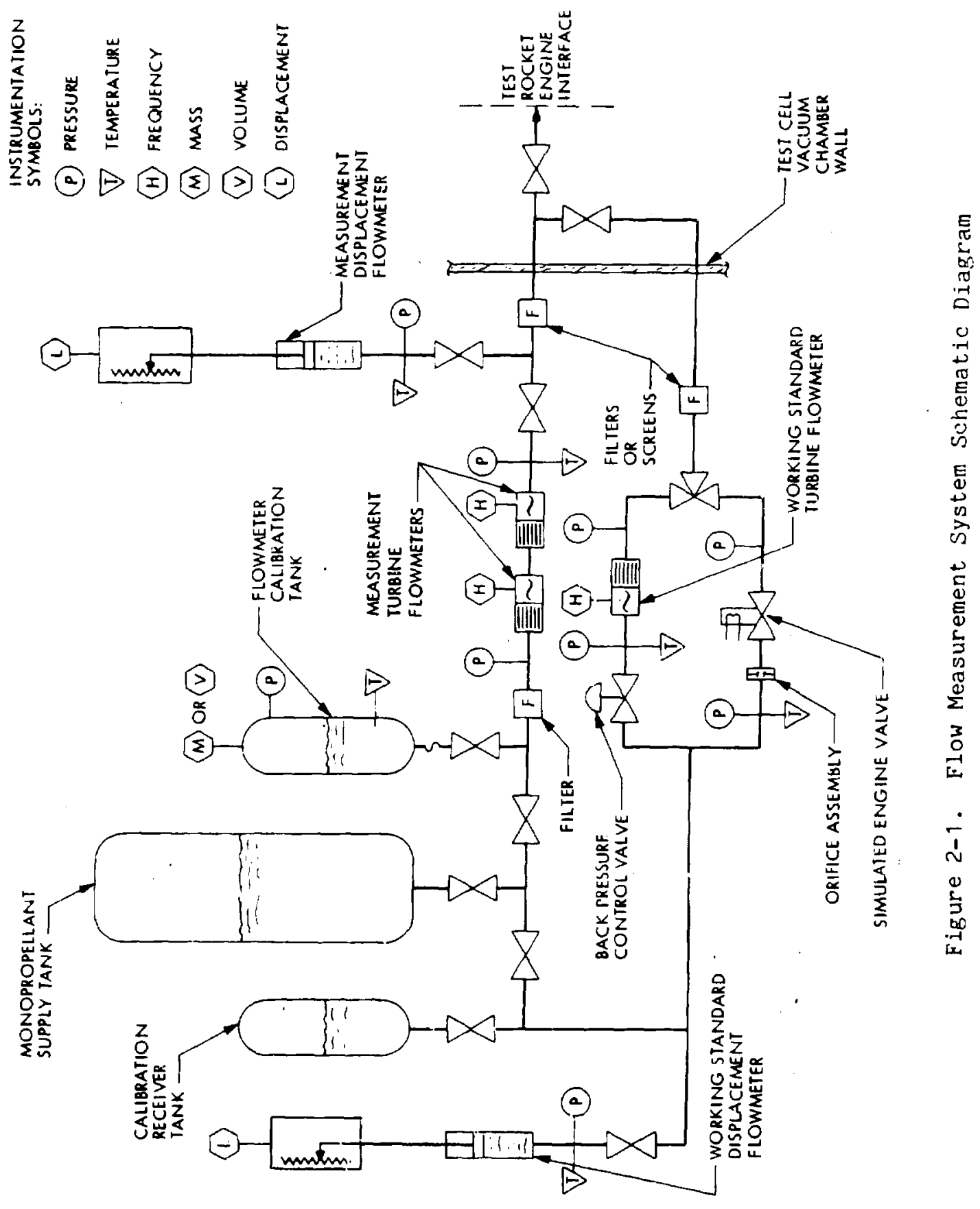


(6) The positive displacement flowmeter should be installed as close to the test engine interface as practical and should be capable of operation independent of the turbine flowmeters.

(7) The propellant piping upstream should contain a filter (or filters) to guard against foreign particles reaching the flowmeter. An additional filter or screen should be installed downstream to prevent damaged flowmeter parts from reaching the engine. The degree of filtration required is a function of meter size and typically ranges from 10 to $50 \mu \mathrm{m}$.

(8) Flow straighteners should be installed at or near the entrance of the turbine flowmeter (Figure 2-2). These may be part of the flowmeter itself.

(9) The propellant piping upstream and dewnstream of the turbine flowmeter should be constant diameter straight sections at least 20 pipe diameters upstream and 5 diameters downstrean from the flowmeter.

(10) Interconnection piping of the flowmeters should be of tre same size or the transiticn should be smooth to avoid introducing inlet/outlet disturbances. The trarsition angle should be no greater than seven degrees.

(11) Adequate taps, installed per ISA recommended practices (Reference 2-2), should be fitted in the propellant piping system to accept temperature ard pressure transducers downstream of the flowmeter. A pressure tap should also be installed upstream of the flowmeter to permit the measurement of the pressure drop across the floweter. These measurements of temperature and pressure should represent conditions at the flowmeter and should have a minimum eifect on the flowmeter output.

(12) Turbine floweter overspeeding should be minimized by opercting technlques and/or devices and the turbine flowmeter should be isolated from pulsed flow conditiors.

(13) Flow throttliag should be accomplished downstream of the flowmeter.

(14) Cire should be taken to zuard against two-phase flow, which may occur du.'ing engine start and shutdow: transients.

(15) The piping fros the tank to the engine should not incluce sections in whicin gas can be trapped. 


$$
\begin{aligned}
& D=\text { TRANSFER INLET I.D. } \\
& A \geq 20 \\
& B \geq 80 \\
& d \leq D / 4
\end{aligned}
$$
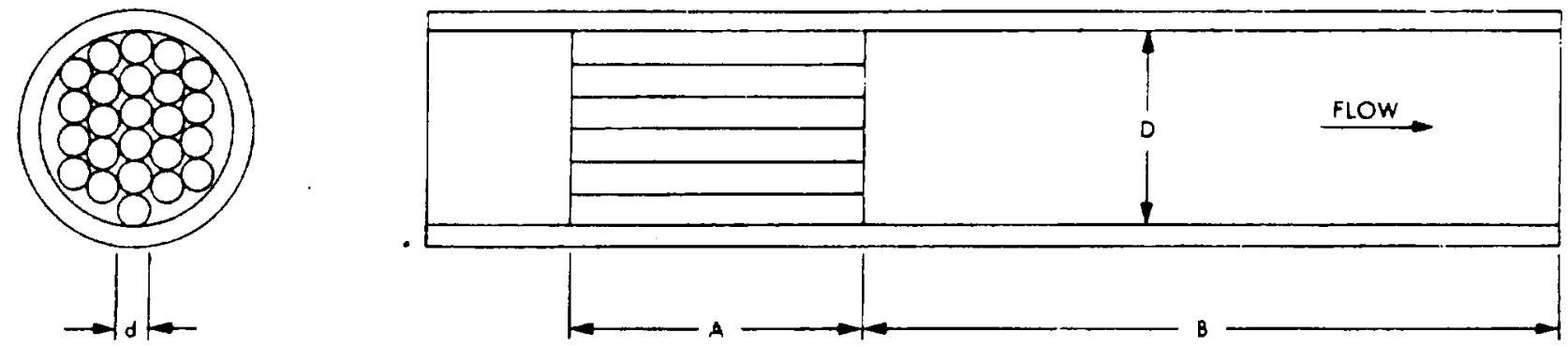

Figure 2-2. Typical Flow Straightener (Reference 2-3)

(16) The flow piping system should have venting capability at its highest point(s) and draining capability at its lowest point(s) with respect to gravity.

(17) Vent and drain lines should be accessible for either visual or instrument monitoring for leakage.

(18) Adequate installation and removal equipment should be provided for handling of larga flowmeters.

(19) Flowmeters should be well isoiated from the shock and vibration caused $0 y$ engine and facility equipment operation.

\subsubsection{Turbine Flowmeter}

The turbine flowmeter with an electrical output is an in-line flow measuring device in which the action of the entire fluid stream in the containing line turns a multibladed turbine at a rotational speed nominally proportional to the rluid volumetric flow. The turbine bledes, combined with a transduction coil, generate or modulate an electrical output signal at a frequer:cy proportional to the turbine rotational speed. The major design considerations for a turbine flowmeter are given in ISA-RP31.1 (Feference 2-2) and are summarized below:

(1) Material selection fo: the wetted parts is determined by compatibiiity with the propellant (for hydrazire, see Reference 2-1).

(2) Type of end connections and nominal size (fiare tube, pipe threads or flarized).

(3) Type of mounting, dimensional size and location, including any lifting provisions. 
(4) The maximum and minimum operating temperatures of the propellant and of the surrounding environment.

(5) Maximum operating pressure of the prcpellant.

(6) Maximum allowable output frequency.

(7) Excitation for modulating types expressed as voits ac/dc at rated frequency.

(8) Output voltage expressed as minimum volts peak to peak within the operating flow range.

(9) Dutput frequency at maximum rated flow.

(10) Normal operating flow range and the extended operating flow range.

(11) Linear operating flow range.

(12) Normal sensitivity ( $K$ factor) over nornal operating range or average sensitivity $\left.\left[\bar{K}=\left(K_{\max }+K_{\min }\right) / 2\right)\right]$ over a specified flow range expressed as frequency per unit volume.

(13) Linearity of the flow vs frequency curve expressed as percentage of average sensitivity ( $\bar{K}$ factor). Turbine flowmeters used in very low flow application generally do not have acceptabla linear sensitivity (constant $k$ factor). However, there are models available which do have acceptable repeatability of better than $\pm 0.25 \%$ of reading. In this instance, a nonlinear polynomial expression for sensitivity resulting from the best curve fit of calibration data is justified.

(14) Pressure drop across the flowmeter at maximum rated flow for specified propellant.

\subsubsection{Positive Displacement Flowmeter}

A positive displacement flowmeter with an electrical output is a flow measuring device in which the incremental volume of fluid expelled under pressure from a confining vessel is continuously monitored by a displacement transducer. The tráasducer generates an electrical signal proportional to the displaced volume. The integrated change in volume par unit time is the measured volumetric flow. Various types of expulsion devices are in use including a piston tank metal teliows tank, or direct reading servomanometer. The types of displacement transducers inclide linear potentiometer, linear va"iable differential transformer (LVDT) and linear variable reluctance transformer (LVFT).

In monopropellant rocket engine testirg the time interval for volume displaceinent is measured between the opening and closing of the eagine propellant valve, utilizing either the valve voltage or current 
signal. In pulse mode engine testing, where vaive on-times are very short, the displaced volume is often totalized for a series of pulses (pulse train) and then proportioned mathematically for each pulse.

The major design considerations for a positive displacement flowmeter are listed below:

(1) Material selection for wetted parts is determined by compatibility with the propellant (for hydrazine, see Reference 2-1).

(2) Type and size of liquid end connection.

(3) Type, size, and method of expulsion.

(4) Type, size, and location of mountings.

(5) Maximum volume of propellant required.

(6) Minimum resolution of incremental volume required for pulse mode operation.

(7) Normal operating flow range for steady state operation.

(8) Maximum operating pressure.

(G) Provisions for priming, bleeding, and purging.

(10) Maximum and minimum operating temperature of propellant ano surrounding environment.

(11) Linearity of expelled volume expressed as percertage of total volume.

(12) Excitation requirements of displacement transducer.

(13) Resistance or impedance of transduction element.

(14) Output signal type and range.

(15) Output signal impedance.

(16) Normal sersitivity ( $K$ factor) over norrial operating range or average sensitivity $\left[\left(\bar{K}=\left(K_{\max }+K_{\min }\right) / 2\right]\right.$ over a specified flow range expressed as output signal quantity per unit volume of fluid displaced.

(17) Linearity of output signal versus volume curve expiessed as percentage of average sensitivity.

(18) Response expressed as aise time anj tracking abilicy for transient fiows. 
(19) Instability resulting from thermal or electrical changes.

(20) Vibration and shock sensitivity.

3.1.4 Galibration System

The flowmeter calibration system should utilize gravimetric, volumetric, or comparison methods of calibration. These three methods are described in detail in Reference 2-2.

If the gravimetric method is used with a calibration fluid other than the propeliant to be measured, an accurate determination of the calibration fluid density must be made for converting weight to volume. The effect or gas in a closed, weighed tank must also be considered. The volumetric and comparison methods, on the other hand, yield the displaced volume or volumetric flow directly.

Calibration systems may be further classified as static or dynamic with reference to the flow of the calibration fluid. The static method requires that the weight or volume of displaced fluid be measured in discrete steps at no-flow conditions, i.e $\therefore$, the liquid is not flowing into or out of the measurement vessel during the measurement. It is recommended that positive displacement flowmeters be calibrated using the static method for pulse flow and short steady state flow applications.

In the dynamic calibration method, the calibration fluid is flowing througin the flowmeter which is being calibrated and may be flowing into a measurement vessel or throligh a reference flowmeter. It is recommended that turbine flowmeters be calibrated using the dynamic method.

3.1.4.1 In-place Calibration. The following ane recommended design considerations for the in-place flowneter calibration system:

(1) It should be an integral part of the fiow measuring

system (Figu:e 2-1).

(2) It should be capable of messuring the nonopropellart

1 flow at the nominal test temperature and pressure conditions.

(3) Calibration flow shculd range above and below nominal test flow.

(4) Calibratior: should be possible during an engine hot firing or at least with the test ceil at operating conditions.

(5) Sensitive calibrating instruments shoulc be protected from vibration and shock caused by normal test operations. 
(6) Working standard flowmeters should be included for pretest and posttest verification by the method of comparison.

(7) The monopropellant used for calibration and verification should be collected in a receiver tank for lacer return directly into the test supply tank without reverse flow through the flow measuring system.

(8) Flow control valves must be located in the calibration branch line to maintain the desired flow and back pressure.

(9) Separate branch lines should be used for steady state flow calibration and pulse jode calibration to prevent damage to the working standard turbine flowmeter.

(10) Dynamic flow characteristics of the pulse mode calibration system should simulate the test engine/valve assembly. A flow control (solerioid) valve should have opening and closing response times similar to the engine injector valve. Also, a flow restrictor orifice should be included which is sized to produce the injector/engine system pressure drop.

(11) Pressure and terperature measurements should be made at both the measurement flowmeters and the flow calibration device.

(12). All calibration system weights and measures should be certified by reference standards traceable to the National Bureau of Standards.

3.1.4.2 Laboratory Calibration. The following are some recommended design considerations for the laboratory flowmeter calibration system:

(1) Water is normilly used as the su'jstitute liquid because it has a kinematic viscosity and specific gravity within 10\% of most monopropellants; also, it has similar lukinicity.

(2) Floweter installation stould include the same type o: flow straightener, straight length of line, line size, and location of pressure and temperature tiransducers as used in the cest cell configuration.

.3) The flowmeter and electrical transduction element should have the same orientation as the test configuration.

(4) The line syatem becween the flowmeter and the measurtment vessel should be short and contain a sma:- volume compared to the measured voluine.

(5) A flow control valve must be located downstream of the flowmeter to maintain desired flov and back presstre. 
(6) A filter ( 10 to $50 \mu \ddot{m}$ ) should be included ahead of the flowmeters to prevent contamination or damage.

(7) There should be provisions for priming and bleeding the line system and to assure that all the calibrating water passing through the flowmeter is measured without any leakage.

(8) The system should be capabie of flowing water at the simulated test temperature and pressure conditions.

(9) Pressure and tèmperature should be measurèd at both the measurement flowmeter and at the calibration device.

(10) Calibration flows should encompass the entire range of interest for the flowmeter.

(11) All laboratory weights and measures should be certified by interlab standards directly traceatle to the Nationai Bureau of Standards.

In designing a test flow measuring system the following electrical and electronic components are of primary importance. They are shown as a block diagram in Figure 2-3.

\section{2.i Signal Decection and Transmission}

(1) The flow measurement system signal-to-noise ratio must be a minimum of $10: 1$.

(2) The flow transducer and cabiins should be "isolated from extraneous magnetic fields.

(3) Some form of electrical simulation of trañsducer output signal should be provided. The transduction coil of salf-generating turbine flowneters can be verifiej by lising an electromagnetically induced signal. An alternate method would be to use fregcency substitution by connecting an oscillator in barallel with the transduction coll. The linear position transducer of a positive displacemeat flowmeter can be simulated using voltage substitution by connecting a power source in parallel with the transducer.

\subsubsection{Signel Conditioning}

Most electronic and electrical equipment used in coijunctiois with test stand operations is available from more than one manufacturer. 


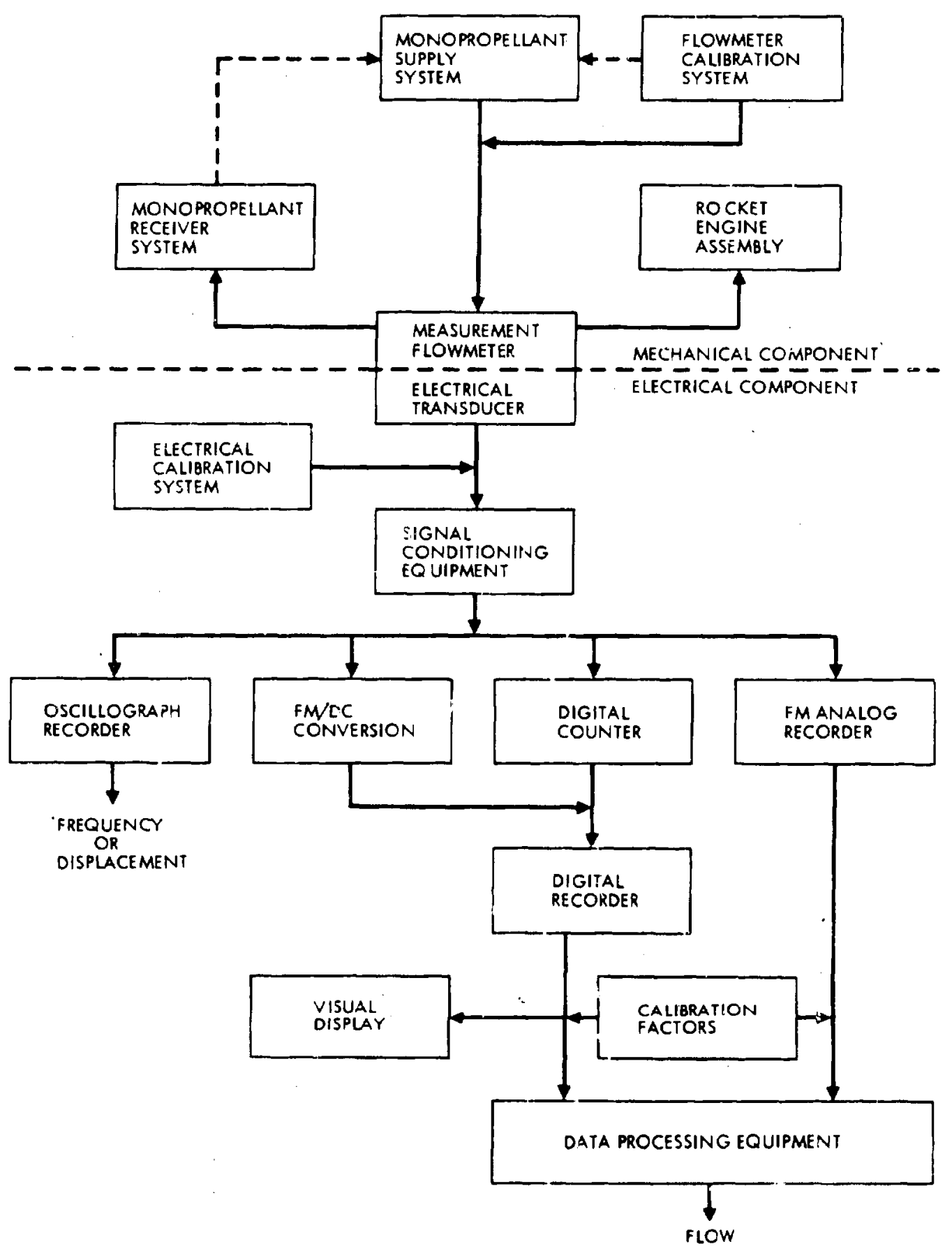

Figure 2-3. Test Flow Measurement S:stem Block Diagrar:

The main concers with component selection will be in evaluating the various manufacturers' specifications in reiation to the pariicliar flow measuring requirements. A suoplementai verification that the equipment complies with the manufacturer's specification is essential. 
Signal conditioning equipment includes the following functional devices: power supplies, amplifiers, electrical cabling, shielding, signal distribution and switching network, and filters. The regulation and stability of this equipment should be $\pm 0.05 \%$; or better, wherever applicable. :The design of these devices varies widely depending on system philosophy and economics; however, certain design principles are universally recommended as follows:

(1) Minimize thermally induced errors in all circuits

- when applicable.

(2) Suppress through filtering all signal components that adversely affect the quality of recorded data. The recording system chosen should have a high enough frequency responise to faithfully record all frequencies of interest.

(3) Minimize electrical noise by the use of proper shieloing and grounding techniques (Reference $2-4$ ).

(4) The floweter/signal conditioning circuit should provide open circuit Indicaticn.

(5) Utilize high-quality equipment providing stability (both with time and temperature), line voitage regulation, iinearity, and common mode rejection.

\subsubsection{Recording}

It is recomended that primary data from a turbine flowneter be recorced on a digital and oscillographic system or on an analog $F / M$. tape. The preferred digital system includes a digital counter with digital recording and visual readout. An alternate recording system utilizes irequency-to-voltage conversion, then analog voltage-to-digital format for data reduction.

The output signai from a positive displacement flowmeter can be recorced on a digitai, graphic, and oscillographic system. The preferred digital system should include a visuel readout.

A timing signal and a correlation signal should be recorded simultaneousiy on the same recording media as the flow trarisduce: signal to correiate all other transducer signals, including the engine valve voltage and current data to determine valve on-time.

\subsection{INSTALLATION AND CHECY.OUT PROCEDURES}

4:1 COMPONENT CERTIFICA:TON

Ail critical componerits of the flow measuring system should be certified for compliance with design specifications before instaildtion. This is jest accomplished bir precision inspection plus standard 
laboratory test and evaluation as appropriate. These components should include the following items:

(1) Measurement turbine flowmeter

(2) Measurement positive displacement flowmeter

(3) Working standard flowmeters

(4) In-place measuring vessel

(5) Pressure measurement transducers

(6) Temperature measurement transducers

Pressure measurement transducers and temperature measurement transducers are covered in sections III and IV respectively in this handbook.

4.1.1 Measurement Elowmeters, General

Certification tests should be verformed on all rewly acquir.. ed or rebuilt flowmeters to establish a data base upon which to build the experimental measurement error or uncertainty and to enter the flowmeter into the record keeping systen.

4.1.1.1 Visual Inspection. The flowmeter should be visually inspected with the following in rormation recorded:

(1) Type of fiowmeter

(2) Manufecturer

(3) Model

(4) Serial number

(5) Identificaition number (in-house system)

(6) General condition (ne), used, or rebuilt)

(7) Configuration and dimensions

(8) Mounting configuration and dimensions

(9) Dry weight

(10) Normal operating flow range

(11) Marimuin operating pressure

(12) Nornal operating temperature range 
(13) Materials of construction (may require detailed inspection if information is not available from the manufacturer)

(14) Normal operating fiuids

(15) Electrical excitation requirements

(16) Electrical output signal

(17) Manufacturer's calibration date and data

4.1.1.2 Weight. The flowmeter shall be weigheo on an appropriate balance to establish compliances with any weight specification.

4.1.1.3 Initial Performance Calibration Test. An initial performance calibration-should be made on the flowmeter in the laboratory calibration flow system using water at room conditions as defined in ISA-S37.1 (Reference 2-5) unless otherwise specified. A minimum of 5 inaividual tests should be conducted using both increasing and decreasing steps of $0,20,40,60,80$, ano $100 \%$ of normal range. This data is to be used as an acceptance test to conrirm the manufacturer's calibration data. :

4.1.1.4 Temperature Test. The flowmeter should be tested in a suitable temperature-controlled laboratory chamber to establish compliance with the minimum and maximum specified operating temperature by conducting a minimum of 2 flow calibration cycles at each combination of fluid temperature limits and envirormental temperature limits.

4.1.1.5 Pressure Test. During the temperature test stated above at maximum measured fluid temperature, the fluid pressure should be raised to the specified pressure limit.

4.1.2 Turbine Flowmeter

In addition to the general flowmeter certification tests described above, a turb:ne flowmeter should be subjected to the following specified tests for acceptance.

4.1.2.1 Run-in Period. The turtile flowmeter should be run in for a period of at least 5 minlises at a midrange floh prior to the initial calibration test.

4.1.2.2 output Vo?tage Test. Following the run-in period, the peak voltage shoult be measured anc recorded at minimum and inaximum rated flow.. The wave shape of the output signal should also be cbserved on a cathode ray oscilloscope to check for transducer characteristics or malfunctions. 
4.1.2.3 Rotor speed Test. Following the initial performance calibration test, the flowmeter should be operated briefly at a flow which produces the maximum rotor speed specified. This test should be followed by at least one complete calibration cycle to verify that the flowmeter performance characteristics have not changed.

\subsubsection{Positive Displacement Flowmeter}

Tests have to be performed on the positive dispiacement flowmeter to certify its capability of measuring the small incremental flow volume associated with a single pulse mode engine operation and/or of totalizing a specified flow volume associated with a finite train of repetitive pulse mode engine firings. Included are tests used to certify the displacement transducer performance. All these tests are conducted at room temperature conditions as defined in ISA-S37.1 (Reference $2-5$ ) and using water as the measurement fluid uniess otherwise specified.

4.1.3.1 Maximum Volume Test. The maximum expelled volume of the flowneter should be measured usiag either volumetric or gravimetric metheds. A mirimum or three individual tests at both minimum and maximum rated flow should be recorded.

4.1.3.2 Linearily of Expeiled Volume Test. The linearity of expelled volume of the flowmeter should be measured using either volumetric or gravimetric methods. A ninimum of 5 individual tests should be recorded fror 0 to $100 \%$ of expelled volume in $10 \%$ or smaller incremental steds.

4.1.3.3 Displacement Transducer Performance Test. The displacement transducer performasce characteristics should be certified independently of the expulsion device, if this is iractical, since this measurement instrument may be used in more tian one application. The ceste for potentiometric displacement transcucers are given in detail in ISA-37.12 (Reference 2-6). Similar tests would apply to linear variable differential traisforcers (LVDT) or linear variable reluctance transformers (LVRT). The foliowing is a sumary of the type of infermation and acceptance test data that should be recorded:

(1) Type of displacement sensed

(2) Type of transduction

(3) Manufacturer, model and serial number

(4) Identification number (ir-house system)

(5) Configuracion, dimensions, mounting and displacement connection

(6) Weight 


\author{
(7) Case material and case sealing (if appropriate) \\ (8) Excitation requirements \\ (9) Resistance or impedance of transduction element \\ (10) Electrical connections \\ (11) Insulation resistance \\ (12) Dielectric strength \\ (13) Range \\ (14) End points \\ (15) Full scale output \\ (16) Linearity \\ (17) Hysteresis \\ (18) Combined linearity and hysteresis \\ (19) Repeatability \\ (20) Static error band
}

4.1.4 Working Standard Flowmeter

The working standard flowmeter which is used for calibration and verification of the measurement flowmeter could be either a turbine flowmeter or a positive displacement flowmeter that would be certified using the same tests indicated above. Since this flowmeter is one step up in the rilerarchy of calibration, it should be certified by a reference standard flowmeter directly traceable to the National Bureau of Standards to an uncertainty of not more than one half the permissible tolerance of the measurerent flowmeter.

\title{
4.1.5 In-place Measuring Vessel
}

The in-place measuning vessel used in either the gravimetric or volumetric wethod of calibration would be classified as a working standard because it is permanently located on the test stand. As sucil, it should be certified, by a reference standard flowmeter which is directly traceable to the Naticnal Bureau of Standards, to an unceriainty of not more than one half the permissible tolerance of the measurement floweter. 


\subsection{FLOW SYSTEM}

(1) The flow system should be cleaned prior to flowmeter installation. Proof pressure, leakage, and flow tests of new tank/line systems should be performed without the flowmeters in. place in order to avoid damage by debris.

(2). The system should be leak checked at a pressure equal to the maximum working pressure.

(3) Install flow transducers with flow direction indicators properly aligned.

(4) Care should be exercised in instaliing the flowmeters to keep from overstressing the end consections.

(5) There should be no unsupported ines or components that could cause undue stress on the flow system.

(6) A vacuum purge to remove all gases from a compiex flow system is recommended before priming.

(7) The flow system should be primed and bled at low pressure and in progressive stages beginni:lg at the supply tank. This will help to prevent overspeeding of turbine flowmeters and sofi response of positive displacement flowmeter due to trapped gases.

(8) The flow system and temperature conditioning equiprent should be carefully checked out for uniformity of temperature. Special attention should be given to excessive heating caused by direct solenoid operated valves in stagnant or low flow liries.

4.3 ELECTRICAL SYSTEM

(1) A rotor spin check, using case not to overspeed, should be performed upon insiallation of the turbine flowmeter to verify operation of associated electrical circuitry and readout equipment.

(2) A manual or oneunatically induced iranslation of the positive displacement transducer shoulo be performed upon the installation of the positive displacement flowmeter to verify operation of its associated eltatrical circuitr. and readout equipient

(3) Electrical connecto: s should be sealec to eliminate problems from water and ot:er contaminants.

(4) Trarsducer cables should be checked for proper shielding and single point grounding. Magnetic fields in close 
proximity to the flowmeter or transmission cable may introduce erroneous signals. Power cables and instrumentation cables must be run in separate conduits.

(5) Transduction coil or similar transducer elements may be damaged by excessive torque or clamping loads.

(6) The transduction coil, assosiated circuitry, and readout equipment of a turbine flowmeter may be checked by an induced signal from an external coil and power source or an oscillator connected in parallel with the transduction coil.

\subsection{CALIBRATION AND VERIFICATION PROCEDURES}

The calibration and verification procedures will vary considerably depending on which calibration method is used for the rlow measuring system. Both specific and general recommended procecures aire presented below for the in-place and laboratory calibration of turbine flowmeters and positive displacement flowmeters.

5.1 IN-PLACE CALIBRATION

(1) The flow measuring system should be calibrated any time one of the following situations occurs:

(a) Initial installation or major fiow system component,

(b) A flowmeter is replaced,

(c) A malfunction or a chenge is made that may influence the rlowmeter calibration, or

(a) Calibration void date is approached, or exceeded.

(2) Replicate measurements should be made to provide increased reliability, diagnostic information, and reduced uncertainty ir. the measured value.

(3) Temperature and pressure of the propellant stould be measured at the flowmeter and at the calibration device.

(4) The calibration of the flowmeter should include sufficient flow data to define the sensitivity over che anticipated range of operation.

(5) The calibration should be performed with the propellant at the specified test operating temperatures and pressures. 
A flowmeter should be calibrated at the following times:

(a) Prior to installaticn in test stand.

(b) When the void date is approached or exceeded, or

(c) At the occurrence of a malfunction or chenge in the flow system that could affect the flowrieter calibration.

(2) The flowmeter should be inspected visually for applicable mechanical specifications including:

(a) Identification

(b) Type of flowmeter

(c) Yanufacture, model, and serial rumber

(d) General conditioi: (new, used, rebuilt, etc.)

(e) Indicated flow direction

(3) The flowmeter calibration assemtly shouic include the same or identical inlet and exit piping, flow straighteners, and instrumentation taps used in actual test assembly.

(4) The flowmeter should be oriented in the same attitude as during actual testing.

(5) Prior to a calibration, the flow system must be crimed and bled to remove entrappec gas.

(6) Bypass lines should be checked for zero leakage.

(7) Connect the reqired electrical leads and associated sircuitry and turn on equipment for specified warm-up period.

(8) Apply the electrical simulation of the transducer and record the cutput signal.

(9) New or robuilt flowmeters should be rur in at a nomina: flow for a period long enough (approximately 5 ininutes) to stabilize the calibration factor.

(10) During the ruil-in period, the voltage output stould be measured and recorded at rated miaimum and maximum flow. The transducer outfut signal should be observed on an oscilloscope to determine signa: characteristics and noise-to-signal ratio. 
(11) The number of calibration points should not be less than 5 and should include the minimum and maximum flow as specified for the test conditions. The number of runs at each calibration point should not be less than 2 and should be taken with both increasing and decreasing flow. The sensitivity, linearity, and linear range for the flowmeter are determined from this data.

(12) All gravimetric calibration methods require an accurate basis for converting mass to volume. The censity of the liquid at the flowmeter temperature and pressure should be determined to an error of $0.05 \%$ or less. The effects of air buoyancy must also be considered.

(13) To correlate the flow calibration system with the National Bureau of Standards for certification purposes, water would normally be used in a hydrazine monopropellant flow measuring system. For this operation a Master Flowmeter would be used as an interlaboratory standard.

\subsection{TURBINE FLOWMETER}

(1) Turbine floweters are normally used and calibrated in a horizontal position with the transduction element in the vertical position unless specified otherwise by the vanufacturer.

(2) Pressure and temperature measurement taps are normally installed 4 line diameters downstream of the turbine meter exit.

(3) If upstream pressure or temperature taps are to be used, they should be installed one diameter ahead of the flow straightening vanes.

(4) A sensitive differential pressure measurement across the turbine flowmete: is a good diagnostic parameter for performance evaluation. The pressure drop should be within $5 \%$ of the actual test value when calibrating with liquid at normal pressures where compressibility is not a factor.

(5) A total cycle count accumulated for a measured volunie (or mass) is the method normally used to calibrate a turbine flowmeter. This method dues not require that the flow be maintained absolutely constant through the run period. A variation of $4 \%$ is acceptable in the calibration region in which the callbration sensitivity ( $K$ factor) is essentially constant. However, in the laminar and transition regions, whe the calibration sensitivity is not constant, the flow should be maintained constant to $1 \%$ or better. 
Alternatively, the duration of the calibration run, as well as the total cycle count, should be measured so that an exact average frequency during the run can be determined.

(6) The total number of cycles accumulated for each calibretion point is dictated by the flow measurement accuracy requirement. Since the electronic counter has an inherent error of $\pm i$ cycle, a sufficient number of cycles should be accumulated to make this error negligible.

(7) The comparison metiod of calibration requires the minimum amount of equipment and is convenient for routine calioration or verification of turbine flowmeters. In operation, a working standard turbine flowmeter is installed in series, in a return line (see Figure 2-1), with the measurement flowmeter. The flow calibration points are set by the frequency output of tre working standard flowmeter and are held constant by using a frequency meter $c$ : electronic counter. The number of cycles per unit volume is used as the basis for the comparison. The time base of the two frequency counters should be synchronized.

(8) Two measurement turbine flowmeters of similar design piumbed togetner in a series with the required flow straightening sections can provide greater reliability than one meter alone. Better precision can be achieved by using the method of frequency ratio calibration. These two flowmeters are calibrated simultaneousiy using one of the primary methods. During this calibration, the ratio of the frequency of the two flowmeters is noted for each flow. When these flowmeters are used in test measurements, if this ratio remains the same, it can be assumed that their calibrations have not chanced. The same method can be used to pair two working standard flowmeters to calibrate one measurement flowlieter, or two master flowmeters can be paired anc used as an iaterlaboratory transfer standard to certify the calibration facility.

\subsection{PCSITIVE DISPLACEMENT FLOWMETER}

(1) A positive displacement flowmeter should be used and calibratec in an irientation that assures expulsion of trapped gas. The system should be pruvided with high-point vent ports that allow trapped gas to be removed during priming ard bleeding operations.

(2) Fresşure and temperature measureinent taps shoulis be insialled just downstream ( 4 line dianeters) of the meter exit. 
(3) A sensitive differential pressure measurement across the head of a pneumatic or hydraulic expulsion device is a good diagnostic parameter for performance evaluation.

(4) The calibration of positive displacement flowmeters should cover the specified range of engine cperating duty cycles. Flow control valve start and stop signals should be provided by the sane valve driver and timing circuit used in the actual engine test.

(5) The static method of calibration with standing starts and stops is the most reiliable way to measure small incremental flow volume or mass accurately. The abjlity to measure a single pulse flow will be determined by the flow and duration of the pulse and the sensitivity and resolution of the calibration device. For very short pulses, the most practical method is to measure the total quantity of liquid collected for a finite number of identical pulses and matheniatically proportion the flow to each pulse.

(6) The comparison method of calibration lising two positive displacement flowmeters of similar design and capacity connected in series through the simulated engine flow contrci valve assembly is most convenient for routine calibration and verification. In operation the measurement flowmeter will expel fluid which is collected by the working standard flowmeter. The simultaneous recording of output signals from both flowmeter jisflacement transducers on the same time base will provide data for flow calibration and dynamic response characteristics.

\section{5}

\section{VERIFICATION PROCELURES}

Aft $\leqslant r$ completing the pretest calibration procedures and certifying that the flow messurement system is within specification, the following are recommended procedures for the verification tests to be performed just prior to a hot engine firing and immedictely after engine shutdown:

(1) Apply and record the electrical calibration.

(2) Provide, through the in-place calibiation system, a propellant which is equal to the expected test condition.

(3) Record the data at a sampling rate and for a period which is normal for establishing equilibrium rest conditions.

(4) Repeat the propellant flow test 10 or more times.

(5) Reduce all verification test data using the same systems and equipmer.t that will be employed during the actual engine test. 
(6) Ensure that the calibration system is isolated from the flow measurement system following the verification tests and before any actual engine test.

\subsection{OPERATING PROCEDURES}

To ensure that maximum quality. flor measurement data are produced during each test run, certain inspections and verifications must be made. Recommended operating procedures for both the pretest and the posttest periods are given below.

\subsection{PRETEST PROCEDURES}

(1) Perform visual inspection of the flow system for plumbing leaks, test configuration, electrical, and instrumentation connections.

(2) Determine and record propellant level.

(3) Set up and verify data acquisition systems.

(4) Close up the test cell and establish the desired pressure and temperature test conditions.

(5) Record verification and/or electrical simulation data, and check these data for conformance to predicted standards for the measurement system.

(6) Establish the run zero reference, and recond this value. In general, electrical zero and spans should not be adjusted unless it is necessary to bring them within the recording acquisition system operating range.

\subsection{POSTTEST PROCEDURES}

(1) Record zero reference.

(2) Record verification and/or electrical simulation data ard check for conformance to predicted values.

(3) Vent up the test ceil and Establish a safe ambient environment befcre allowing access to the test area for inspection of the flow measurement system.

(4) Determine and record propellant level. 


\subsection{DATA ACQUISITION AND PROCESSING TECHNIQUES}

Many generalized standard techniques must be applied in the acquisition and processing of the calibration, verification, and run flow measurment data even though a wide range of equipment types and processing techniques will be used for handing these data. No attempt is made in this section to specify the detailed techniques which are appropriate to the various items of equipment supplied by different manufacturers. For additional details, see Reference 2-7.

\subsection{CALIBRATION AND VERIFICATION DATA}

Recommended practices for the acquisition and processing of calibration and verification data for flowmeters are as follows:

(1) Calibration and verification data should be recorded on the same equipment as run data.

(2) Initial system calibration data must be used to determine whether the flow system design requirements (e.g., range, sensitivity, and linearity, if applicable) have been met.

(3) Afier the initial calibration of the flow system, the system should be verified a number of times to determine the short-term uncertainty of the system. For each verification, a factor for use in determining uncertainty should be calculated.

(4) Verification daca are used to compute the measurement uncertainty of the system, to compute a period of precicted satisfactory performance, and to check the system for trends and excursions.

(5) If the alculated uncertainty of the systen exceeds the allowable limit, the system should be improved until such time as the allowable limit is not exceeded. The total uncertainty of the flow measureme:at produced by a system designed in accurdance with the practices outlined in this randbook is obtained by combining all the elemental uncertainties (Appendix II-A). The accepted method for the calculation of total uncertainty is presented in Reference 2-8.

(6) Posttest verifications should be carefully'examined for any deviation from pretest calibration and/or ve:ification: If such deviations are outside acceptable limits, corrective action should be taken immediately and the validity of the test data stiould be questiorad. 
(7) Periodic (e.g., at least once a month or before each test, whichever is shorter) reevaluations consisting of a calibration of the flow measurement system and computation of system uncertainty must be made as long as the flow system is in. use.

(8) Calibration and verificatior records should contain at least the following data:

(a) Flowmeter identification number

(b) Calibration fluid or propellant

(c) Temperature of calibrating fluid at flowmeter

(d) Fluid pressure at flowmeter

(e) Range of transducer

(f) Recording system ioentification

(g) Calibration run number

(b) Identification of calibration equipment not normally part of the calibration system, i.e., operating standards

(i) Specific gravity and temperature of fluid sample(s)

(j) Date

(k) Identification of operators

7.2 RUN DATA

Recommended practices for the acquisition and processing of flow measurement run data are as follows:

(1) Engine flow test data shall be accumliated only after uncertainty' lequirements have been met (Reference 2-8).

(2) Engine flow test data should be accimulated in zccordance with Paragraph 3.2.3.

(3) Data reduction for each test poini is to be based on the transducer average output signal as determined during the specified interval, and the application of calibraticn iactors.

(4) Fluid temperacure and pressure measurements which are rep:esentative of flowmeter conditicr.s should be recorded. 
(5) Run data should be examined to identify gross malfunctions such as failure to record, intermittent connections, dropouts, and other equipment malfunctions.

(6) Final reduced data should be tabulated in such a way as to make possible convenient comparisons with user specifications.

(7) All calibration, verification, calculated uncertainty and engine test data shoulo be retained until a data release is dictated by the program requirements. In general, this includes all information rej.ated to the interpretation of the measured flow.

(8) In the event of equipment malfunction, all data associated with that equipment should be examined for validity. This process wiil be simplified if all equipment used is appropriately identified and the identification is made $a$ part of the permanent test records.

\subsection{GLOSSARY}

dir Euoyancy. The lifting effect or buoyanay of the ambient air which acts during a "weighing" procedure with open gravimetric calibrations. This is caused by displacement of air from the measuring vessel during the calibration run. The standard air (dry) for correcting the weights in vacuum has a densicy of $1.2250 \mathrm{~kg} / \mathrm{J}^{3}$ at $288.15 \mathrm{~K}$ and $10.13250 \mathrm{~N} / \mathrm{m}^{2}$. Witen weighings are mace against weights, the buoyancy force on these must aiso be considered. For brass weights the net effect of air buoyancy in air at standard conditions is about $0.015 \%$. Exact values can be determined by procedures outlined in Paragraphs 3059 and 3060 of API Standard 1101, 1960 Edition, and NBS Handbook 77, Volume III, pages 671-682.

Eack Pressure. The absolute pressure level as measured 4 pipe diameters downstream from the turbine flowmeter under operating conditions, exfressed in $\mathrm{N} / \mathrm{m}^{2}$.

Calibration. A test during which known values of measurand are applied to the transducer and corresponding output readings are recorded under specified conditions. (Cnly during a calibration may adjustments be made so that a relationship convenient for data reduction purposes can be established.)

Calibration system. A complete system consisting of liquid, storage; pumps; filters; flow, pressure, and temperature controls; the quantity neasurirg apparatus; and the electronic instruments used to calibrate; flowmeters.

Calibration Void Date. A aate which marks the end of a preestablished time interval since a flowmeter wes last calibiated and placed in service. Beyond this void date, the saipration is considered questionable, and a new calibration should be performec prior to use of: the flowmeter. 
Correlation Check. A procedure whereby the performance and accuracy of a calibration system are checked against a higher order calibration system using master flowneters as the transfer standard.

Density. The mass per unit volume of a liquid at a specified temperature. The units shall be stated, such as kilograms per cubic meter. The form of expression shall be: density___ $\mathrm{kg} / \mathrm{m}^{3}$ at___ $\mathrm{kelvin}$.

Dynamic Calibration. A calibration procedure in which the quantity of liquid is measured while liquid is flowing into or out of the measuring vessel.

Electronic Counter and Timer. An electronic device with automatic on and off actuation used to count and indicate the total number of cycles generated by the turbine flow transducer during the calibration interval or to irdicate the time period of the calibration interval. Also, used as a rrequency meter to count total cycles generated during preselected time intervals such as one second.

Flow. The rate of flow of a liquid expressed in volume units per unit of time. Exánple: cubic meters/second $\left(\mathrm{m}^{3} / \mathrm{s}\right)$.

Elowmeter or Flow Transducer. An electrical device used to transmit quantitative information on the rate of fluid flow.

Flow Straightener. A supplementary length of straight pipe on tube, containing straightening vanes or the equivalent, which is installed directly upstream of the turbine flowmeter for the purpose of eliminating swirl from, and giving a uniform velocity distribution to, the fluid entering the flowmeter.

Frequency. Refers to the frequency of the output signal generated directly by the spinning rotor of a turtine flowmeter. This frequency is nominally proportional to volume flow.

Gravimetric. A descriptive term used to designate an instrument or procedure in which gravitational forces are uivilized.

In-place Calibration. Calibration of a flowmeter while it is physically in the engine propellant flow measuring system.

Linearity of a flowmeter. The maximum percentage deviation from the average sensitivity ( $K$ ) acrose the linear range.

Linear fiange of a Flowmeter. The flow range over which the output sigral is propcrtional to flow within the limics of linearity specinied.

Master Flowmeter. Flowmeter used as an interlabcratory standaró in correlation checks of calibration systems.

Measurand. A physical quantity: property or cordition which is measured (such as flow). 
Measuring Vessel. The container in which the liquid metered by the flowmeter during the calibration interval is collected and measured. In at direct-gravimetric calibration system, this is a tank on a weight scaie and the exact dimensions are not significant. In indirect gravimetric systems and volumetric systems the cross-sectional area or actual volume, respectively:, must be known to a precision compatible with the desired accuracy of calibration.

Positive Disolacement Flowmeter with an Electrical Outout. A flow measuring device in which an incremental volume of fluid expelled under pressure from a confining vessel is continuously monitored by a displacement transducer that generates an electrical signal proportional to the displaced volume. The indicated change in volume per unit time is the measured volumetric flow.

Pressure Drop. The differential pressure across a flowmeter as measured between 4 pipe diameters upstream and 4 pipe diameters downstream from its ends, using a specified fluid, and using pipe size matching the fittings provided.

Propellant Compatibility. A measure of the reactivity between a given propellant and a structurai or seal material used to contain the propellant. A propellant and a material are compatible when neither is physically or chemically changed due tc contact with the other.

Pulse Mode Operation. For the purpose of this section, pulse mode operation is defined as occurring whenever (a) the thruster.valve is commanded closed prior to the attainment of $95 \%$ of the steady state catalyst bed temperature as measured at the outer wall surface, or (b) the performance of the thruster is to be monitored cver a time period which includes both the start-up and shut-down transients, and during which time the transient portions of any measurement are significant with respect to any steady state measurements.

Reference Standard Flowmeter. Flowmeter used as a transferistandard for in-system and comparison calibrations of working standard flowmeters.

Sensitivity.: The racio of output quantity to measured volume of a flowmeter, designated by the le teter $K$, usually. expressed in cycles per cubic meter for a turbine flowmeter and voltage per cubic meter fo: positive displaceinent flowmeter with the following conditions specified:

(1) Calibration Fluid

(a) Density $\left(\mathrm{kg} / \mathrm{m}^{3}\right)$

(b) Viscosity $\left(\mathrm{m}^{\bar{c}} / \mathrm{s}\right)$

(c) Downstream tempe:ature (K)

(d) Eack pressure (N/m $m^{2}$ abs)

(e) Flow $\left(\mathrm{m}^{3} / \mathrm{s}\right)$ 
(2) Line Configuration (for turbine flowmeters only)
(a) Length of straight line upstream
(b) Length of straight line downstream
(c) Conflguration of flok straightener

Static Calibration. A calibration procedure during which the quanticy of liquid is measured while the liquid is not flowing into or out of the measuring vessel.

Steady State Oseration. For the purpose of this section, steady state operation is defined as that portion of a test after which the temperature at the outer surface of the catalyst bed wall has achieved $95 \%$ of its equable asymptotic value, but prior to the time at which the propellant valve is commanded closed. Steady state measurements should be made only after the attainment of this condition.

Transition Angle. The angle between the axial centerline and one wall of a taperec stetion of piping which is used to join two pipes of different diameters having a common centerline.

Turbine Flowmeter With an Electrical Output. A flow measuring device in which thie action of the entire fluid strean turns a bladed turbine at a speed nominally proportional to the volume flow, and which generates or modulates an output signal at a frequency proportional to the turbine speed.

Vacor Pressure, Reid. The vapor pressure of a liquid at $311 \mathrm{~K}\left(100^{\circ} \mathrm{F}\right)$ as determined by ASTM Desigration D 323-58, Standard Method of Test for Vapor Pressure of Petroleum Products (Reid Method).

Verificazion. A verification confirms an established relationship to a standard. (Confirmation implies that no adjustments have been made since the last calibration because an adjustment might void tine statistical. history of the system.) Verification data are also used to compute the measurement uncurtainty of the system, to compute a period of predicted satisfactory performance, and to check the system for trends and excursions.

Viscosity. Absolute. The property by which a fluid in motion offers resistance to shear. Usuálly expressed in $\mathrm{N}-\mathrm{s} / \mathrm{in}^{2}$.

Viscosioy, Kinematic. The ratio of absolute viscosity to density, expressed in $\mathrm{m}^{2} / \mathrm{s}$.

Volumetric Flow. Rate of flow expressed as volum: per unit time (as $\mathrm{m}^{3} / \mathrm{s}$, etc.), same as flow.

Weight. The force with which a booy is attracted by gravity.

Weights. Reference units of force such as counterpoise weights used with lever balances and dead weights used in calibrating balances, scales, ar.d pressure gages. 
Working Standard Flowmeter. An in-place flowmeter used in the calibration of a measurement flowmeter in the flow measurement system.

\subsection{REFERENCES}

2-1. Hydrazine Compatibility Design and Hardiling Caiteria - Design Handbook, AFRPL-TR-75-46, TRW Systems Groci, Redondo Beach, California, December 1975.

2-2. Specification. Installation and Calibration of Turbine Flowmeters, ISA-RP31.1, Instrumentation Society of America, 1972.

2-3. Fluid Meters. Their Theory and Application, Sixth Edition, American Society of Mechanical Engineers, 1971.

2-4. Morrison, R., Grounding and Shielding Techniques in Instrumentation, Second Edition, John Wiley \& Sons, New York, 1977.

2-5. Electrical Transducer Nomenclature and Terminology, ISA-S37.1, Instrumentation Society of America, 1969.

2-6. Specification and Tests for Potentiometric Displacement Iransducers, ISA-S37.12, Instrumentation Society of America, 1977.

2-7. Thompson, R., and Grey, J., Iurbine Elowmeter Performance Model, Final Report to U.S. Army Missile Command Redstone Arsenal, Report Al:C-3, AD No. 823 354, Greyrad Corporation, October 1967.

2-8. ICRPG Handbook of Estimating the Uncertainty of Measurements Made Witr Liquid Progellant Rocket Engine Systems, CPIA Publication Nc. 180, ICPPG Performance Standaroization Working Group, April 1969. 


\section{APPENDIX II-A}

FLOWMETER MEASUREMENT ELEMENTAL UNCERTAINTIES

To calculate the overall uncertainty in the measurement of propellant flowrate or usage, it is necessary to consider each of the elemental uncertainties which contribute to the overall uncertainty. Figure II-A-1 gives a breakdown of those elements or components which should be considered in the measurement uncertainty model. The reference document for the calculation of uncertainty is the ICRPG Handbook for Estimating the Uncertainty in Measurements Made With Liquid Propellant Rocket Engine Systems (Reference 2-8). 


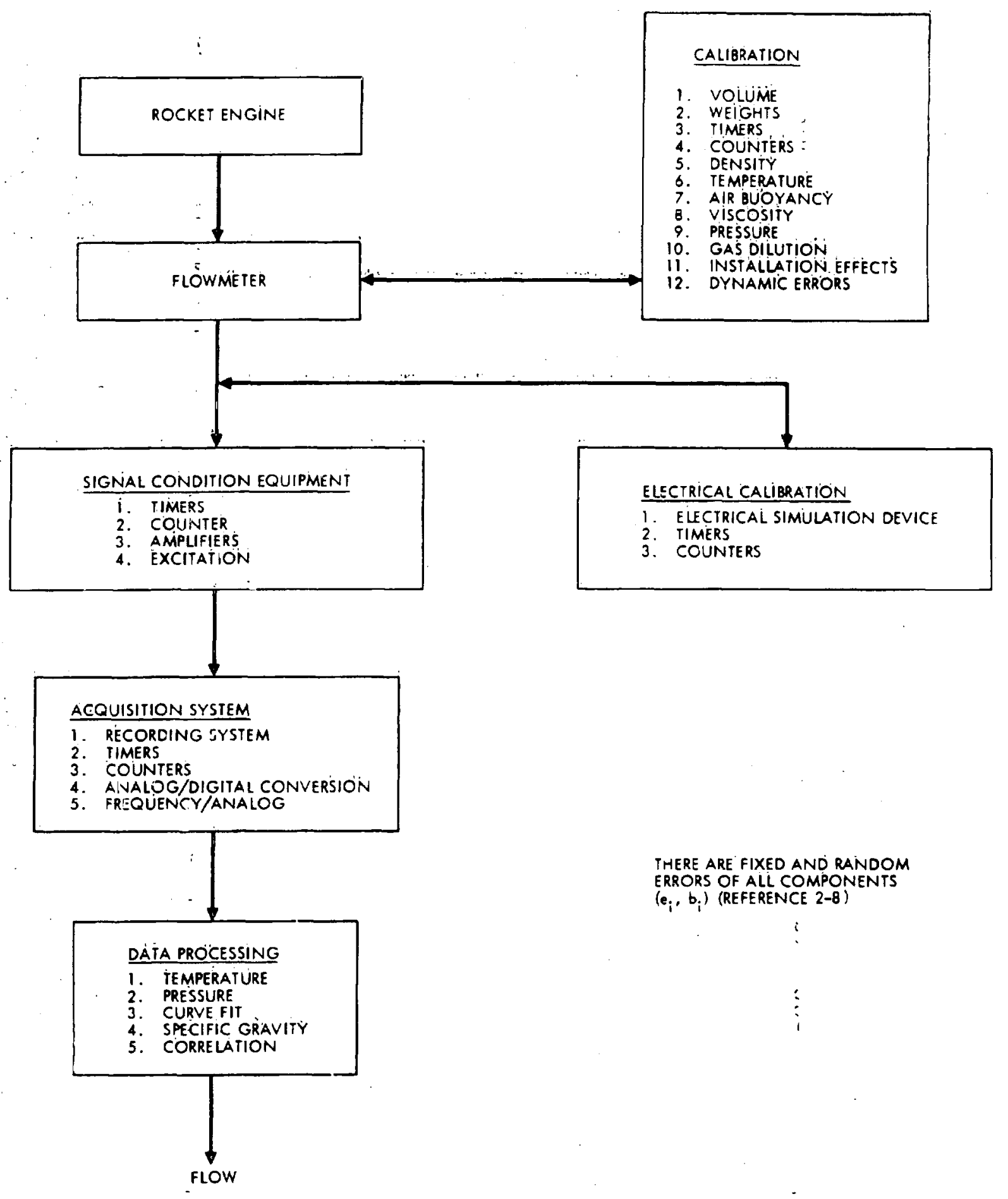

Figure II-A-1. Flowmeter Measurement Elènental Uncertaintiès 


\section{SECTION III}

\section{PRESSURE MEASUREMENT}

\section{PRESSURE MEASUREMENT}


SECTION III

PRESSURE MEASUREMENT

CONTENTS

1.0

2.0

2.1

2.2

3.0

3.1

3.1 .1

3.1 .2

3.1 .3

3.2

3.2 .1

3.2 .2

3.2 .3

4.0

4.1

4.1 .1

4.1 .2

4.2

$4 \cdot 3$

$4 \cdot 3 \cdot 1$

$4 \cdot 3 \cdot 2$

4.4
INTRODUCTION

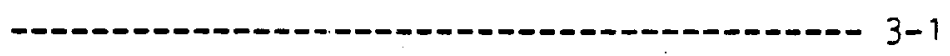

SCOPE

OBJECTIVE

LIMITATIONS

S -

DESIGN CONSIDERATIONS

$3-2$

PRESSURE TRANSDUCERS

$3-3$

Performance Characteristics

3-3

Electrical Design $3-7$

Mechanical Considerations 3-7

ELECTRICAL AND ELECTRONIC COMPONENTS $3-14$

Signal Conditioning Equipment 3-14

Electrical Calibration Equipment $3-15$

Data Processing Equipment $3-16$

PERFORMANCE VERIFICATION $3-16$ TRANSDUCER TESTING AND CALIBRATION $3-17$

Transducer Testing 3-17

Transducer Calibration $3-21$

SYSTEM CALIBRATION $3-23$

DYNAMIC CALIBRAT:ON 3-24

Transient Pressure Method 3-25

Sinusoidal Stimulation Method $3-28$

STANDARDS $3-29$

$$
3-i 2
$$




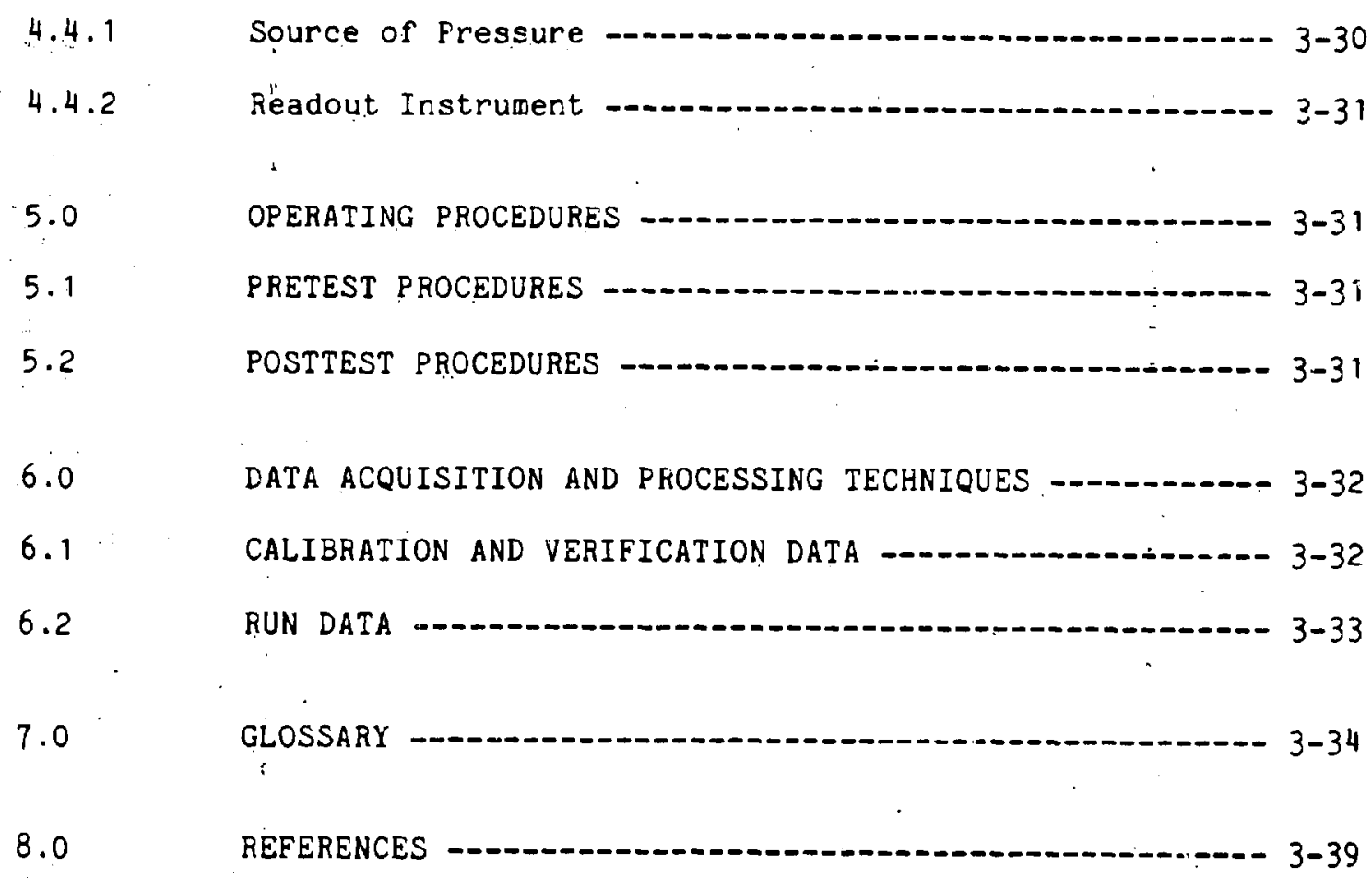

APPENDIXES

III-A PRESSURE MEASUREMENT SYSTEM ELEMENTAL UNCERTAINTIES - 3 A-1

III-B SHORT- AND LONG-TERM PRESSURE MEASUREMENT SYSTEM UNCERTAINTY -

III-C SHUNT CALIBRATION OF PRESSURE TRANSDUCERS -

IIIT-D SPECIAL CONSIDERATIONS FOR VACUUM MEASUREMENT -

III-E METHODS OF DETERMINING THE DYNAMIC CHARACTERISTICS OF PRESSURE TRANSDUCERS -

\section{Eigures}

$\begin{array}{ll}\text { 3-1 } & \text { Pressure Measurement System Block Diagram } \\ \text { 3-2 } & \begin{array}{l}\text { Conventional 6-Wire Strain Gage Bridge } \\ \text { Transducer }\end{array} \\ \text { 3-3 } & \begin{array}{l}\text { Chamber Pressure Veasurement Coupling Line } \\ \text { Configuration }\end{array} \\ \text { Thermal Corduction Along Transducer Connecting } \\ \text { Lines }\end{array}$




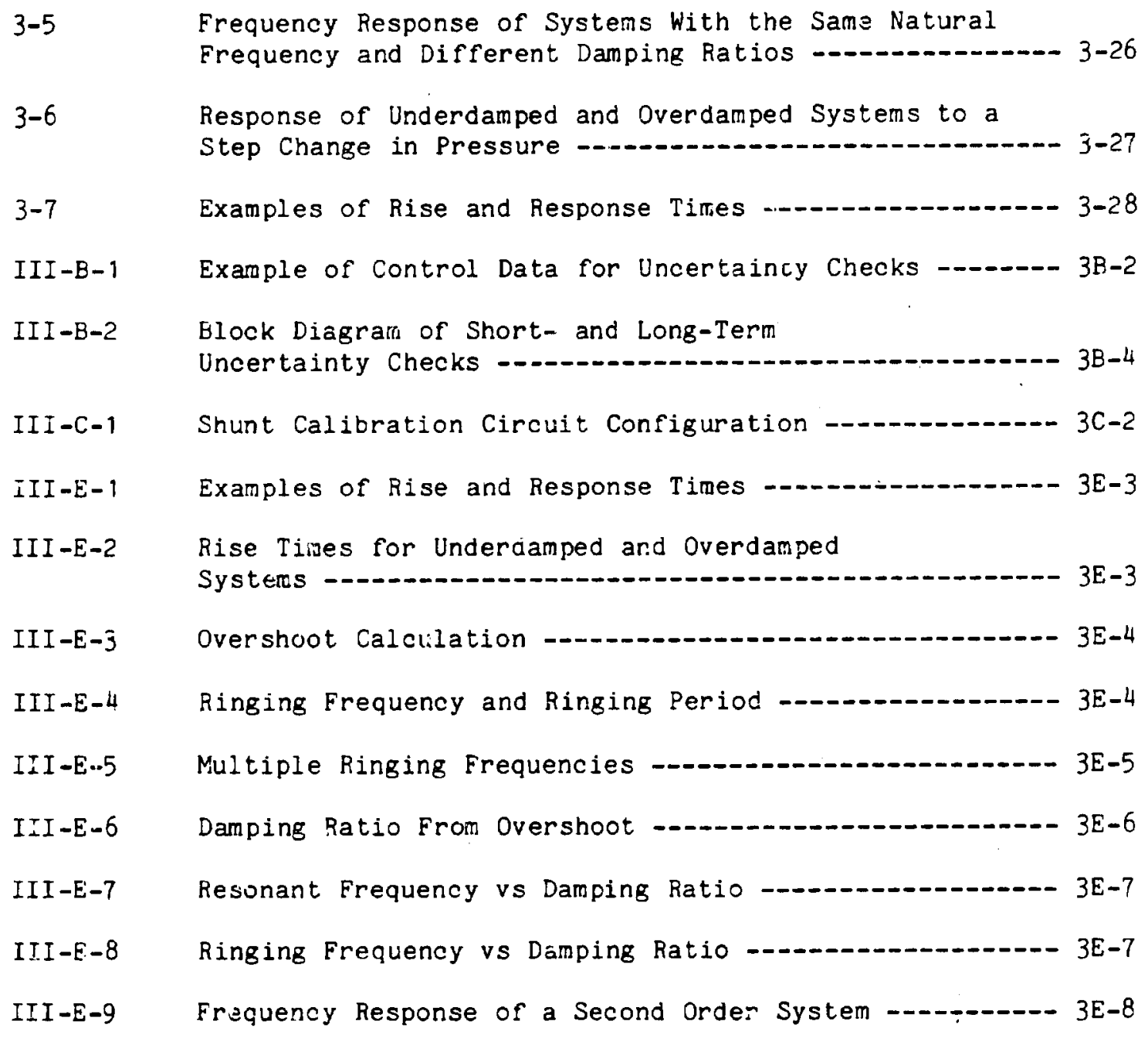


SECTION III

PRESSURE MEASUREMENT

\subsection{INTRODUCTION}

Recommended practices are outlined for the design, installation, checkout, calibration, and operation of a pressure measuring system to be used during tests of a liquid monopropellant rocket engine. Five appendixes are included: III-A, Pressure Measurement System Elemental Uncertainties; III-B, Short- and Long-Term Pressure Measurement System Uncertainty; III-C, Shunt Calibration of Pressure Transducers; III-L, Special Considerations for Vacuum Measurement; and III-E, Methods of Determining the Dynamic Characteristics of Pressure Transducers.

\subsection{SCOPE}

This section has been written to serve as a guide for the experienced engineer in the design, installation, and operation of a pressure measurement system for measuring the pressures related to performance evaluation of a liquid monopropellant rocket engine. Design guidelines rather than detailed specifications are provided for the critical components of each portion of the system. These glidelines, used in conjunction with current state-of-the-art, commercially available equipment and good engineering practices, will provide a pressure measurement system which meets the performance criteria specified.

\section{$2.1 \quad$ OBJECTIVE}

Pressure measurements are made at a number of locations in a monopropellant rocket engine test system, including: thrust chamber, thruster propellant inlet, propellant flowmeter lines, propellant storage tank, and vacuum chamber. The measurements with which engine performance is primarily concerned are thrust chamber pressure and propellant tank pressure. Chamber pressure is produced by the catalytic decomposition of monupropellant hydrazine in the reaction chamber of a rocket engine at pressures ranging from os to $3450 \mathrm{kN} / \mathrm{m}^{2}(10$ to $500 \mathrm{psia})$. These engine tests are normally conducted in an altitude simulation chamber where simulated altitudes of $30 \mathrm{~km}(100,000 \mathrm{ft})$ or higher can be maintained. The recommended practices contained in this handbook are intended to yield thrust chamber and propellant tank measurements over the range from 0 to $3450 \mathrm{kN} / \mathrm{m}^{2}$ ( 0 to $500 \mathrm{psia}$ ) with ur:certainties (related to pulse duration) as follows: 
Minimum Pulse Duration (second) (increasing to steady state)

0.005

0.050

Steady state
Uncertainty in Measurement ${ }^{1}$

(F of reading)

$\pm 5.0$

$\pm 2.0$

$\pm 0.25$

The importance attacined to other pressure measurements

will depend on the user's interest and the purpose of the tests.

\subsection{LIMITATIONS}

When concerned with thrust chamber and propellant storage measurements (those parameters where minimum uncertainty is required), these practices are restricted to systems that infer a pressure from a bonded metallic strain gage measurement.

As used in this section, the term pressure refers to that state property as it appears at the last interface of the measurement system with the monitored environment. Thus, if the probe entrance is a tap into a wall which is parallel to a fluid flow having a substantial lateral velocity (relative to the tap), the measurement becomes a static pressure measurement. If the interface between environment and measurement system is normal to the fluid velocity, the measurement is a total pressure measurement. In view of the complexity of separating these components with a single interface, the recomendations contained herein will be restricted to situations where only one or the other component is presumed to exist. Probe design recommendations must necessarily be derived from other sources.

\subsection{DESIGN CONSIDERATIONS}

A pressure measuring system capable of obtaining accurate data requires that careful consideration be given to selecting and assembling the transducer ${ }^{2}$ and supporting electrical and electronic equipment. When selecting the transducer, one should consider the electrical and mechanical characteristics of the device, the manner in which it is connested to the pressure source, and the influence of the anticipated environmental conditions. Electrical and electronic components include signal conditioning, electrical calibration, recording, visual display, and data processing equipment. They are shown as a block diagram in Figure $3-i$.

1 Measurement. uncertainty values are for the minimum pulse duration. They will generally decrease as pulse durations approach steady state.

2Transducer and sensor can be synonymous words describing devices which convert physical phenomena into measura'sle electrical signals. 


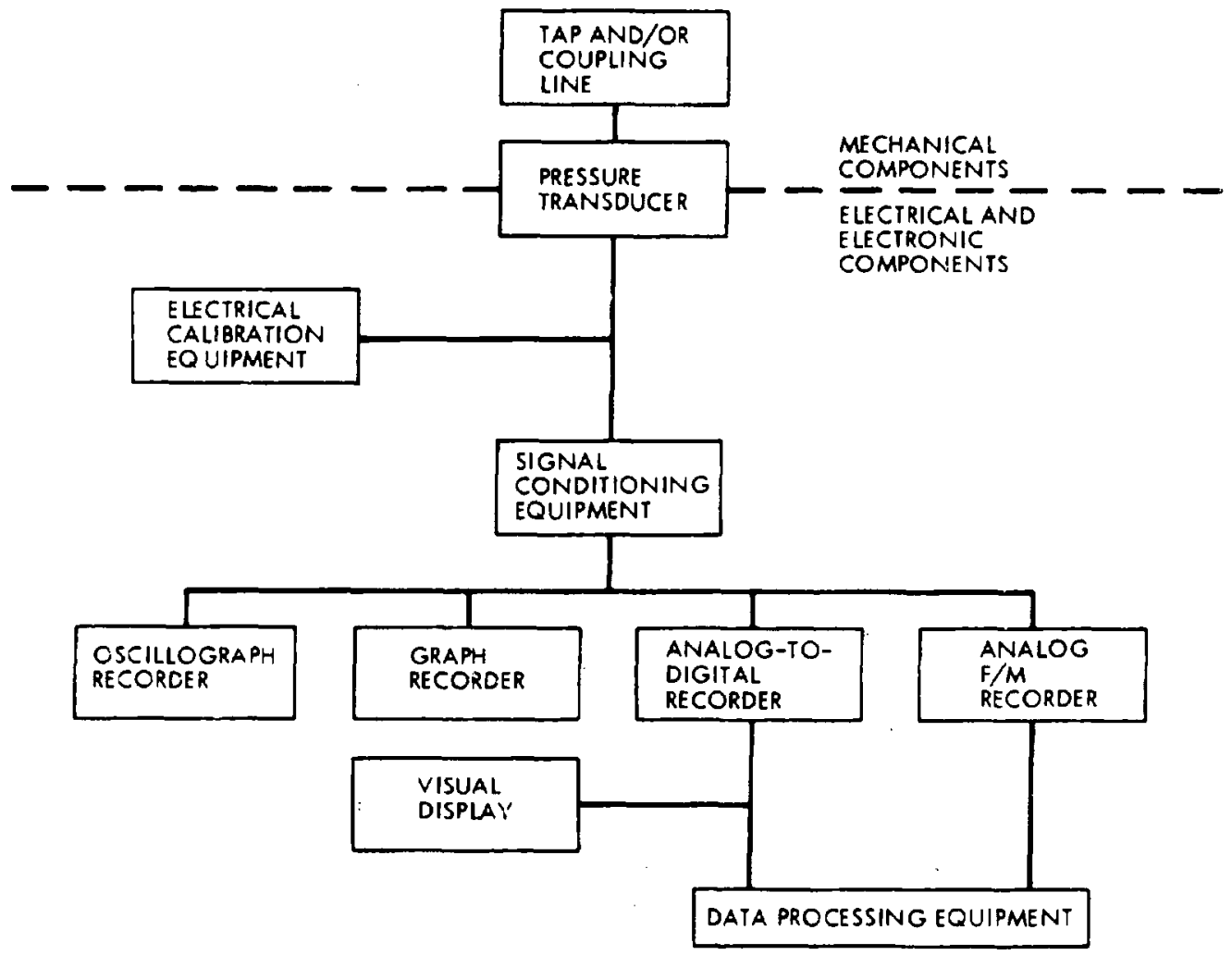

Figure 3-1. Pressure Measurement System Block Diagram

$3.1 \quad$ PRESSURE TRANSDUCERS

In order to achieve the desired uncertainty requirements

(Section 2.1), bonded metallic strain gage transducers should be used for all steady state or slowly varying (up to $100 \mathrm{~Hz}$ ) engine pressure measurements. These recommended practices will also make mention of other types of transduction which might be required in such speclal measurement applications as vacuum, high-frequency pressure variations, etc.

\subsubsection{Performance Characteristics}

The transducer performance characteristics (sometimes referred to as properties - Reference 3-1) which are of greatest interest to the user are listed below. A brief commentary and suggested specifications are included where applicable. Unless otherwise specified they apply at the following ambient conditions: temperature $25 \pm 10^{\circ} \mathrm{C}\left(77 \pm 18^{\circ} \mathrm{F}\right)$; relative humidity $90 \%$ maximum; barometric pressure $73 \pm 7 \mathrm{~cm} \mathrm{Hg}(29 \pm 2.8 \mathrm{in} . \mathrm{Hg})$.

3.1.1.1 Transduction Element. Most pressure trensducers sense the pressure to be measured by a mechanical sensing element such as relatively thin-walled elastic members, plates, shells, or tubes which deflect when 
pressure is applied. This elastic element is coupled to a transduction element which produces an electrical output by such techniques as variable resistance (bonded metallic or semiconductor strain gages), variable capacitance or reluctance, magnetic coupling, and so forth.

Transducers which use transduction techniques other than bonded metallic strain gages may have advantages iri some areas such as size, cost, compatibility with existing equipment, frequency response capabilities, or special measurement applications. For maximum overall accuracy of measurement, however, in the environment likely to be encountered during monopropellant testing, the bonded metallic strain gage is the recomended standard.

3.1.1.2 Piange. Range selection should be made such that the transducer is nominally operating at 75 to $90 \%$ of its full range. Exceptions may occur when transients are expected, depending on the type of transducer used. In those instances where transducers are operated outside the 75 to $90 \%$ of full range special consideration should be given to the calibration technique employed.

3.1.1.3 Sensitivity. Transducer output compatibility with data acquisitionirecording devices is a prime consideration in selection. In systems with good operational amplifiers, a low-sensitivity transducer is sufficient. Most bonded wetallic strain gage transducers are standardized somewriere in the range of 2 to $4 \mathrm{ml}$ output/ $\mathrm{V}$ excitation. With $10 \mathrm{~V}$ excitation this provides a full scale output of 20 to $40 \mathrm{mV}$, sufficient to be amplified by conventional electronics to drive most standard recording devices.

Transducers with other types of transduction, as well as those with integral electronics, of ten have higher full scale outputs, generally in the range of 5 to $10 \mathrm{~V}$.

3.1.1.4 Linearity, Hysteresis, and Repeatability. Overail measurement uncertainty is more dependent on the mechanical aspects of the transduction process than any other single portion of the measurement system.. That this is true may be seen by comparing the relatively large error $(0.1$ to $0.5 \%)$ introdiced by the process of converting a physical stimulus, so the electrical analog of that stimulus with the small error $(0.05$ to $0.1 \%)$ introduced by the signal corditioning and recording equipment. Correction can be made for transducer nonlineality, altholigh it is difficult at best (especia?ly for individual transducers) and is not usually done. Corrections cannot be made for hysteresis and nonrepeatability.

A combined effect (nonlinearity, hysteresis, and repeatability) of less than $\pm 0.25 \%$ of full scale deviation from an ideal strraight line between end points can be achieved rather easily. Transducers with combined effecis of less than $0.10 \%$ are available.

3.1.1.5 Dynamic Response. Even when the intent is to determine a steady state pressure, the frequency response of the transducer must be sufficiently high to follow the transient pressure signal which precedes the steady state 
portion. In other words, the electrical analog of the pressure transducer achieves steady state only after its transient excursion has been completed. Hence, the period of time required for that excursion must be sufficiently short so as not to interfere with the steady state portion of interest.

For additional discussion of dynamic response characteristics including such items as natural frequency, rise time, cavity volume, etc., see Section 4.3, Dynamic Calibration.

3.1.1.6 Environmental Erfects. In addition to the inaccuracies inherent in the mechanical/electrical transduction process are those which arise due to unfavorable environmental conditions. Major contributions are listed below. If either (1) some sort of protection, e.g., temperature control, vibration isolation, etc., is not provided or (2) a transducer with low sensitivity to such effects is not selected, considerable error can enter frozi this source. Paragraph 3.1 .3 .3 gives specific techniques that can be used to minimize these effects regardless of the basic transducer sensitivity.

(1) Thermal Sensitfvity Shift. Temperature compensation should be provided over a temperature range, known as the compensated temperature range, so that sensitivity shift will not be more than $\pm 0.25 \%$ of full scale per $38^{\circ} \mathrm{C}\left(100^{\circ} \mathrm{F}\right)$ over this range. Errors from this source are difficult to compensate for. A typical compensated temperature range is $0^{\circ}$ to $66^{\circ} \mathrm{C}\left(32^{\circ}\right.$ to $\left.150^{\circ} \mathrm{F}\right)$.

(2) Thermal Zere shift. Zero should not shift more than $\pm 0.75 \%$ of full scale per $38^{\circ} \mathrm{C}\left(100^{\circ} \mathrm{F}\right)$ over the compensated temperature range. In many cases shift of this type can be compensated for in data reduction if the transducer characteristics are precisely known.

(3) Acceleration Sensitivity. Should be less than $0.02 \%$ of full scale per $g$ in any direction.

3.1.1.7 Supplemental Performance Characteristics. Performance characteristics which are generally of less interest (but should still be considered) are listed below:

(1) Creep is the change in output occurring over a specific time period while the pressure and all environmental conditions are held constant.

(2) Environmental conditions which should not change transoucer performance beyond specified limits include:
(a) Triaxial shock
(b) High-level acoustic excitation
(c) Humidity 
(d) Corrosive spray

(e) Corrosive gases

(f) Electromagnetic fields

(g) Magnetic fields

(3) Cycling life is the minimum number of full range cycles or specified partial range cycles over which the transducer will operate without changing its performance beyond specified tolerances.

(4) Overload rating is the maximum pressure which can be applied to a transducer without causing a change in performance beyond a specified tolerance.

(5) Stability is the ability of a transducer to retain its performance characteristics for a relatively long period of time. Specifically, it is the ability of a transducer to reproduce output readings obtained during its original calibration for a specified period of time (usually months). Stability is expressed as a percent of full scale output.

(6) Static error band is the combined linearity, hysteresis and repeatability, expressed as a percent of full scale output, referred to a straight line between the end points.

(7) Storage life is the time period the transducer can be stored in a specified environment without changing performance characteristics beyond their specified tolerances.

(8) Temperature gradient error is the transient deviation in output at constant pressure caused by a rapid change in ambient or fluid temperature. It is usually determined at atmospheric pressure by subjecting the transducer to.a step function temperature change over a specified range in $C\left({ }_{F}\right)$ lasting for a specific time period, and applied to a specific part of the transducer.

(9) Warm-up period is that time period, starting with the application of excitation, which is requitred to assure that subsequent shifts in sensitivity and zero will not exceed the specified percent of full scale output.

(10) Zere pressure olitput is the output of a transducer at atmospheric pressure (unless otherwise specified), with nominal excitation. 
3.1.2 Electrical Design

The following electrical desien characteristics are recommended where bonded metallic strain gage pressure transducers are used. Most of them do not apply to transducers whish employ other types of transduction techniques.

(1) The type of strain gage used should be bonded metallic.

(2) The strain gage bridge should have 4 active arms.

(3) Recommended excitation should be a regulated voltage of 5 to $28 \mathrm{~V}$ de. Maximum excitation voltage which will not permanently damage the transducer should be $20 \%$ or greater than the rated voltage.

(4) Input and eutput resistance for dc excitation is specified in ohms at a specific temperature in ${ }^{\circ} \mathrm{C}\left({ }_{\mathrm{F}}{ }^{\circ}\right.$. Common values are 120 and 350 ohms.

(5) The electrical connections for each bridge circuit should conform to the pin designation shown in Figure 3-2. The output polarities indicated on the wiring diagram apply when an increasing pressure is applied to the transducer.

(6) The electrical connections can be either multipin standard connectors mounted on the outer case or a flexible cable providing the required connectors and shield for each bridge circuit.

(7) Insulation resistance is specified in megaohms at a specific voltage and temperature between all terminals or leads connected in parallel and the transducer case. A value of 5000 megohms or greater is recommended.

(8) Shunt calibration resistance should be specified in ohms for a nominal percentage of full scale outfut at a specific temperature. The terminals across which the resistor is placed shall be specified.

(9) The modulus (or sensitjvity adjustment) resistance must be split equally between each input (excitation) lead internal to the transducer. See Appendix III-C.

\subsubsection{Mechanical Considerations}

Of primary interest are items related to the transducer itself, the manner in which it is connected to the pressure source, and the techniques used to reduce the af iects of adverse environmental conditions. 


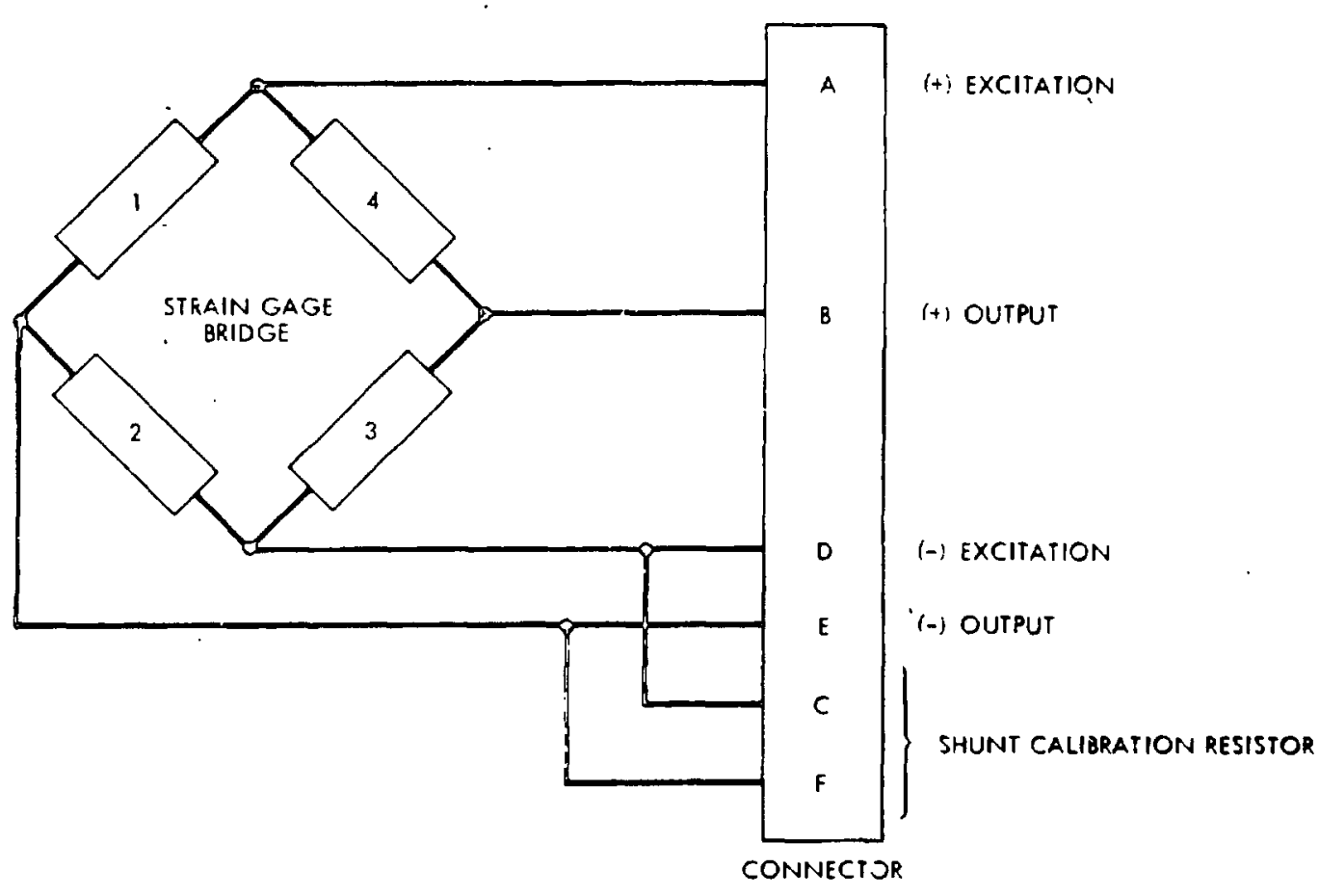

NOTES:

1. THE OUTPUT POLARITIES INDICATED ON THE WIRING DIAGRAM APPLY WHEN AN INCREASING ABSOLUTE PRESSURE IS APPLIED TO THE PRESSURE PCRT (SENSING END) OF AN ABSOLUTE PRESSURE TRANSSOUCER. FOR DIFFERENTIAL AND GAGE PRESSURE TRANSDUCEPS, THE INDICATEO POLARITIES APPLY WHEN THE ABSOLUTE PRESSURE AT MEASURAND PORT IS GREATER THAN THE ABSOLUTE PRESSURE AT THE REFERENCE PRESSURE PORT.

2. THE MEASURAND (PRESSURE; PORT OF DIFFERENTIAL PRESSURE TRANSDUCERS SHALL BE MARKED "+" OR OPTIONALLY "HIGH" OR "MEAS" WHILE THE REFERENCE (PRESSURE) PORT SHALL BE MARKED "-" OR OPTIONALLY LOW" OR "REF.

3. THE BRIDGE ELEMENTS SHALL BE ARRANGED SO THAT FUNCTIONS PRODUCING POSITME OUTPUT WILL CAUSE INCREASING RESISTANCE IN ARMS I AND 3 OF THE BRIDGE.

4. POSITION OF ANY INTERNAL COMPENSATION NJEIWORK SHOULD BE INDICATED. SEE APPENDIX III-C.

Figure 3-2. Conventional 6-Wire Strain Gage Eridge Transducer 
3.1.3.1 Transducer

(1) Transducer construction materials must be compatible with any corrosive fluids which might be encountered durine tests. Material selection for all transducer components should acknowledge possible contact with liquid hydrazine or hydrazine decomposition products (Reference 3-2). Metal parts which experience temperatures above $94^{\circ} \mathrm{C}\left(200^{\circ} \mathrm{F}\right)$ while exposed to ammonia may be nitrided. Stress corrosion cracking is also accelerated under these conditions.

(2) Mounting force or torque must be known, if variations in it will aifect transducer performance.

(3) The size and weight of the transducers are not usually critical items in static test firings. They should be considered, however, if shock mounts are necessary to reduce vibration effects or if physical dimensions prevent close mounting of the transducer to the pressure source (because of mechanical interference) and thus reduce frequency response by requiring longer connecting lines.

(4) The natural frequency of the transducer should be 5 times the highest frequency of interest. (See also Reference 3-3.)

(5) A. maximum operating temperature range that is compatible with the test cell environment should be specified for the pressure transducer in addition to the compensated temperature range. There should be no permanent calibration shift or permanent change in any of the transducer characteristics over this specified operating temperature range. Maximum operating and storage temperature range should be at least $-54^{\circ}$ to $+94^{\circ} \mathrm{C}\left(-65^{\circ}\right.$ to $\left.+200^{\circ} \mathrm{F}\right)$.

(6) Transducer proof pressure is the maximum pressure that car be applied to the sensing port without causing a permanent shift in calibration. Proof pressure should be at least 1.5 times the full range pressure.

(7) Transducer burst pressure is the maximum pressure that can be applied to the sensing port without causing rupture, although the transducer is usualiy permanently damaged. Burst pressure should be at least 4 times the full range pressure.

(8) A maximum leakage rate for the sensing port should apply when the port is pressurized to proof pressure.

(9) A minimum cycling life should be specified for the number of full scale (or specified range such as 20 tc $80 \%$ of full scale) pressure cycles that can be applied without changing transducer performance beyond specified tolerances. 
(1) Insofar as practical, the transducer diaphragm should be flush mounted to the wall of the container in which the pressure is being measured. There are two obvious advantages of such an instailation:

(a) It minimizes the ircrease in the volume containing the pressure to be measured. This is especially important where the chamber pressure of small thrusters or propellant pressures in lines or systems is to be determined without significantly changing the dynamic characteristics of those systems.

(b) Frequency response suffers greatly as connecting line length increases. If connecting tubing must be used, keep the tubing as short as possible and as large in diameter as practical.

The connecting line should be completely filled with the same medium being measured, i.e., a gas filled line for chamber pressure, and a liquid filled line for propellant manifolds, fuel tanks, etc. Combinations 'of gas and Iiquid, especially gas bubbles entrapped in a liquid rilled line, result in unpredictable and sometimes transducer-damaging response characteristics. Entrapped gas can best be avoided by filling the transducer cavity and connecting line with liquid under vacuum conditions. A liquid filled line should be used only when measuring the pressure of liquid. In measuring gas pressure, an oil filled line is detrimental to response, is difficult to use, and is probably unnecessary for heat insulation.

(3) The pressure port, the fittings, the transducer cavity itself, and the connecting line should exhibit as few discontinuities as possible to prevent reflections. These reflections, when they do occur, result in (usually) small disturbances which appear as noise.

(4) A non-flush-mounted transducer should have as small a cavity or dead volume as possible. The change in this volume due to the application of pressure should be known. A transducer with a very flexible diaphragm generally has a greater volume change, a lower natural frequency, and a correspondingly lower frequency response.

(5) When a coupling line is utilized, it is essential that the dynamic effects on observed mean pressure be minimized. Starting transients, combustion noise, and systematic perturbations can drive spurious oscillations within such a line that precludes steady state measurements. The incorporation of a damping mechanism to control these acoustic phenomena is desirable. An orifice at the 
transducer end of the tubing will add damping to what would otherwise probably be a lightly damped system. Figure 3-3 is an example of a system that has good damping and response over a specific frequency range.

(6) For information on how to determine the frequency response of a system which uses a connecting line, cavity, etc., see Appendix III-E.

\subsubsection{Environmental Protection}

(1) Vibration and Acceleration. A transducer which attaches to the pressure source by a portion of the case should be checked for output sensitivity due to mounting torque. Any effect on transducer characteristics should be accounted for. The transducer should be mounted from fixtures or brackets that transmit no deleterious forces to the transducer sensing element. It should be mounted so that the most sensitive plane is parallel to the vector of the largest acceleration on the engine. Mounting brackets should be designed to eliminate vibration modes and frequencies which are detrimental to the transducer output signal. The following items should also be considered:

(a) If vibration effects are to be eliminated they must be prevented from becoming mixed with the pressure signal. Once the two have been combined, they are almost impossible to separate.

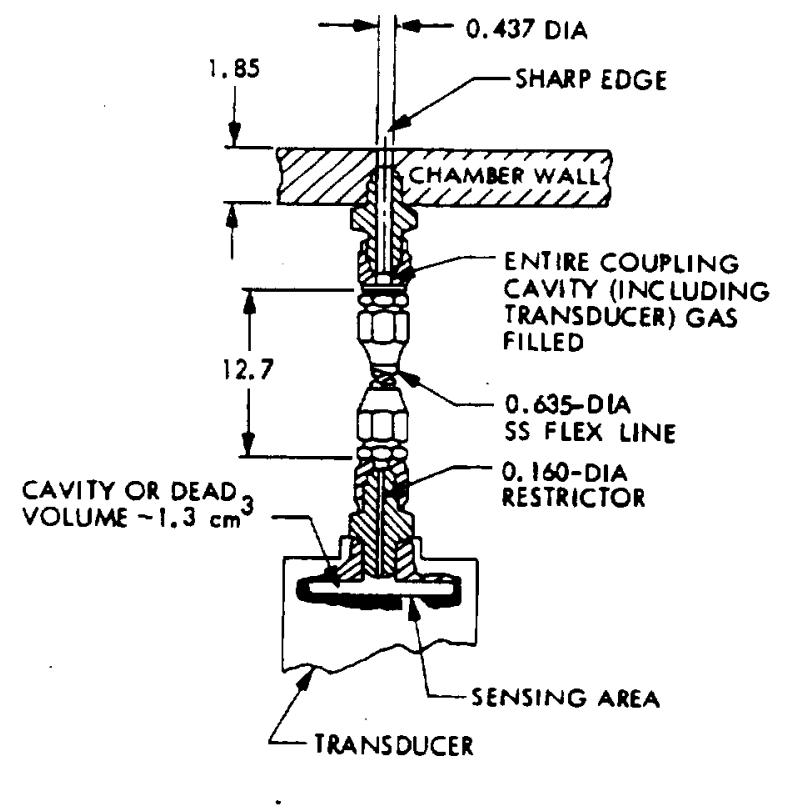

- RINGING fREQUENCY: OVERDAMPED, NATURAL FREQUENCY

- damping ratio: (CALCULATED) $380 \mathrm{~Hz}$

- fREQUency for RESPONSE $\pm 2 \%$ :

$\geq 1.0$

- FRE QUENCY For

RESPONSE $\pm 10 \%$ :

$65 \mathrm{~Hz}$

$125 \mathrm{~Hz}$

ALL DIMENSIONS IN CENTIMETERS

Figure 3-3. Chamber Pressure Measurement Coupling Line Configuration 
(b) An indication of the effect of acceleration on the output of a pressure transducer may be obtained by closing of the pressure inlet to an otherwise normally operating transducer and observing its output during a firing.

(c) A short length of flexible tubing will usually improve vibration isolation between the transducer and the engine.

(d) Shock mounts to support the transducer away from the engine will reduce vibration transmission through the case.

(e) In most cases where vibration isolation is not practical, the design and construction features of the transducer become even more important. A bonded strain gage transducer is generally less sensitive to vibration than an unbonded one.

(2) Thermal conduction and Radiation. Although temperature changes can affect such basic transducer !characteristics as linearity and hysteresis, it is thermal sensitivity and thermal zero shift that are of the most concern: As discussed in Paragraph 3:i.1.6, Environmental Effects, they can be a significant source of error and, if at all possible; should be prevented from entering the data, since once mixed they are difficult to separate. By selecting a transducer with low thermal sensitivity and observing the applicabie suggestions iisted below, the detrimental effects can be significantly reduced or eliminated entirely:

(a) Conduction and radiation effects can be reduced by remote location; i.e., by using a connecting ine of sufficient length. The required isolation length of a particular type of tubing as a function of the thermal source temperature and an assumed transducer temperature is shown in Figure $3=4$.

(b) Where close coupling to a combustion chamber is required for frequency response or other reasons it may be advantageous to cool the transducer body by an external jackeit of air or water. Transducer diaphragm protection may include water or gas cooling. Various types of ablative coatings are useful for protecting the transducer diaphragin during short duration tests (References 3-4; $3-5$; and $3-6$ ).

(c) Wherever possibie, localized hot spots should be avoided as locations for mounting temperature triansducers. 


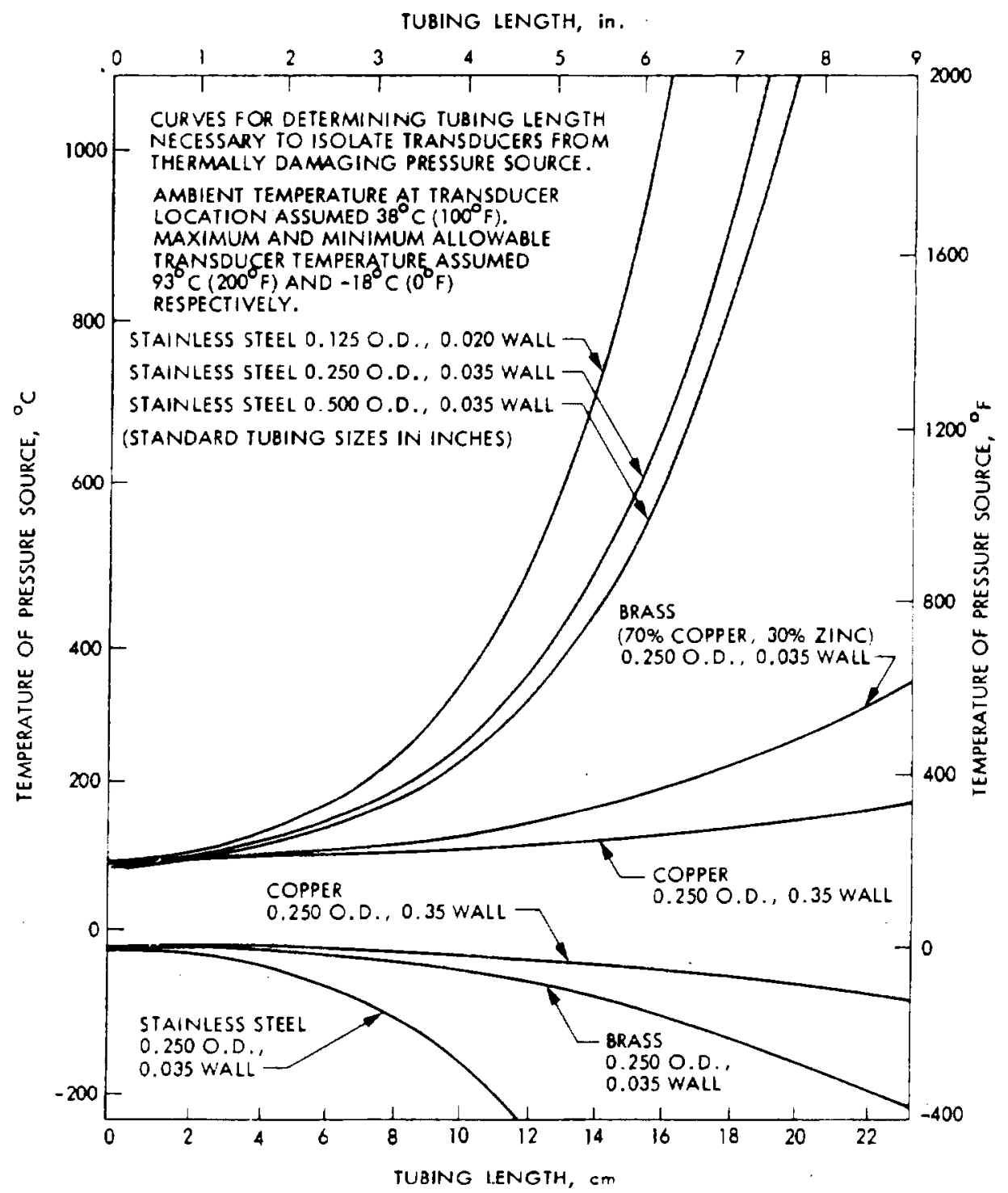

Figure 3-4. Thermal Conduction Along Transducer Connecting Lines

(d) A sun shade, asbestos wrap, etc., should be used for thermal isolation from temperature changes or gradients.

(e) In some instances small, well-regulated heaters might be used, in conjunction with insulating wrap, to maintain a constant, elevated temperature.

(f) Internal electrical compensation or mechanical orotection techniques should always be analyzed to see if they affect other transducer characteristics such 
as frequency response, linearity and hysteresis, electrical calibration, excitation requirements, etc.

(g) As part of the selection process, a transducer should be checked for sensitivity to thermal gradients as well as rapid changes in the temperature of the redium being measured, e.g., combustion gases (fieference 3-7).

(h) In those instances where thermal effects cannot be prevented from affecting the transducer output, correction for such effects must be made during the data reduction process.

\subsection{ELECTRICAL AND ELECTRONIC COMPONENTS}

The major electrical and electronic components to be considered in the design of a pressure measurement system include (1) signal conditioning equipment, (2) electrical calibration equipment, (3) recording equipment, (4) visual display equipment, and (5) data processing equipment. These components are shown in the pressure measurement system block diagram, Figure 3-1. In general all of these components are commercially available, off-the-shelf items. Most of the items are available from more than one manufacturer. The major concern in the selection of these components must be the evaluation of the various manufacturers' general specifications in relation to the specialized pressure measurement reuirement. A subsequent verification that the equipment finally selected conforms to the manufacturer's specifications is essential.

\subsubsection{Signal Conditioning Equipment}

Signal conditioning equipment includes the following functional devices: power supplies, amplifiers, electrical cabling, shielding, signal distribution and switching network, and filters. The regulation and stability of this equipment should be $\pm 0.05 \%$, or better. The designs for these devices vary widely depending on system philosophy and economics. Certain design principles, however, are universally recommended as follows :

(1) Power Supolies. Constant voltage excitation is the primary type used with high-accuracy pressure measurement systems. Power supplies can be individual rack mounted units or miniature (several on one card) devices integral with other signal conditioning equiprent. Generally, there are provisions for voltage adjustments, less often for zero balance. Ripple should be less than $100 \mu \mathrm{V}$ peak to peak.

(2) Amplifiers. The use of high-quality differential amplifiers is now almost universal. With a transducer full scale output of 20 to $40 \mathrm{mV}$, an amplifier gain of 
50 to 500 is sufficient for most conventional analog-to-digital conversion and recording systems. It should be verified that peak common mode voltages do not exceed the rejection limits of the amplifier.

(3) Electrical Cabling and Shielding. Electrical noise can be minimized by use of proper shielding and grounding techniques (see Reference 3-8). Transmission cables between the transducer and the recording system usually consist of multiple pairs of twisted, shielded, splicefree conductors. A total of 6 conductors should be used for each transducer as shown in Figure 3-2. The wire gage and corresponding resistance of the excitation and calibration leads should be taken into account when developing calibration techniques. Each transducer cable should be individually shielded, with continuity of shield to the operational amplifier. The shield grounding connection should be in accordance with the amplifier manufacturer's recommendations. Multichannel cables consisting of inner cable shielding and overall shielding of the large cable are recommended for long transmission lines. The outer shield of the multiconductor cable should also be terminated to the single point ground. The outer shield and all inner shields should be insulated from each other.

(4) Other signal conditioning equipment includes such items as filters, distribution and switching units, and impedance matching devices. The design of these and related devices varies depending on system philosophy, but should in all cases be high-quality equipment providing stability (both with time and temperature), line voltage regulation, and linearity. Thermally induced errors should be minimized in all circuits.

\subsubsection{Electrical Calibration Equipment}

Some form of electrical simulation of the transducer response to pressure should be provided. This simulation should track any change in the system sensitivity that is caused by changes in the environmental conditions. The two most commonly used electrical calibration systems that adapt readily to automated periodic tests are discussed below. The first of these techniques includes the transducer in the calibration and is thus quasi end to end. The other involves only the electrical and electronic equipment. The advantages (convenience, technical, or economic) of each systen will largely depend on the user's existing transducers, signal conditioning equipment, cabling, etc.

(1) Shunt calibration with a constant voltage system requires a 6-wire system to the transducer if an external signal shunt resistor is used: 2 wires are used for excitation, 2 for output, and 2 for shunt simulation. The technique for using a 6-wire 
shunt resistor calibration method is presented in Appendix III-C.

(2) Voltage substitution techniques can be used to calibrate the electronics system (amplifier, recorder, etc.) in addition to or in lieu of any transducer electrical or end-to-end calibration. This method requires that the transducer be electrically disconnected (usually by a switching network) and a known voltage substituted. Such a calibration technique will not necessarily provide any information about changes in ambient output nor even reveal if the transducer has been disconnected. It should therefore not be the only type of electrical calibration employed.

\subsubsection{Data Processing Equipment}

The data processing equipment is not generally regarded as a specific portion of the pressure measurement system, but is usually a separate system and is used to process many other parameters also. This equipment should be chosen and used with care so that the data are not degraded significantly and the uncertainty of the data is not made larger.

\subsection{PERFORMANCE VERIFICATION}

All critical components of the pressure measurement system should be certified for compliance with design and performance specifications before installation. This is best accomplished by precision inspection plus standard laboratory test and evaluation as appropriate. It is imperative that any testing or calibration performed be a true characterization of the transducer and its associated signal conditioning equipment. This involves not only the individual transducer calibration, but also some type of calibration of the entire measuring system as installed. In this section the following topics related to. performance verification are discussed:

(1) Testing and calibration of the individual transducer.

(2) Overall system calibration by end-to-end or electrical simulation techniques.

(3) Dynamic calibration of transducers and coupling lines.

(4) Standards used to accomplish the various calibrations.

While only those tests and calibrations related to transducers are considered in this section, performance verification can and should apply equally to all other system components. 
The performance characteristics and accuracies of a pressure transducer are determined through testing and calibration procedures. Three types are generally used and may be described as follows:

(1) Qualification tests are performed to evaluate those characteristics which are a function of transducer design. They thus would not be expected to vary appreciably from one unit to another for a particular transducer model. The performance of a representative sample of units should represent the performance of an entire lot.

(2) Individual acceptance tests (IAT) are performed to evaluate those characteristics which are a function of transducer piece parts, assembly, or adjustment, and might vary considerably from one unit to the next.

(3) Periodic and special calibrations are performed routinely or when required (as specified by the user) to verify consistency in such critical performance characteristics as sensitivity, linearity, hysteresis, repeatability, and shunt-to-pressure correlation. This type of test should always be performed after any sort of transducer disassembly for cleaning or repair, or after severe service.

\subsubsection{Transducer Testing}

Whenever possible the user should verify transducer performance by qualification and acceptance testing. Where the quantity of transducers used makes justification of qualification testing difficult, such tests may be waived provided the manufacturer is able to certify compliance from previous testing on similar units.

Individual acceptance tests are done on all units. A representative sample (minimum of two) is then selected for qualification tests. Qualification testing concludes with a repeat of the individual acceptance test, and, finally, ary destructive testing required, such as burst test or sectioning for internal inspection.

4.1.1.1 Individual Acceptance Test. The acceptance tests for pressure. transducers from Reference 3-1 are summarized as follows:

(1) Inspect the transducer for mechanical defects, poor finish and improper identification markings. Also inspect the electrical connector.

(2) Connect the transducer to the pressure source-and secure it with the recommended force or torque. Connect the excitation source and readout instrument 
and turn on for specified warm-up period. Prior to calibration, the transducer should be exercised by applying rated pressure and returning to zero for three cycles. The pressure source, connecting tubing and transducer system should be checked for leaks that would cause calibration errors.

(3) Conduct two or more calibration cycles, including at least eleven data points in both ascending and descending directions while monitoring excitation amplitude and recording output signal. Pressure steps must be achieved without overshoot. From the data obtained in these tests the following characteristics should be determined:

(a) End points

(b) Full scale output

(c) Linearity

(d) Hysteresis

(e) Linearity and hysteresis combined

(f) Repeatability

(g) Static error band

(4) Repeat the calibration cycles over a specified period of time after warm-up. This data establishes the following characteristics for that period of time:

(a) Zero shift

(b) Sensitivity shift

(5) Apply the rated pressure to the transducer during a specified short period of time. The measurement of changes in output at constant excitation during the time period should establish:

Creep

(6) At zero pressure, measure output and sensitivity over a period of time, up to one hour, starting with the application of excitation to the transducer. The observed time to stablize will determine the following characteristic:

\section{Warm-up period}

(7) Measure the insulation resistance between all terminals, or leads connected in parallel, and the case of the 
transducer with a megohmmeter using a potential of $50 \mathrm{~V}$, unless otherwise specified, at room temperature to establish:

\section{Insulation resistance}

(8) A Wheatstone bridge should be used to measure and determine the following:
(a) Input impedance
(b) Output impedance

(9) Calibration cycles performed before and after applying the specified proof pressure for the specified period of time will establish the effects of:

Proof pressure

(10) Pressurize the transducer to the specified proof pressure with helium. Inspection of the transducer with a helium leak detector probe will establish:

Leak rate

NOTE: This test is best performed during manufacture using the sensing port only, before the outer case is installed.

4.1.1.2 Qualification Test. The qualification tests for pressure transducers from Reference $3-1$ are sumarized as follows:

(1) The transducer should be installed in a suitable temperature controlled chamber. After stabilizing the chamber and transducer at a specified temperature, one or more calibration cycles should be performed. The procedure should be repeated at an adequate number of selected temperatures over the compensated temperature range. From these tests the following characteristics should be determined:

(a) Thermal sensitivity shift

(b) Thermal zero shift

(2) While installed in the temperature chamber, the transducer should be callbrated at room temperature. The temperature should then be reduced to the lower limit of the operating temperature range and held for the specified duration. The transducer should then be returned to room temperature, allowed to stabilize, and calibrated. The temperature should then be raised to the upper limit of the operating temperature range 
and held for the specified duration. The transducer should then be returned to room temperature, allowed to stabilize, and calibrated. Inspection of the three calibrations at room temperature will establish the effects of:

\section{Maximum operating temperature range}

(3) The sensing end of a flush diaphragm transducer should be inserted rapidly from room conditions into a measured fluid which is maintained at a specified temperature above or below room temperature. The output should be monitored over a specified period of time starting from the moment of insertion.

For a cavity-type pressure transducer the same type of transient temperature test is accomplished by applying the fluid through the sensing port to the sensing element. These tests will determine:

\section{Temperature transient error}

(4) The transducer should be weighed on an appropriate balance or scale to determine its:

Weight

(5) The pressure cavity should be filled with a noncorrosive fluid and the contents poured into a graduate to determine:

Dead volume

(6) A fluid pressure system, including a pressure gage in parallel and a graduated reservoir, should be connected to the transducer. (Provisions shall be made for isolating the transducer when filled.) The pressure system should be evacuated and filled with fluid, the valve to the transducer closed, the valve opened in order to determine:

Volume change due to full scale pressure

(7) The mounting arrangement of an actual installation should be duplicated as closely as possible and a calibration run performed before and after: mounting in order to establish:

(a) Mounting error

(b) Mounting force or torque

(8) Place the transducer on a centrifuge, apply specified acceleration along specifled axes and measure changes in output to determine: 
(9) Vibrate the transducer along specified axes at desired acceleration amplitudes and over the specified frequency range with an electromagnetic or hydraulic shaker and observe or record the transducer output by means of oscilloscopes or high-speed recorders. This will provide information on:

\section{Vibration error}

(10) Application of pressure to the transducer for the specified minimum number of cycles, over the specified range of pressures, will establish:

\section{Cycling life}

(11) The transducer should be subjected to a final complete individual acceptance test to verify that qualification testing has not caused the transducer to exceed specified tolerances.

(12) After completing all of the above tests, the transducer 3 should be connected to a test apparatus which is suitable ${ }^{4}$ for burst tests. The pressure should be increased to the specified burst pressure for the specified number of times and durations. While held at burst pressure, the input pressure should be sealed off and monitored for leaks. The absence of leaks verifies:

Burst pressure

\subsubsection{Transducer Calibration}

When calibrating a pressure transducer, a series of pressures of known magnitude are applied to the transducer and corresponding output readings are recorded, under specified conditions. The output signal from the transducer is then compared to the known pressure stimuli and a statement, curve, table or equation describing this comparison is formulated. This becomes the certificate of calibration.

Many problems associated with static calibration are caused by a misunderstanding concerning definitions of terms, data reduction, and analysis. The methods of computing nonlinearity, hysteresis, total

3The transducer used in the burst test will most likely be damaged, so it should be identified as expendable.

${ }^{4}$ For safety reasons, a well-bled hydraulic pressure system is recommended as suitable for burst testing. 
error band, etc., sometimes vary considerably from one facllity to another and result in confusion. It would be helpful to refer definitions of transducer properties and their determination to a common standard such as ANSI MC88.4-197X, A Guide for the Static Calibration of Pressure Iransducers (Reference 3-9), or ISA S37.3, Specifications and Tests for Strain Gage Pressure Transducers (Reference 3-1). Failing reference to either of these documents, the standard, procedure, or reference which was used in the calibration should be identified.

Meaningful determination of transducer characteristics in the laborationy requires consideration of operating conditions at the test area. For instance, many transducers are sensitive to stresses produced by tightening the mounting hardware or the connection to the pressure port. Strains can also be set up due to nonconcentric clearances, or nonparallel, rough or poorly mated surfaces. Some transducers, particularly those designed for low range, are orientation sensitive with respect to earth's gravitational field. This effect can be manifested by a zero shift or sensitivity change or both. Local temperature conditions (steady state or transient), the presence of shock and vibration, and/or exceptionally strong light sources (especially in certain semiconductor strain gage models) may affect the transducer output. Often these test area conditions are difficult to accurately reproduce in the calibration lab. The user should be made aware of their effects, however, and they must be taken into account if the specified overall uncertainty is not to be exceeded.

4.1.2.1 Periodic and Special Calibrations. These types of calibrations, and their frequency of repetition, will be determined and specified by the user based on local procedures, available equipment, uncertainty requirements, etc. The items that make up the calibration should be taken from those included in the acceptance and qualification tests of Paragraphs 4.1 .1 .1 and 4.1 .1 .2 , plus References $3-1$ and $3-9$. There may of course be other additional tests which are required because of the nature of the operation.

4.1.2.2 Electrical Calibration. Most pressure measurement systems provide for an electrical simulation of the transducer response as part of the system calibration. This simulation should include the transducer as one of the components of this system (as opposed to disconnecting it and substituting a voltage) and should provide a transducer output equivalent to a known pressure which can then be used in the data reduction process. This equivalent to a known pressure, or correlation, must have been determined at the same time the pressure calibration was performed.

4.1.2.3 Shunt calibration. For the purpose of this discussion shunt calibration refers to that technique in which a specified resistance is shunted across one arm of a 4-arm strain gage pressure transducer in order to determine a correlation (or pressure equivalent) between an output produced in this manner and one produced by the application of a physical stimulus or measurand. 
The primary value of using the shunt calibration technique is that changes in the absolute values of many system parameters (e.g., excitation voltage) between calibration and measurement will not affect the accuracy of the test data. The shunt-to-pressure correlation may therefore be determined under controlled laboratory conditions, the transducer stored for some period of time, and later used in a different test location without the need for precise monitoring of excitation, system gain, etc., to verify that the values are the same as they were during the lab calibration. When recording data which will be converted into engineering units through use of a shunt-to-pressure correlation, the absolute values of many system parameters are of little concern so long as they remain constant during the time period initiated by the recording of the shunt-to-pressure correlation and terminated by the completion of the recording of all test data of interest. The shortterm stability and repeatability of most modern test equipment is excellent and error from instability of this type is usually insignificant.

An example of a 4-arm bridge circuit used in a 6-wire system with explanations of how to (1) determine calibration resistance values and (2) measure and compute shunt-to-pressure correlation values is given in Appendix III-C. A more complete discussion of shunt calibration system variables and their effects is contained in Reference 3-9.

\subsection{SYSTEM CALIBRATION}

End-to-end calibrations are generally thought of as those where known pressures are applied to the measurement system transducer and the output, having been subjected to all the conditioning, amplification and recording components of the system, is then analyzed to determine the values of such system performance characteristics as are of interest, e.g., sensitivity, repeatability, linearity, etc. The use of end-to-end calibrations to determine shunt-to-pressure correlations (Paragraph 4.1.2) or such other parameters as are required to perform data reduction is not recommended. The most significant disadvantages of end-to-end calibrations are lack of a controlled environment, inconvenience, insufficient time with respect to other test stand activities (often resulting in haste and increased operator error), and the nonportability of precision pressure generating equipment. Proper system design and careful attention to the details associated with using laboratory determined performance characteristics and test stand application of electrical simulation will produce data within the required uncertainty limits.

End-to-end calibrations or system tests are of great value in certain speciflc instances:

(1) An end-to-end calibration should be performed once a new system has been assembled and is in a ready-fortest condition, but prior to beginning the actual testing. Such a test may serve as an initial system verification or certification. A test of this type is performed by using a precision pressure source and reference standard (Section 4.4) to apply the physical stimulus at the transducer. The electrical signal thus generated is 
transmitted through the signal conditioning equipment to the recording system. By reducing this data to engineering units and comparing it with the known pressure input, a measured uncertainty value can be determined. This sort of test permits a comparison of measurèd endto-end uncertainty with the theoretical uncertainty values determined by combining individual component uncertainty specifications. In some instances such tests would reveal calculation errors due' to omissions or bad information. The end result, when'all differences are resolved, should be an increased level of confidence in the stated uncertainty value.

(2) Slightly less than an overall verification is obtained by perforning such electrical simulations as shunt or constant current calibrations. These types of checks verify the entire system except for the mechanical portion of the transduction system. They are used to determine scaling factors, verify amplifier gains, etc., and should be performed immediately before every test.

(3) A make-and-break test where Individual, installed transducers are electrically disconnected (at the transducer) while an observer monitors the output is often of value. This kind of test is advisable when there has been any significant change in instrumentation channel assignment, or channel identification for some reason becomes necessary. It is performed infrequently, usually only when changes are made.

4.3

DYNAMIC CALIBRATION

Investigations in developmental and production fields necessitate faithful measurement of pressure variations over a wide range of frequencies. The degree of accuracy with which these measurements must be made varies with the test requirements, as does the use made of information derived from such measurements. There are often other complicating factors; such as severe environmental effects, ${ }_{i}$ which must also be considered if meaningful information is to be obtained.

When a transducer is used to measure rapid variations or step changes in pressure levels, the transducer's dynamic characteristics must be established. This can be accomplished either with transient stimulation devices, e.g., shock tubes, or with sinusoidal pressure generators. (For a more in-depth discussion of this topic the reader should see Reference 3-10, A cuide for the Dynamic Calibration of Pressure Transducers.

Appendix III-E, Methods of Determining the Dynamic Characteristics of Pressure Transducers, provides instructions as to how resonant frequency, rise time, frequency response, etc., can be determined from transient stimulation and gives further explanation of the terms contained in this section. 


\subsubsection{Transient Pressure Method}

A positive step function of pressure may be generated in gases with a shock tube or a quick opening valve. A hydraulic quick opening valve is used to generate a positive pressure step function in a liquid medium. A burst diaphragm generator produces a negative pressure step in a gas medium. In all cases, the rise time of the generated step function shall be sufficiently short to excite all resonances in the transducer under test. It shall also be one fifth or less of the anticipated rise time of the transducer under test.

Since the tubing used to mechanically connect the transducer to the test setup will drastically affect the dynamic characteristics (Appendix III-E), the tubing and fittings used must duplicate as closely as possible the actual installation.

By applying step functions of pressure at room conditions within the full scale range of the transducer, and analyzing the electronic or electro-optical recording of the transducer output (usually by photographing a single sweep on an oscilloscope) the following characteristics can be determined.

4.3.1.1 Frequency Response (Amplitudel. The change with frequency of the output/input amplitude ratio for a sinusoidally varying pressure applied to the transducer is usually expressed as "within \pm o (or $\mathrm{dB}$ ) from _to to Hz." Frequency response may also be calculated from the transducer's transient response (see Appendix III-E for an example), its mechanical properties, or its geometry and should be so identified. Frequency response should be referred to a specific frequency, usually $0 \mathrm{~Hz}$. A frequency response curve is often normalized to show deviations from a flat amplitude response. Figure $3-5$ is an illustration of the amplitude response of systems with the same natural frequency, but different damping ratios.

4.3.1.2 Erequency Respense (Phase). A time difference always exists between the input pressure variation and the transducer output. The output lags the pressure input. If this phase shift, or time lag, is significant to the measurement, frequency response can be stated in terms of the phase difference between output and input. Phase shift is expressed either as (1) phase shift linear within $\pm \ldots$ from 0 to __ Hz, reaching __ degrees at Hz or (2) phase shift less than __degrees between $\mathrm{O}$ and $\mathrm{Hz}$.

4.3.1.3 Resonant Frequency. The frequency of the input pressure at which a transducer responds with maximum output amplitude is the resonant frequency. When a transducer has little or no damping (usually the case with the type of transducer used in applications discussed herein) its resonant frequency will be very close to its ringing frequency or the frequency of the oscillatory transient occurring in the transducer output as a result of a step change in the pressure input. 


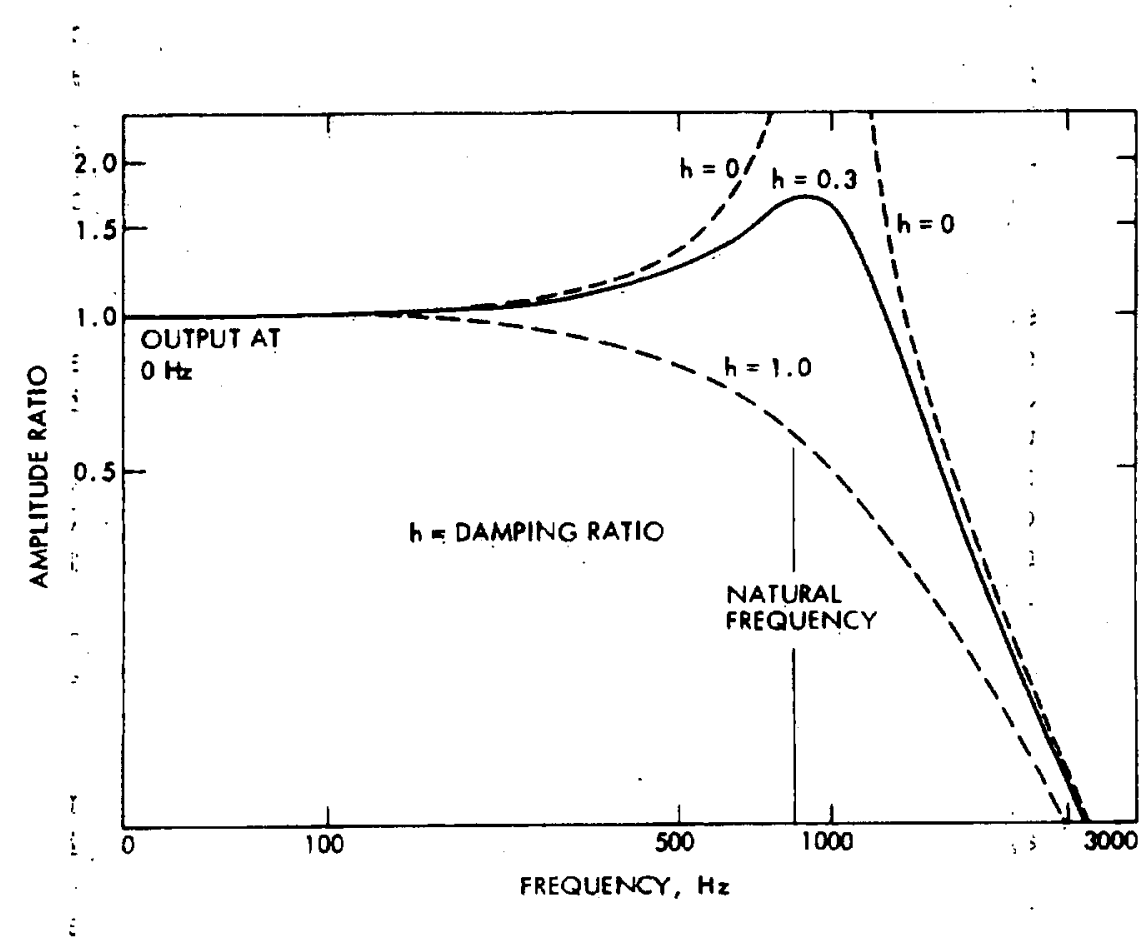

Figure 3-5. Frequency Response of Systems with the Same Natural Frequency and Different Damping Ratios

A transducer may have more than one resonance (major amplitude peaks at more than one frequency). All should be listed. The lowest of these frequencies is usually considered the most important and is generally referred to as the resonant frequency. A peak is considered major when it has an amplitude at least 1.3 times the amplitude of the frequency to which the specifled frequency response is referred.

4.3.1.4 Damping Ratio. The upper limit of frequency response and the response time characteristics of a transducer are affected by the energy dissipating property: damping. In response to a step change of pressure input the output of an underdamped transducer will rise above its final steady state value, (overshoot) and then oscillate about the final value with decreasing amplitude until the oscillations come to rest at this value (Figure 3-6a). The output of an overdamped system w1ll reach its final value without overshoot or oscillations (Figure $3-6 b$ ). A critically damped transducer operates at the point of change between the underdamped and overdamped conditions.

The ratio of the actual damping to the damping required for critical damping is known as the damping ratio. A damping ratio of 1.0 (by definition) signifies critical damping. Damping ratios larger than 1.0 signify overdamped systems; less than 1.0 , underdamped systems. A chart for determining damping ratio is shown in Appendix III-E. 
(a) UNDERDAMPED

(b) OVERDAMPED

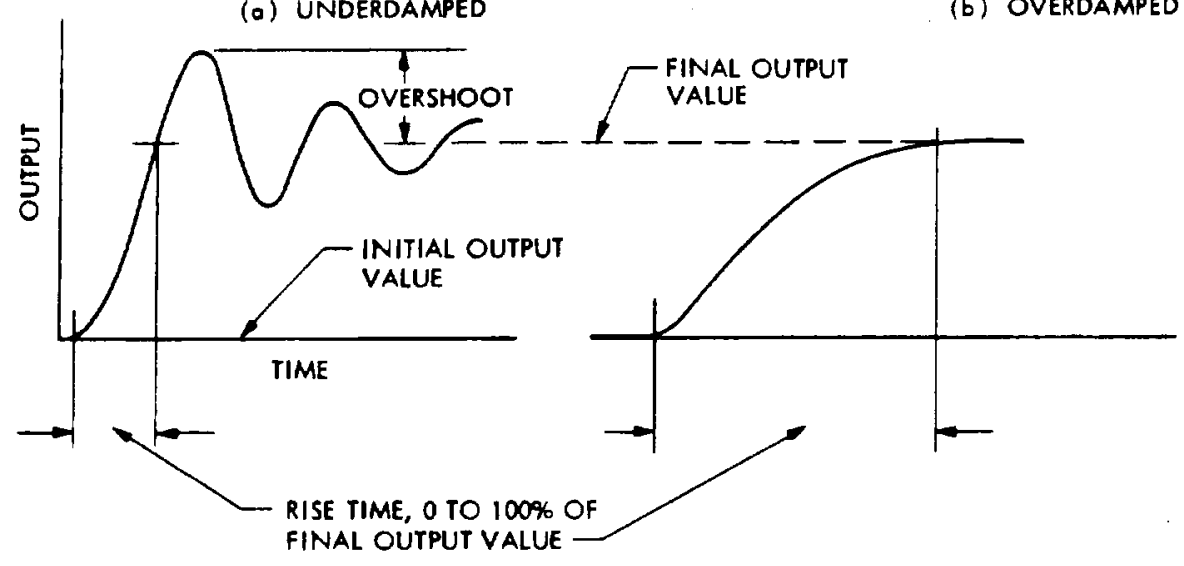

Figure 3-6. Response of Underdamped and Overdamped Systems to a Step Change in Pressure

4.3.1.5 Ringing Eregency. The frequency of the oscillatory transient occurring in the output of an underdamped transducer as a result of a step change in pressure input is called the ringing frequency. See Appendix III-E for a discussion of systems with more than one ringing frequency.

The ringing period (that period of time during which the amplitude of oscillations produced by the step change exceed the final steady state value) is considered terminated when the output osclllations no longer exceed some specified percentage of the final steady state output value.

4.3.1.6 Oversheet. This is the value to which the output of an underdamped transducer rises above the final, steady state value in response to a step change of pressure output. Overshoot is expressed as percent of the equivalent step change in output.

4.3.1.7 Bise and Response Times. When a step change of pressure is applied to a transducer, its output will change in the direction of the pressure change. The time required for the corresponding output change to reach $63 \%$ of its final (steady) value is the time constant $(T)$ of a transducer. The time required to reach a different specified percentage of this final value (e.8., 90, 98, or 994) is the response time. The time in which the output changes from a small to a large specified percentage of the final value is the rise time. (The small percentage is usually 0 to $10 \%$; the large 90 to $100 \%$. See Figure 3-7.)

In conducting a transient pressure test, the initial pressure level can be atmospheric or some other point within the range (so long as the initial value plus the step change do not overpressurize the. transducer to the point of damage). The amplitude of the pressure 


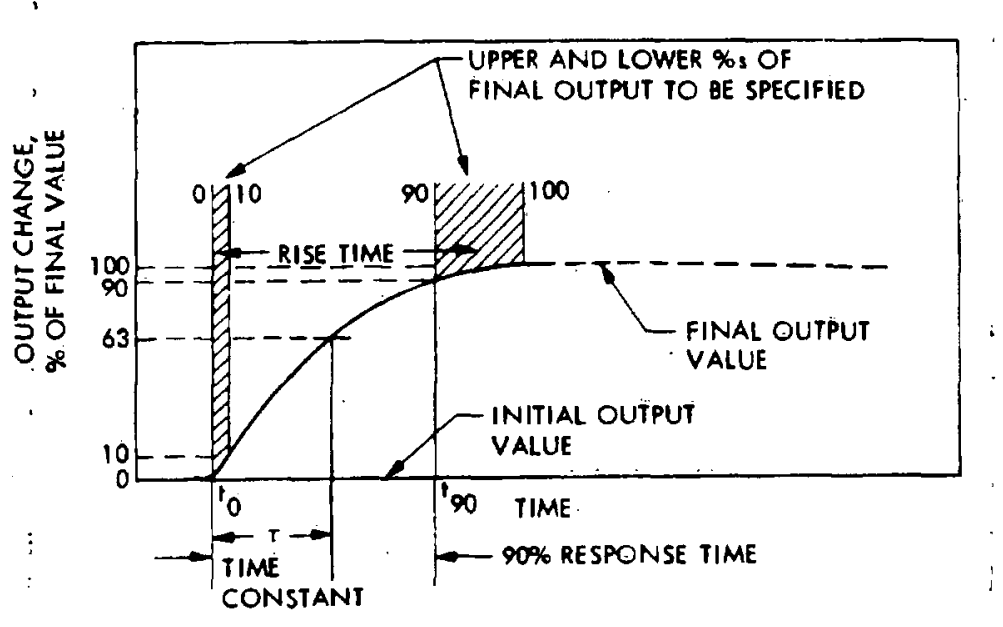

Figure 3-7. Examples of Rise and Response Times

step can theoretically be of any value, however, $10 \%$ of full scale or greater is recommended.

When the rise time, response time, or time constant is to be determined by transient excitation, the ramp of the step change 5 itself (rate of change of pressure) should be negligible when compared to the expected rate of change of the output. If the damping ratio of the transducer is less than 0.5 (most are less than 0.1 ) the rise time of the step input must be less than one fifth that of the transducer for the transducer's rise time to be within $1 \%$ of its asymptotic value. When this ramp (step change of pressure) is insufficiently steep, suitable corrections must be made to the time value obtained.

\section{3 .2 \\ Sinusoidal Stimulation Method \\ Generators are now available which produce sinusoidal}

pressures in liquids or gases, and thus permit a direct measurement of frequency response. This method has considerable advantage over the transient excitation method because the system response can be measured directly instead of being calculated from other parameters (damping ratio, ringing frequency, etc: ). These generators are, however, relatively rare and costly with such possible shortcomings as wave shape impurities, frequencies limited to less than several $\mathrm{kHz}$, or peak dynamic pressures below a few hundred psi. (At higher frequencies pressure amplitudes may be only a fraction of 1 psi.)

5 In actuality, existing test equipment generates a ramp function rather than a step function. The rise time of these step pressure generators nominally varies from less than $1 \mu \mathrm{s}$ in properly designed shock tubes to several milliseconds in quick opening valve apparatus ,(Reference $3=10$ ). 
Among the relatively successful types of sinusoidal pressure generators are those which use one of the following operating principles:

(1) A quick acting servo valve driven by an audio oscillator through a power amplifler to vary the pressure from a hydraulic supply.

(2) A rotating disc to alternately decrease and increase the pressure of a gas supplied from one tubing section, through the perforated disc, to the other tubing section (as exemplified by a siren).

(3) A sound emitter (or a strong loudspeaker voice coil element) acting on a test fluid in a closed system.

(4) Acoustic calibration devices, usable only for very low-pressure transducers.

By applying a sinusoidal pressure wave form of varying frequency and of constant and specified amplitude, the following can be obtained directly:

(1) Frequency response (amplitude)

(2) Phase shift

and the following can be established from the frequency response:

(1) Resonant frequency or frequencies

(2) Damping ratio

For an explanation of these terms see Paragraphs 4.3 .1 .1 through 4.3.1.7. A more thorough treatment of their determination as well as descriptions of the use of transient and sinusoidal test equipment is contained in References $3-10$ and 3-11.

4.4 STANDARDS

Systems used to calibrate pressure transducers must contain these elements: (1) a variable pressure source, (2) a way of measuring the applied pressure to a greater accuracy than the device being calibrated, (3) equipment to measure the electrical output of the transducer and (4) auxilary electrical equipment such as power supplies, bridge balance units and electrical simulation circuits. The combined uncertainties of the calibration system should be one fifth the maximum uncertainty permitted In actual test stand measurements. In practice, an uncertainty of one half or one third may be the best attainable. Whatever the case, the error in the calibration system must be taken into account in determining the accuracy of the calibration.

Calibration standards should be traceable to a better standard. In wost situations traceability to NBS is required. In any event, the 
traceability of a static calibration system should be identified and included in the calibration: report of every test measurement transducer.

\subsubsection{Source of Pressure}

The most commonly used pressure generating systems are (1) hydraulic pumps, (2) compressed gas with regulators, (3) variable liquid height in a tube or pressure vessel, (4) servo-operated gas pressure generators, and (5) fluld deadweight testers.

Pressure reference standards may be broadly divided into two classes: primary standards and secondary standards. Primary standards are those for which a calibration can be established by measuring physical characteristics of dimension and mass. A deadweight tester is an example of a primary standard. Secondary standards (e.g., a Bourdon tube gage) undergo an elastic deformation as a result of applied pressures. This deformation or deflection is measured. The relationship between the deformation and applied pressure is usually determined by comparison with a primary standard. For a thorough discussion of pressure generating systems and standards, see Reference $3-9 !$

A pressure medium similar to the one which the transducer is intended to measure should be used for testing. The accuracy of the pressure source should be at least 5 times greater than the permissible tolerance of the transducer performance characteristic under evaluation. The range of the instrument supplying or wonitoring the calibration pressure should be selected to provide the necessary accuracy to $125 \%$ of the full scale range of the transducer.

The source of callbration pressure way be either continuousIy variable over the range of the instrument, or may be in discrete steps as long as the steps can be programmed in such a manner that the transition from one pressure to the next during calibration is accomplished without creating a hysteresis error in the measurement due to overshoot. Typlcal examples are:

(1) Mercury manometer (pressure 1ndicating device) ${ }^{6}$ Typical range ${ }^{7}$ is 0 to $100 \mathrm{in}$. Hg with an uncertainty of $\pm 0.010 \mathrm{in}$. Hg.

(2) Air piston gage (pressure source). Typical range is $2 \mathrm{kN} / \mathrm{m}^{2}$ to $3 / \mathrm{MN} / \mathrm{m}^{2}(0.3$ to $500 \mathrm{psi})$ with an uncertainty of $\pm 0.025 \%$ of reading.

${ }^{6}$ Pressure indicating devices require a supply of dry gas (e.g.., breathing quality alr, nitrogen, helium) for operation.

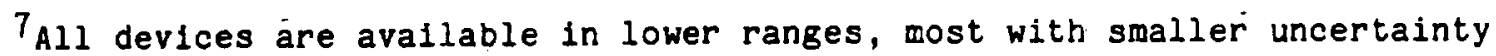
values. See Reference 3-1. 
(3) Precision dial gage (pressure indicating device). Typical range is 0 to $700 \mathrm{MN} / \mathrm{m}^{2}$ ( 0 to $100,000 \mathrm{psi}$ ) with an uncertainty of $\pm 0.1 \%$ full scale.

(4) 0 il piston gage (pressure source). Typical range is $41 \mathrm{kN} / \mathrm{m}^{2}$ to $1400 \mathrm{MN} / \mathrm{m}^{2}$ (6 to $200,000 \mathrm{psi}$ ) with an uncertainty in piston area of less than $\pm 0.012 \%$.

4.4.2 Readout Instrument

The following are examples of suitable devices:

(1) Manually balanced potent1ometer. Typical range is 0 to $11.11 \mathrm{~V}$ with an uncertainty of $\pm 0.006 \%$ of reading $+100 \mu \mathrm{V}$.

(2) Digital electronic voltmeter/ratio meter. Practically infinite ranges with uncertaintles of $\pm 0.01 \%$ of reading +1 digit ( 4 digits display) and $\pm 0.005 \%$ of reading +1 digit (5 digits display).

\subsection{OPERATING PROCEDURES}

To insure that maximum quality measurement data are produced during each test run, certain inspections and verifications must be made. Some of the recommended procedures are shown below for both the pretest and the posttest periods.

\subsection{PRETEST PROCEDURES}

(1) Visually inspect transducer plumbing and mounting.

(2) Verify transducer range, serial number, and instrumentation electrical channel.

(3) Set up and verify data acquisition system.

(4) Record calibration and/or electrical simulation data and check for conformance to predicted values for the measurement system.

(5) Establish pretest zero reference and record.

\subsection{POSTTEST PROCEDURES}

(1) Record zero reference.

(2) Record calibrations and/or electrical simulation data and check for conformance to predicted values.

(3) Visually inspect transducer plumbing and mounting. 


\subsection{DATA ACQUISITION AND PROCESSING TECHNIQUES}

Many generalized standard techniques must be applied in the acquisition and processing of the calibration, verification, and run data even though a wide range of equipment types and handling techniques will be used for these functions. No attempt is made in this section to specify the detailed techniques which are appropriate to the various items of equipment supplied by different manufacturers.

\subsection{CALIERATION AND VERIFICATION DATA}

Recommended practices for the acquisition and processing of calibration and verification pressure measurement data are as follows:

(1) System calibration and verification data should be recorded on the same equipment as run data.

(2) Initial system calibration data must be used to determine whether or not the system design requirements, e.g., hysteresis, linearity, sensitivity, repeatability, etc., have been met.

(3) The system should be verified a number of times to determine the short-term uncertainty. For each verification, a factor for use in determining uncertainty should be calculated. This factor will be a function of the applied pressure (approximately equal to the nominal pressure produced during operating conditions), the net electrical output from the transducer produced by this pressure, and the net output of the electrical simulation signal. A discussion of a method of short-and long-term uncertainty analysis is found in Appendix III-B.

(4) Verification data are used to compute the measurement uncertainty of the system, to compute a period of predicted satisfactory performance, and to check the system for trends and excursions.

(5) If the calculated uncertainty of the system exceeds the allowable limit, the system should be improved until such time as the allowable limit is not exceeded. The total uncertainty of the measurements produced by a system designed in accordance with the practices outlined in this handbook is obtalned by combining all the elemental uncertainties (Appendix III-A). The accepted method for the calculation of total uncertalnty is presented in Reference 3-12.

(6) Posttest verifications should be carefully examined for any deviation from pretest calibrations and/or verifications. If such deviations are outside 
acceptable limits, corrective action should be taken immediately and the validity of the test data should be questioned.

(7) A periodic reevaluation of the measuring system uncertainty should be made as long as the system is in use. Ideally, this period should be a function of the ratio of the maximum allowable uncertainty to the observed uncertainty, the average elapsed time between verifications, and the number of verifications being used in the current evaluation. This verification date is commonly called a void date.

(8) Calibration and verification records should contain at least the following data:
(a) Test stand identification
(b) Parameter identification
(c) Recording system identification
(d) Date, time, ambient temperature, and barometric pressure
(e) Identification of the standard used
(f) Identification of the pressure transducer
(g) Range of the pressure transducer
(h) Calibration range of the system
(i) Run number (where applicable)
(j) Propellant conditioned temperature
(k) Test cell conditioned temperature
(1) Test cell ambient pressure (altitude simulation level)
(m) Test engine identification
(n) Identification of the operators

\author{
6.2 RUN DATA \\ Recommended practices for the acquisition and processing \\ of run pressure measurement data are as follows:
}


(1) Engine test data should be accumulated with this pressure measurement system only after the uncertainty requirements have been met.

(2) Data reduction for each run should be based on the average factor as determined from the pretest and posttest verifications.

(3) Run data should be examined to identify gross malfunctions such as fallure to record, intermittent connections, dropouts, and other equipment malfunctions.

(4) The period of observation for data reduction must be chosen such that the system meets the requirements for the specified test conditions.

(5) Data reduction using a predetermined procedure should be done as quickly as possible after completion of a test so that, in the event of data discrepancy, troubleshooting will be expedited.

(6) Final reduced data should be tabulated for convenient comparison with user specifications.

(7) All calibration, verification, calculated uncertainty, and engine test data should be retained until a data release is dictated by the program requirements. In general, this includes all information related to the interpretation of the measured pressure.

(8) In the event of equipment malfunction, all data associated with that equipment should be examined for validity. This process will be simplified if all equipment used is appropriately identified and the identification is made a part of the permanent test records.

\subsection{GLOSSARY}

Accuracy. The closeness or agreement between a measured válue and a standard or true value.

Ambient Conditions. The conditions (pressure, temperature, etc.) of the medium surrounding the case of the transducer.

Best Straight Line. A line midway between two parallel straight lines closest together and enclosing the calibration curve.

Bonded. Permanently attached over the length and width of the active element.

Eurst Pressure Rating. The pressure which may be applied to the sensing element or the case (as specified) of a transducer without rupture of either the sensing element or transducer case as specified. 
Calibration. A test during which known values of measurand are applied to the transducer and corresponding output readings are recorded under specified conditions. (Only during a calibration may adjustments be made so that a relationship convenient for data reduction purposes can be established.)

Calibration Traceability. The relation of a transducer calibration, through a specified step-by-step process, to an accepted national standard; usually maintained by the National Bureau of Standards.

Creep. A change in output occurring over a specific time period while the pressure and all environmental conditions are held constant.

Damping. The energy dissipating characteristic which, together with natural frequency, determines the upper limit of frequency response and the response time characteristics of a transducer.

Dead Volume. The total volume of the pressure port cavity of a transducer with room barometric pressure applied.

Dead Volume Change. The change in dead volume when pressure at the port is increased from zero pressure to full range pressure.

Diaphragm. A sensing element consisting of a thin, usually circular, plate which is deformed by pressure differential applied across the plate.

Drift. An undesired change in output over a period of time, which is not a function of pressure.

End Points. The outputs at the specified upper and lower limits of the pressure range.

Error. The indicated value minus the true or ideal value:

Ercor Band. The band which includes the deviation of output values from a specified reference line or curve due to those causes attributable to the transducer, as measured over two consecutive calibration cycles unless otherwise specified.

Excitation. The external electrical voltage and/or current applied to a transducer for its proper operation.

Frequency Response (Amplitude). The change with frequency of the output/input amplitude ratio (and of the phase difference between output and input), for a sinusoidally varying pressure applied to the transducer.

Fuld scale output (ESO). The algebraic difference between the outputs at the end points.

Hysteresis. The maximum difference in output, at any pressure within the specified range, when the value is approached first with increasing and then with decreasing pressure. 
Input Impedance. The impedance (presented to the excitation source) measured across the excitation terminals of a transducer.

Leakage Rate. The maximum rate at which a specified fluid applied to the sensing element at a specified pressure is determined to leak out of the case.

Life cycling. The specified minimum number of full range excursions or specified partial range excursions over which a transducer will operate without changing its performance beyond specified tolerances.

Linearity. The closeness of a calibration curve to a specified straight line (such as the line between end points). (Nonlinearity is expressed as the maximum deviation of any calibration point from the specified straight line, during any one calibration cycle. It is expressed as "less than $\pm \ldots$ of full scale output.")

Line Pressure Effects. Zero shift or sensitivity shift caused by changes in the line reference pressure in differential pressure transducers.

Measurand. A physical quantity, property or condition which is measured (such as pressure).

Mounting Error. The error resulting from mechanical deformation of the transducer caused by mounting the transducer and making all pressure and electrical connections.

Output. The electrical quantity which is produced by the transducer as a function of the applied pressure.

Output Impedance. The impedance across the output terminals of a transducer presented by the transducer to the associated external circuitry.

Pressure, Absolute. The difference between a pressure and vacuum reference pressure.

Pressure, Differential. The difference between two pressures where the selected reference pressure is referred to as line pressure.

Pressure, Gage. The difference between a pressure and ambient (or atmospheric) reference pressure.

Pressure, Stagnation (Total Pressure). The total pressure measured at a stationary point located at the terminus of a stagnation streamline.

Pressure, Static. The pressure measured at a point traveling along a streamline at the velocity of a fluid.

Proof pressure. The maximum pressure wh1ch may be applied to the sensing element of a transducer without changing the transducer performance beyond specified tolerances. 
Pulse Mode Operation. For the purpose of this section, pulse mode operation is defined as occurring whenever (a) the thruster valve is commanded closed prior to the attainment of $95 \%$ of the steady state catalyst bed temperature as measured at the outer wall surface, or (b) the performance of the thruster is to be monitored over a time period which includes both the start-up and shut-down transients, and during which time the transient portions of any measurement are significant with respect to any steady state measurements.

Range. The pressure values, over which a transducer is intended to measure, specified by their upper and lower limits.

Reference Pressure. The base pressure from which other pressures are measured.

Repeatability. The ability of a transducer to reproduce output readings when the same pressure is applied to it repeatedly, under the same conditions, and in the same direction. (Nonrepeatability is expressed as the maximum difference between output readings; it is expressed as "less than __ of full scale output.")

Resolution. The least discernible output change which reflects a change in pressure (expressed in percentage of full scale output).

Resonant Frequency. The pressure frequency at which a transducer responds with maximum output amplitude.

Response Time. The length of time required for the output of a transducer to rise to a specified percentage of its final value as a result of a step change of pressure.

Rise Time. The length of time for the output of a transducer to rise from a small specified percentage of its final value to a large specified percentage of its final value.

Sensing Element. That part of the transducer which responds directly to pressure.

Sensitivity. The ratio of the change in transducer output to a change in the pressure.

Stability. The ability of a transducer to retain its performance throughout its specified operating life and storage life.

Static Calibration. A calibration performed under stated environmental conditions by application of the measurand to the transducer in discrete amplitude intervals (in the absence of any vibration, shock, or acceleration).

Steady State operation. For the purpose of this section, steady state operation is defined as that portion of a test after which the temperature at the outer surface of the catalyst bed wall has achieved 959 of its equable asymptotic value, but prior to the time at which the propellant valve is commanded closed. Steady state measurements should be made only after the attainment of this condition. 
Strafn. The mechanical deflection of a structural element in the context used in Hooke's Law which states that the modulus of elasticity is equal to the stress divided by the strain.

Temperature compensation. Provision of a supplemental device, circuit, or spectal materials to counteract known sources of temperature errors.

Temperature Range, Compensated. The range of ambient temperatures, given by their extremes, within which the transducer is intended to operate within specified tolerances; within this range of amblent temperature error band, temperature gradient error, thermal zero shift and thermal sensitivity shift are applicable.

Temperature Range, Operating. The temperature range in which a transducer may be operated without damage.

Thermal Sensitivity Shift. The sensitivity shift due to changes of the ambient temperature within the compensated temperature range.

Thermal Zere Shift. The changes in output at zero applied pressure, when the transducer is subjected to changes of ambient temperature within the compensated! temperature range.

Threshold. The smallest change in pressure that will result in a measurable change in transducer output.

Total Error Band. The band of maximum deviations of calibration output values from a specified reference line or curve due to those causes attributable to the transducer.

Iransducer. A device which provides a usable output in response to a specified measurand.

Unbonded. Stretched and unsupported between ends (usually refers to strain-sensitive wire).

Uncertainty, Measurement. The term meaning the difference between the true value and the measured value and including both bias and random error. The term accurate implies small measurement error and small uncertainty (see Reference 3-12).

Verification. A verification confirms an established relationship to a standard. (Confirmation implies that no adjustments have been made since the last calibration because an adjustment might void the statistical history of the system.) Verification data are also used to compute the measurement uncertainty of the system, to compute a period of predicted satisfactory performance, and to check the system for trends and excursions.

Vibration and Acceleration Error. The maximum change in output, at any pressure within the specified range, while vibration or acceleration levels of specified amplitude and range of frequencies are applied to the transducer along a specified axis at room conditions.

Zero Shift. Any change in output at zero applied pressure. 


\section{NOTE: Definitions and nomenclature used in the glossary and throughout this handbook conform to the Instrument Society of American Standard for Electrical Transducer Nomenclature and Technology (Reference 3-13) wherever applicable.}

\subsection{REFERENCES}

3-1. Specifications and Tests for Strain Gage Pressure Transducers, ISA-S37.3 (ANSI MC6.2-1975), Instrument Society of America, 1975.

3-2. Hydrazine Compatibility Design and Handling Criteria, AFRPL-TR75-46, December 1975.

3-3. Gardenshire, L. W., "Selecting Sample Rates," ISA Journal, pp. 59-64, April 1964.

3-4. Harrje, D. T., and Reardon, F. H., Liquid Propellant Rocket Combustion Instability, NASA SP-194, 1972.

3-5. Soecial Considerations for Combustion Instability Instrumentation and Data Fresentation, CPIA Publication No. 170, ICRPG Comittee on Instrumentation and Test Data, June 1968.

3-6. Hilten, J. S., et al., Experimental Investigation of Means for Reducing the Response of Pressure Transducers to Thermal Transients, NBS Technical Note 961 , January 1978.

3-7. Hilten, J. S., A Test Method for Determining the Effect of Thermal Transients on Pressure-Iransducer Response, NBS Technical Note 905 , March 1976.

3-8. Morrison, R., Grounding and Shielding Techniques in Instrumentation, Second Edition, John Wiley \& Sons, New York, 1977.

3-9. A Guide for the Static Calibration of Pressure Transducers, ANSI MC88.4-197X, American Society of Mechanical Engineers (to be published in 1979).

3-10. A Guide for the Dynamic Calibration of Pressure Transducers, ANSI MC88.1-1972 (R1978), American Society of Mechanical Engineers, 1972.

3-11. Norton, H. N., Handbook of Iransducers for Electronic Measuring Systems, Prentice-Hall, 1969.

3-12. ICRPG Handbook for Estimating the Uncertainty in Measurements Made With Liquid Propellant Recket Engine Systems, CPIA Publication No. 180, ICRPG Performance Standardization Working Group, April 1969 .

3-13. Electrical Transducer Nomenclature and Terminology, ISA-S37.1, (ANSI MC6.1-1975), Instrument Society of America, 1975. 


\section{APPENDIX III-A}

PRESSURE MEASUREMENT SYSTEM ELEMENTAL UNCERTAINTIES

The following identifiable elemental uncertainties must be quantified in order to ascertain the overall uncertainty in the reported pressure measurement. The reference document for the calculation of the uncertainty is the ICRPG Handbook for Estimating the Uncertainty in Measurements Made With Liquid Propellant Rocket Engine Systems (Reference 3-12).

I.

STANDARDS CALIBRATION SYSTEM

A. National Bureau of Standards

Overall uncertainty, including bias and precision.

B. Primary Standard

Deadweight tester and liquid manometer; overall uncertainty including bias and precision.

C. Pressure Secondary Standard

Precision Bourdon gage, servobalancing system, reference transducers; overall uncertainty including bias and precision.

D. Transducer Calibration

Variability in the transfer function; linearity, hysteresis, repeatability, etc.

II.

PRESSURE MEASUREMENT SYSTEM

A. Probe, Lap, Cavity Volume, and Connecting Tubing Effects

Consider frequency and wave form of physical variable;

if possible, use response curve to define this.

See Appendix III-E.

B. Transmission Lines

Include connect/disconnect and switching effects, plug, shielding, grounding, noise, resistance, and attenuation of higher frequencies. 


\section{Transducer}

Derive uncertainty from known physical stimulus and electrical output; include linearity, hysteresis, repeatability.

III.

ELECIRICAL CALIBRATION EQUIPMENT

A. Electrical Excitation

1. Balance units

2. Power supplies

B. Electrical Simulation

Shunt calibration. See Appendix III-C.

IV.

SIGNAL CONDITIONING EOUIPMENT
A. Power Supply
B. Amplifier
1. Gain stability
2. Nonlinearity

V.

RECORDING EQUIPMENT
A. Nonlinearity
B. Stability
C. Resolution

VII. DATA PROCESSING EQUIPMENT RESOLUTION 


\section{APPENDIX III-B}

\section{SHORT - AND LONG-TERM PRESSURE MEASUREMENT SYSTEM UNCERTAINTY}

Short-term uncertainty is determined from verifications taken at frequent intervals. The elapsed time between these verifications must be at least equal to the anticipated elapsed time between the pretest and posttest verifications.

An alternate type of analysis called long-term uses data from verifications taken at least 48 hours apart when analyzing the system for uncertainty. If the uncertainty limit cannot be met, then the data will be reduced based upon verifications taken during each test. If the limits are met, then the test data are reduced using the long-term average data reduction factor. New verifications are added to the statistical history of the system on a periodic basis. Ideally, this period should be a function of the ratio of the maximum allowable uncertainty to the observed uncertainty, the average time elapsed between verifications and the number of verifications being used in the current evaluation.

After each addition is made, the system is analyzed to check for compliance to the uncertainty limits and a new average data reduction factor is generated. Testing is allowed to continue so long as the uncertainty limit is not exceeded. Once the uncertainty limit is exceeded, engine testing is to stop and the system is to be improved. Subsequent to the improvement, a new statistical history is to be started.

The following additional requirements shall be placed on the verification data used in the analysis of the pressure system.

(1) Only verifications made since the latest calibration shall be used.

(2) Only the most recent verifications shall be used. (It is recommended that this be limited to the last ten samples. A sample size of ten is enough to obtain a good statistical average for the data reduction factor but small enough so that trends can be detected.)

(3) Verifications resulting from erroneous procedures or faulty verification equipment shall be excluded.

(4) All verifications meeting these requirements are to be included in the statistical history of the system.

It is also recommended that a chart be kept showing for each verification: (1) the data reduction factor (in pounds per square inch), (2) the level of the simulation signal (in millivolts), (3) the system sensitivity (in pounds per square inch per millivolts), and (4) the system unbalance at zero load (in millivolts). With this chart potential system problems can be spotted. The plots of successive data reduction factors and system unbalances should remain flat, while the other two plots track each other but in opposite directions, as shown in Figure III-B-1. 

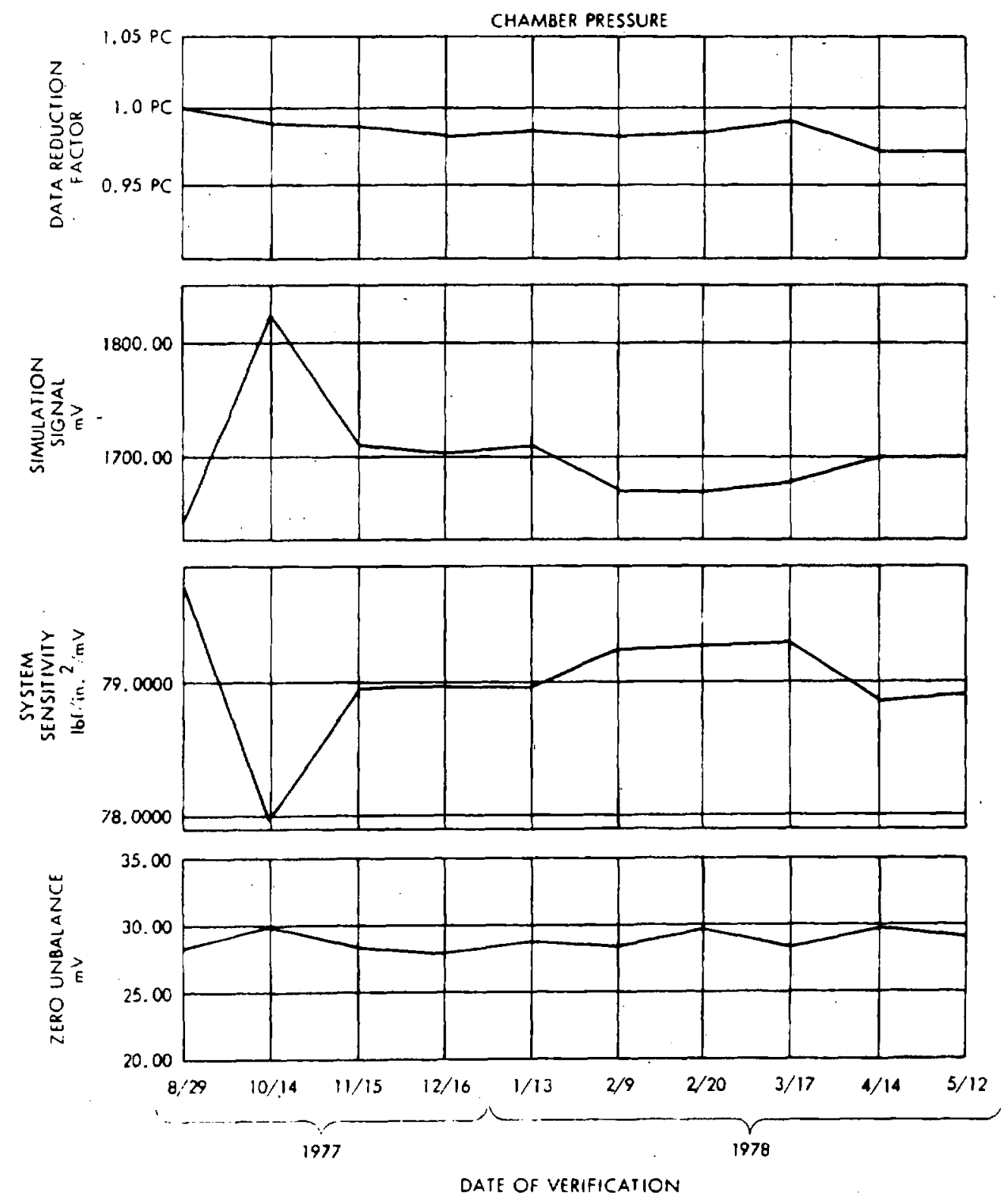

Figure III-B-1. Example of Control Data Uncertainty Checks 
Figure III-B-2 shows in block diagram form the relationship between calibration and verlfication data as well as the relationshio between short-term and long-term uncertainty. It also shows the typical paths for corrective action that can be taken when the system requirements are not met. 


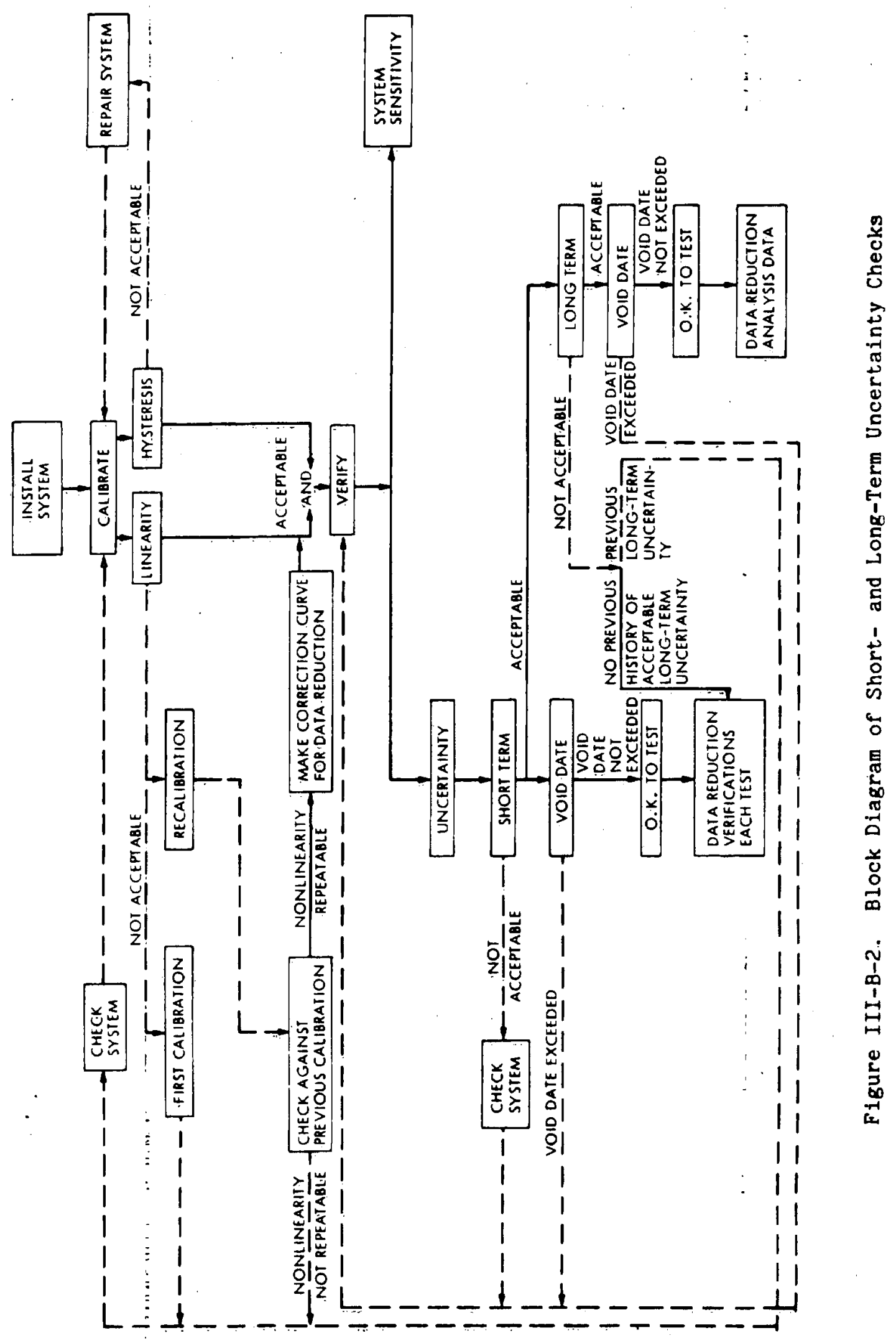


APPENDIX III-C

SHUNT CALIBRATION OF PRESSURE TRANSDUCERS

It is beyond the scope of this document to provide an indepth mathematical analysis of all possible configurations, techniques and sources of error associated with shunt calibration. Instead, discussion will be confined to a 6-wire measurement system and a single method of applying the calibration resistor. For a discussion of the effects and possible sources of error from several circuit and procedure variables see Reference 3-9, A Guide for the Static Calibration of Pressure Transducers.

\section{CIRCUIT CONFIGURATION}

Figure III-C- 1 shows a 4-arm bridge circuit with balancing network and shunt calibration resistor. The 6 wires that make up the transmission lines are of equal size and thus have approximately equal resistance ( $R$ line). The values of the balance and limiter resistors are typical for this configuration. The shunt calibration resistor shown in Figure III-C-1 produces a pesitive signal output when the calibration switch is closed.

\section{DETERMINATION OF CALIBRATION RESISTANCE VALUE}

The values of the calibrating resistors $\left(R_{c}\right)$ used will vary according to the preferences of the user. In some instances standard values of $R_{c}$ are chosen to fairly close tolerance and the shunt-topressure correlation values are allowed to vary from transducer to transducer. This results in uneven correlation values - a situation of no consequence so long as the precise values for the individual transducers are used. In other applications the preference is to trim the bridge resistance and transducer sensitivity so that a constant value of $R_{c}$ will produce the same percentage of full scale output in all similar transducers. Either technique will work so long as a consistent procedure is followed and the measurement techniques are understood by those involved.

The sensitivity adjustment resistor $R_{S}$ is normally split equally between the two excitation loads. In this case $\beta=0.5$. Also, under this condition the effects of all other resistances except $R$, the bridge resistance itself, or $R_{c a l i b r a t e}\left(R_{c}\right)$ are zero or negligible. $\mathrm{R}_{\mathrm{c}}$ can be determined by:

$$
R_{C}=\frac{R}{4 K S}-\frac{R}{2}
$$

where $R_{c}$ is the calibration resistance value, $R$ the bridge resistance, $K$ the percentage of full scale output desired $(10,25,50 \%$, etc.) and $S$ the full scale sensitivity of the transducer in volts output/volts 


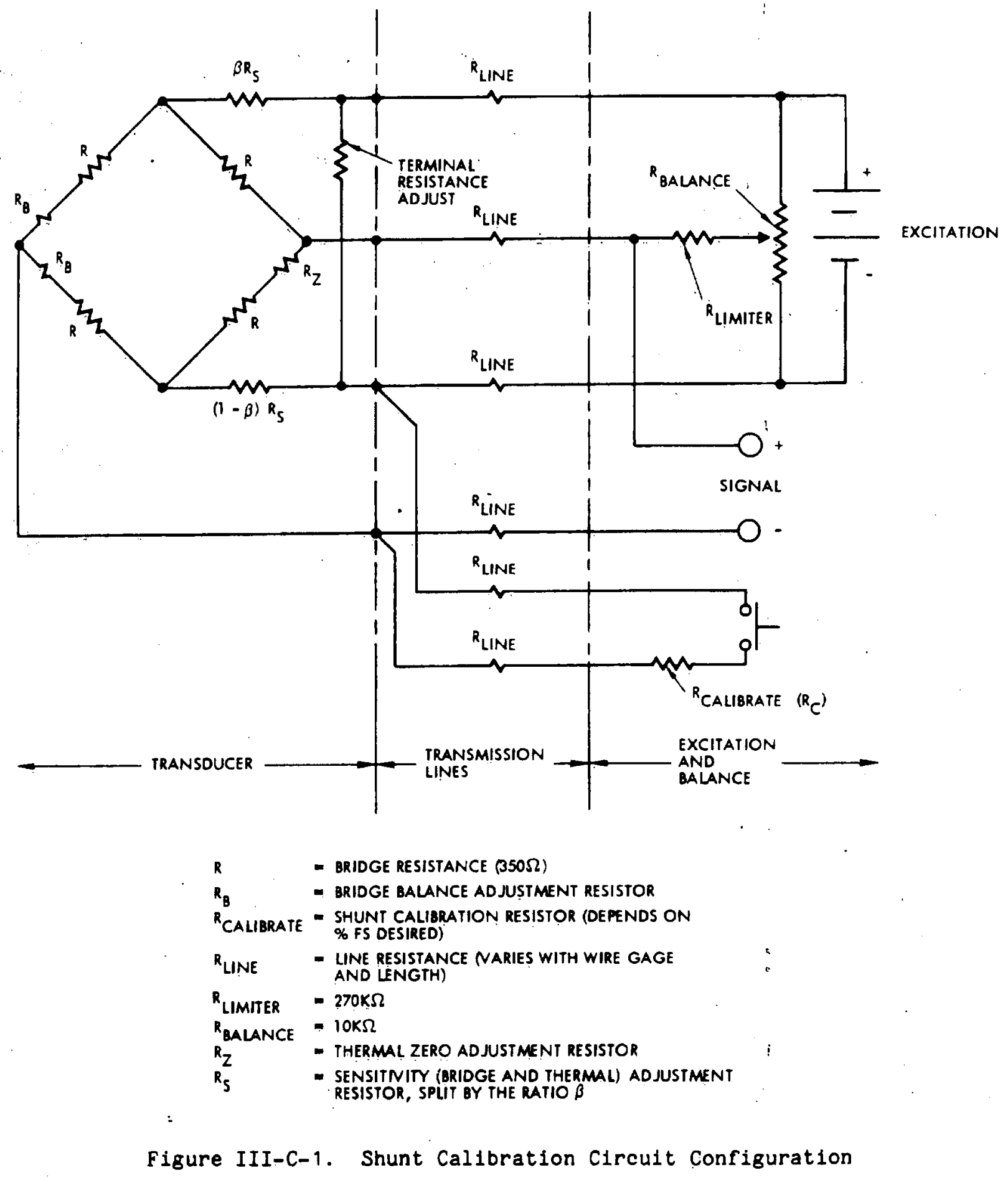

.

• 
excitation $(0.002,0.003$, etc.). For a transducer with a 350-ohm bridge and $3 \mathrm{mV} / \mathrm{V}$ sensitivity the following $R_{C}$ values correspond to the given percentages of full scale output values:

$\begin{array}{rr}\frac{\text { FS }}{10} & \mathrm{~B}_{\mathrm{C}} \frac{\text { (ohms) }}{291.5 \mathrm{~K}} \\ 25 & 116.5 \mathrm{~K} \\ 50 & 58.2 \mathrm{~K} \\ 80 & 36.3 \mathrm{~K} \\ 100 & 29.0 \mathrm{~K}\end{array}$

In the foregoing example, bridge resistance and sensitivity are nominal values and will vary from one transducer to another. Sensitivity can be standardized with adjustment of $R_{s}$. Variations in bridge resistance will result in changes in $K$ for a given $R_{\text {. T }}$. Transducers are sometimes standardized for output due to shunt califration by varying $\beta$, the ratio of the split in $R_{s}$ between the two excitation leads. The computation however then becomes more complex:

$$
R_{C}=\frac{R\left(R+2 \beta R_{S}\right)-R K S\left(2 R+3 R_{S}\right)-4 \beta K S(1-\beta) R_{S}^{2}}{4 K S\left(R+R_{S}\right)}
$$

The third term in the numerator has negligible effect on the result, so that a simplified expression for $\beta$, when $R_{c}$ and $S$ are
standardized, becomes:

$$
\beta=\frac{4 R_{c} K S\left(R+R_{S}\right)+R K S\left(2 R+3 R_{S}\right)-R^{2}}{2 R R_{S}}
$$

Standardization of output due to shunt calibration adds complexity and cost to the measurement process and has no advantage in modern automated data reduction. It is therefore not recommended. Standard $R_{c}$ values should be used and the resultant $K$ allowed to vary slightly from one transducer to another. $R_{s}$ should be split equally in each excitation lead.

MEASURING AND COMPUTING SHUNT-TO-PRESSURE CORRELATION

Shunt-to-pressure correlations are usually determined under laboratory conditions as part of the routine transducer calibration. When such is the case the transducer outputs at various pressures are recorded and upon return to zero the desired calibration resistor(s) are applied and the corresponding output( $s$ ) recorded. Data taken in this manner has the advantage of containing little, if any, time dependent variation.

To calculate the shunt-to-pressure correlation for a particular $R_{c}$, the following formula may be used:

$$
R_{c} \text { (equivalent) }=\frac{E_{p}}{E_{p}} \times P
$$


where $E_{r}$ is the output produced by application of $R_{c}$, and $E_{p}$ is the output produced by a particular pressure $P$. For example, where $E_{r}$ $=15.535 \mathrm{mV}$ and $E_{p}=15.123 \mathrm{mV}$ at $P=3447.379 \mathrm{kN} / \mathrm{m}^{2}(500.000 \mathrm{psi})$, the shunt-to-pressure correlation or pressure equivalent value of $R_{c}$ would be $3541.2990 \mathrm{kN} / \mathrm{m}^{2}(513.622 \mathrm{psi})$.

Then, in a measurement application, if the same value $R_{c}$ produces an output of $14.926 \mathrm{mV}$ and the pressure produces an output of $16.204 \mathrm{mV}$ the value of the pressure (P) can be determined by:

$$
\begin{aligned}
P(p s 1) & =\frac{E_{p}}{E_{r}} \times R_{c} \text { (equivalent) } \\
& =\frac{16.204}{14.926} \times 3541.2990 \mathrm{kN} / \mathrm{m}^{2} . \\
\text { Pressure } & =3844.514 \mathrm{kN} / \mathrm{m}^{2}(557.600 \mathrm{psi})
\end{aligned}
$$

- Generally, if there is a cholce of more than one $R_{c}$ to use during a test, the one nearest the expected value of the measurand will provide data with the minimum uncertainty.

.
.




\author{
APPENDIX III-D \\ SPECIAL CONSIDERATIONS FOR VACUUM MEASUREMENT
}

REGION OF APPLICATION

Rocket engines are tested under simulated altitude conditions in order to provide data for predicting flight performance. For the thrust range discussed in the handbook, most static rocket engine testing will be conducted at simulated altitudes of from $46 \mathrm{~km}(150,000 \mathrm{ft}, 1$ torr $)$ to $100 \mathrm{~km}\left(350,000 \mathrm{ft}, 10^{-4} \mathrm{torr}\right)$, depending upon the back pressure required to ensure a full-flowing nozzle condition.

\title{
DESIGN CONSIDERATIONS
}

\section{Point of Measurement}

It is important that the measuring point be representative of the simulated environment. Under some test conditions pressure gradients may exist in the altitude chamber. For this reason, measurements should be made at several points in the vacuum chamber on unfamiliar or new setups to determine if a pressure gradient exists in any given region. A minimum of 2 points should be monitored on all test firings once the reliability of the measurement points has been established.

\section{Mechanical Impedance}

Care must be taken in making the connection between the vacuum tanks (point of measurement) and the transducer. The number of connections should be kept to a minimum to reduce the probability of leaks in the measurement system. The size and length of the lines must be consistent with the anticipated condition. Since the velocity of sound is independent of pressure (to a first order approximation), the controlling factor for pressure propagation in a connecting tubing is the relationship between the mean free path (distance of travel between molecular collisions) of the molecules at the specific pressure and the diameter of the tubing. As an example, the mean free path of the molecules at $133 \mathrm{~N} / \mathrm{m}^{2}$ (1 torr) is $2.5 \times 10^{-3} \mathrm{~cm}\left(1.0 \times 10^{-3} \mathrm{in.}\right)$. With this molecular density there should be no problem measuring rough vacuum quality with $1.3-\mathrm{cm}(1 / 2-$ in.) diameter lines connecting the pressure gage to the chamber. For much lower pressures, connecting lines of $1.9 \mathrm{~cm}(3 / 4 \mathrm{in.})$ in diameter may be required for accurate measurements, and coupling line lengths should be kept to an absolute minimum.

\section{TRANSDUCERS}

A differential pressure transducer which is based upon the principle of a balanced capacitive circuit may be used over the entire vacuum range of interest here. Multiple gages of other types may also be used to cover a desired vacuum range; however, thermocouple-type 
gages may give erroneous readings in an ammonia environment and are thus not recommended for monitoring vacuum during the firing of a monopropellant hydrazine, engine.

\section{OPERATING TECHNIQUES}

The transducers should be connected to the altitude chamber directly without an intervening vapor trap. When a McLeod mercury gage is used either as a standard for field calibration or as a diagnost 1 c tool, a vapor trap should be used to prevent contamination of the mercury and erroneous measurements resulting from condensable gases. In this case all transducers being compared must be downstream of the vapor trap.

If a vapor trap is required there are two types which can be used. One is a dry chemical trap where a desiccant or other absorptive material is used to dry the gas. The other is the cold trap, which requires the gas to pass through a line to a trap area which is immersed in a Dewar of liquid nitrogen and out to the measurement device. In this case, the liquid nitrogen freezes out the condensable vapors on the side of the cold trap. The vapor trap should have sufficient capacity so that condensed fluids do not plug the measurement line.

Low-pressure transducers are very vibration sensitive; therefore they should be shock mounted and mechanically isolated from the test environment. It is a good practice to monitor two transducers from the same tap to achieve an initial pumpdown comparison. If a disagreement occurs or a check is desired, the vapor trap can be installed and direct comparison made downstream of the vapor trap between a McLeod gage and the transducer.

SIGNAL COṄDITIONING AND RECORDING

Recording of the output of a pressure transducer can be accomplished as outlined in Paragraph 3.2 .3 of this section; however, it should be pointed out that the McLeod gage is not a recording device and must be visually read. It is used as a field standard to verify other gages. 
By applying a step pressure input to a pressure measuring system ${ }^{1}$ and analyzing the recorded transducer output (usually the photograph of a single sweep on an oscilloscope), various dynamic characteristics can be determined. This appendix suggests ways to determine the most common characteristics. For a more in-depth discussion see Reference 3-10, A Guide for the Dynamic Calibration of Pressure Transducers.

\section{CAVITIES AND PASSAGES}

The manner in which a transducer is mechanically coupled to the pressure can significantly affect the response of that transducer. Meaningful measurements of pressure fluctuations at frequencies around $10^{3} \mathrm{~Hz}$ or higher can only be made with transducers having flush diaphragms. The use of any connecting line or cavity will limit the freouency response characteristics of the measurement system to those of the connectine. system.

There are instances where a connecting line or passage cannot be avoided. In such a case, its length will have to be selected to be consistent with the highest frequency to be measured. The lowest longitudinal resonant frequency of a cylindrical passage js:

$$
f=\frac{c}{4 L}
$$

where $c$ is the speed of sound in the gas at the given temperature and $L$ is the length of the passage.

If a dynamic measurement or calibration has to be performed through a passage, the highest frequency considered should be less than $1 / 10$ of the resonant frequency of the passage. In air at room temperature $(c=334 \mathrm{~m} / \mathrm{s}, 1097 \mathrm{ft} / \mathrm{s})$ and a passage length of only $0.64 \mathrm{~cm}(1 / 4 \mathrm{in.})$, for instance, frequencies up to $1400 \mathrm{~Hz}$ will result in less than $1 \%$

${ }^{1}$ In this appendix the terms transducer and pressure measuring system are used somewhat interchangeably since the calculations presented will work equally well with both. In actual practice the user should know whether the data provided pertains to the transducer alone or if it includes such installation hardware as connecting lines, orjfices, etc. (for reasons discussed in Paragraph 3.1.3.2). Measuring system electronics (signal conditioning and recording) can also affect overall system response, especially at frequencies above $5 \mathrm{kHz}$, and thus should also be clearly defined. 
dynamic error. Equation (III-E-1) applies only for straight passages. A small passage leading to a cavity in front of the transducer will result in much lower resonant frequencies. The following relation (Reference $3-10$ ) shows the effect of a gas-filled passage and cavity:

$$
\begin{aligned}
& f=\frac{c d}{7.09}[(L+0.85 d) V]^{-1 / 2} \\
& \text { providing } d^{2} L<\frac{4 V}{\pi}
\end{aligned}
$$

where

$$
\begin{aligned}
& d=\text { inside diameter of tube (orifice), inches } \\
& L=\text { length of tube (orifice), inches } \\
& V=\text { cavity volume, cubic inches. }
\end{aligned}
$$

When $d^{2} \mathrm{~L} \gg \frac{4 \mathrm{~V}}{\pi}$ the cavity resonance approaches the longitudinal resonant frequency described by Equation (III-E-1).

It is important to determine all mechanical resonances of the system over the frequency range to be measured. The nature of these resonances may be somewhat obscure, and care must be exercised to insure their repetition from one installation to the next if a response analysis is to be valid: Resonances other than the major ringing frequency may sometimes be caused by nonflush diaphragms, discontinuities in the surface near the transducer, vibration, etc. In short, modulating frequencies above or below the ringing frequency may not be inherent to the transducer at all. The presence of these associated resonances emphasizes the fact that if evaluations of transducer response are to be meaningful, the mounting configuration employed for the calibration must be identical to that used in the actual application. Liquid-filled systems may introduce additional measurement uncertainties due to cavitation and inertial effects which are not readily predictable.

\section{RISE AND RESPONSE TIME}

The time required for a transducer's output to reach $63 \%$ of its final (steady) value is the time constant $(T)$ of that transducer. The time required to reach a different specified percentage of this final value (e.g., 90, 98, or 99\%) is the response time. The time in which the output changes from a small to a large specified percentage of the final value is the rise time (Figure III-E-I). In some cases the terms cise time and response time may mean the same thing. To avold confusion the levels of the initial and final output values should be clearly stated. Figure III-E-2 depicts the 0 to $100 \%$ of final value rise times for underdamped (a) and overdamped (b) systems. 


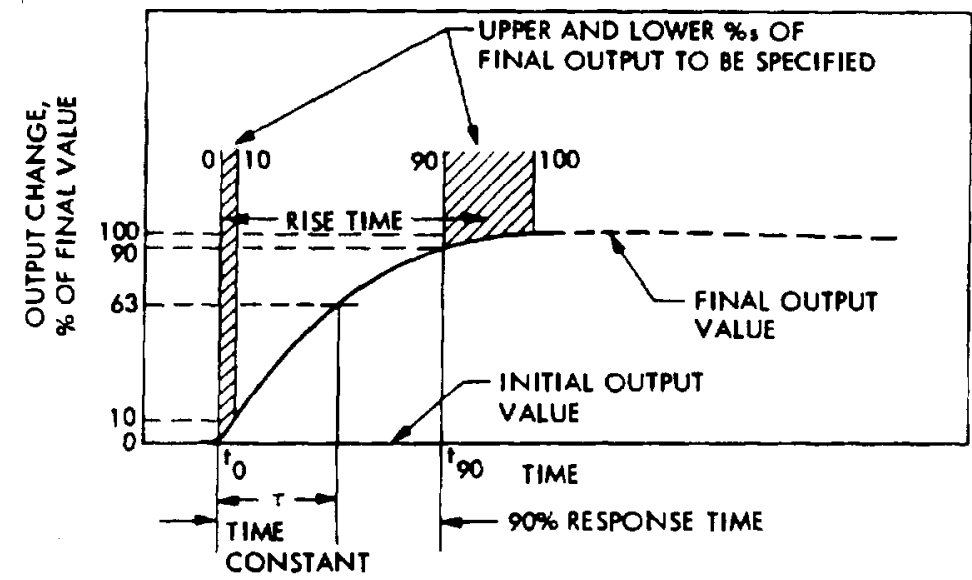

Flgure III-E-1. Examples of Rise and Response Times

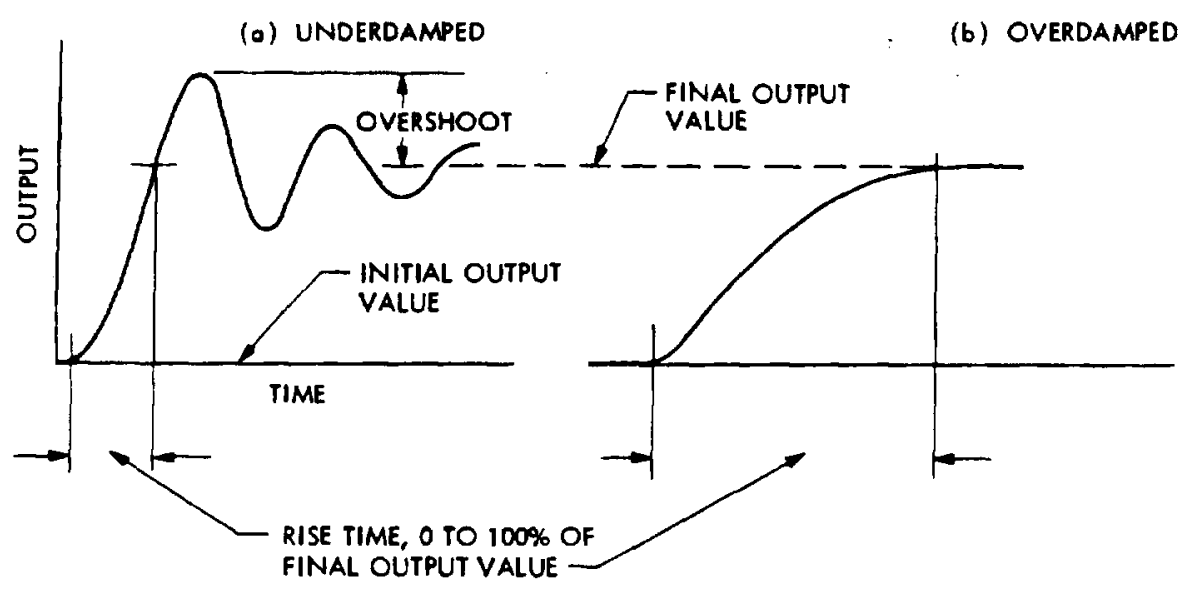

Figure III-E-2. Rise Times for Underdamped and Overdamped Systems

OVERSHOOT

The value to which the output of an underdamped transducer rises above the final steady state value in response to a step change of pressure input is known as overshoot. It is expressed in percent of the equivalent step change in output (Figure III-E-3). 


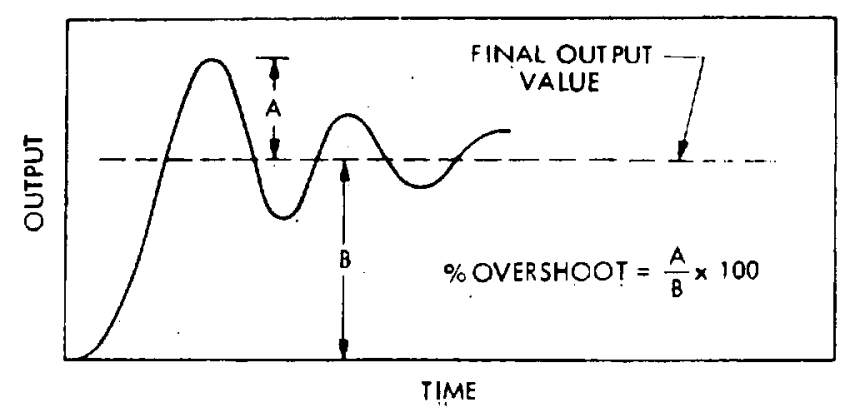

Figure III-E-3. Overshoot Calculation

\section{RINGING FREOUENCY}

When an underdamped transducer is excited by a step change in pressure the resulting oscillatory transient which occurs in the output is known as the ringing frequency. Where damping is near zero the ringing frequency and the natural frequency will be very nearly the same. The value of the ringing frequency can be determined as shown below:

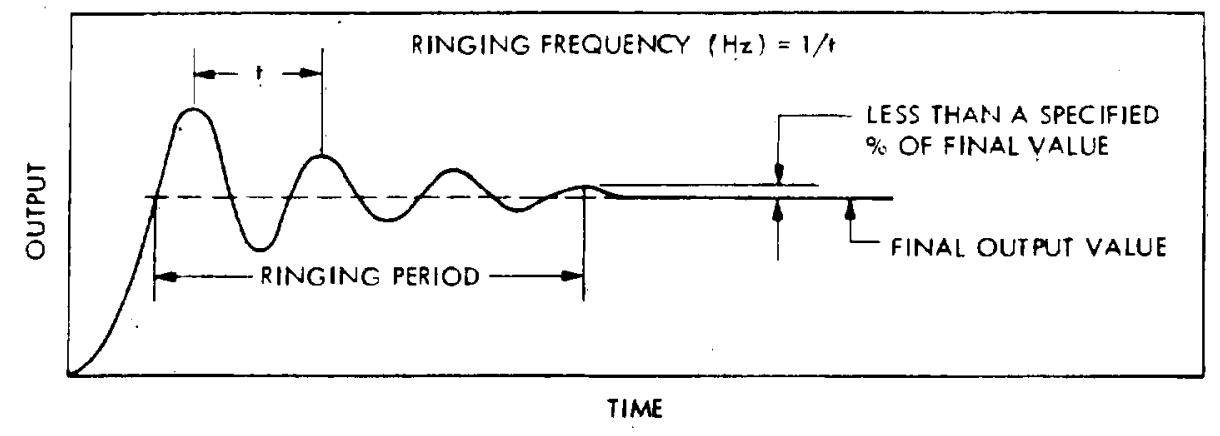

Figure III-E-4. Ringing Frequency and Ringing Period

The accuracy to which the ringing frenuency is determined is dependent on the time interval ( $t$ ) measurement. Data reduction error can usually be reduced by measuring the time interval over several cycles and then dividing that period by the number of cycles for an. average value of $t$.

The ringing (or settling) period (Figure III-E-4) is that interval of time from the initial crossing of the final output value to the point at which the oscillations are less than some specified percentage (usually 5 to $10 \%$ ) of the subsequent final output value. 
Sometimes 2 ringing frequencies are present in the output trace. An example would be a system involving a transducer and connecting line. The ringing frequency of the line as measured by the transducer might be a few hundred hertz with the ringing frequency of the transducer diaphragm (perhaps several thousand hertz) superimposed upon it (Figure III-E-5). The presence of more than 2 ringing frequencies is difficult to determine without electronic analyzing techniques. It is always of value to know what ringing frequencies are present in a system, especially if they are likely to appear in the actual test data.

DAMPING RATIO

Damping ratios in underdamped systems can be determined from Figure III-E-6 (Reference III-E-1). The damping ratios of overdamped systems are not generally of interest.

Pressure transducers are not normally damped by any means other than internal friction of the elements, although some damping will be introduced by the fluid upon which measurements are being made. Even though damping is generally negligible the amplitude response will still be less than $5 \%$ above the reference amplitude (at $0 \mathrm{~Hz}$ ) up to 0.2 of the natural frequency.

In estimating the frequency response of a system, the length and size of the connecting tubing and the effect of cavity volume are usually the controlling factors since acoustic resonance effects can easily mask any resonances in the instrument itself, In general, a pressure transducer can be used with confidence to within 0.2 of its natural frequency, and unless oscillations at the natural frequency are excited because of high-frequency fluctuations in the gas being measured, there will be no adverse effects from the low damping. The mass and viscosity of the gas in contact with the diaphragm will have a small effect on the frequency response characteristics of the transducer; however, the natural frequency should be close to that determined by calculation, or by observing a free transient oscillation (see Natural Frequency). The effects of a liquid medium on system damping, natural frequency, etc., are usually more pronounced and less predictable.

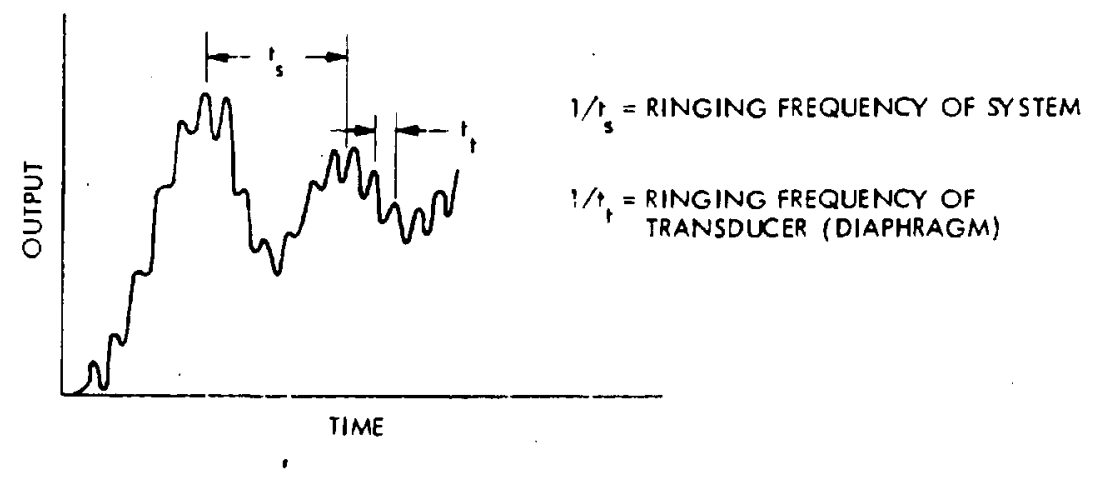

Figure III-E-5. Multiple Ringing Frequencies 


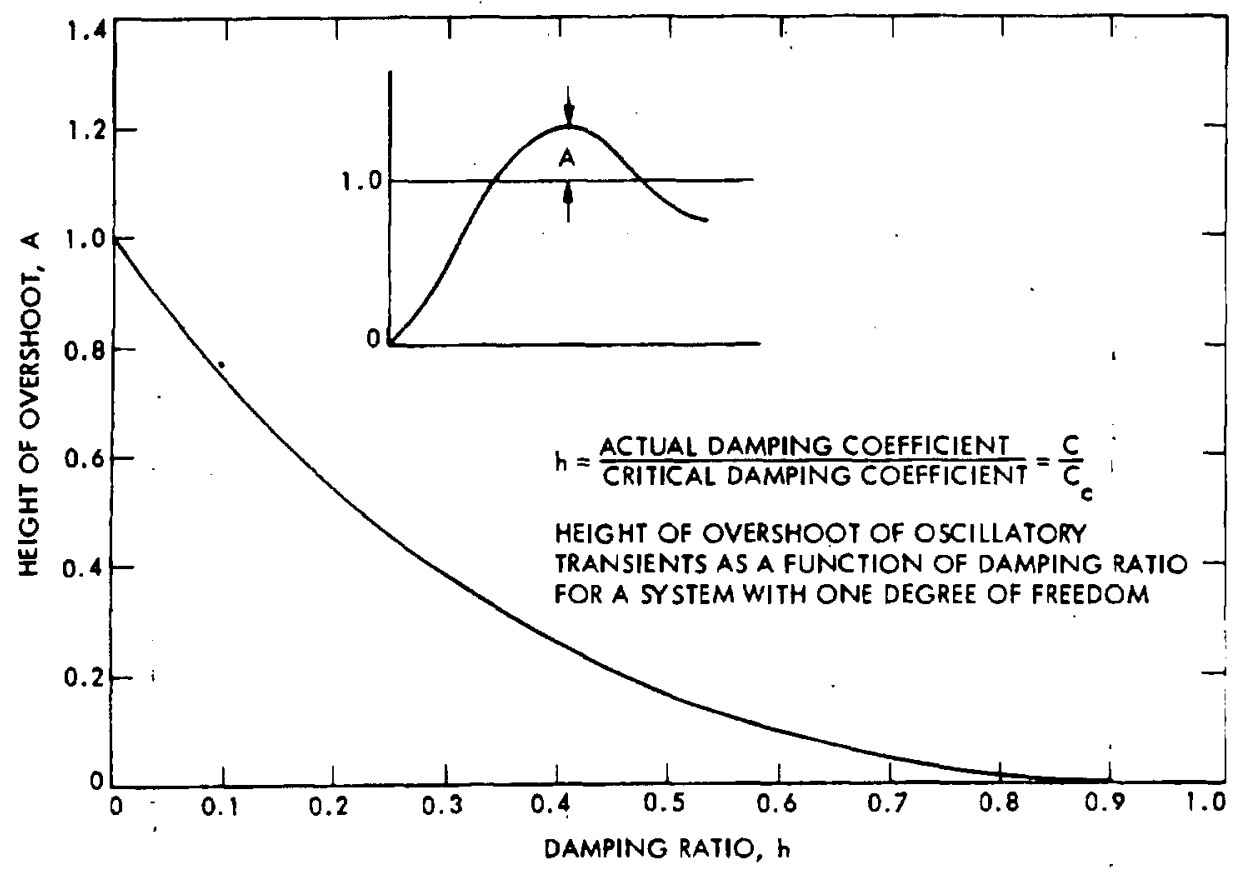

Figure III-E-6. Damping Ratio From Overshoot

\section{NATURAL FREQUENCY}

In a system containing a mass and a spring restraint (typical of pressure transducers) the natural frequency is given by:

$$
f_{n}=\frac{1}{2 \pi} \sqrt{\frac{k}{m}}
$$

where $f_{n}$ is the natural frequency of the system and $k$ is the spring constant of the suspended mass $m$. It may also be defined as the frequency at which the output lags the input by $90^{\circ}$. This term $\left(f_{n}\right)$ is sometimes called the undamped natural frequency. In reality, damping has nothing to do with the natural frequency but does affect the period at which free oscillations occur (ringing frequency).

If a sinusoidal input is applied to a transducer and the output is recorded, there will of ten be a frequency at which the response is at a maximum. The frequency at this maximum is the resonant frequency, not the natural frequency. Only if the damping is zero does the maximum response occur at the natural frequency. As the damping is increased, the frequency at which the peak response occurs is lowered and, at a damping ratio of $1 / \sqrt{2}$, the peak response is at zero frequency. For greater damping, no real maximum exists at all. The frequency at which maximum response occurs is shown in Figure III-E-?. 


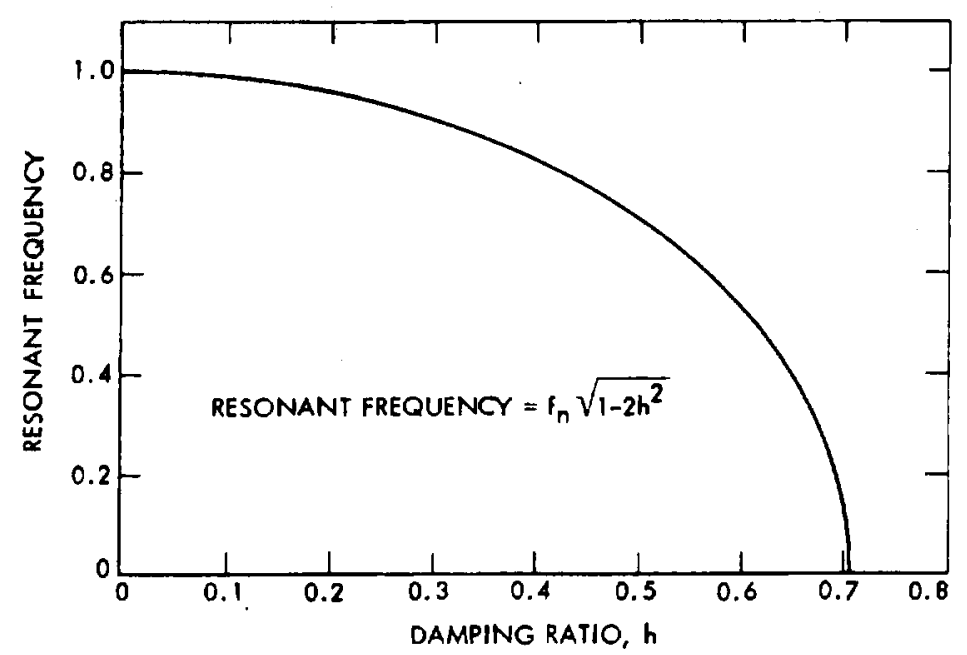

Figure III-E-7. Resonant Frequency vs Damping Ratio

If the transducer diaphragm is displaced and then allowed to execute a typical damped transient, it may be found that the transient decay is oscillatory (ringing frequency) and a freouency may be assigned to it. This is not the natural frequency. Only at a zero damping is the frequency of the oscillatory transient (ringing frequency) the same as the natural frequency. As the damping is increased, the freauency of oscillation decreases and, at a damping ratio of unity (by definition), the oscillatory nature of the transient has entirely disappeared. The frequency of transient oscillation is plotted in Figure III-E-8.

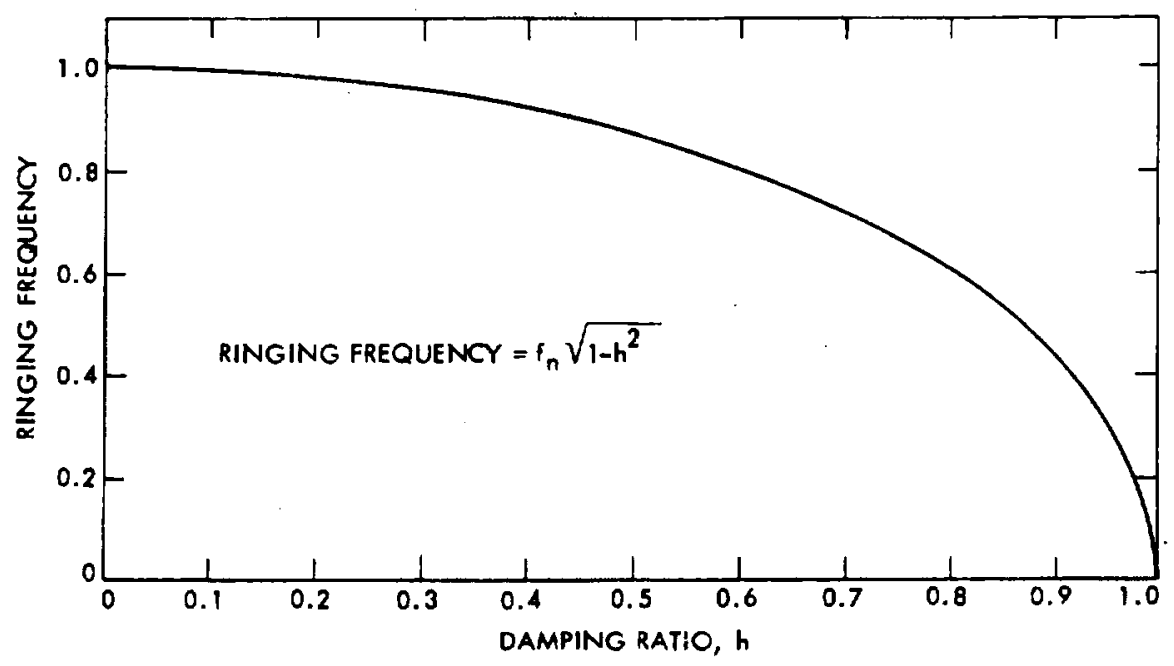

Figure III-E-8. Ringing Frequency vs Damping Ratio 
FREQUENCY RESPONSE (AMPLITUDE)

The amplitude of the system transfer function versus frequency is often referred to as the frequency response. It is freouently normalized to show deviations from an amplitude ratio of one. Figure III-E-9 illustrates the response to a sinusoidal input of second order systems with various damping ratios. This plot is a good representation of the response of a pressure transducer to sinusoidal pressure variations if there is a single major resonant frequency.

An approximation of the frequency response of an underdamped system $(h<1.0)$ can be made from the curves of Figure III-E-9 once the ringing frequency, damping ratio, and natural frequency have been determined by the application of a step pressure input and the analysis methods described in this appendix.

Example: Assume a flush mounted transducer whose response to a step input indicates a ringing frequency of $1000 \mathrm{~Hz}$ with overshoot of slightly less than $40 \%$ (Figure III-E-3). From the curve in Figure III-E-6 the damping ratio $h$ can be determined to be approximately 0.4 . Knowing the

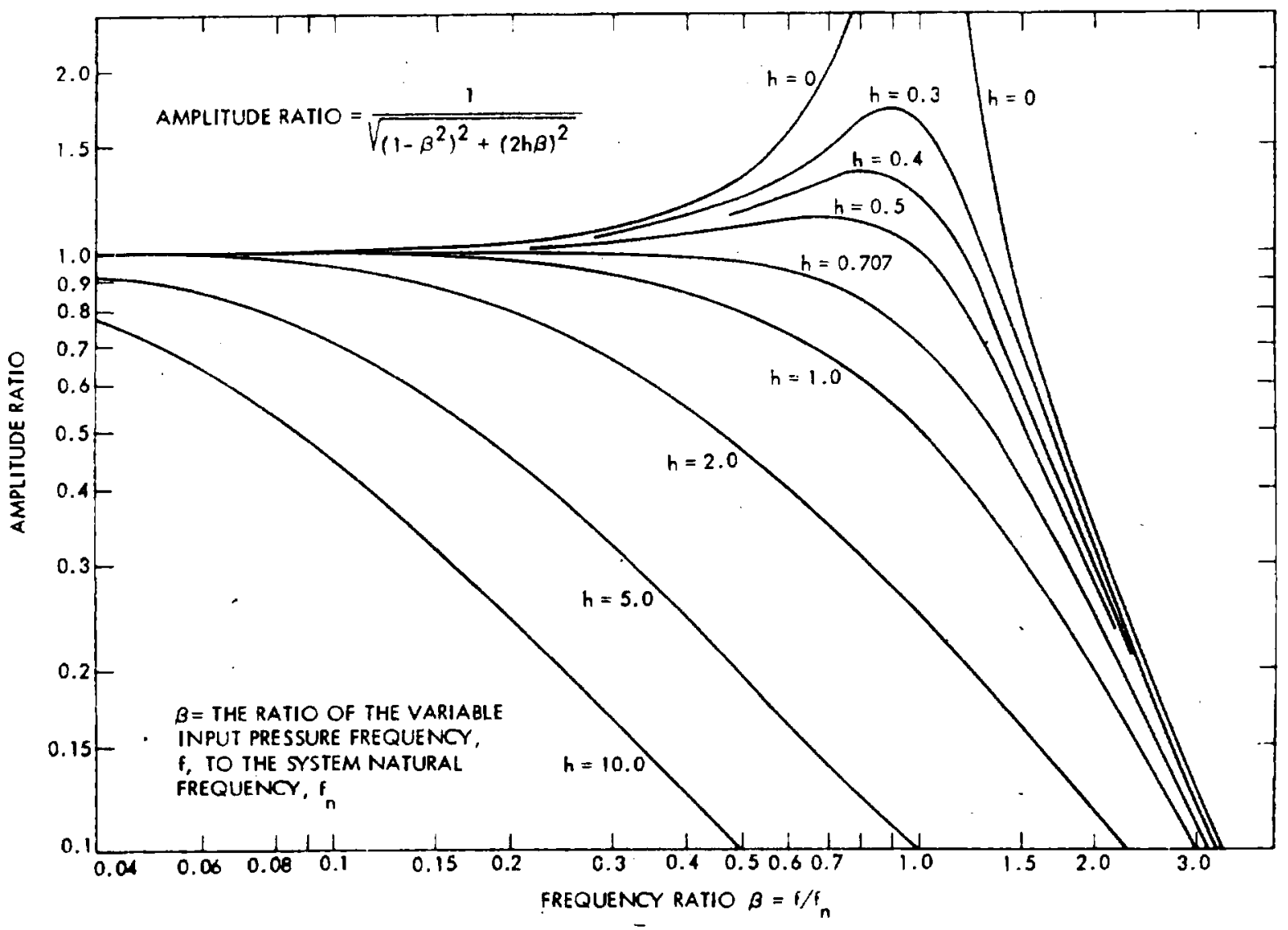

Figure III-E-9. Frequency Response of a Second Order System 
damping ratio and the ringing frequency, the natural frequency (Figure III-E-8) is found to be approximately $1000 / 0.91$ or $1100 \mathrm{~Hz}$. Using Figure III-E-9 it can be shown that for a system with a natural frequency of 1100 the output readings will be about $40 \%$ high at $0.8 \mathrm{f}_{\mathrm{n}}$ or $880 \mathrm{~Hz}$. They will be $10 \%$ high at $0.4 f_{n}(440 \mathrm{~Hz})$ and $5 \%$ high at $0.25 f_{n}(275 \mathrm{~Hz})$.

In the case of an overdarped or critically damped transducer, with less than $10 \%$ overshoot, a coarse value $( \pm 10 \%)$ for the frequency response can be determined from the response time data:

$$
\mathrm{f}_{3 \mathrm{~dB}}=\frac{1}{\tau}
$$

where $f_{3 \mathrm{dE}}$ is the frequency at which the output amplitude is reduced by $50 \%(3 \mathrm{~dB})$ and $T$ is the time constant of the transducer as measured during a test. While this relationship can be applied to an ideal transducer under ideal test conditions, it appears that a more realistic conversion is obtained by replacing $T$ in the above equation, with $t 95 \%$, the 95: response time (Reference 3-9). See also Rise and Response Time plus Figure III-E-1, this appendix.

\section{REFERENCE}

III-E-1. Burns, J., and Rosa, G., Calibration and Test of Accelerometers, Statham Instrument Notes, Number 6, December 1948. 


\section{SECTION IV}

\section{TEMPERATURE MEASUREMENT}


SECTION IV

TEMPERATURE MEASUREMENT

CONTENTS

1.0

2.0

2.1

2.2

3.0

3.1

3.1 .1

3.1 .2

3.1 .3

3.1 .4

3.2

3.2 .1

3.2 .2

3.2 .3

3.2 .4

3.2 .5

4.0

4.1

4.1 .1

4.1 .2

$4 \cdot 1 \cdot 3$
INTRODUCTION

$4-1$

SCOPE

$4-1$

OBJECTIVE

$4-1$

LIMITATIONS

$4-2$

DESIGN CONSIDERATIONS

$4-2$

TEMPERATURE TRANSDUCERS

$4-2$

Transduction Element

$4-2$

Performance Characteristics

$4-5$

Mechanical Design

$4-7$

Electrical Design

ELECTRICAL AND ELECTRONIC COMPONENTS

$4-12$

Signal Conditioning Equipment -......... 4-12

Electrical Calibration Equipment

Recording Equipment $4-16$

Visual Display Equipment _-_.

Data Processing Equipment

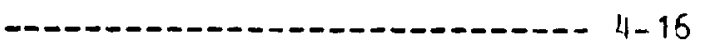

PERFORMANCE VERIFICATION -

TRANSDUCER TESTING AND CALIBRATION _.

Visual Inspection -

Range, Output, and Error Limits -

Repeatability

$4-18$

$$
4-i a
$$




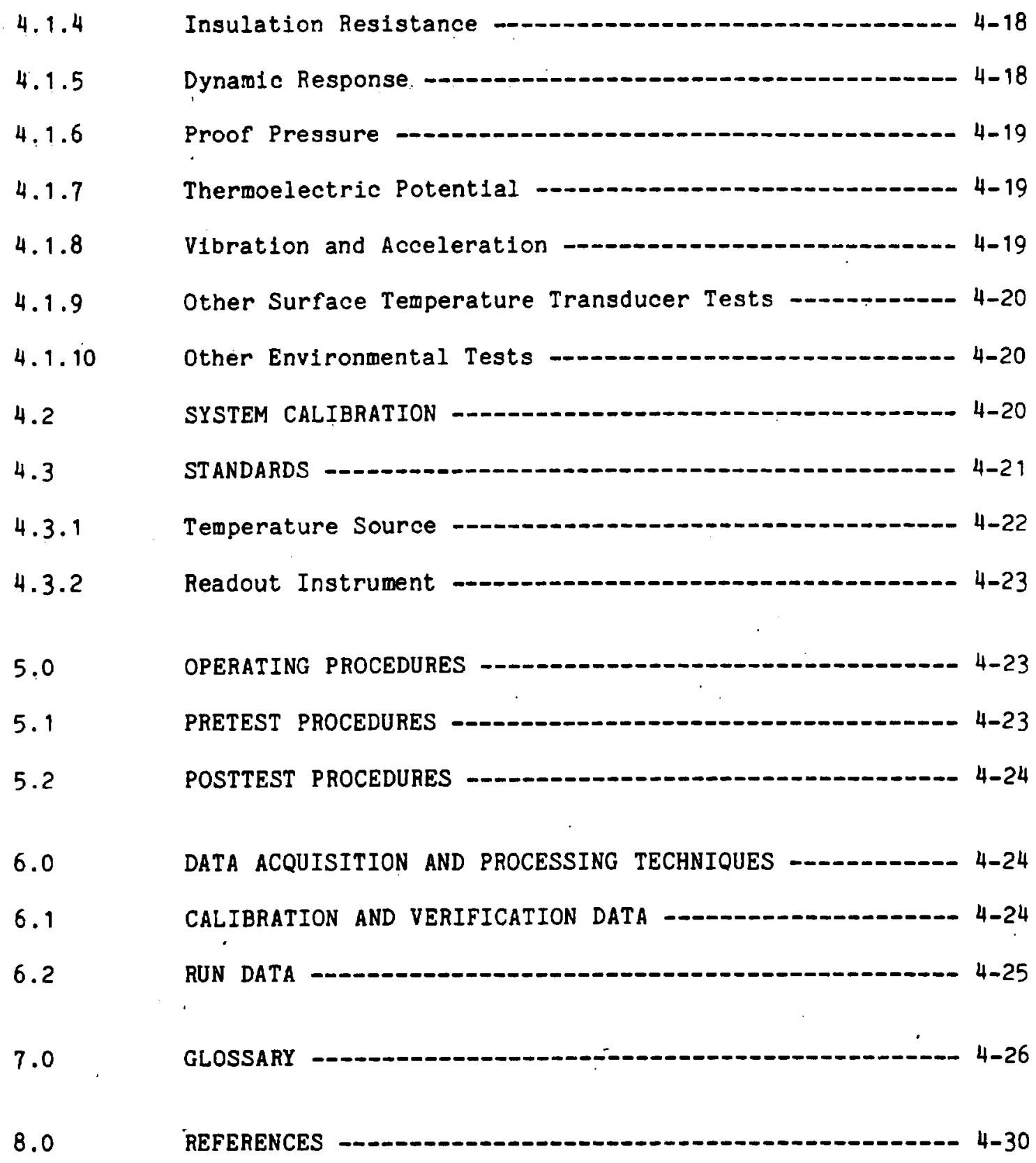

APPENDIXES

IV-A TEMPERATURE MEASUREMENT SYSTEM ELEMENTAL

UNCERTAINTIES -

IV-B TABLES AND EQUATIONS FOR USE WITH THERMOCOUPLES

AND RESISTANCE THERMOMETERS - 


\section{Eigures}

4-1 Temperature Measuring System -

4-2 Basic Thermocouple Circult

4-3 Measuring Circuits for Resistance Thermometer

Transducers -

Tables

IV-B-1 Characteristics of Common Thermocouple Materials -..-.- 4B-1

IV-B-2 Callendar-Van Dusen Equation -

IV-B-3 Thermocouple Materials, Type Letters, and Color Codes for Duplex Insulated Thermocouples and

Extension Wires -...... $4 \mathrm{E}-3$

IV-B-4 Fixed Points Available for Calibrating

Thermocouples and Resistance Thermistors -........... 4B-4 
SECTION IV

TEMPERATURE MEASUREMENT

\subsection{INTRODUCTION}

Recommended practices are outlined for the design, installation, checkout, calibration, and operation of a temperature measuring syster to be used during tests of a liquid monopropellant rocket engine. Two appendixes are included: IV-A, Temperature Measurement System Elemental Uncertainties, and IV-B, Tables and Equations for Use With Thermocouples and Resistance Thermometers.

\subsection{SCOPE}

This section has been written to serve as a guide for the experienced engineer in the design, installation, and operation of a temperature measurement system for measuring the temperatures related to performance evaluation of a liquid monopropellant rocket engine. Design guidelines rather than detailed specifications are provided for the critical components of each portion of the system. These guidelines, used in conjunction with current state-of-the-art, commercially available equipment and good engineering practices, will provide an optimum temperature measurement system which meets the performance criteria specified.

\section{$2.1 \quad$ OBJECTIVE}

Temperature measurenents are made at a number of locations in a monopropellant rocket engine test system, including propellant storage tank, propellant supply lines, propellant flowmeter, thruster catalyst bed, thruster chamber wall and throat, valves, brackets, and flanges. These measurements have different accuracy requirements.

One objective of these recommended practices is to provide the propellant temperature data necessary to obtain the density factor which, together with compressibility effects, is required to determine propeliant mass flow from simultaneously obtained volumetric flowmeter measurements. In order to do this within the required uncertainty limits for flow, propellant temperature must be determined to within $\pm 0.56^{\circ} \mathrm{C}\left( \pm 1^{\circ} \mathrm{F}\right)$ over the range from $0^{\circ}$ to $80^{\circ} \mathrm{C}\left(32^{\circ}\right.$ to $\left.176^{\circ} \mathrm{F}\right)$.

Nozzle throat and thrust chamber temperatures, when used for performance calculations, should be measured to within $\pm 1.2 \%$ over the range from $705^{\circ}$ to $871^{\circ} \mathrm{C}\left(1300^{\circ}\right.$ to $\left.1600^{\circ} \mathrm{F}\right)$.

The importance attached to other temperature measurements will depend on the user's interest and the purpose of the tests. 
These practices are limited to temperature measurements made with thermocouples and resistance thermometers. 1 Although not restricted to the measurement of steady state values, the response of thermocouples and resistance thermometers usually limits temperature measurement to an averaige of that produced by a pulse train when the engine is operated in the pulsed mode.

These practices do not include recommendations concerning the direct measurement of temperatures related to the determination of exhaust gas composition.

\subsection{DESIGN CONSIDERATIONS}

A temperature measuring system capable of obtaining accurate data requires that careful consideration be given to selecting and assembling the transducer ${ }^{2}$ with its supporting electrical and electronic equipment. The type of transducer and the manner in which it is installed along with the effects of environmental conditions are important from the mechanical viewpoint.: Electrical and electronic components include signal conditioning, electrical calibration, recording, visual display, and data processing equipment. They are shown as a block diagram in Figure 4-1.

\subsection{TEMPERATURE TRANSDUCERS}

Thermocouples are used for the great majority of temperature measurements on monopropellant rocket engine test systems. This is because they are easy to use, economical, and provide sufficient accuracy for most applications. The resistance thermometer may provide greater accuracy in those cases where measurement uncertainty is dominated by thermocouple inaccuracy wherever greater accuracy is required. A few special measurement applications may employ such types of transducers as thermistors, scanning pyrometers and temperature sensitive photographic film.

\subsubsection{Transduction Element}

3.1.1.1 Thermocouples. Thermoelectric sensing elements are used in thermocouple circuits. A basic thermocouple circuit, as shown in Figure $4-2$, consists of a pair of conductors of dissimilar metal welded or fused together at one end to form a measuring junction and connected via transmission ines to a reference junction which 1 maintained at a well-defined temperature. The circuit is completed with signal conditioning or recording equipment.

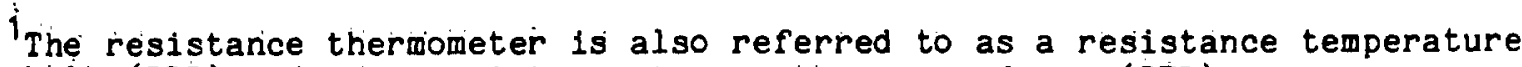
buib (RTB) and as a resistance temperature transducer (RTD).

2 Transducer and sensor can be synonymous words describing devices which convert physical phenomena into measurable electrical signals. 


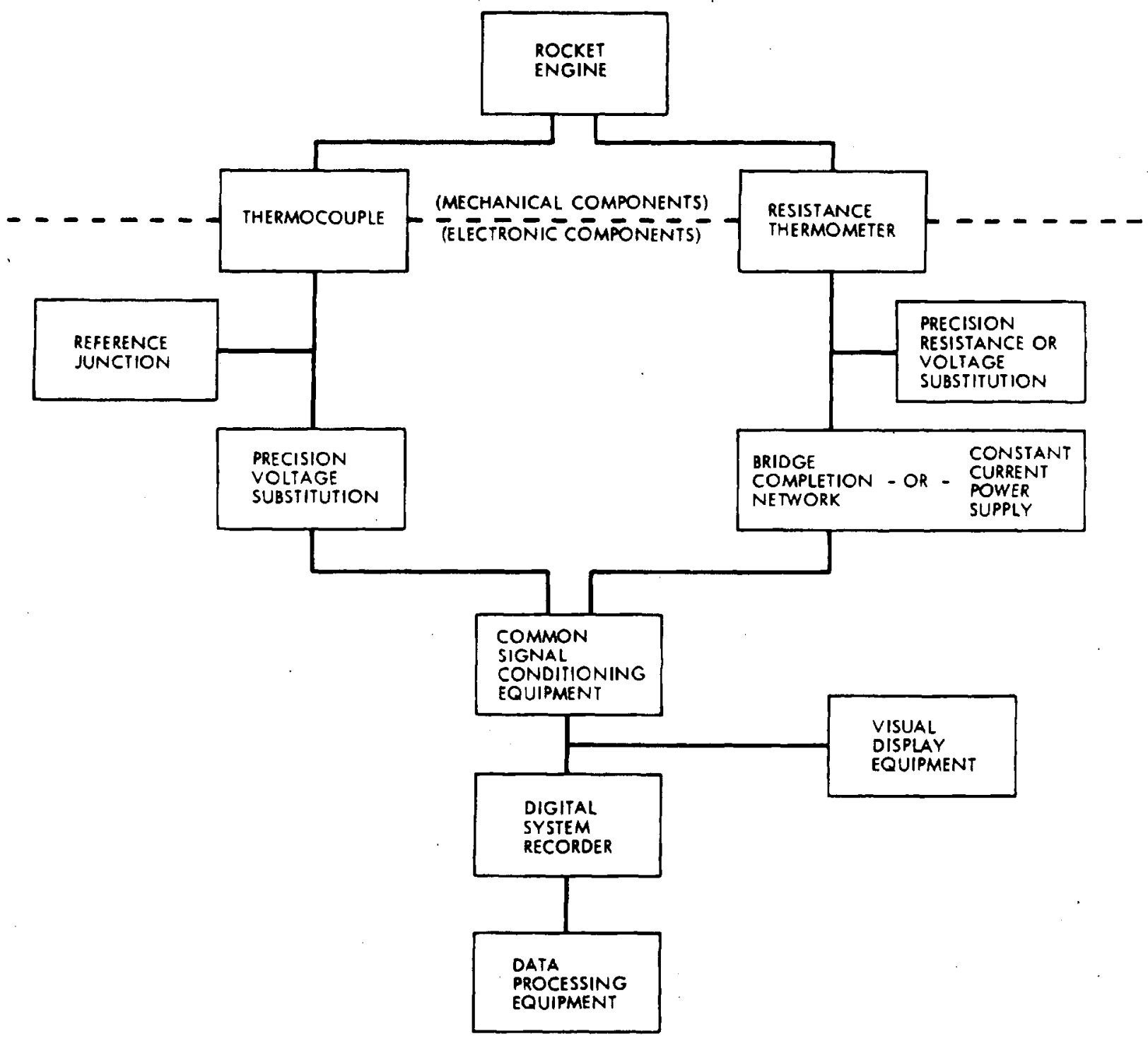

Figure 4-1. Temperature Measuring System

By using various types of metals thermocouples can be constructed to cover the messurement range from $-253^{\circ} \mathrm{C}\left(-424^{\circ} \mathrm{F}\right)$ with copper/constantan-type $\mathrm{T}$ to $+1538^{\circ} \mathrm{C}\left(+2800^{\circ} \mathrm{F}\right)$ with platinum/platinum- $10 \%$ rhodium-type S. See Table IV-B-1 in Appendix IV-B. The recommended upper temperature limit for a thermocouple decreases with wire size. The limit for chromel/constantan, for example, decreases from $1260^{\circ} \mathrm{C}\left(2300^{\circ} \mathrm{F}\right.$ ) for a No. 8 AWG wire to $871^{\circ} \mathrm{C}\left(1600^{\circ} \mathrm{F}\right)$ for a No. 28 AWG wire. Limits shown in Table IV-B- 1 are primarily intended for enclosed-element (protected) thermocouples; limts are somewhat lower for exposed (bare wire) sensing functions. 
When used within their optimum ranges the uncertainty values will generally be $1 \%$ of reading or less with standard materials, construction, etc., down to less than $0.5 \%$ of reading with special materials, maximum purities, etc. The Type $S$ thermocouple is the standard by which the international temperature scale from $660^{\circ}$ to $1063^{\circ} \mathrm{C}\left(1220^{\circ}\right.$ to $\left.1945^{\circ} \mathrm{F}\right)$ is defined by the International Practical Temperature Scale.

The temperature sensitive element in a thermocouple may be made arbitrarily small thus facilitating precise measurement of temperature at a point. The low thermal capacity of the element, resulting from this small size, insures quick response. (See Paragraph 3.1.3.1, item 6.)

3.1.1.2 Resistance Thermometers. A resistance thermometer usually consists of a coil or grid of temperature sensitive wire whose resistance, when exposed to the temperature to be measured, varies in a precise and predictable manner. The auxiliary instruments which are used to measure these changes in resistance generally consist of a Wheatstone bridge with constant voltage excitation or a constant current with voltage readout proportional to resistance.

The resistance thermometer is regarded as the most precise and reliable device for the range $-190^{\circ}$ to $+660^{\circ} \mathrm{C}\left(-310^{\circ}\right.$ to $\left.+1220^{\circ} \mathrm{F}\right)$. In the vicinity of $-18^{\circ} \mathrm{C}\left(0^{\circ} \mathrm{F}\right)$, or at room temperature, measurements with an uncertainty of less than $2.8 \times 10^{-40^{\circ}} \mathrm{C}\left(5 \times 10^{-4} \mathrm{O} F\right)$ can be made; however, the error is normally several thousandths of a degree. At $316^{\circ} \mathrm{C}\left(600^{\circ} \mathrm{F}\right)$. the uncertainty is about $1 / 10^{\circ} \mathrm{C}$ or $1 / 5^{\circ} \mathrm{F}$.

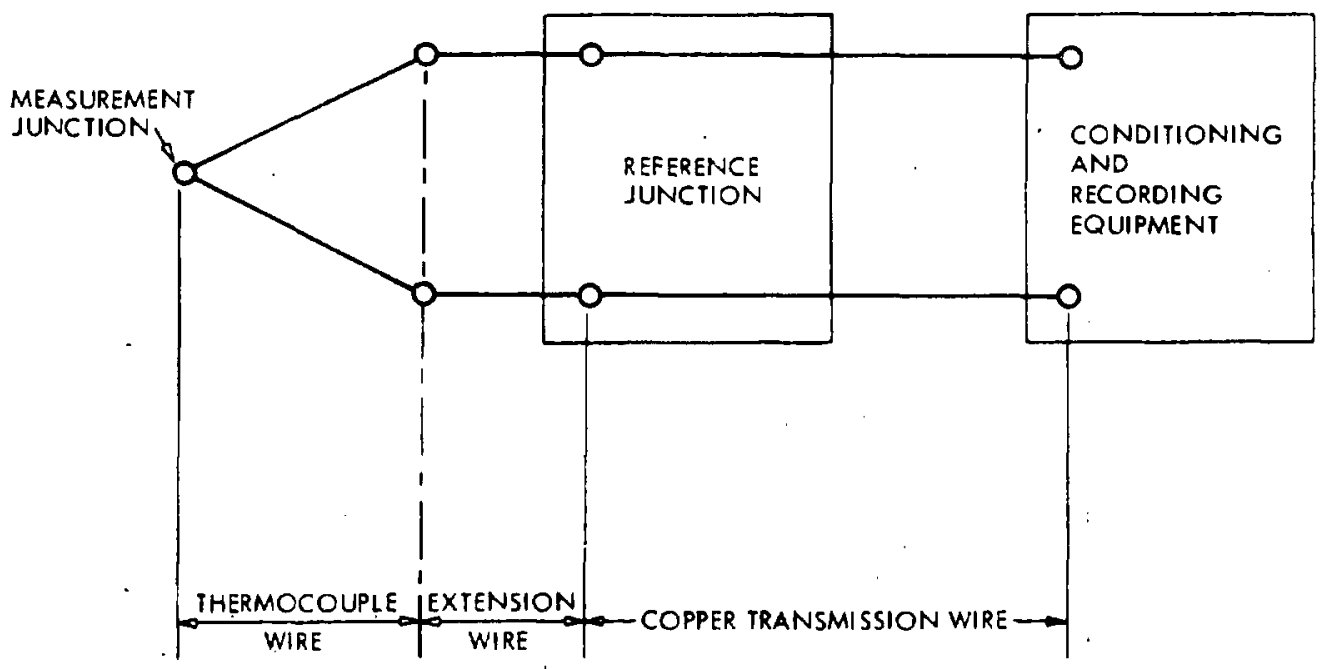

Figure 4-2. Basic Thermocouple Circuit 
A winding of pure, strain-free, annealed platinum wire is widely used in transducers for precise temperature measurement. An element of this type is used to define the International Practical Temperature Scale between the limits of $-183^{\circ}$ and $+630^{\circ} \mathrm{C}\left(-298^{\circ}\right.$ and $\left.+1165^{\circ} \mathrm{F}\right)$. An element wound from pure nickel wire or from nickel alloy wire such as "Balco" is used in the medium temperature range $-100^{\circ}$ to $+300^{\circ} \mathrm{C}\left(-148^{\circ}\right.$ to $\left.+572^{\circ} \mathrm{F}\right)$; it is less costly than a platinum wire element.

3.1.1.3 Thermistors. A thermistor is a semiconductor whose resistance varies strongly with temperature. The semiconductor materials, usually sintered mixtures of sulfides, selenides, or oxides of metals such as nickel, manganese, cobalt, copper, iron, or uranium, are formed into small glass-enclosed beads, disks, or rods. They have high resistivities and high negative temperature coefficients of resistance. Their resistancevs-temperature characteristics are not linear, and it is difficult to maintain narrow resistance tolerances during manufacture.

A thermistor must be individually calibrated and is inclined to drift; however, its wide variation in resistance and extremely small size make it desirable for certain applications. The thermistor is generally powered by a few microamps from a constant current source. The resistance is then inferred from voltage measurements. A thermistor is normally used over the temperature range of $-75^{\circ}$ to $+250^{\circ} \mathrm{C}\left(-103^{\circ}\right.$ to $+482^{\circ} \mathrm{F}$ ).

\subsubsection{Performance Characteristics}

The transducer performance characteristics (or properties) which are of greatest interest to the user are listed below. A brief commentary and suggested specifications are included where applicable. Unless otherwise specified they apply at the following ambient conditions: temperature $25 \pm 10^{\circ} \mathrm{C}(77 \pm 180 \mathrm{~F})$; relative humidity. $90 \%$ maximum; barometric pressure $73 \pm 7 \mathrm{~cm} \mathrm{Hg}(29 \pm 2.8 \mathrm{in}$. $\mathrm{Hg})$.

3.1.2.1 Range. Range is usually specified as a nominal temperature range over which all other performance characteristics apply. It is frequently selected as a range narrower than that given by the transducer's capability.

3.1.2.2 Qverload Temperature. Overload temperature is the maximum or minimum temperature which is beyond the specified range limit, but to which the transducer can be exposed without incurring damage or subsequent performance changes beyond stated tolerances.

3.1.2.3 Output. Output can be stated as nominal full-scale output over the transducer's span between its range limits, e.g., "Full-Scale Output: $36 \mathrm{mV}$ (with reference junction at $0^{\circ} \mathrm{C}$ )" or "Full-Scale Output: 250 ohms." Since most temperature transducers have a norlinear outputvs-temperature relationship, the variation of output over the range 
is best described by a table listing output values at several temperatures including the range limits. The curve established by such a table is often referred to as a theoretical or reference curve. This curve is often based partly or wholly on empirical data.

3.1.2.4 Repeatability. Repeatability and bias are usually the only steady state static accuracy characteristics specified for temperature transducers. Linearity is rarely specified since the reference curve of a large majority of temperature transducers is inherently nonlinear. Hysteresis and friction error are virtually nonexistent in temperature transducers. Repeatability, the maximum difference in repeated output readings from one another, can be expressed in percent of full-scale output but is usually stated in output units or output-equivalent temperature units, e.g., "Repeatability: within $0.01^{\circ} \mathrm{C}$ " or "Repeatability: within $1.0 \mathrm{ohm}$ " or "Repeatability: within $0.5 \mathrm{mV} . "$ Repeatability has also been expressed in percent of reading (percent of reading-equivalent temperature correlated on the basis of a reference curve), e.g., "Repeatability: within $0.5 \%$ of reading." The tolerance specification can be followed by a statement of the period of time over which it is considered applicable.

3.1.2.5 Calibration Interchangeability. The maximum deviation over the specified range of the calibration curve of any one transducer from a reference curve is established for a group of transducers. A reference curve is often established for a certain transducer part number. Calibration interchangeability then applies to all transducers identified by this part number. It is normally expressed in the same terms as repeatability but with bipolar tolerances, e.g., "Calibration Interchangeability: within \pm 2.0 ohms." Calibration interchangeability tolerances can be specified as larger in some portions of the range than in others.

3.1.2.6 Conduction Error. Conduction error is caused by heat conduction between the sensing element and the mounting of the transducer. It occurs primarily in immersion probes, especially when the stem is short. Conduction error can be specified as the maximum difference in output reading when the transducer is first immersed, to just below the electrical connections, in an agitated temperature bath and when it is immersed up to the mounting fitting while the fitting and leads are artificially cooled or heated so that it attains the specified environmental temperature. The difference between sensing.element and environmental temperatures should be chosen as large as is estimated will occur in the end-use application of the transducer.

3.1.2.7 Mounting Error. Mounting error tolerances (also referred to as strain effects or strain error) should be specified for surface temperature transducers. This error is introduced mostly by strain in the transducer after it is welded, cemented, or otherwise attached to a surface. It is specified as the maximum difference in output reading before and after mounting the transducer to a sample surface by a specified mounting method. 
3.1.2.8 Time Constant. The time constant is an important dynamic performance parameter of an ideal transducer having a first order characteristic. It is specifically defined as the length of time required for the output of the transducer to rise to $63.2 \%$ of its final value as a result of a step change in temperature.

3.1.2.9 Response Time. The time required for the transducer's output to rise to a specified percentage of its final value (say 98 or 99\%) under the same test conditions as applicable to time constant determination. The limits of the step change in temperature and type and flow rate of the measured fluid at both limits must also be given, e.g., "from still air at $25 \pm 5^{\circ} \mathrm{C}$ to distilled water at $80 \pm 2^{\circ} \mathrm{C}$ moving at $1 \mathrm{~m} / \mathrm{s} . "$

\subsubsection{Mechanical Design}

The mechanical design of a temperature measuring system includes consideration of the characteristics of the type of transduction method selected and installation of the transducer in the system so as to obtain accurate measurement of the test item or medium with minimum effect on its temperature. These factors are discussed in the following paragraphs.

\subsubsection{Thermocouples}

(1) The performance of a fine gage thermocouple deteriorates more rapidly at elevated temperature than does that of a heavy gage thermocouple. The wire not only physically deteriorates, but the calibration of the wire irreversibly changes.

(2) Thermocouple materials are normally furnished to a standard accuracy or calibration. There is usually an extra charge for both special accuracy and calibrated wire. The limits of error for standard and special accuracy are given in Table IV-B-1. No standardized limits have been established for calibrated wire.

(3) Since spurious emfs are produced by temperature gradients in heterogeneous wire, all purchased lots of thermocouple wire should be checked for homogeneity.

(4) The thermocouple junction may be formed by any of the following techniques which are presented in decreasing order of preference: electric, gas, or discharge welding, brazing, silver or soft soldering, immersion of the leads in a liquid metal pool, or mechanically forcing the wires into contact. For detailed information on thermocouple construction (both probe and surface installation) see References 4-1 and 4-2. 
(5) In any junction there is always a region of uncertainty near the junction which consists of materials different from the original wire: This may be regarded as a short length of wire composed of a third metal. In order to make accurate measurements the temperature must be uniform over this region of uncertainty.

(6) The response time of the thermocouple should be consistent with the requirements. Closed sheath thermocouples may have a time constant of from 200 to $500 \mathrm{~ms}$. If constructed from small gage bare wire, a thermocouple may have response down to $50 \mathrm{~ms}$ or less.:

(7) Connections in the vicinity of known thermal gradients must be avoided.

(8) If splices or connections in the thermocouple material cannot be avoided, carefully matched materials must be used to avoid large errors due to gradients (Reference 4-3).

(9) The reference oven thermal block temperature should be accurately and continuously monitored.

\subsubsection{Resistance Thermometers}

(1) Resistance thermometers may be purchased as fully developed units with performance and specific size tailored to the specific application.

(2) The transduction element should be wound of strainfree wire.

(3) Platinum wire should conform to the standard resistance thermometer curve with alpha (a) equal to 0.003925 .

(4) Most metals show an increase of resistivity, $R$, with temperature which is first linear and then increases in an accelerated fashion. In particular iron, nickel and cobalt behave in this way. Although platinum is almost universally used for high-accuracy resistance thermometers, nickel also makes a good thermometer at temperatures below $649^{\circ} \mathrm{C}\left(1200^{\circ} \mathrm{F}\right)$.

(5) A special form of resistance thermometer element for surface temperature measurements is commercially available. This element consists of a grid of temperature sensitive wire bonded between two thin pieces of flexible, electrically insulating material. 
3.1.3.3 Transducer Mounting Conflguration. The following items should be considered during the mechanical design and installation of temperature transducers. They are divided into three categories general, probes, and surface measurements. Unless otherwise specified the listed items pertain to either thermocouples or resistance thermometers.

(1) General

(a) Measured fluids and associated limitations on sensing element protection, stem materials, and surface transducer covering should be defined.

(b) The material used in the sensing element and its exposure (exposed, enclosed, coated) for an immersion probe or mounting method for a surface transducer should also be stated.

(c) The identification markings or nameplate of the transducer should include such information as nomenclature, e.g., transducer, temperature, resistance, platinum-wire, or exposed-element.

(d) Other nameplate information includes part and serial number, manufacturer's name, identification of external electrical connections, and at least one operating characteristic deemed essential, such as nominal range or resistance at a stated temperature.

(e) Consideration should be given to any separable parts to be furnished with the transducer, such as a throwaway protecting tube, a disposable substrate (carrier) for surface transferable transducers, mounting hardware, or a mating electrical connector.

(2) Probes

(a) The stem of an immersion probe must be long enough to minimize conduction errors. At least 10 times the diameter of the protection tube is recommended.

(b) The stem length of an immersion probe intended for installation in a propellant line should be so chosen as to place the center of the sensing element at a radial position located $0.72 \mathrm{r}$ (for turbulent flow) or $0.56 \mathrm{r}$ (for laminar flow) from the center of the line, where $r$ is the line radius.

(c) Any special modifications to a probe configuration, such as a stagnation housing, should be specified. 
(d) Allowable welght should be considered:

(e) The maximum transverse loading due to flow induced forces should be determined and a probe safety factor of two (minimum) maintained.

(f) The transducer sheath must be ductile; compatible with the propellant (Reference $4-4$ ), and capable of withstanding ilne pressure.

(8) The operating and proof pressure and a burst pressure rating must al ways be spectified.

(h) All conditions, before, during and after installation, that contribute to external strains on the transduction element should be avolded.

(1) Electrically conducting fluids make thie use of an exposed element resistance thermometer. transducer inadvisable.

(j) Temperature probes must be installed a minimum of 4 pipe diameters downstream from the flowmeter. The installation must not interfere with propellant flow, particularly with regard to disturbing the flow pattern at the transducer.

(k) Catalyst bed thermocouples are typlcally small probes, $0.1 \mathrm{~cm}(0.040 \mathrm{in.})$ in diameter, with sheaths of stainless steel or inconel material.

(a) Surface temperature measurement requires a very thin transducer whose housing, if any, should be of a material at least similar to that of the surface.

(b) Lead pull out strength (maximur force not causing lead separation) and preformed on maximum bend radius are important characteristics of surface temperature transducers.

(c) A number of different types of weldable, cementable, and surface-transferable reslst I ve transducers have been designed with an overall thickness, including the housing, of less than $1 \mathrm{~mm}(0.04 \mathrm{in}$.$) .$

(d) Foil therwocouples and thin wire thermocouples are useful for surface measurements. Metal sheathed, ceramic insulated thermocouple wire is avallable with an overall diameter of less than $0.3 \mathrm{~mm}$ $(0.012$ in $)$. 
(e) When extension wires of larger diameter must be used for the sake of ruggedness, the connection between transducer wires and extension wires should be as remote from the transducer location as is feasible to minimize changes to the configuration of the surface in the Immediate vicinity of the transducer.

(f) Skin thermocouples are generally spot welded to the surface and have a ceramic, epoxy, or other waterproof coating applied.

\subsubsection{Electrical Design}

Many of the following concerns are of a general nature and apply to all types of temperature transducers. When the application is specific it is so noted.

(1) Insulation resistance or breakdown voltage is normally specified for all types of transducers having an ungrounded sensing element. Additional characteristics of resistive transducers include nominal and maximum excitation current or excitation voltage and power for any integral conditioning circuitry and the resistance of any internal resistive components other than the sensing element. This may even apply to the resistance of internal leads where critical to the application.

(2) External electrical connections (terminal block, leads, receptacle, etc.) should be specified in detail.

(3) Leads should be routed along a predicted isotherm.

(4) In addition to the spurlous thermoelectric emfs due to heterogeneous materials and third metals, spurious voltaic effects of a significant level can be introduced electrochemically where there is a break in insulation in the presence of moisture. Voltaic effects can be miniolized by (a) not exposing any part of the circuit to acids or alkalides at any time, (b) malntaining the relative humidity as low as possible, and (c) thoroughly insulating or waterproofing all portions of the circult exposed to humid conditions or condensing vapor.

(5) To reduce the number of wires in a thermocouple installation a common return circuit is sometimes considered. The use of this circuit is almost invariably unsatisfactory because insulation leakage of one thermocouple affects all the thermocouples. Further, all thermocouple junctions must be isolated from ground in order to avold emfs at the function between the thermocouple materials and the parent metal. This electrical isolation invariably results in poor thermal contact. 
(6) A 3- or 4-wire interconnecting system should be used with resistance thermometers.

(7) The effect of element self-heating should be minimized to less than $0.01^{\circ} \mathrm{C}\left(0.02^{\circ} \mathrm{F}\right)$ change due to current flow.

(8) To protect the leads from the surrounding thermal environment, a reflective or insulating tape is sometimes used.

The major electrical and electronic components to be considered in the design of a temperature measurement system include (1) signal conditioning equipment, (2) electrical calibration equipment, (3) recording equipment, (4) visual display equipment, and (5) data processing equipment. These components are shown in the temperature measurement system block diagram, Figure 4-1. In general all of these components are commercially available, off-the-shelf items. Most of the items are available from more than one manufacturer. The major concern in the selection of these components must be the evaluation of the various manufacturers general specifications in relation to the specialized temperature measurement requirement. A subsequent verification that the equipment finally selected conforms to the manufacturer's specifications is essential.

\subsubsection{Signal Conditioning Equipment}

Signal conditioning equipment includes the following functional devices: reference junctions, power supplies, amplifiers, electrical cabling, shielding, signal distribution and switching networks, and filters. The regulation and stability of this equipment should be $\pm 0.05 \%$ or better, wherever applicable. The design of these devices varies widely depending on system philosophy and economics; however, certain design principles are universally recommended as follows:

(1) Reference Junction. Thermocouples require the use of a reference junction as near to the measurement location as possible. The use of a reference junction whose temperature is electrically maintained higher than the surrounding environment is recommended: A typical reference junction temperature is $65^{\circ} \mathrm{C}\left(150^{\circ} \mathrm{F}\right)$. The reference junction temperature should be constant $\pm 0.2^{\circ} \mathrm{C}\left( \pm 0.40^{\circ} \mathrm{F}\right)$. For temperatures below $250^{\circ} \mathrm{C}\left(480^{\circ} \mathrm{F}\right)$, a uniform nonconstant reference junction eliminates the error due to the parasitic junction where the external and internal chromel or alumel wires join at the reference junction terminal face.

(2) Extension Wire. Where there is considerable distance between the measuring and reference junction locations thermocouple extension wire must be used. Existing 
standards differentiate between thermocouple wires which form the measuring junction and the thermocouple extension wires which can be connected to the thermocouple wires for longer cable runs without introducing thermoelectric potentials at these connections. When the appropriate extension wire is properly connected to a thermocouple, the reference junction is in effect transferred to the other end of the extension wire.

Table IV-B-3 shows standard letter designations and color codes for commonly used thermocouples and extension wires, in addition to suggested abbreviations for materials. See also Reference 4-1.

(3) Power Supply. Resistance thermometers may be used in conjunction with either constant voltage or constant current power supplies. When used in the constant voltage mode they may be connected in a bridge circuit configuration as shown in Figure 4-3a. This arrangement is sometimes used to compensate for changes in the resistance of long connecting wires between transducer and bridge. Of the two wires of equal resistance connected to the same point at the transducer, one is placed in the excitation branch, the other in the opposite leg of the bridge. The third wire (to the other transducer terminal) is in the same bridge leg as the transducer. Hence, wire resistance changes in the transducer leg are compensated by equal changes in the $R_{3}$ leg when the resistance of $R_{3}$ is approximately equal to that of the transducer. A constant current configuration is shown in Figure 4-3b. This is perhaps the most commonly used circuit arrangement for rocket engine applications.

Power supplies can be individual rack mounted units or miniature (several on one card) devices integral with the data gathering system. Generally, there are provisions for voltage or current adjustments, less often for zero balance. Ripple should be less than $100 \mu \mathrm{V}$ peak to peak.

(4) Amplifiers. The use of high-quality differential amplifiers is now almost universal. With a transducer full scale output of 20 to $40 \mathrm{mV}$, an amplifier gain of 50 to 500 is sufficient for most conventional analog-to-digital conversion and recording systems. It should be verified that peak common mode voltages do not exceed the design limits of the amplifier.

(5) Electrical Cabling and Shielding. Electrical noise can be minlmized by the use of proper shielding and grounding techniques (see Reference 4-5). Transmission cables between the transducer or reference junction and the recording system usually consist of multiple 


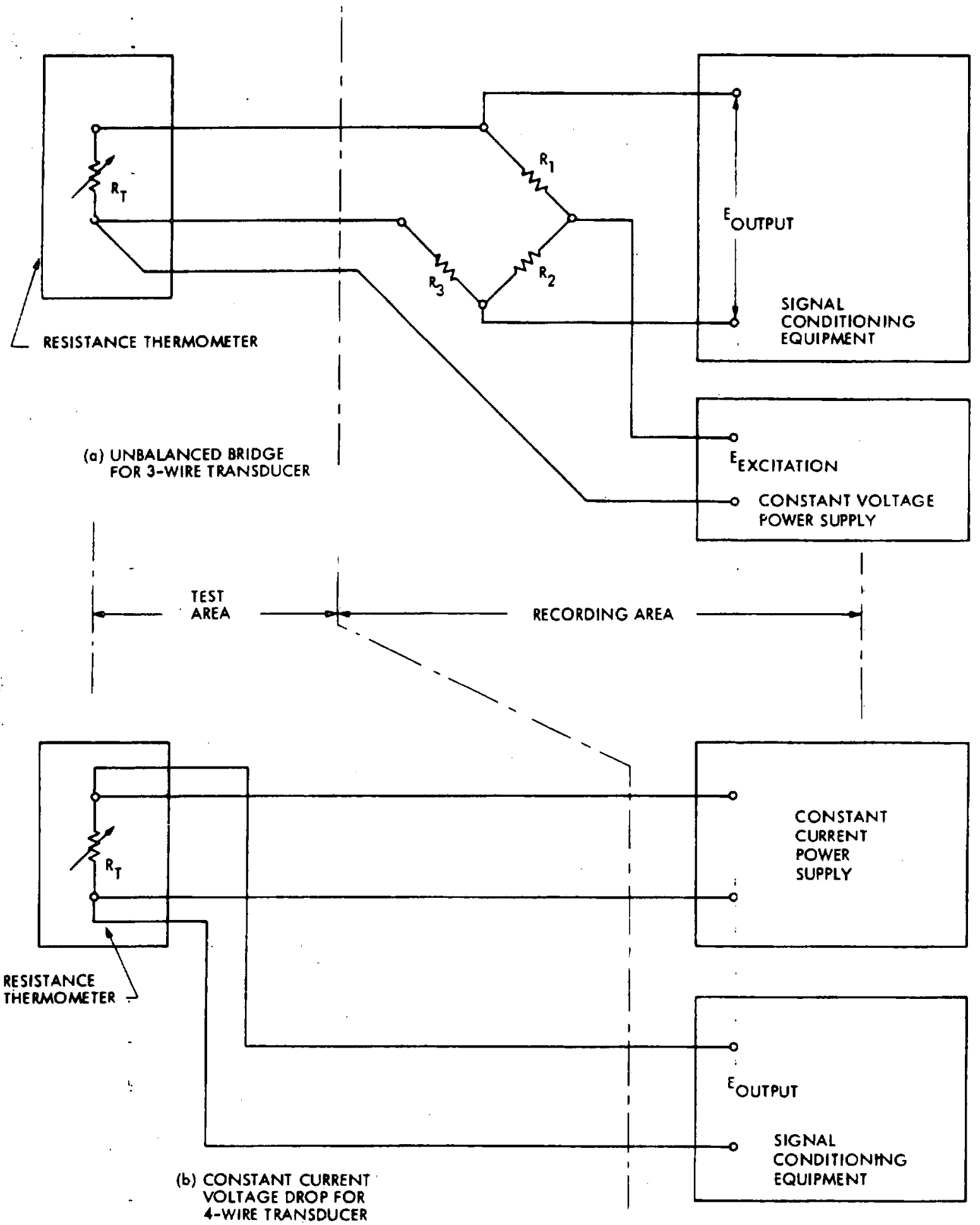

Figure 4-3. Measuring Circuits for Resistance Thermometer Transducers 
pairs of twisted, shielded, splice-free conductors. The wire gage and corresponding resistance should be taken into account when developing calibration techniques and other system design considerations. Each transducer cable should be individually shielded with continuity of shield to the operational amplifier. The shield grounding connection should be in accordance with the amplifier manufacturer's recommendations. Multiconductor cables consisting of inner cable shielding and overall shielding of the large cable are recommended for long transmission runs. The outer shield of the multiconductor cable should also be terminated to the single point ground. The outer shield and all inner shields should be insulated from each other.

(6) Other signal conditioning equipment includes such items as filters, distribution and switching units, and impedance matching devices. The design of these and related devices varies depending on system philosophy, but should in all cases be high-quality equipment providing stability (both with time and temperature), line voltage regulation, and inearity. Thermally induced errors should be minimized in all clrcuits.

\subsubsection{Electrical Calibration Equipment}

Some form of electrical simulation for the transducer response to temperature should be provided. This simulation should track any change in the system sensitivity that is caused by changes in the environmental conditions.

Calibration of the thermocouple electronics system (amplifier, recorder, etc.) may be accomplished by substituting simulated precision voltages for those produced by the sensing element. These voltages should correspond to the thermocouple output over the range of interest. This method requires that the transducer be electricaliy disconnected (usually by a switching network) and a known voltage substituted.

The use of a resistance thermometer sensor as the active arm of a wheatstone bridge provides a convenient means of converting a resistance change to an equivalent voltage. This equipment may be calibrated by substituting precision resistors for the resistive sensor over the anticipated range.

Constant current calibration of resistance thermometer systems may be accomplished by substituting precision resistors for the sensing element over the range of interest.

The above techniques will not provide any information about changes in ambient output, nor even reveal if the transducer has been disconnected. There should, therefore, be additional checks, such as monitoring of the amblent output or measurement of the output impedance to verify proper system operation. 


\subsubsection{Recording Equipment}

The four commonly used systems for recording temperature measurement data are (1) digital system, (2) graphic records, (3) oscillograph, and (4) analog magnetic tape. Two or more of these systems are combined to provide high accuracy, high-frequency response, and quick readout.

\subsubsection{Visual Display Equipment}

A visual display of real time measured data in engineering units along with other critical operating parameters is required for both pretest and posttest calibration and for monitoring purposes during the engine test. Th1s alphanumeric data can be presented in either hard copy (printed) or non-hard copy (CRT display) form or both. The non-hard copy is usually displayed on some type of cathode ray tube (CRT) device through a selective preprogrammed format.

Data Processing Equipment

The data processing equipment is not generally dedicated exclusively to the temperature measurement system, but is used to process many other parameters also. This equipment should be chosen and used with care so that the uncertainty of the data is not increased during processing.

\subsection{PERFORMANCE VERIFICATION}

All critical components of the temperature measurement system should be certified for compliance with the design and performance specifications before installation. This is best accomplished by precision inspection plus standard laboratory test and evaluation as appropriate. It is imperative that any calibration be a true characteristic of the transducer and its associated signal conditioning equipment. This involves not only the individual transducer calibration, but also some type of calibration of the entire measuring system as installed. In this section the following types of calibration are discussed: (1) calibration of the individual transducer (temperature and electrical), (2) overall system calibration by end-to-end or electrical simulation techniques, and (3) types, techniques of operation and certification of the standards used to accomplish the various calibrations.

\subsection{TRANSDUCER TESTING AND CALIBRATION}

When calibrations are not performed on either the individual transducer or a representative sample of transducers of a given type, the uncertainty assigned to the measurement must include such standard error values as specified by ISA-American National Standard MC96.1 (Reference $4-1$ and Table IV-B-i) or the manufacturer, whichever is greater. 
Considerable reduction in uncertainty can be realized when some sort of individual or representative sample calibration is performed. It is, for instance, possible to reduce uncertainty values to less than $\pm 0.1^{\circ} \mathrm{C}\left( \pm 0.2^{\circ} \mathrm{F}\right)$ for type $\mathrm{K}$ thermocouples in the $-17^{\circ}$ to $+260^{\circ} \mathrm{C}\left(0^{\circ}\right.$ to $500 \%$ F) range by performing individual calibrations (Reference 4-3). Whether or not such calibrations are performed will depend to a large extent on the availability of funds and calibration equipment.

A group of thermocouples made from the same reel of wire can be calibrated on a sampling basis by cutting a length of wire from each end of the reel, forming a junction on each of the two thermocouple samples, and calibrating them against a reference thermocouple. The other transducers in the group can then be assumed to have characteristics sufficiently close to those of the two test specimens that no further calibration is required when a brief functional test on each transducer indicates that it operates. Output measurement at ore temperature will suffice in such a functional test.

The calibration of a platinum wire element resistive transducer is calculated by use of the Callendar-Van Dusen equation after the constants $a, \beta$ and $\delta$ are determined (Table IV-B-2). Only $a$ is always based on measurements for each transducer. The constants $\beta$ and $\delta$ may be taken as being typical for a group of transducers of the same design and with elements made from the same reel of platinum wire.

The performance characteristics and accuracies of a temperature transducer are determined through testing and calibration procedures. Three types are generally used and may be described as follows:

(1) Quafification tests are performed to evaluate those characteristics which are a function of transducer design. Results would not be expected to vary appreclably from one unit to another for. a particular transducer model. Tests should be repeated with adequate statistics to ensure that results are representative of the lots.

(2) Individual acceptance tests are performed to evaluate those characteristics which are a function of transducer piece parts, assembly, or adjustment, and wight vary considerably from one unit to the next.

(3) Periodic and special salibrations are performed routinely or when required (as specified by the user) to verify consistency in critical performance characteristics.

The following tests should be performed under one of the three categories discussed above. They are arranged in decreasing order of general importance. 
4.1.1 Visual Inspection

A yisual inspection of those visible mechanical characteristics considered important normally precedes any acceptance or qualification test. Dimensional checks, scrutiny of welded, brazed, soldered, and threaded joints, nameplate verification and examination of cable, connector, or other external electrical connections are usually included.

4.1.2 Range, Output, and Error Limits

Thermocouples and metal wire element transducers are calibrated by recording the output at only a few (usually three, but not less than two) temperature points and then obtaining the output-vs-temperature characteristic at intermediate points by interpolation. The measured points should be selected fixed points if possible (see Table IV-B-4). Temperature points obtained from variable temperature baths are less accurate but are frequently more convenient to obtain than fixed points; this is usually an acceptable procedure for calibration of transducers which are not used as transfer or reference standards.

A properly prepared calibration record shows not only the measured and calculated output-vs-temperature values, but-also reveals the deviation of each of these polnts (error) or the maximum deviation of any point along the entire calibration curve (error band) from a specified theoretical curve. The record should also indicate whether any specified error tolerance has been exceeded.

\subsubsection{Repeatability}

Repeatability is a measure of the extent to which measurements within a set agree with one another. (See Reference 4-6.)

\subsubsection{Insulation Resistance}

A test of insulation resistance is necessary only when the transducer contains an ungrounded sensing element. If the transducer has a metaliic case (cover, stem, head, or mounting), the insulation resistance is measured between the external electrical connections to both sides of the sensing element (connected together) and the case. Surface sensors without metallic cases, such as cementable transducers, can be clamped firmly to a metallic surface and the insulation resistance measured between this surface and both of the sensing element leads connected together.

\subsubsection{Dynamic Response}

Time constant and response time tests are performed by applying a step change of temperature to the sensing element of a transducer and observing the time required for the transducer's output to reach, respectively, 63\%, and a second specified level such as $99 \%$, of the final value. The test always requires readout on an oscilloscope or 
on a high-speed strip chart recorder. The associated amplifier or resistance bridge or other network should be so adjusted that a deflection of several inches will be obtained between the initial and final values of the transducer output.

The magnitude of the step change of temperature is normally selected to lie within the range of the transducer. Several methods can be used to provide the step change. The essential characteristic of any test setup is the minimization of transit time between immersion in the initial and final fluids. The initial fluid used most frequently is relatively still air at room temperature near the temperature bath contalning the agitated final fluid whlch can be liquid nitrogen, liquid oxygen, a dry ice mixture, distilled water, mineral oil, or silicone oil.

To obtain meaningful readings the velocity of the final liquid relative to the transducer should be established when st1ll air is used as the initial fluid.

\subsubsection{Proof Pressure}

A proof-pressure test is performed on immersion probes when an internal seal is required. The probe is mounted into a narrow cylinder equipped with a pressure gage. A gas such as helium is admitted into the cylinder through a valve unt1l the gage indicates the required proof pressure. The valve is closed and the gage is observed for a perlod of time so that any pressure drop, indicating a leakage, can te noticed. If the internal volume of the cylinder is known, and if the temperature of the gas is determined by connecting the transducer under test to appropriate readout equipment, the equivalent volume of gas escaping per unit time (leakage rate) can be calculated. A liquid pressurizing medium should be used only when it is known that the transducer will not be required to provide a seal against gas pressure. If the temperature of the pressurizing medium is expected to affect the performance of the transducer's internal seal, the medium should be heated or cooled before it enters the cylinder.

\subsubsection{Thermoelectric Potential}

This test can be performed on a resistive transducer by connecting it to a thermocouple potentiometer while the sensing element is immersed in a bath maintained at a temperature near the transducer's upper range end point and measuring the potential developed. Such potentlals are normally less than $9 \mathrm{mV}$.

\subsubsection{Vibration and Acceleration}

These tests are required for probe type transducers that will be used in environments where these forces are present. The transducer is installed into a fixture by using its mounting thread or flange. The ffxture is then installed on the test equipment (shaker or centrifuge), 
and the output is monitored for discontinuities or indications of shorting, between portions of the sensing elements or between internal leads while the equipment is subjected to the required vibration or acceleration program.

4.1.9 Other Surface Temperature Transducer Tests

Additional tests are sometimes performed, especially on cementable and weldable transducers, to determine errors due to strains. introduced by bending over a mandrel of specified diameter, by bonding with a specific cement and subsequent drying of this cement, or by installation of the transducer on an appropriate sample surface which must be made in accordance with specified methods.

Another important test is a verification of lead pullout strength. This can be accomplished by clamping the transducer securely in a vertical position and carefully attaching a weight equivalent to the specified (minimum) pull out force to each lead.

4.1.10 : Other Environmental Tests

Additional tests may be required to verify performance in the transducer's expected end-use environment. Performance may have to be verified, for example, by one-point calibration at a convenient fixed point, after exposure of the transducer to mechanical shock. Verification tests during and after exposure to long-term immersion In a specified liquid, specified humidity levels, or to variations in ambient pressure may also be necessary.

\subsection{SYSTEM CALIBRATION}

An end-to-end calibration is generally thought of as a procedure where known temperatures are applied to the measurement system transducer and the output, having been subjected to all the conditioning, amplification and recording components of the system, is then analyzed to determine the values of such system performance characteristics as are of interest, e.g., sensitivity, repeatability, linearity, etc. The use of end-to-end calibrations to determine the closeness of the transducer output to a specified or theoretical curve, or any other parameters as are required to perform data reduction, is net recommended. The most significant disadvantages of using end-to-end calibrations are lack of a controlled environment, inconvenience and insufficient time in consideration of other test stand activities (often resulting in. haste and increased operator error), and the nonportability of precision calibration equipment. Proper system design and careful attention to the details associated with using laboratory determined performance characteristics, and test stand application of electrical simulation, w11l produce data within the required uncertainty limits. 
End-to-end callbrations or system checks are, however, of great value in certain specific instances:

(1) An end-to-end calibration should be performed once a new system has been assembled and is in a readyfor-test condition, but prior to beginning the actual testing. Such a test may serve as an initial system certification or verification. A test of this type is performed by applying a known temperature to the transducer. The electrical signal thus generated is transmitted through the signal conditioning eouipment to the recording system. By reducing this data to engineering units and comparing it with the known temperature input a measured uncertainty value can be determined. This sort of test permits a comparison of measured end-to-end uncertainty with the theoretical uncertalnty values determined by combining individual component uncertainty specifications. In some instances such tests would reveal calculation errors due to omissions or bad information. The end result, when all the differences are resolved, should be an increased level of confidence in the stated uncertainty value.

(2) Ambient temperature readings coupled with continuity measurements can give a good indication of syster operation.

Slightly less of an overall test can be made by such electrical simulations as voltage or resistance substitution. Th1s type of check verifies the entire system except for the transduction portion and is used to determine scaling factor, verify amplifier gain, etc. Some combination of ambient temperature continuity test and voltage or resistance substitution should be performed before every engine test.

(3) Simple polarity verification can be accomplished using heat guns or Freon gas. A make-and-break test, where Individual transducers are electrically disconnected (at the transducer) while an observer monitors the output, is also of value. These kinds of tests are advisable when there has been any significant change in instrumentation channel assignment or if channel identification for some other reason becomes necessary. They are performed infrequently, usually only when changes are made.

\subsection{STANDARDS}

Systems used to calibrate temperature transducers must contain these elements: (1) a temperature source, (2) a way of determining the applied temperature to a greater accuracy than the device being calibrated, (3) equipment to measure the electrical output of the transducer and (4) 
auxillary electrical equipient such as power supplies; electrical simulation and resistance substitution circuits. Whatever the case, the error in the calibration syster must be taken into account in the development of accuracy statements for the calibration.

Callbration standards should be traceable to a better standard. In most situations traceability to the National Bureau of standards is required. In any event, the traceability of a static calibration system should be identified and included in the calibration report of every test measurement transducer.

\subsubsection{Temperature Source}

The temperature sources used for calibration are fixed and variable temperature baths as weil as melting and freezing standards: Reference thermometers or thermocouples are used to measure the bath temperature accurately.

4.3.1.1 Fixed Points. Fixed points are transition points at which a material changes its state (solid, liquid, gas) at a precisely known temperature. Frequentily used fixed points are the bolling poirits of nitrogen, oxygen, and sulfur, the sublimation point (solid-gaseous) of carbon dioxide, the freezing points of water (ice point), tin, zinc, and antimony, and the melting point of silver and gold. (See Table IV-B-4.).

The temperature of a fixed point bath is usually monitored with a platinum resistance thermometer, the calibration of which has been certified by the National Bureau of Standards.

4.3.1.2 Freezing Points. Freezing point standards, used to determine freezing points of metals, are usually not monitored by a reference thermometer or reference thermocouple. Instead, the pure metal samples themselves are certified.

Since the ice point, $0^{\circ} \mathrm{C}\left(32^{\circ} \mathrm{F}\right)$, is basic to most temperature callbrations, the ice bath is the most commonly used fixed point bath.

The triple point of water, $0.01^{\circ} \mathrm{C}\left(32.02^{\circ} \mathrm{F}\right)$, can be measured accurately and with relative ease by using a triple point cell. This measurement is preferred over the ice point if a very accurate determination is required.

4.3.1.3 Temperature Baths. Temperature baths are electricaily heated; double wall tarks containing a bath medium appropriate for a given temperature range. The tank is set in a housing or console and is equipped with an agitator for stirring: $\dot{A}$ cooling tube may be coiled around the inner tank to permit rapid reduction of the bath temperature. Comonly used bath media include a mixture of dry ice and trichloroethylene, acetone, or methanol (driy ice mixture bath) for temperatures between $-73^{\circ}$ and $0^{\circ} \mathrm{C}$ $\left(-100^{\circ}\right.$ and $\left.+32^{\circ} \mathrm{F}\right)$, acetone or methanol for temperatures between $0^{\circ}$ and $38^{\circ} \mathrm{C}$ 
( $32^{\circ}$ and $100^{\circ} \mathrm{F}$ ), silicone oil (such as Dow Corning No. 550 ) for the range $21^{\circ}$ to $260^{\circ} \mathrm{C}\left(70^{\circ}\right.$ to $\left.500^{\circ} \mathrm{F}\right)$ for oil bath, and eutectic salts (e.g., sodium and potassium nitrates and nitrides) for temperatures between $205^{\circ}$ and $705^{\circ} \mathrm{C}\left(400^{\circ}\right.$ and $\left.1300^{\circ} \mathrm{F}\right)$ for salt bath.

The bath temperature is controlled by very accurate thermostatic or proportional control circuitry so that its stability within narrow temperature limits can be relied on.

4.3.1.4 Qvens. Electrically heated muffle ovens, kilns, and other furnaces are used primarily for the calibration of thermocouples at high temperatures. Optical pyrometers are employed for calibration above the gold point of $1063^{\circ} \mathrm{C}\left(1945^{\circ} \mathrm{F}\right)$.

When an oven is used, the test specimen and standard element should be welded together or located very close to one another in a block of highly conductive material such as copper. The entire block should be well insulated.

4.3.2 Readout Instrument

The following are examples of suitable devices:

(1) Manually balanced potentiometer. Typical range is 0 to $11.11 \mathrm{~V}$ with an uncertainty of $\pm 0.006 \%$ of reading $\pm 100 \mu \mathrm{V}$.

(2) Digital electronic voltmeter/ratio meter. Practically infinite ranges with uncertainties of $\pm 0.01 \%$ of reading +1 digit ( 4 digits display) and $\pm 0.005 \%$ of reading +1 digit ( 5 digits display).

(3) Precision resistance bridges (for use with resistance thermometers).

\subsection{OPERATING PROCEDURES}

In order to insure that maximum quality measurement data are produced during each test run, certain inspections and verifications must be made. Some of the recommended procedures are shown below for both the pretest and the posttest periods.

5.1 PRETEST PROCEDURES

(1) Inspect installation visually.

(2) Set up and verify data acquisition system.

(3) Verify that reference junction is operating properly. 
(4) Record calibration and/or electrical simulattion data and check for conformance to predicted values for the measurement system.

Establish run zero reference and record.

5.2

P.OSTTEST PROCEDURES

(1) Record zero reference.

(2) Record calibration and/or electrical simulation data and check for conformance to predicted values.

(3) Inspect Installation visually.

\subsection{DATA ACQUISITION AND PROCESSTING TECHNIQUES}

Many generalized standard techniques must be applied in the acquisition and processing of the calibration, verification, and run data even though a wide range of equipment types and handling techniques will be used for these functions. Certalnly no attempt is made th this handbook to specify the detalled techniques which are appropriate to the various items of equipment supplied by different manufacturers.

6.1

CALIBRATION ANT VERIFICATTION DATA

Recompended practices for the acquistition and processing of calibration and veriffication temperature measurement data are as follows:

(1) Calibration and verification data should be recorded on the same equipment as run data.

(2) Initial system calipration data must be used to determine whether on not the system design requirements, e.g., sensitivity, repeatability, etc., have been net.

(3) Verification data are used to compute the measurement uncertainty of the system, to compute a period of predicted satisfactory performance, and to check the system for trends and excursions.

(4) If the calculated uncertainty of the system exceeds the allowable limit, the system should be improved until such time as the allowable limit is not exceeded. The total uncertalnty of the measurements produced by a system designed in accordance with the practices outlined in this handbook is obtalned by: combining all the elemental uncertainties (Appendix IV-A). The accepted method for the calculation of total uncertainty is presented in Reference $4-7$. 
(5) Posttest verification data should be carefully examined for any deviation from pretest calibrations and/or veriflcations. If such deviations are outside acceptable limits, corrective action should be taken immediately and the validity of the test data should be questioned.

(6) A periodic reevaluation of the measuring system uncertainty should be made as long as the system is in use. This data may revise the claimed system accuracy or 1 ts calibration interval.

(7) Calibration and veriflcaton records should contain at least the following data:
(a) Test stand identification
(b) Parameter identification
(c) Recording system identification
(d) Date, time and ambient temperature
(e) Identification of the standard used
(f) Identification of the temperature transducer
(g) Reference junction temperature
(h) Range of the temperature transducer
(i) Calibration range of the system
(j) Run number (where applicable)
(k) Propellant conditioned temperature
(1) Test cell conditioned temperature
(m) Test cell ambient pressure (altitude simulation level)
(n) Test engine identification
(o) Identification of the operators

\author{
6.2 RUN DATA \\ Recommended practices for the acquisition and processing \\ of run measurement data are as follows:
}

(1) Engine test data should be accumulated with a temperature measurement system only after the uncertainty reauirements have been met. 
(2) Data reduction for each run should be based on the average factor as determined from the pretest and posttest verifications.

(3) Run data should be examined to 1dentify gross malfunctions such as fallure to record, intermittent connections, dropouts, and other equipment malfunctions.

(4) The period of observation for data reduction must be chosen such that the system meets the requirements for the specified test conditions.

(5) Data reduction using a predetermined procedure should be done as quickly as possible after completion of a test so that, in the event of data discrepancy, troubleshooting will be expedited.

(6) Final reduced data should be tabulated for conventent comparison with user specifications.

(7) All calibration, verification, calculated úncertainty, and engine test data should be retalned until a data release is dictated by the program requirements. In general, this includes all information related to the interpretation of the measured temperature.

(8) In the event of equipment malfunction, all data associated with that equipment should be examined for validity. This process will be simplified if all equipment used is appropriately identified and the Identification is made a part of the permanent test records.

\subsection{GLOSSARY}

Accuracy. The closeness or agreement between a measured value and a standard or true value.

Amblent conditions. The conditions (pressure, temperature, etc.) of the medium surrounding the case of the transducer.

Calibration. A test during which known values of measurand are applied to the transducer and corresponding output readings are recorded under specified conditions. (Only during a calibration may adjustments be made so that a relationship convenfent for data reduction purposes can be established.)

Calibration Traceab1lity. The relation of a transducer calibration, through a specified step-by-step process, to an accepted national standard, usually maintained by the National Bureau of Standards.

End Polnts. The output's at the specified upper and lower limits of the temperature range. 
Error. The indicated value minus the true or ideal value.

Errer Band. The band of maximum deviations of output values from a specified reference line or curve due to those causes attributable to the transoucer, as measured over two consecutive calibration cycles unless otherwise specified.

Error. Limit of. The limit of error of a thermocouple or extension wire is the maximum allowable deviation in degrees from the standard EMF-temperature values for the type of thermocouple in question when the reference junction temperature is at the ice point and the measuring junction is at the temperature to be measured.

Excitation. The external electrical voltage and/or current applied to a transducer for 1 ts proper operation.

Extenston Wire. An extension wire is a pair of wires having such temperature-EMF characteristics relative to the thermocouple with which the wires are intended to be used that, when properly connected to the thermocouple, the reference function is transferred to the end of the wires which is opposite the thermocouple.

Fuld Scale Output. The algebralc difference between the outputs at the end points.

Input Impedance. The impedance (presented to the excitation source) measured across the excitation terminals of a transducer.

Junction. Measucing. That junction of a thermocouple which is subjected to the temperature to be measured.

Junction. Reference. That junction of a thermocouple which is at a known temperature.

Leakage Rate. The maximum rate at which a specified fluid applied to the sensing element at a specified pressure is determined to leak in to the case.

Life creing. The specified minimum number of full range excursions or spectfied partial range excursions over which a transducer will operate without changing its performance beyond specified tolerances.

Linearity. The closeness of a calibration curve to a specifled straight line (such as the line between end points). (Nonlinearity is expressed as the maximum deviation of any calibration point on a specified straight line, during any one calibration cycle. It is expressed as "less than $\pm$ s of full scale output.")

Measurand. A physical quantity, property or condition which is measured (such as temperature).

Qutput. The electrical quantity which is produced by the transducer as a function of the applied temperature. 
Output Impedance. The impedance across the output terminals of a tratisducer presented by the transducer to the assoclated external circuitry.

Precisien.' Quality of belng exactly stated or sharply defined. The precision of temperature measurement is the degree of reproducibility among several independent measurements of the same value under specified conditions.

Pulse Mode Operation. For the purpose of this section, pulse mode operation is defined as occurring whenever (a) the thruster valve is commanded closed prior to the attainment of $95 \%$ of the steady state catalyst bed temperature as measured at the outer wall surface; or (b) the performance of the thrister is to be monitored over a time perlod which includes both the start-up and shut-down transients; and during which time the transient portions of any measurement are significant with respect to any steady state measurements.

Repeatability. The ability of a transducer to reproduce output readings when the same temperature is applied to it repeatedly, under the same conditions; and in the same direction. (Nonrepeatability is expressed as the maximum difference between output readings; it is expressed as "less than $\pm \ldots$ of full scale output").

Resistance Thermometer. A temperature measuring device consisting of a coil or grid of wire whose resistance varies with temperature in a precise and predictable manner.

Response Time. The length of time required for the output of a transducer to rise to a specified percentage of its final value as a result of a step change of temperature.

Rise Time. The length of time required for the output of a transducer to rise from a small specified percentage of its final value to a large specifled percentage of its final value.

Sensing Element. That part of the transducer which responds directly to temperature.

Sensitivity. The ratio of the change in transducer output to a change in the temperature.

stability. The ability of a transducer to retain its performance throughout its specified operating life and storage life.

Static Calibration. A calibration performed under stated environmental conditions by application of the measurand to the transducer in discrete amplitude intervals (in the absence of any vibration, shock, or acceleration).

Steady State. Steady state measurements ideally rèquire a measuring system that is capable of producing an exact electrical analog of what mây be a slowly varying temperature. In this generalized statement, the term slowly must be constdered as relative to the response of the overall measuring system. The period of observance for a specified value for the parameter (or in reality, the average of that value) 
must be at least 5 times the natural period $\left(5 / f_{n}\right)$ of the temperature measuring system as determined from the response to a step change in temperature. The system is considered to be at steady state conditions for the period of observance when the average value of the parameter for this period of observance differs by no more than $0.25 \%$ from the preceding or succeeding average over a like time period.

Steady State Operation. For the purpose of this section, steady state operation is defined as that portion of a test after which the temperature at the outer surface of the catalyst bed wall has achieved $95 \%$ of its equable asymptotic value, but prior to the time at which the propeliant valve is commanded closed. Steady state measurements should be made only after the attainment of this conditon.

Iemperature Range, operating. The temperature range in which a transducer may be operated without damage.

Thermocouple. A thermocouple consists of two dissimilar thermoelements so joined as to produce a thermal EMF when the junctions are at different temperatures.

Thermocouple, Sheathed. A sheathed thermocouple is a thermocouple having its thermoelements, and sometimes its measuring junction, embedded in ceramic insulation.

Thermoelement. A thermoelement is one of the two dissimilar electrical conductors comprising a thermocouple.

Threshold. The smallest change in temperature that will result in a measurable change in transducer output.

Total Error Band. The band of maximum deviations of calibration output - values from a specified reference line or curve due to those causes attributable to the transducer.

Iransducer. A device which provides a usable output in response to a specified measurand.

Uncertainty. Measurement. The collective term meaning the difference between the true value and the measured value. Includes both bias and random error. The term accurate implies small measurement error and small uncertainty (see Reference 4-7).

Verification. A verification confirms an established relationship to a standard. (Confirmation implies that no adjustments have been made since the last calibration because an adjustment might void the statistical history of the system.) Verification data are also used to compute the measurement uncertainty of the system, to compute a period of predicted satisfactory performance and to check the system for trends and excursions. 
NOTE: Definitions and nomenclature used in the glossary and throughout this handbook conform to the Instrument Society of American Standard for Electrical Transducer Nomenclature and Technology (Reference 4-8) wherever appilicable.

\subsection{REFERENCES}

4-1. American National Standard for Temperature Measurement Thermocouples, ANSI-MC96.1-1975, Instrument Society of America, 1975.

4-2. Norton, H. N., Handbook of Transducers for Electronic Measuring Systems, Prentice-Hall, 1969.

4-3. Bliss, P., and Morgan, R. K., "Errors in Temperature Measurement," Instrumentation Technology, March 1971.

4-4. Hydrazine Compatibility Design and Handling Criteria, AFRPL-TR-75-46, December 1975.

4-5. Morrison, Grounding and Shielding Techniques in Instrumentation, Second Edition, John Wiley and Sons, New York, 1977.

4-6. ASTM Standards on Prec1sion and Accuracy for Various Applications, American Society for Testing and Materials, Philadelphia, Pennsylvania, 1977 .

4-7. ICRPG Handbook for Estimating the Uncertainty in Measurements Made With Liquid Propellant Rocket Engine Systems, CPIA Publication No. 180, ICRPG Performance Standardization Working Group, April 1969.

4-8. Electrical Transducer Nomenclature and Terminology, ISA-S37.1 (ANSI MC6.1-1975), Instrument Society of America, 1975. 


\author{
APP ENDIX IV-A \\ TEMPERATURE MEASUREMENT SYSTEM \\ ELEMENTAL UNCERTAINTIES
}

The following identifiable elemental uncertainties must be qualified in order to ascertain the overall uncertainty in the reported temperature measurement. The reference document for the calculation of this uncertainty is the ICRPG Handbook for Estimatios the Uncertainty in Measurements Made With Liquid Propellant Rocket Engine Systems (Reference 4-7).

I.

STANDARDS CALIBRATION SYSTEM

A. National Bureau of Standards

Overall uncertainty, including bias and prectsion

B. Interlab Standard

Overall uncertainty, including bias and precision

C. Reference Standard

Overall uncertainty, including bias and precision

D. Working Standard

1. Residual bias from curve fit

2. Variance of the data about the data curve

E. Transfer Standard

1. Residual bias from curve fit

2. Varlance of data about the data curve

II. TEST STAND

A. Stand Calibrator

1. Residual bias from curve fit

2. Varlance of the data about the data curve

B. Transducer

1. Blas caused by transducer stem conduction

2. Bias caused by propellant flow

3. Bias caused by lead resistance drift

4. Blas caused by resistance network drift 
III. ELECTRICAL CALIBRATION EQUIPMENT

A. Electrical Excitation

1. Balance units

2. Power supplies

B. Electrical Simulation

Shunt calibration. See Appendix III-C.

IV. SIGNAL CONDITIONING EQUIPMENT

A. Power Supply

Drift

B. Amplifier

1. Gain stability

2. Nonlinearity

v.

PECORDING EQUIPMENT

A. Nonlinearity

B. Stability

C. Resolution

VI.

DATA PROCESSING EQUIPMENT

Resolution 
TABLES AND EQUATIONS FOR USE WITH THERMOCOUPLES AND RESISTANCE THERMOMETERS

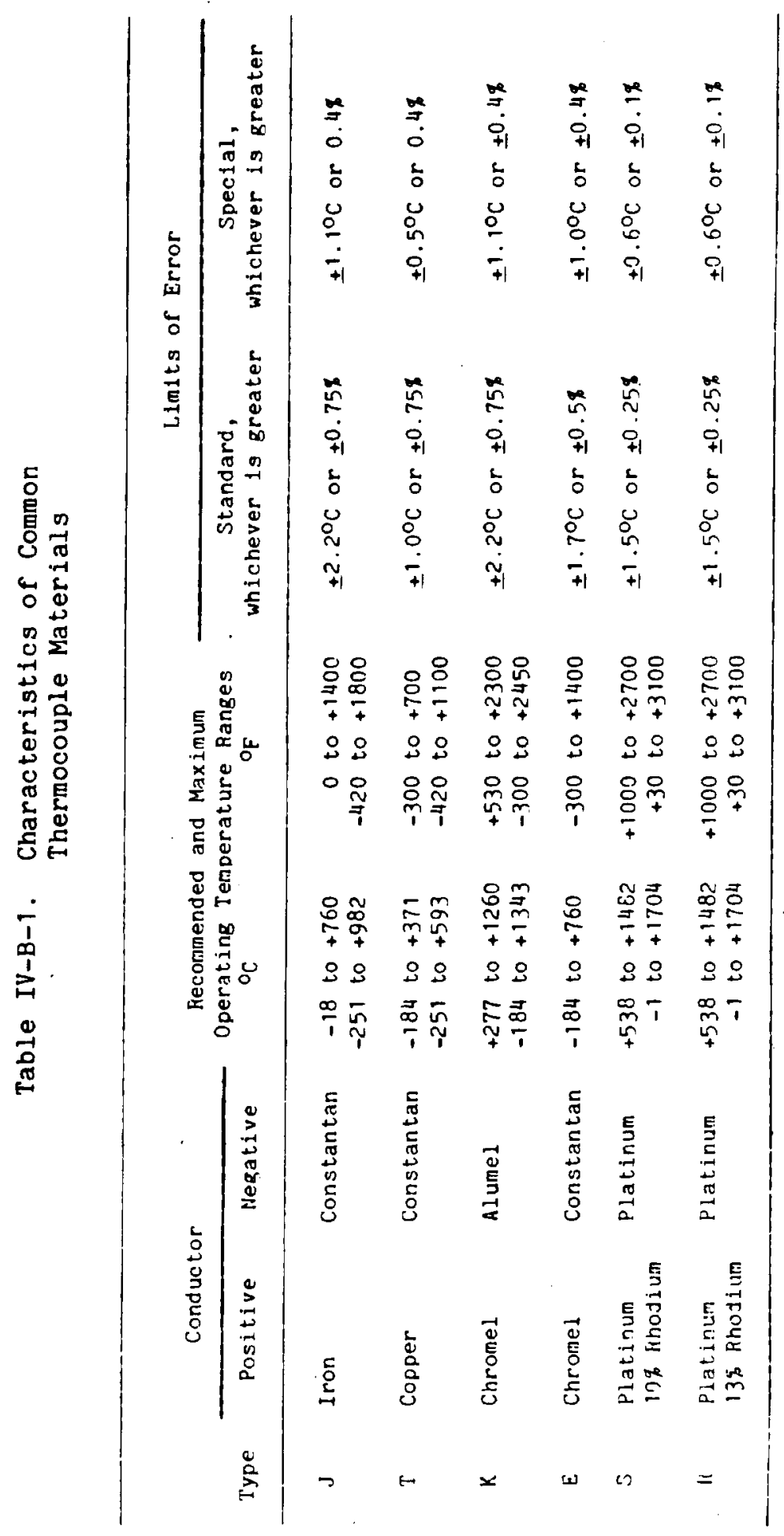


Table IV-B-2. Callendar-Van Dusen Equationa

The Resistance-vs-Temperature Relationship of a Platinum Wire Element

$$
R_{t}=R_{0}+R_{0}\left[t-\delta(0.01 t-1)(0.01 t)-\beta(0.01 t-1)(0.01 t)^{3}\right]
$$

where $R_{t}=$ resistance at temperature $\left({ }^{\circ} \mathrm{C}\right)$

$R_{0}=$ resistance at $0^{\circ} \mathrm{C}$ (ice point resistance)

$a, \beta, \delta$ are constants; typical values are:

$a=0.003925$ (temperature coefficient of resistance near $0^{\circ} \mathrm{C}$ )

$\delta=1.49$

$\beta=0.11$ (if $t$ is negative)

$\beta=0$ (if $t$ is positive)

aThis equation is applicable over the range $-183^{\circ}$ to $+630^{\circ} \mathrm{C}$. Values of decreasing accuracy are obtained when these limits are exceeded on elther side of the applicable range. 
Table IV-B-3. Thermocouple Materials, Type Letters, and Color Codes for Duplex Insulated Thermocouples and Extension Wires

\begin{tabular}{|c|c|c|c|c|c|c|}
\hline \multicolumn{2}{|c|}{ Typical Conductor Material } & \multirow[b]{2}{*}{$\begin{array}{c}\text { Material } \\
\text { Abbreviation }\end{array}$} & \multirow[b]{2}{*}{$\begin{array}{l}\text { ANSI } \\
\text { Type }\end{array}$} & \multicolumn{3}{|c|}{ ANSI Color Code } \\
\hline+ & - & & & Overall & +Cond & -Cond. \\
\hline \multicolumn{7}{|c|}{ Thermocouples } \\
\hline Iron & Constantan & $\mathrm{Fe} / \mathrm{CN}$ & $\mathrm{J}$ & Brown & White & Red \\
\hline Copper & Constantan & $\mathrm{Cu} / \mathrm{CN}$ & $\mathrm{T}$ & Brown & Blue & Red \\
\hline Chromel & Alumel & $\mathrm{CR} / \mathrm{AL}$ & K & Brown & Yellow & Red \\
\hline Chromel & Constantan & $\mathrm{CR} / \mathrm{CN}$ & $\mathbf{E}$ & Brown & Purple & Red \\
\hline $\begin{array}{l}90 \% \text { Platinum } \\
10 \% \text { Rhodium }\end{array}$ & Platinum & Pt $-10 \mathrm{Rh} / \mathrm{Pt}$ & $s$ & & & \\
\hline 87\% Platinum & Platinum & $\mathrm{Pt}-13 \mathrm{Rh} / \mathrm{Pt}$ & $R$ & & & \\
\hline
\end{tabular}

Extension Wires

\begin{tabular}{lllllll}
\hline Iron & Constantan & $\mathrm{Fe} / \mathrm{CN}$ & $\mathrm{SX}$ & Black & White & Red \\
Copper & Constantan & $\mathrm{CU} / \mathrm{CN}$ & $\mathrm{TX}$ & Blue & Blue & Red \\
Chromel & Alumel & $\mathrm{CR} / \mathrm{AL}$ & $\mathrm{KX}$ & Yellow & Yellow & Red \\
Chromel & Constantan & $\mathrm{CR} / \mathrm{CN}$ & $\mathrm{EX}$ & Purple & Purple & Red \\
Copper & Alloy $11^{\mathrm{a}}$ & - & $\mathrm{SX}$ & Green & Black & Red \\
Iron & Alloy $125^{\mathrm{a}}$ & - & WX & White & Green & Red \\
& & & & & & \\
\hline
\end{tabular}

aTypical material as used by Thermo Electric Co., Inc.

bused with type $R$ and $S$ thermocouples as alternate extension wire.

CUsed with type $K$ thermocouples as alternate extension wire. 
Table IV-B-4. Fixed Points Avallable for Callbrating Thermocouples and Resistance Thermistors

\begin{tabular}{|c|c|c|c|c|}
\hline \multirow{3}{*}{ Thermometric Fixed Point } & \multicolumn{4}{|c|}{$\begin{array}{c}\text { Values on the International } \\
\text { Temperature Scale }\end{array}$} \\
\hline & \multicolumn{2}{|c|}{$\begin{array}{l}\text { Assigned, } \\
\text { Primary Points }\end{array}$} & \multicolumn{2}{|c|}{$\begin{array}{l}\text { Determined, } \\
\text { Secondary Points }\end{array}$} \\
\hline & ${ }^{\circ} \mathrm{C}$ & ${ }^{\circ} \mathrm{F}$ & ${ }^{\circ} \mathrm{C}$ & $o_{F}$ \\
\hline $\begin{array}{l}\text { Boiling point of oxygen } \\
\text { Sublimation point of carbon } \\
\text { dioxide } \\
\text { Freezing point of mercury } \\
\text { Melting point of ice } \\
\text { Bolling point of water } \\
\text { Boiling point of naphthalene } \\
\text { Freezing point of tin } \\
\text { Bolling point of benzophenone } \\
\text { Freezing point of cadmium } \\
\text { Freezing point of lead } \\
\text { Freezing point of zinc } \\
\text { Boiling point of sulfur } \\
\text { Freezing point of antimony } \\
\text { Freezing point of aluminum } \\
\text { Freezing point of Cu-Ag eutec- } \\
\text { tic alloy ( } 28.1 \% \text { Cu - } 71.9 \$ \mathrm{Ag} \text { ) } \\
\text { Freezing point of silver } \\
\text { Freezing point of gold } \\
\text { Freezing point of copper } \\
\text { Melting point of palladium } \\
\text { Melting point of platinum }\end{array}$ & $\begin{array}{r}0.000 \\
100.000\end{array}$ & $\begin{array}{r}32.000 \\
212.000\end{array}$ & $\begin{array}{l}-78.5 \\
-38.87 \\
. \\
217.96 \\
231.9 \\
305.9 \\
320.9 \\
327.3 \\
419.5 \\
630.5 \\
660.1 \\
778.8\end{array}$ & $\begin{array}{c}424.33 \\
449.4 \\
582.6 \\
609.6 \\
621.2 \\
787.1 \\
. \\
1166.9 \\
1220.2 \\
1433.8\end{array}$ \\
\hline $\begin{array}{l}\text { aThe values in the table are accur } \\
\text { one standard atmosphere. }\end{array}$ & te to 0 . & and apply & for a $p$ & ire of \\
\hline
\end{tabular}




\section{SECTION V}

\section{EXHAUST GAS COMPOSITION MEASUREMENT}




\section{SECTION $V$}

EXHAUST GAS COMPOSITION MEASUREMENT

\section{CONTENTS}

\section{0}

INTRODUCTION

$5-1$

2.0

SCOPE

$5-1$

2.1

OBJECTIVE

$5-1$

2.2

LIMITATIONS

5-1

3.0

DESIGN CONSIDERATIONS

$5-2$

3.1

MECHANICAL COMPONENTS

$5-2$

3.1 .1

General

$5-2$

3.1 .2

High-Pressure System

$5-2$

3.1 .3

Low-Pressure System

$5-4$

3.2

ELECTRICAL AND ELECTRONIC COMPONENTS

$5-4$

4.0

INSTALLATION AND CHECKOUT PROCEDURES

5-5

4.1

PIPING SYSTEM

5-5

4.2

ELECTRICAL SYSTEM

5-5

5.0

CALIBRATION TECHNIQUES

5-5

5.1

GAS SAMPLING SYSTEM

5-5

5.2

GAS ANALYSIS SYSTEM

5-6

6.0

OPERATING PROCEDURES

$5-6$

6.1

HIGH-PRESSURE SYSTEM

$5-6$

6.1 .1

Pretest Procedures

5-6

6.1 .2

Posttest Procedures

$5-7$

6.2

LOW-PRESSURE SYSTEM

5-7

$$
5-i a
$$




\begin{tabular}{|c|c|c|}
\hline 6.2 .1 & Pretest Procedures & $5-7$ \\
\hline 6.2 .2 & Posttest Procedures & $5-8$ \\
\hline 7.0 & DATA ACQUISITION AND PROCESSING & $5-9$ \\
\hline 7.1 & DATA ACQUISITION AND ANALYSIS & $5-9$ \\
\hline 7.1 .1 & Manometric Measurement & $5-9$ \\
\hline 7.1 .2 & Mass Spectrometry & $5-9$ \\
\hline 7.1 .3 & Gas Chromatography -. & $5-11$ \\
\hline 7.1 .4 & Liquid Residue Analysis & $5-11$ \\
\hline 7.2 & DATA PROCESSING & $5-11$ \\
\hline 8.0 & GLOSSARY - & $5-11$ \\
\hline 9.0 & 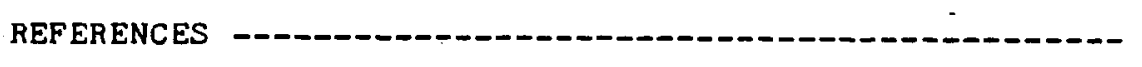 & $5-13$ \\
\hline
\end{tabular}

\section{E1gures}

5-1

Exhaust Gas Sampling System Flow Schematic Diagram ---- 5-3

$5-2$

Exhaust Gas Sample Analysis Block Diagram

$5-10$ 
SECTION $V$

EXHAUST GAS COMPOSITION MEASUREMENT

\subsection{INTRODUCTION}

Recommended practices are outlined for the design, installation, checkout and operation of an exhaust gas composition measurement system to be used during tests of a liquid ronopropellant rocket engine.

\subsection{SCOPE}

This section has been written to serve as a guide for the experienced engineer in the design, installation, and operation of an exhaust gas composition measurement system for collecting and analyzing the exhaust gas from a liquid monopropellant rocket engine. Design guidelines rather than detailed specifications are provided for the critical components of each portion of the system. These guidelines, when used in conjuction with current state-of-the-art, commercially available equipment and good engineering practices, will provide an exhaust gas composition measurement which meets the performance criteria specified.

\section{$2.1 \quad$ OBJECTIVE}

The measurement of exhaust gas composition for a monopropellant rocket engine provides an alternative method of determining performance. It is assumed that the composition of this gas mixture remains frozen upon leaving the catalytic bed and that no further change occurs during the collection and analysis process.

In the case of a monopropellant hydrazine rocket engine the exhaust gas composition analysis will determine the mole percent of ammonia dissociation that has taken place, thus providing an assessment of the adiabatic reaction temperature. Using this temperature and the measured propellant flow and reaction chamber pressure, it is possible to calculate the thrust, thrust coefficient, characteristic velocity, and specific impulse.

This recommended practice is directed toward an exhaust gas composition measurement uncertainty goal of less than $\pm 2.0 \%$.

\subsection{LIMITATIONS}

It is recommended that the exhaust gas composition measurement be limited to discrete samples collected under vacuum from a monopropellant rocket engine operating at steady state conditions. At present there is no proven method of collecting gas samples during pulse mode operation that does not interfere with or compromise the normal engine operation. 


\subsection{DESIGN CONSIDERATIONS}

The design of an exhaust gas composition measuring system requires consideration as to the location of the sampling port, the location of the sampling cylinder, the size and operating pressure of the sampling cylinder, and the location and method of analysis. Since it is seldom possible to have an onsite gas analysis facility, the gas sample normally has to be transported to an offsite analytical chemistry laboratory. The gas sampling system will be covered in this section and the gas analysis system will be discussed in Section 7.0, Data Acquisition and Processing.

\subsection{MECHANICAL COMPONENTS}

The location of the gas sampling port will determine the operating pressure requirements of the system. A sampling port attached directly to the rocket engine reaction chamber will require a highpressure system. If the sampling port or probe is located at the engine exhaust nozzle exit, a low-pressure collection system is required. Both sysțems are shown in the schematic diagram, Figure 5-1.

\section{1 .1}

General

(1) The gas sampling system should be designed to withstand the maximum anticipated operating pressure with a safety factor of 4.

(2) All piping and components should be compatible with the propellant exhaust products. Stainless steel is normaily specified for monopropellant hydrazine (Reference 5-1). Glass can be used in low-pressure applications, but requires extra care in handling.

(3) The sample cylinder should be limited in size to ; that volume required by the analysis method.

(4) The sample cylinder should be designed for easy flow through cleaning and should be provided with manual isolation valves and threaded unions for ease of installation.

(5) The sampling system should be provided with pressure and temperature instrumentation to monitor the gas sampling operation.

3.1.2 High-Pressure System

(1) The gas sampling port for the high-pressure system should be located in the reaction chamber. downstream of the last catalyst bed retainer and upstream of the exhaust nozzle entrance. The tap used for 


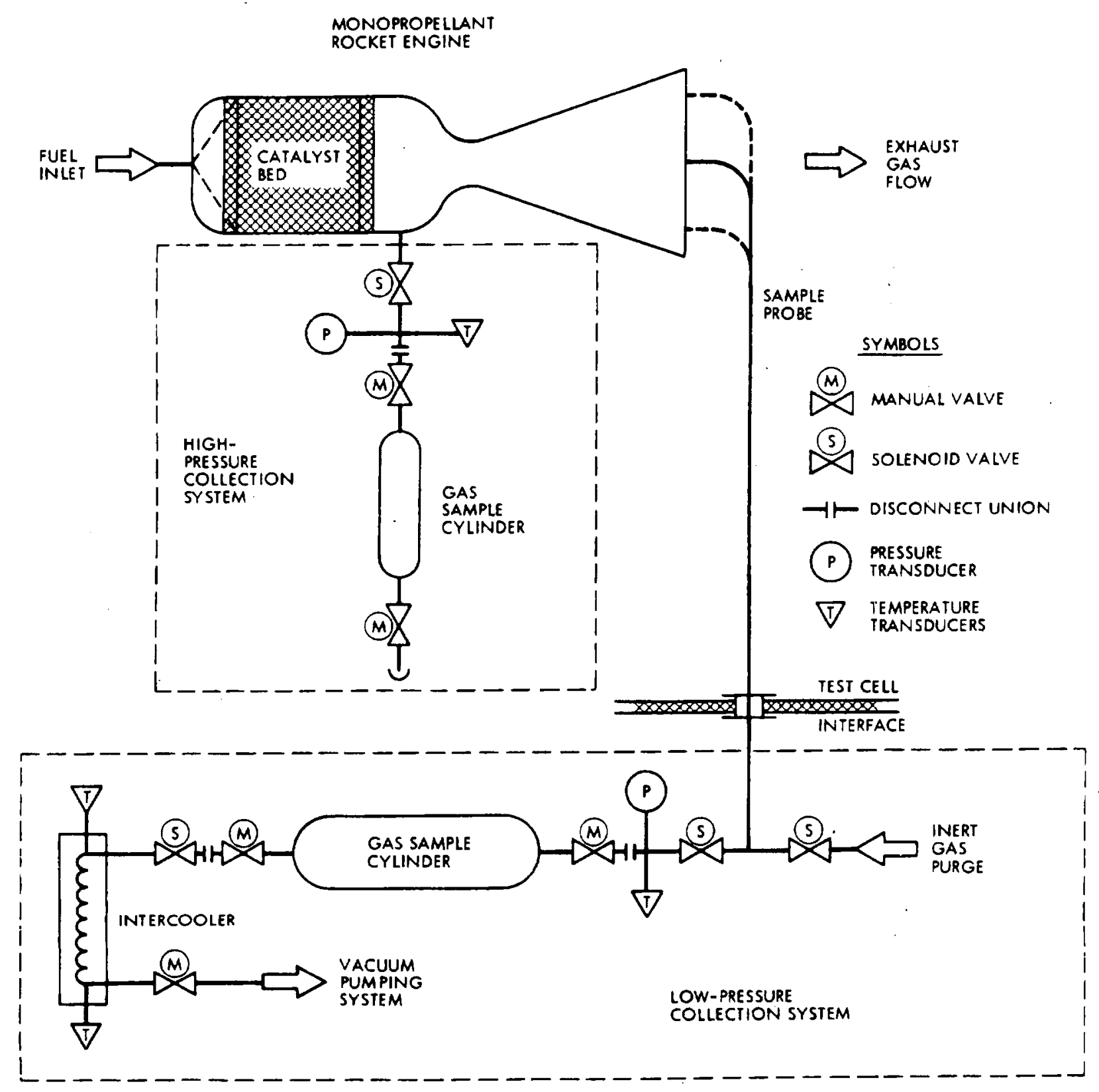

Figure 5-1. Exhaust Gas Sampling System Flow Schematic Diagram 
monttoring chamber pressure can normally be used for sampling purposes.

(2) The system piping should be designed for' close coupling of the sample cylinder to the engine and should be provided with both manual and remotely operated valving. These valves should be made fror stainless steel, have seat material which is compatible with hightemperature exhaust gases, and be capable of sealing both pressure and vacuum.

3.1.3 : Low-Pressure System

(1). The gas sample port for the low-pressure system should be a probe or rake located at the exhaust nozzle exit plane.

(2) The probe should be provided with an inert gas purging system to keep the probe clean when not in use.

(3) The piping system should be designed to conduct the exhaust gas from the probe out through the test cell wall to an externally connected sample cylinder.

(4) The sample cylinder should be provided with both manual and remotely operated valving. These valves should be made from stainless steel, have seat material which is compatible with high-temperature exhaust gases and be capable of sealing both pressure and vacuum.

(5) The sample cylinder should be provided with a vacuum purging system including an intercooler to protect the vacuum pump. This will assure that a representative sample is drawn into the cylinder through the long delivery line.

\subsection{ELECTRICAL AND ELECTRONIC COMPONENTS}

The electrical and electronic components of the gas sampling system consist of the remote valve operators and pressure and temperature instrumentation. Pressure and temperature measurements are covered in the preceding sections of this handbook.

(1) The remote valve operator's principal design requirements are reliability and compatibility with the existing test facility power and control circuitry. Valve position indicators are recomended.

(2) Power and control cabling for valve operation must be installed in conduits which are separate from the instrumentation cabling. 


\subsection{INSTALLATION AND CHECKOUT PROCEDURES}

\subsection{PIPING SYSTEM}

(1) All components of the gas sampling system should be cleaned prior to initial installation (Reference 5-1).

(2) The system should be leak checked at a pressure level equal to the maximum allowable operating pressure.

(3) The system should be vacuum leak checked at an absolute pressure of $6.7 \mathrm{~N} / \mathrm{m}^{2}$ ( $50 \mathrm{mtorr}$ ) or lower.

(4) The system should be flow checked with filtered, inert.gas at the normal operating pressure.

(5) The system, including all sample cylinders, should be passivated with anhydrous ammonia for 48 hours, purged with nitrogen, and subjected to a vacuum prior to operational use.

(1) Inspect electrical cables and connectors of the remotely controlled valves and associated instrumentation transducers. Power and control cables should be isolated and identified separately from the instrumentation cables.

(2) A functional check of all remotely controlled valves and instruments should be conducted using simulated test operating procedures.

\subsection{CALIBRATION TECHNIQUES}

\section{1}

\section{GAS SAMPLING SYSTEM}

(1) A mixture of gases should be prepared that simulates the antlcipated exhaust gas composition. A suggested mole fraction mixture for hydrazine decomposition is $30 \% \mathrm{~N}_{2}$, $50 \% \mathrm{H}_{2}$, and $20 \% \mathrm{NH}_{3}$ at $7435 \mathrm{~N} / \mathrm{m}^{2}$ and $21^{\circ} \mathrm{C}$. $(450 \mathrm{psia}$ and $\left.70^{\circ} \mathrm{F}\right)$.

(2) The gas mixture should be injected into the exhaust gas sampling system under conditions simulating a normal test operation. Three or more sarples should be taken.

(3) Using normal handling procedures, the prepared gas samples should be delivered to the analysis laboratory. 
(1) The gas analysis system should be calibrated using standard laboratory methodology specifled for the particular system in use. The limits of detectability and degree of uncertainty in the measurement of typical exhaust gases and condensable vapors should be ascertained.

(2) A minimum of three composition analyses should be made of the simulated exhaust gas taken directly from the supply cylinder. This will provide information as to the expected accuracy and repeatability of the analysis process.

(3) The gas samples obtained from the simulated engine test should be analyzed using the verified laboratory method. A favorable comparison of these results with those obtained directly from the supply cylinder should verify an uncertainty of less than $\pm 2.0 \%$ in the test gas composition measureiment.

\subsection{OPERATING PROCEDURES}

The operating procedures for the gas sampling syster will vary depending on which system is employed.

The high-pressure method has the advantage of being much simpler and requiring less facility equipment; it does, however, require a direct attachment port on the rocket engine chamber. This results in a measurable loss in chamber pressure during the brief extraction period. The magnitude of this loss varies depending on the relative sizes of the test engine and sample cylinder. In addition, the test cell is normally required to be at atmospheric pressure for the manual installation and removal of the close coupled sample cylinder.

The low-pressure method does not require any fixed attachments to the rocket engine and the sample cylinder can be installed and removed without back filling the test cell, a distinct advantage during live cycle testing. The two principal disadvantages of this method are the considerably more complex equiprient and operating procedures, and a longer extraction time required to thermally stabllize the gas transmission line. The recommended operating procedure for each method is presented below.

\subsection{HIGH-PRESSURE SYSTEM \\ 6.1.1 Pretest Procedures}

(1) Verify that the gas sample cylinder has been cleaned and evacuated:

(2) Check out the operation of the gas sampling control eircuit. 
(3) Install the gas sample cylinder making sure the cylinder is secured, the interconnecting line is leak tight, and that there is no undue strain on the engine sample port. Open the manual cylinder inlet valve.

(4) Close up the test cell and establish desired test conditions of pressure and temperature.

(5) Before the engine test firing, when the test cell is at lowest vacuum condition, open solenoid sample valve to evacuate sample cylinder.

(6) During the operation of the test rocket engine allow approximately 10 seconds to obtain the gas sample, preferably after the engine has reached thermal equilibrium.

(7) Verify that the sample cylinder has been pressurized up to the normal engine operating chamber pressure and has stabilized.

6.1 .2

Postiest Procedures

(1) Vent up the test cell and verify that the test area is safe to enter.

(2) Confirm that the sample cylinder is still at test pressure.

(3) Close the manual isolation valves and remove the sample cylinder. Cap all ports and plug all lines.

(4) Transport the sample cylinder to the analysis laboratory as quickly as practical.

(5) If the high-pressure sample has to be held for many. hours or days before the analysis, it should be transfersed into a larger cleaned and evacuated low-pressure cylinder to reduce the possibility of gas leakage.

\subsection{LOW-PRESSURE SYSTEM}

6.2.1 Pretest Procedures

(1) Verify that the sample cylinder has been cleaned and evacuated.

(2) Check out the operation of the gas sampling control circuit.

(3) Install the sample cylinder, make sure the interconnecting lines are leak tight, and open the manual isolation valves. 
(4) Verify the position of the gas sampling probe to assure that it will not make contact with the engine exhaust nozzle during normal operations.

(5) Check out the operation of the probe inert gas purge system:

(6) Check out the operation of the gas sampling vacuum system and intercooler.

(7) Close up the test cell and establish desired test conditions of pressure and temperature.

(8) Activate the probe purge system and set the delivery pressure to slightly above the maximum anticipated nozzle exit plume total pressure.

(9) Activate the vacuum system and intercooler.

(10) Energize to open the exit valve on the sample cylinder and verify that the vacuum level has stabilized in the gas sampling system; leave valve open.

(11) During the operation of the test rocket engine, allow approximately 30 seconds to obtain the gas sample, preferably after the engine has reached thermal equilibrium, unless otherwise specified.

(12) Valve sequence is as follows:

(a) Close the inert gas purge valve.

(b) Open the sample cylinder inlet valve for 20 seconds allowing exhaust gas to flow through the system under vacuum purging.

(c) Close the sample cylinder exit valve and allow 10 seconds for the pressure to stabilize.

(d) Close the sample cylinder iniet valve.

(e) Open the probe inert gas purge valve.

(13) Verify that the sample cylinder has been pressurized up to normal engine nozzle exit pressure and has stabilized.

\subsubsection{Posttest Procedures}

(1) Verify that the test area is safe to enter.

- (2) Verify that the gas sample cylinder is still at test pressure. 
(3) Close the manual isolation valves and remove the sample cylinder. Cap all ports and plug all lines or install a second sample cylinder.

(4) Transport the sample cylinder to the analysis laboratory as quickly as practical.

(5) If the low-pressure gas sample has to be held for a long period before analysis, no special handling is required. The sample is normally at less than 1-atm pressure so any leakage would be recognized as oxygen contamination.

\subsection{DATA ACQUISITION AND PROCESSING}

7.1 DATA ACQUISITION AND ANALYSIS

The measurement of exhaust gas composition is normally performed in an analytical chemistry laboratory using standard methods and equipment including the following:

(1) Manometric measurement

(2) Mass spectrometry

(3) Gas chromatography

(4) Spectrophotometry

(5) Colorimetric techniques

Special methods have been devised to measure those constituents which are difficult to identify or are present in such small quantities that they are below the detection limit of standard gas analyzers. A recommended gas analysis block diagram is shown in Figure 5-2.

7.1.1 Manometric Measurement

The quantity of sample gas collected can be determined manometrically using a mercury-filled manometer. A high-pressure sample is slowly expanded into an evacuated collecting vessel before the volumetric measurement. The sample cylinder is evacuated with a Toepler pump while the wall of the cylinder is heated slightly to ensure that all condensed vapors are driven out; heating should not be great enough to yield a sample cylinder wall temperature which will cause distortion of the constituent gases.

\subsubsection{Mass Spectrometry}

The exhaust gas sample to be analyzed with a mass spectrometer is first separated using a series of two liquid nitrogen cold traps held at $-195^{\circ} \mathrm{C}\left(-320^{\circ} \mathrm{F}\right)$. The gases not frozen in the cold traps are measured 


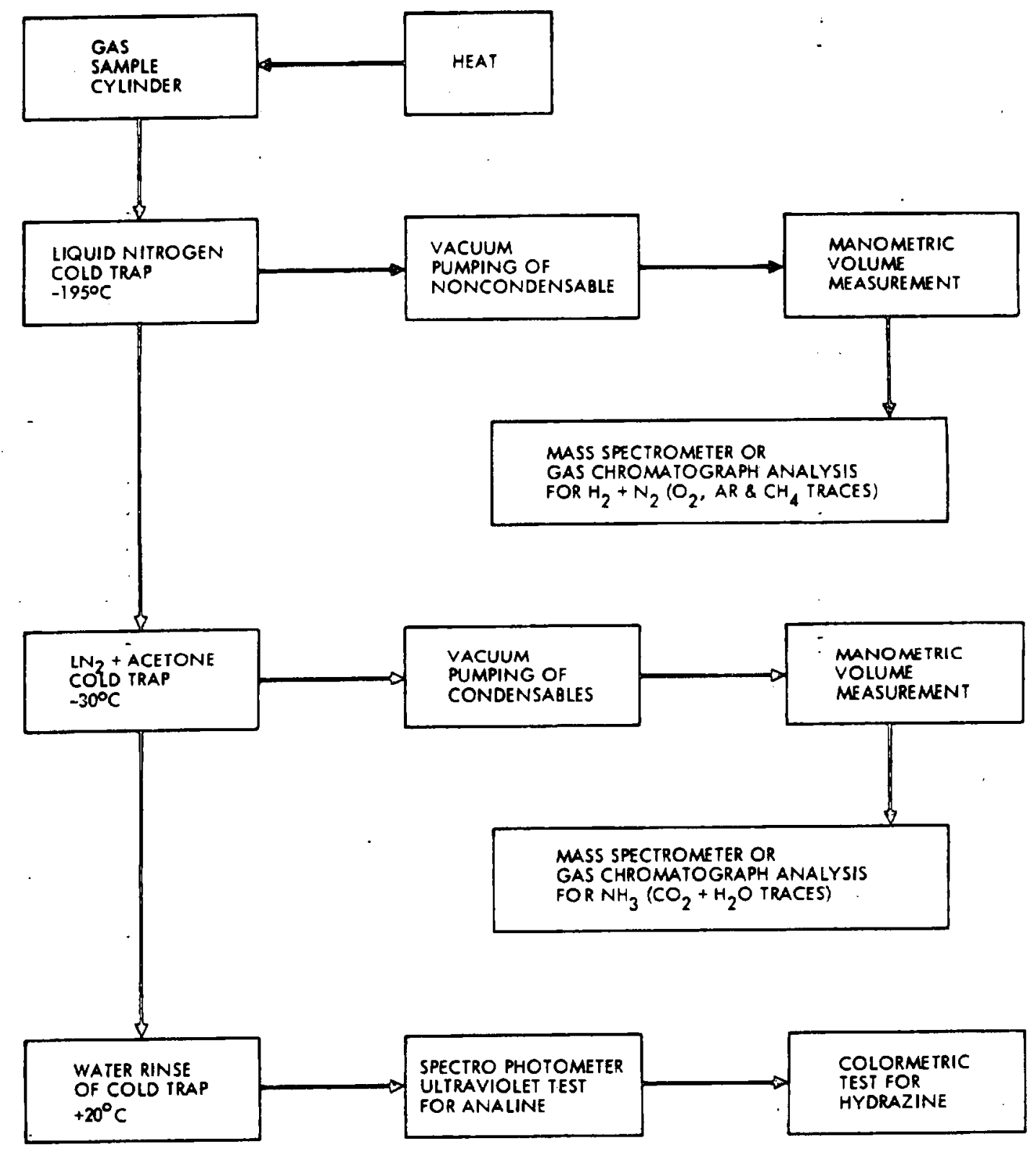

Figure 5-2. Exhaust Gas Sample Analysis Block Diagram

manometrically and analyzed with the mass spectrometer; these gases normally consist of hydrogen and nitrogen, with swall amounts of oxygen, argon and methane appearing as contaminants. The cold traps are then warmed to $-30^{\circ} \mathrm{C}\left(-23^{\circ} \mathrm{F}\right)$ by the addition of acetone. The condensable gas residue is drawn off and collected using the Toepler pump. This gas is also measured manometrically and analyzed with the mass spectrometer. Typically, the condensables consist primarily of ammonia with trace amounts of carbon dioxide and water vapor. 


\subsubsection{Gas Chromatography}

The gas samples collected above can also be analyzed using the method of gas chromatography. A 6-foot molecular sieve 13X (Reference 5-2) can be used for the noncondensable gases, including hydrogen, nitrogen, oxygen and methane using argon as the carrier gas. A Porapak $T$ column (Reference 5-3) can be used for the condensable gases, including ammonia, carbon dioxide, and water vapor. Gas samples in the collector vessels are at subatmospheric pressure $(0.1$ to $0.3 \mathrm{~atm})$ following manometric measurement and have to be compressed back to atmospheric pressure before injecting into the gas chromatograph. This could be accomplished by using a rising column of mercury. A minimum volume of $0.5 \mathrm{ml}$ at 1 atm is normally required.

\subsubsection{Liquid Residue Analysis}

Any condensable vapor present in the gas sample will normally be caught in the first cold trap during the separation process. The closed cold trap, when warmed to room temperature, is rinsed out with a small amount of distilled water to collect any unreacted hydrazine and traces of analine. In general, the quantity of hydrazine will range from very small to none with analine only a very small fraction of the total collected. Special detection and analysis methods have been used with some success. The spectrophotometer ultraviolet test (Reference 5-4) is recommended as the most sensitive analysis for analine and the colorimetric technique using 2,4,6-trinitrobenzenesulfonic acid is recommended for hydrazine detection (Reference 5-5).

\subsection{DATA PROCESSING}

The main constituents measured in the gas sample analysis are hydrogen, nitrogen and ammonia. The mole percent of nitrogen measured in the exhaust may be slightly greater than the theoretical decomposition of hydrazine would predict. This may be caused by saturation of nitrogen pressurant in the hydrazine. Since this is a variable which is not readily predicted, the mole percent of ammonia dissociation is determined from the mole fraction ratio of hydrogen to ammonia (see Section VI, Paragraph 4.3.6). No correction is made for the small amount of ammonia initially present in the liquid hydrazine. Any loss of hydrogen through leakage or ammonia absorption on the walls of the sample cylinder is minimized by expeditious and careful handling of the sample and heating and evacuation of the cylinder during the extraction process.

\subsection{GLOSSARY}

Ammonia Dissociation. The endothermic reaction in which the ammonia $\left(\mathrm{NH}_{3}\right)$ molecule is broken into its constituent molecules of nitrogen $\left(\mathrm{N}_{2}\right)$ and hydrogen $\left(\mathrm{H}_{2}\right)$ according to the following equation:

$$
4 \mathrm{NH}_{3} \longrightarrow 2 \mathrm{~N}_{2}+6 \mathrm{H}_{2}
$$


Gas Chromatography (GC). A method used to measure and record by graphical means the identification and concentration of components in a gasvapor mixture. The process involves volatilizing the sample mixture into a carrier gas stream which is passing through and over a column of dry granular solid or a liquid supported by the granules or by the walls of the column or both. Separation is achieved by differences in partition - distribution of the components in the sample mixture - and carrier gas causing them to move through the column at different rates. Thus, they appear one after the other at the effluent. end, where they are detected and measured by thermal conductivity changes, density differences, or various types of ionization detectors.

Manometric Measurement. The method of measuring the volume and pressure of an evolved gas or vapor by means of the measured displacement of liquid (usually mercury) in a manometer.

Mass Spectrometry. A technique for the analysis of matter by means of ionization of the molecules followed by the separation of ions according to mass-to-charge ratio and the recording of the numbers of various ions. The mass distribution and relating abundance of ionic products provide the mass spectrum which is a unique fingerprint representing the molecules of matter from which it was formed. Information thus provided includes the exact molecular formulas and molecular weight and in some instances the molecular structure.

Measurand. A physical quantity, property, or condition which is measured (such as pressure).

Pulse Mode Operation. For the purpose of this section, pulse mode operation is defined as occurring whenever (a) the thruster valve is commanded closed prior to the attainment of $95 \%$ of the steady state catalyst bed temperature as measured at the outer wall surface, or (b) the performance of the thruster is to be monitored over a time period which includes both the start-up and shut-down transients, and during which time the transient portions of any measurement are significant with respect to any steady state measurements.

Reaction Chamber. The structural component of a monopropellant rocket engine between the propellant injector head and the exhaust nozzle. It encloses the catalyst bed, the bed retainer grids or screens, and the plenum leading to the exhaust nozzle.

Steady State operation. For the purpose of this section, steady state operation is defined as that portion of a test after which the temperature at the outer surface of the catalyst bed wall has achieved $95 \%$ of its equable asymptotic value, but prior to the time at which the propellant valve is commanded closed. Steady state measurements should be made only after the attainment of this condition.

Thermal Equilibrium. A thermal state in the rocket engine operation where the heat addition originating from the reacting propellant is in balance with the heat loss through conduction, radiation and expulsion of exhaust gases. This is normally witnessed by a constant temperature measurement on the wall of the reaction chamber. 
Toepler Pump. A method used to transfer gases at subatmospheric pressure utilizing an alternating rising and falling column of mercury in a cylindrical glass vessel. Two valves are operated in sequence with the movement of the mercury column to allow introduction and expulsion of the gas from the cylinder.

\subsection{REFERENCES}

5-1. Hydrazine Compatibility Design and Handling Criteria - Design Handbook, AFRPL-TR-75-46, TRW Systems Group, Redondo Beach, California, December 1975.

5-2. "Analysis of Reformed Gas by Gas Chromatography," 1975 Annual Book of ASTM Standards, ASTM D1946-67, Part 26, Gaseous Fuels; Coal and Coke; Atmospheric Analysis.

5-3. Wilhite, W. F., and Hollis, 0. L., "Use of Porous Polymer Beads for the Analysis of Martian Atmosphere," Journal of Gas Chromatography, Volume 6, February 1968.

5-4. Military Specification Propellant, Hydrazine, MIL-P-26536C, Amendment 1, Par. 4.5.5.1., 25 July 1974.

5-5. LaRue, T. A:, "Selective Spot Test for Hydrazine," Talanta, Volume 14, p. $1344,1976$. 


\section{SECTION VI}

\section{DATA REDUCTION AND PERFORMANCE DETERMINATON}


SECTION VI

DATA REDUCTION AND PERFORMANCE DETERMINATION

CONTENTS

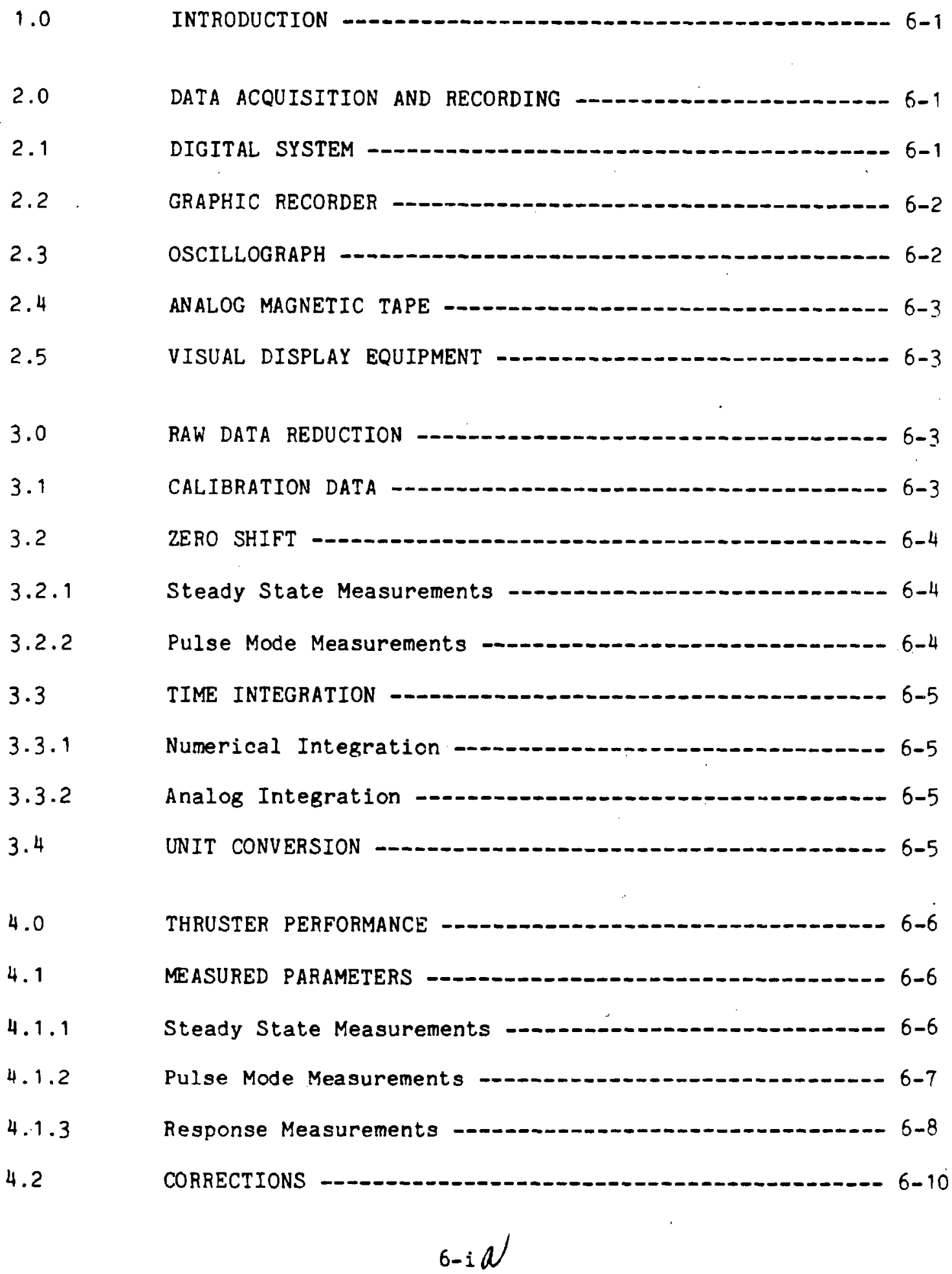




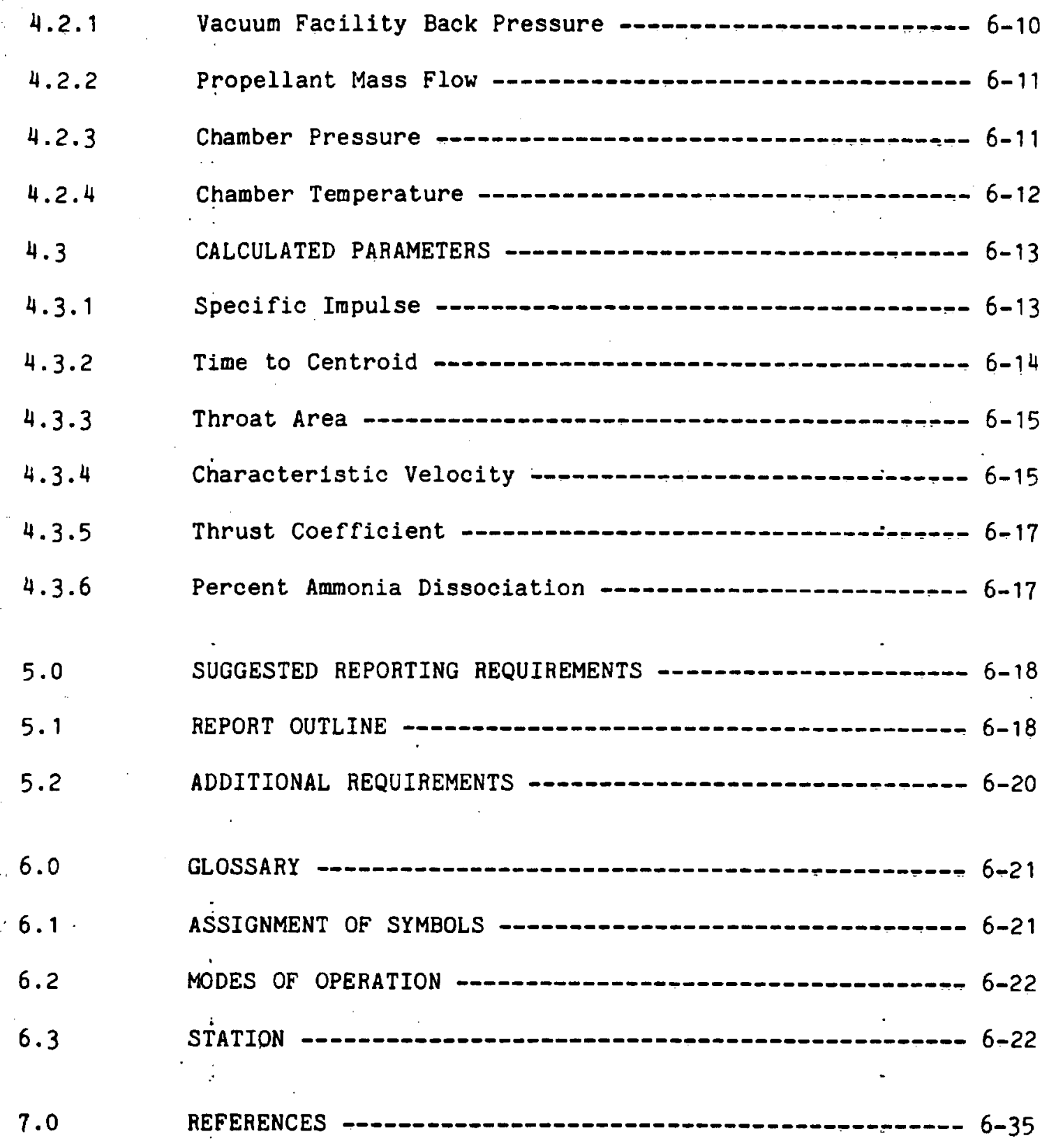

\section{APPENDIXES}

VI-A THEORETICAL PERFORMANCE OF MONOPROPELLANT

HYDRAZINE -

VI-B CALCULATION OF ROTATIONAL PERFORMANCE - 


\section{Eigures}

6-1 Thruster/Valve Response Definitions -

6-2 Chamber Pressure Tap Location - 6-12

6-3 Throat Area Variation With Temperature -

VI-A-1 Theoretical Specific Impulse for Monopropellant

Hydrazine -

VI-A-2 Theoretical Thrust Coefficient for Monopropellant Hydrazine -

VI-A-3 Theoretical Characteristic Velocity and Adiabatic Reaction Temperature for Monopropellant

Hydrazine -

VI-A-4 Ratio of Specific Heats and Molecular Weight of Product Gases at Chamber Conditions for Monopropellant Hydrazine

VI-B-1 Rotational Terms

\section{Table}

$6-1$ 
SECTION VI

\section{DATA REDUCTION AND PERFORMANCE DETERMINATION}

\subsection{INTRODUCTION}

This section provides the definitions, algorithms, and procedures for the reduction to performance parameters of the monopropellant thruster measurements which have been obtained as per the recommendations outlined in Sections I through $V$ of this handbook. A brief discussion of acquisition and recording systems is also included. Emphasis has been placed upon monopropellant hydrazine engines, and some parameters relate specifically to the catalytic decomposition of hydrazine $(\mathrm{e} . \mathrm{g}$. , percent ammonia dissociation). Performance of other types of monopropellant thrusters may, however, be determined by using procedures similar to those discussed herein. Two appendixes are included: VI-A, Theoretical Performance of Monopropellant Hydrazine, and VI-B, Calculation of Rotational Performance.

A fundamental objective in the development of these procedures is the promotion of a uniformity of methodology in the reduction of thruster test data by the engine manufacturer, thus providing a potential user with a common basis for comparing the performance of various engines. To achieve this end, it becomes imperative that the manufacturer directly measure those quantities which are the thruster's primary purpose to provide; specifically, steady state thrust and pulse mode impulse. The primary derived performance parameter, specific impulse, similarly requires the direct measurement of steady state propellant flow and pulse mode propellant usage. Enphasis has been placed on minimizing indirectly obtained or calculated performance.

The user, on the other hand, may not have impulse measurement or steady state thrust measurement instruments available. A secondary objective of the following procedures is to have the manufacturer provide the user with a thrust and impulse correlation which will allow the user to verify the manufacturer-supplied characterization.

\subsection{DATA ACQUISITION AND RECORDING}

The preferred system for the acquisition, recording, and reduction of monopropellant thruster test data is the digital system. The digital system is frequently combined with analog magnetic tape, graphic recorders, or oscilloscopes which yield high-frequency response, quick-look data, and flexible calculational abilities.

\section{$2.1 \quad$ DIGITAL SYSTEM}

The digital system may provide acquisition uncertainties of $\pm 0.25 \%$ or less and, in addition, entire test sequences may frequently be programmed for automatic execution. 
The most common type of digital system consists of a muitiplexer, ànalog-to-digltal converter, format and controi linit; and a recording device employing magnetic tape, magnetic disc; punched cards, or punched paper tape as the output medium.

Another comnon type of digital system consists of a voltake-tofrequency converter and digital counter: The voitage-to-frequency converter generates a frequericy the value of which is proportional to the measurewent. This is totalized on the counter for a desired period of time. The total count this produced is proportional to the time integral of the measurement over the period of interest. The counter readings may be recorded at known intervais so that a time history of successive measurenents may be obtained.

Major characteristics of the digital system are resolution and sampiling rate. System resolution should exceed $i$ part in 2000 for chamber pressure and thiust measurements. In addition, the sampling rate (measurements per second) should be sufficiently high to characterize the signal being sampled (Reference $6-1$ ). The recording system chosen should have frequency response capable of faithfuliy recording all frequencies of interest.

The most common type of graphic recorder is the strip chart recorder which typically introduces uncertainties of from \pm 0.2 to $\pm 0.5 \%$ of the strip chart span.

Strip chart recorders are often used to augment the more accurate digltal system by supplying a ouick-look displày. When these two devices are operated in parallel, care should be taken to prèvent off-null error voltages (produced by the strip chart recorder under transient or dithering conditions) from affecting the digital data.

\section{$2: 3$ OSCILLOGRAPH}

Oscillograph recorders produce measurement uncertainties of \pm 2.0 to $\pm 3.0 \%$ of rull scale. Oscillographs are of ten used to acigment the more accurate digital recorder by supplying higher frequency data. Multiplexing and quantization generally associated with multichannel digital recorders usually limit information bandwidth to $100 \mathrm{~Hz}$ or lower. Oscillograjphs may record frequencies to $5000 \mathrm{~Hz}$ or higher, but are normallv used at less than $1000 \mathrm{~Hz}$.

Initial system checkout should include the use of galvanometers with frequency response capabilities high enough to determine the presence of any suich high-frequency fluctuations. Once the system frequency response characteristics are evaluated, it may be advisable to substitute galvanometers whose response capabilities are no higher than reauired to monitor the frequencies of interest. For monopropellant rocket engine testing a frequency response of $300 \mathrm{~Hz}$ is usually sufficient. 
When an oscillograph and digital recorder are operated in parallel, system design should insure no degradation of digital data caused by the higher current requirement of the oscillograph galvanometer.

\subsection{ANALOG MAGNETIC TAPE}

FM analog tape recorders usually have measurement uncertainties of at least \pm 1.0 to $\pm 2.0 \%$ of full scale and are therefore not used as the primary recording device for steady state measurements with low uncertainty. They are used primarily to record high-frequency data up to $40,000 \mathrm{~Hz}$. They have the additional flexibility of being able to play back the data at a rate other than that at which it was recorded. This permits time expansion of the data for increased resolution, which is especially helpful when high-frequency phenomena are present.

In a special application the analog tape recorder can be used without an increase in uncertainty when obtaining time integrals of measurements. This is accomplished by recording the frequency of the voltage-to-frequency converter on a direct analog channel and then integrating the signal digitally.

\section{$2.5 \quad$ VISUAL DISPLAY EQUIPMENT}

A real time visual display in engineering units of measured thruster data, along with other critical operating parameters, is required for both pretest and posttest calibrations and for monitoring during the engine test. This alphanumeric data can be presented in hard-copy (printed), non-hard-copy (no record) form, or both. The non-hard-copy is usually displayed on some type of cathode ray tube (CRT) device through a selective preprogramed format.

\subsection{RAW DATA REDUCTION}

As a first step in the data reduction procedure, signal quantities are converted to engineering units. It is strongly recommended that a standard computer code be developed for compatible use with all digitally acquired monopropellant engine test data.

\subsection{CALIERATION DATA}

Calibration information for each channel sampled by a digital data acquisition system may be supplied to the raw data reduction program in any of several ways, depending upon the instrument involved and its behavior in use. For example, coefficients describing a polynomial fit to the calibration data may be input for each transducer, or a table of values may be employed. This calibration data for each transducer is typically input to the raw data reduction program in the form of magnetic tape or punched cards. Shunt, calibration, or calibration of the acquisition system, is performed immediately prior to a run by introducing an electrical signal to each channel sampled by the data acquisition system. This calibration 
is then combined with the transducer calibration to convert the transducer signal quantities to engineering units. Digital integration routines may be checked in a similar manner.

During any given test, a measurement system may undergo chanzes due to thermal expansion of test hardware, temperature and pressure effects on the transducer, or electrical component specification changes. These effects manifest themselves by causing a change in the level of recorded system output signal for zero applied sensor input, and the phenomenon is labeled zero shift. Raw data is to be corrected for zero shift as described in the following paragraphs.

\subsubsection{Steady State Measurements}

Steady state thruster data is obtained over a time interval after the thruster has reached equable asymptotic conditions. It is recommended that this time interval be defined as occurring at the end of any particular run and that the data be corrected for the posttest zero shift, where the zero is determined immediately after shut-down transients have decreased below the measurement threshold, but prior to the onset of any detectable thermal soakback effects. For a very long steady state burn (several minutes to hours), it is recommended that steady state measurements also be acquired as soon as possible after reaching steady state conditions. Pretest zero is to be applied to this measurement interval and posttest zero applied to the final measurement if zero shift is noted to have occurred after the test. Discrepancies between pretest and posttest zeros of greater than $3 \%$ of the maximum value registered for the given parameter will be cause to doubt any measurements intermediate to the first and the last since the time into burn and the manner of shift occurrence will be unknown. Intermediate measurements for shifts of less than $3 \%$ may be corrected by assuming that the shift occurs linearly with time between the zero determinations.

\subsubsection{Pulse Mode Measurements}

For a single puise, or for a series of pulses.for which the time between pulses is sufficient to acauire a zero, the prepulse data may be corrected either by averaging the prepulse and postpulse zero or by assuming that the zero shift occurs linearly with time during the period between zero determinations. If the frequency of the pulses is such that a zero cannot be acquired between pulses, the pretest and posttest zeros shall be assumed to vary linearly with the time between acquiring the first and last zero reading. In any case, discrepancies between pretest and posttest zeros of greater than $3 \%$ of the maximum value registered for the given parameter during any pulse shall be cause to terminate the test, rectify the problem responsible for the shift, and repeat the run sequence. 
For some measurements, reduction of raw data will include the time integration of a signal quantity. This integration may be performed electronlcally in real time as the signal quantity is varying or numerically by the raw data reduction program after all the data to be integrated has been acquired. In either case an estimate of integration uncertainty must be made.

\subsubsection{Numerical Integration}

The numerical integration of digitally acquired data is the preferred method for obtaining time integrated values of any variable. Ideally, the data recording system (whether magnetic tape or computer core memory) will be capable of storing the discretized data until the posttest zero is obtained. After the data have been corrected for zero shift. (Section 4.2), the integration can be performed by using any of a number of numerical integration schemes (References 6-2 and 6-3). However, a minimization of the integration uncertainty can be achieved only by considering both the digital sampling rate (Reference 6-1) and the integration algorithm.

\subsubsection{Analog Integration}

Electronic integration is used extensively throughout the industry to obtain real time display of integrated data. Operational amplifier integrators of the type used in general purpose analog computers may produce integration uncertainties as low as $\pm 0.1 \%$. The use of simple $R-C$ circuits as integrators will yield approximate integrals with somewhat higher uncertainties.

A disadvantage of electronic integration is the difficulty of rigorously accounting for zero shift after the run is complete and the integral has been obtained; this is particularly true if track-and-hold amplifiers are utilized to obtain integrals of a time varying parameter over a series of pulses. In this case, even if a zero is acquired between pulses, the total integral must be corrected by assuming a linear variation of zero shift over the integral period; i.e., a quantity equal to one half the zero shift times the integration interval is algebraically subtracted from the integration total. This correction is only to be applied if the zero shift is less than $3 \%$ of the maximum value for the parameter which is being integrated. Zero shifts of greater than 3\% shall invalidate any integral obtained by electronic means.

\subsection{UNIT CONVERSION}

After the data have been acquired, signal quantities converted to engineering units, corrections for zero shift included, and certain quantities time integrated, the conversion from miscellaneous units into Système International d'Unités (SI units) must often be performed. This conversion is to be made using the physical constants and conversion factors given in NASA SP-7012 (Reference 6-4) or equivalent. 


\subsection{THRUSTER PERFORMANCE}

This section details the measurements which are required to determine thruster performance, the corrections which are to be applied to those measurements, and the definitions and algorithms for the calculation of performance parameters.

4.1

\section{MEASURED PARAMETERS}

Any monopropellant thruster test program will include a variety of measurements taken for the purpose of ensuring correct and safe operation of the test facility. The number and location of such measurements will necessarily vary from facllity to facility and will not be discussed in this section. However, the minimum acceptable number and type of measurements which are necessary to determine the performance of a monopropellant thruster can and must be specified if a standardization of data reduction procedures is to be achieved. These measurements are discussed in the following paragraphs. Additional measurements which may be useful in characterizing thruster behavior are included in the glossary at the end of this section. The measurement uncertainty limitations established in Sections I through $V$ of this handbook apply to the measurements discussed in this paragraph.

\subsubsection{Steady State Measurements}

A typical catalytic hydrazine thruster may require 30 seconds to several minutes of firing to achieve thernal equilibrium at the outer surface of the catalyst bed wall; other parameters respond much more rapidly. For the purpose of this handbook, steady state is defined as that portion of a test after which the temperature at the outer surface of the catalyst bed wall has achieved $95 \%$ of its equable asymptotic value, but prior to the time at which the propellant valve is commanded closed. The following measurements should be made after the attainment of this condition and immediately prior to engine shutdown and zero reference determination.

4.1.1.1 Thrust. Thrust shall be determined by digitally acquiring no fewer than 100 samples of the load cell signal over a period of not less than. $100 \mathrm{~ms}$. These values may be either averaged or time integrated over the sampling period to obtain a characteristic thrust value.

4.1.1.2 Mass Flow. The transducer signal corresponding to propellant mass flow shall be digitally acquired during the same time interval that the thrust measurement is being obtained.

4.1.1.3; Chamber Pressure. Chamber pressure shall be determined by digitally acquiring no fewer than 100 samples of the transducer signal over the same time interval as that used for determining thrust. These values may be either averaged or time integrated over the sampling period to obtain a characteristic chamber pressure value. 
4.1.1.4 Ancillary Measurements. The following measurements are useful for data corrections and correlations or are necessary to characterize the thruster operating conditions and test environment. These measurements should be obtained during the same time interval that the thrust is being defined.

(1) Propellant pressure at thruster valve inlet

(2) Propellant temperature at thruster valve inlet

(3) Vacuum pressure within the test facility

(4) Catalyst bed outer wall temperature

(5) Nozzle throat temperature

(6) Propellant temperature at the flow measurement device

\subsubsection{Pulse Mode Measurements}

For the purpose of this handbook, pulse mode operation is defined as occurring whenever (a) the thruster valve is commanded closed prior to the attainment of $95 \%$ of the steady state catalyst bed temperature as measured at the outer wall surface, or (b) the performance of the thruster is to be monitored over a time period which includes both the start-up and shut-down transients, and during which time the transient portions of any measurement are significant with respect to any steady state measurements.

It will be noted below that several of the "measurements" are time-integrated totals of a directly measured signal. These integrations are taken here to be measurements also. During operation of the thruster in the pulse mode, the following measurements will be obtained for each pulse for which thruster performance is to be determined.

4.1.2.1 Impulse Bit. Impulse bit is defined as the time integration of the thrust signal for a single pulse. The digital sampling shall be at a sufficiently high rate to characterize the load cell signal and to perform the integration within the uncertainty limitations established in Section I of this handbook. Integration of the signal shall begin at the valve open signal and may not extend beyond the time at which it becomes impossible to distinguish the thruster-induced signal from the background noise environment.

4.1.2.2 Propeliant Usage. The mass of propellant admitted to the catalyst bed shall be determined by digitally acquiring, at a minimum, the prepulse and postpulse signal from a volumetric displacement flowmeter. The postpulse sample shall be acquired prior to the onset of any detectable thermal soakback effects which may alter the volume of propellant between the thruster valve and the propellant measurement device. Other types of flow measurement devices shall be digitally sampled at a rate sufficiently high to obtain the time integration of propeliant flow within the uncertainty limitation specified in Section II of this handbook. 
4:1:2:3 chamber Pressure Integräl. The simnal from the chamber bressure transducer shail be digltally sampled at a rate which is sufficiently rapid to accurately characterize the sichal and berform the time integration. The integration shall begin at the valve open signal and shali not extend beyond the time at which the transducer signal has decayed to 18 of the maximuin pressure recorded during the puise or to $6.9 \mathrm{kN} / \mathrm{m}^{2}(1 \mathrm{psi})$; whichever is iess.

4:1.2.4 Chamber Pressure Product of Inertia: The chamber pressiure product of inertia is defined as the time intekrai of chamber pressure muitipilied by the time from the valve open command. This product and integration should be formed at the same time and according to the same guidelines as established for the chámber pressurê intêgral. (Thè chamber prèssurelproduct ôf inertia wili be used in a subsequent calculation to define the time-to-pulse centroid.)

4.1:2:5 Ancillary Measuirements. The following measurements are usefui for data corrections and correlations; or are necessary to characterize the thruster operating conditions and test environment during pulse mode measurements.

(1) Initial propellant inlet pressure
(2) Initial propellant inlet temperature
(3) Initial catalyst bed temperature
(4) Valve supply voltage and current
(5) Electrical puise width
(6) Vacuum facility back pressure

\section{4. $1: 3$ Response Measurements}

The measurements which describe the transient response of the thruster àre defined in the following paragraphs: These response terms áre nôt tỳpicallì determined for every pulse and may be defitied by a combination of digital and anälog techniques, including oscillograph or oscilloscope träces of valive current, valve voltage, and chamber pressure às depiet'ed in Figure 6-1: Additional response measurements are defiried in the glossary at the end of this section.

4:1:3.1 Valye Openjig. Résponse Time. The valve opening response time is the interval which elapses between thruster value opening signal and the attainiment of a fully open valve position.

4. $1: 3.2$ Rise Time. Rise time is defined as the time interval which ela pses betweén attainment of a fuliy open valve position and a chamber pressure 1ncrease corresponding to $90 \%$ of: 


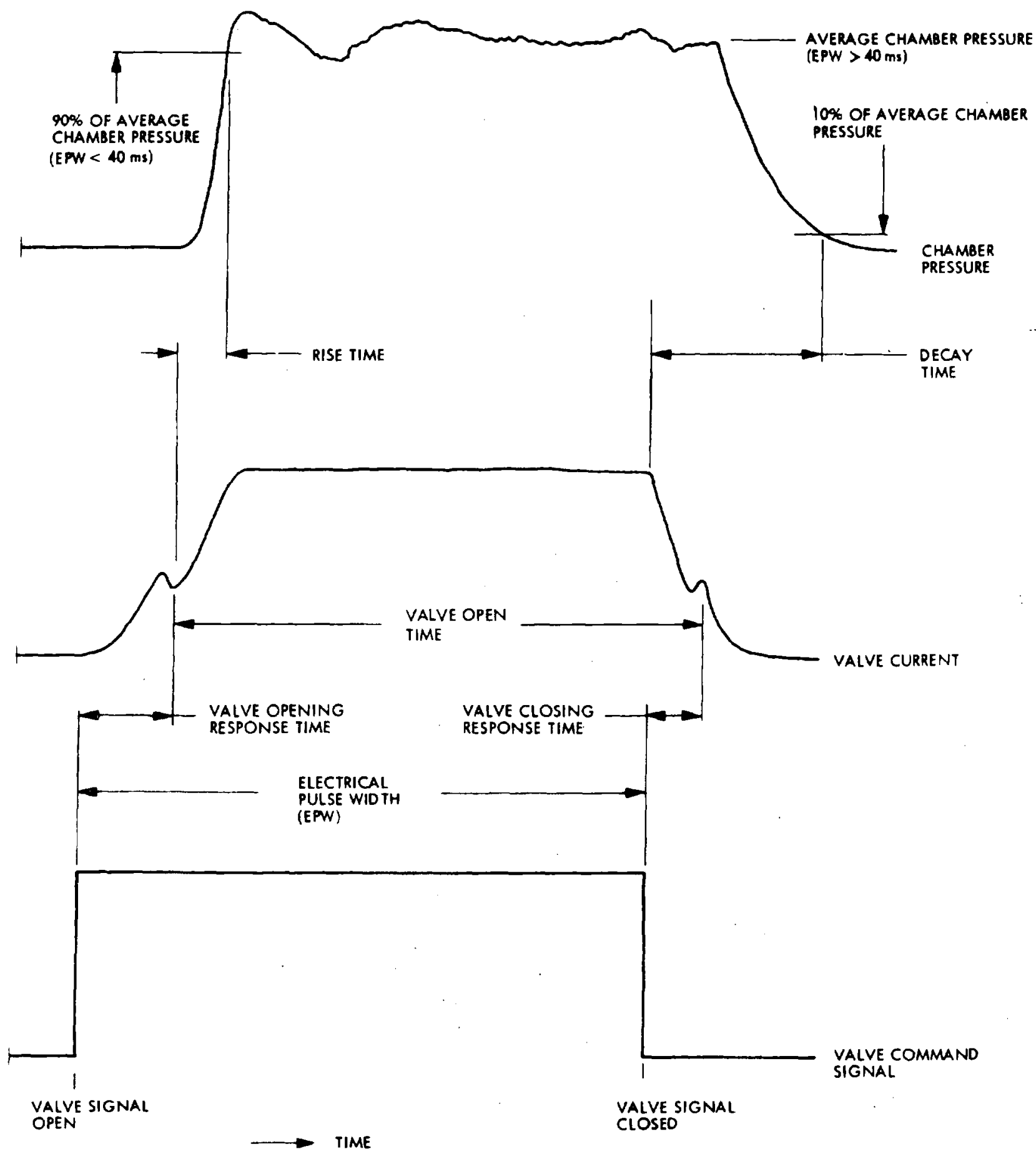

Figure 6-1. Thruster/Valve Response Definitions 
(1) The peak chamber pressure obtained for electrical pulse widths of less than $40 \mathrm{~ms}$, or

(2) The average chamber pressure, measured over an interval which excludes any thrust overshoot, for electrical pulse widths of greater than $40 \mathrm{~ms}$.

4.1.3.3 Valve Closing Respense Time. The valve closing response time is the interval which elapses between thruster valve closing signal and the attainment of a fully closed valve position.

i

4.1.3.4 Decay Time. Decay time is defined as the time which elapses between the attainment of a fully closed valve position and chamber pressure decay to $10 \%$ of the peak or average chamber pressure as defined in Paragraph 4.1.3.2.

4.1.3.5 Anc1llary Measurements. The measurements necessary to characterize the thruster operating and environmental conditions during thruster and valve response measurements are the same as those riven in Paragraph 4.1.2.5. These measurements should be recorded at the same time that response is determined.

\subsection{CORRECTIONS}

The following corrections are the only approved changes to be made to test data. Any other manipulation of measured data, excluding accountability for zero shift as discussed in Section $3: 2$, is discouraged.

\subsubsection{Vacuum Facility Back Pressure}

Measured thrust and 1mpulse values should be corrected to vacuum conditions by accounting for the finite back pressure which exists during engine firing in most space simulation facilities. This is usually done by adding the product of exit area and back pressure to the measured instantaneous thrust. However, this correction is only valid if flow. separation has not occurred within the nozzle due to expansion of the gases below a critical fraction of the back pressure. Several theories have been proposed which attempt to establish what this fraction of nozzle exit static pressure to test cell back pressure should be to preclude separation (References $6-5,6-6$, and 6-7). Since these results are functions of nozzle chamber pressure and nozzle expansion contour as well as exit static pressure and back pressure, it is recommended, based primarily on the conclusions drawn in Reference 6-8, that the vacuum facility back pressure not be allowed to exceed the static pressure at the nozzle exit. This recommendation is applicable to nozzles operating with throat Reynolds numbers of greater than approximately 2000. (Reference 6-9). For nozzles operating at or below this range, tests must be conducted to ensure that the nozzle is flowing 
full; this criterion may also become important for pulse operation where a significant portion of the impulse is produced at a low throat Reynolds number. For these low-density nozzle flows, back pressures below $10^{-2}$ $\mathrm{N} / \mathrm{m}^{2}\left(10^{-4}\right.$ torr) may be required to obtain accurate thrust and impulse data (Reference 6-10).

The following corrections apply to full-flowing nozzles only.

4.2.1.1 Steady State. The steady state thrust should be increased by an amount equal to $A_{e} P_{b}$, where $A_{e}$ is the nozzle exit area and $P_{b}$ is the back pressure as measured in a region near the thruster upstream of the nozzle exit and at a time corresponding to the measurement of the steady state thrust.

4.2.1.2 Pulse. Impulse bit measurements may be corrected for facility back pressure by adding a term equal to $A_{e} \cdot \bar{P}_{b} \cdot$ (EPW), where $A_{e}$ is the nozzle exit area, EPW is the electrical pulse width, and $\bar{P}_{b}=\left(P_{b i}+P_{b f}\right) / 2$, where $P_{b i}$ and $P_{D f}$ are the prepulse and postpulse facility back pressures as measured near the thruster upstream of the nozzle exit.

\subsubsection{Propellant Mass Flow}

Measured propellant mass flow or per-pulse propellant mass usage may be corrected for the density and viscosity differences which exist between the fluid used to calibrate the flow measuring device and the propellant. In addition, the mass of propellant measured may be corrected for the density differences which exist between the measurement device and the thruster inlet due to a measured temperature difference between these two points.

\subsubsection{Chamber Pressure}

Ideally, the chamber pressure tap will be located so as to yield a true chamber stagnation pressure measurement. However, due to the small size of some monopropellant thrusters, the taps are often unavoidably placed flush with the inside surface of the convergent portion of the nozzle. If the tap must be placed in this position, care should be taken to locate it downstream of the circular arc transition between the chamber cylindrical section and the convergent conical portion since boundary layer separation may occur in this region (Reference 6-11). See Figure 6-2. Assuming that the chamber pressure measurement has been taken at a point where the boundary layer has reattached to the wall, and further assuming that the pressure variation across the tap itself is small, the measured pressure can be corrected to a chamber stagnation pressure using the following relationship (Reference 6-12):

$$
\frac{P_{c m}}{P_{c}}=1-\left(\frac{A_{t}}{A_{m}}\right)^{2} \frac{\gamma}{2}\left(\frac{2}{\gamma+1}\right)^{\frac{\gamma+1}{\gamma-1}} f^{2}
$$




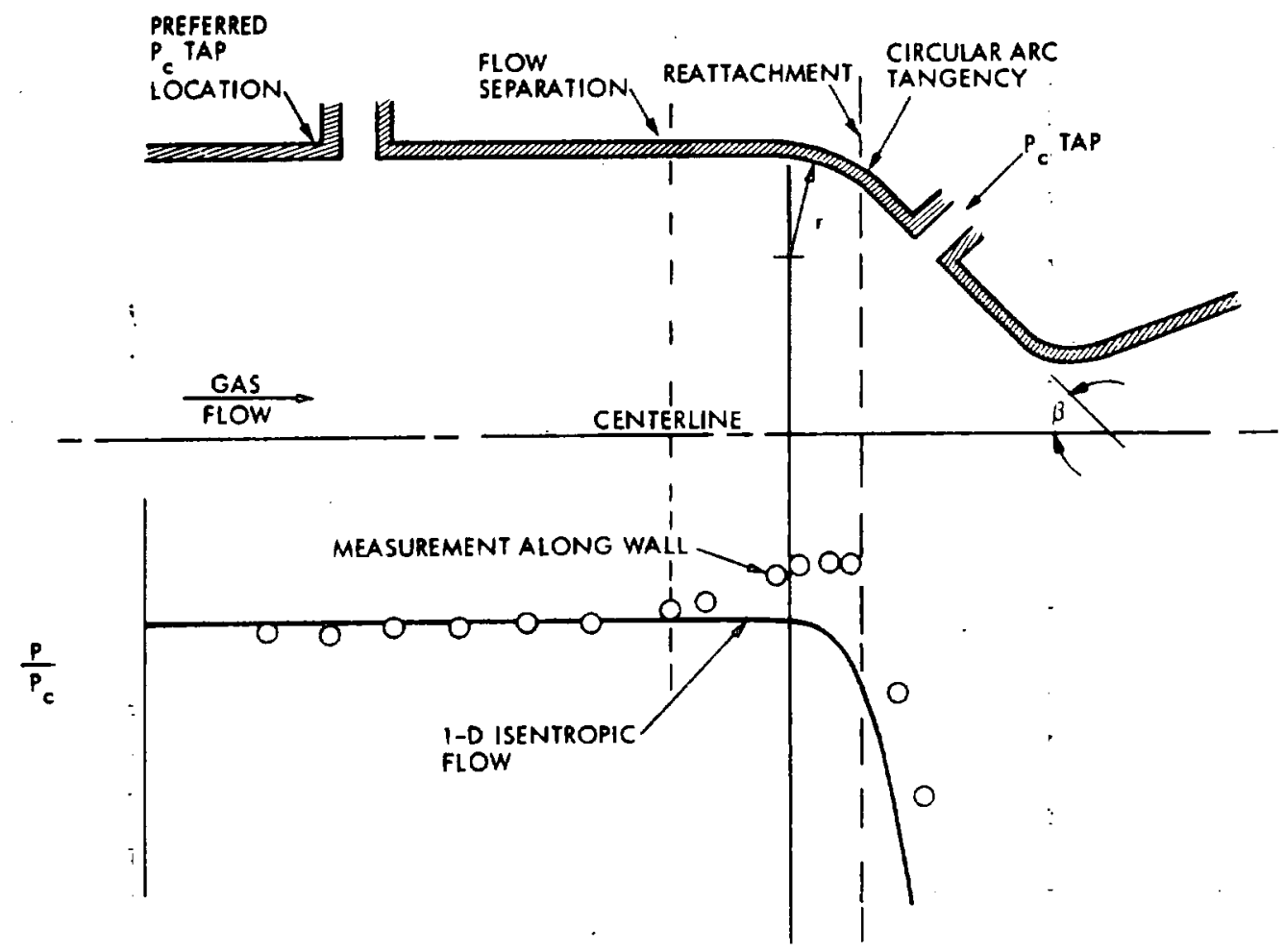

Figure 6-2. Chamber Pressure Tap Location

where $P_{c m}$ is the measured pressure at the tap, $P_{c}$ is the calculated chamber pressure, $A_{t}$ is the nozzle throat area, $A_{m}$ is the cross-sectional area at the convergent portion of the cone where the tap is located, $\gamma$ is the ratio of specific heats for the gas at chamber stagnation temperature, and $f=$ $1 / 2(1+\cos \beta)$ where $\beta$ is the half angle of the convergent section.

Measurements of thruster chamber pressure made with transducers which are referenced to the vacuum facility pressure may be modifled for this effect by subtracting the facility pressure from the measured chamber pressure. This correction is expected to be negligibly small if the conditions of Paragraph 4.2 .1 are met.

\subsubsection{Chamber Temperature}

The temperature as measured at the outer surface of the catalyst bed may have been correlated with measured internal gas temperatures at some point during engine development. This correlation may be used to convert from the external wall temperature measurement to an internal gas temperature, providing the thruster operating conditions and environment are similar to those for which the original correlation was formulated. 


\subsection{CALCULATED PARAMETERS}

The defining formulations to be used in the determination of thruster performance from test measurements are given in this section. Additional definitions are included in the glossary.

\subsubsection{Specific Impulse}

The fundamental parameter describing thruster performance is the thrust per unit mass flowrate or directed impulse per unit mass of propellant expended. This parameter is termed specific impulse and is to be.calculated from corrected engine measurements as follows.

4.3.1.1 Steady State. Steady state specific impulse $\left(I_{S P}\right)$ is defined as :

$$
I_{S P}=\frac{F}{\dot{m}}
$$

where $F$ is the steady state thrust and $\dot{m}$ is the steady state propellant mass flow.

4.3.1.2 Pulse. Specific impulse for a single pulse ( SPP $_{\text {}}$ ) is defined as:

$$
I_{S P p}=\frac{I_{b i t}}{m_{p}}
$$

where $I_{b i t}$ is the measured impulse delivered during the pulse (Paragraph 4.1.2.1) and $m_{p}$ is the total mass of propellant expended during the pulse.

4.3.1.3 Pulse Train. For a series or train of pulses, the specific

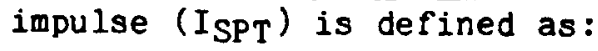

$$
I_{S P T}=\frac{\sum_{i=1}^{N}\left(I_{b i t}\right)_{i}}{m_{T}}
$$

where $\mathrm{N}$ is the number of pulses in the train, ( $\left.I_{\text {bit }}\right)_{j}$ is the impulse bit produced during $i$, and $\mathrm{m}_{\mathrm{T}}$ is the total mass of propellant expended during the train. 


\subsubsection{Time to Centrold}

A second fundamental performance parameter for pulse operation is the time from some reference time to the point at which the total impulse produced may be assumed to act. This is called the time to centrold (or centroid) and may be defined as follows.

4.3.2.1 Pulse. The time to centroid (C) for a single pulse may be obtained by dividing the time integral of the product of chamber pressure and time by the time integral of chamber pressure:

$$
c=\frac{\int_{t_{0}}^{t_{f}} P_{c} d t}{\int_{t_{0}}^{t_{f}} P_{c} d t}
$$

where $t_{0}$ is the time of valve signal open, $t_{f}$ is the point at which the integral is terminated (see Paragraph 4.1.2.3), $P_{C}$ is the measured, time-varying chamber pressure, and $t$ is the time, measured from $t_{0}$, at which the chamber pressure measurement is taken.

4.3.2.2 Pulse Train. The time to centroid for a train of pulses $\left(C_{T}\right)$ may be defined as:

$$
c_{T}=\frac{\sum_{i=1}^{N}\left[\int_{ \pm=0}^{t_{f}} P_{c t} d t\right]_{i}^{N}\left[\int_{1=1}^{t_{f}} P_{c t} d t\right]}{\left.\sum_{t_{0}}\right]_{i}}
$$

where the summation is performed over the number of pulses $N$ in the train, $t_{0}$ is the time of valve signal on for the 1 th pulse, $t_{f}$ is the time at which the integration over the 1 th pulse is terminated, $P_{c}$ is the time-varying chamber pressure, and $t$ is the time as measured from valve signal open of the first pulse in the train. 


\subsubsection{Throat Area}

Throat area may change by a significant percentage due to thermal expansion during firing. In some cases the throat static pressure may also have an effect on the throat area.

As the throat material is heated by the exhaust gases, the throat area first decreases (unless pressure stress dominates) as the hot region near the throat expands under the constraint of the still cold outer material, and then increases as the entire wall is heated (References $6-13$ and $6-14$ ). Approximate relationships are shown in Figure 6-3.

4.3.3.1 Steady State. Steady state throat area may be calculated using the following expression:

$$
A_{t}=A_{t r}\left[1+\frac{2 P}{E}(1+v)+2 a\left(T_{t}-T_{r}\right)\right]
$$

where $A_{t}$ is the hot throat area at temperature $T_{t}, A_{t r}$ is the throat area as measured at temperature $T_{r}, P_{t}$ is the static pressure at the throat, and $E, v$, and a are the modulus of elasticity, Poisson's ratio, and coefficient of linear thermal expansion, respectively, of the nozzle materlal. In most cases involving monopropellant thrusters, the throat static pressure contribution can be shown to produce a negligible area change and can thus be ignored.

4.3.3.2 Puise. Due to the thermal transients within the nozzle material, the throat area may vary in a manner which is not amenable to simplified analysis. It is thus recommended that the steady state throat area formulation given in Paragraph 4.3 .3 .1 also be used to evaluate the throat area for a pulse, where the temperature $T_{t}$ is taken as being the prepulse throat temperature and the throat static pressure term is ignored.

\subsubsection{Characteristic Velocity}

The characteristic exhaust velocity is an indication of the effectiveness of reactions taking place within the combustion chamber. It may be calculated as follows.

4.3.4.1 Steady State. The steady state characteristic velocity (c*) is defined as:

$$
c=\frac{A_{t} B_{c}^{P} c}{\dot{m}}
$$



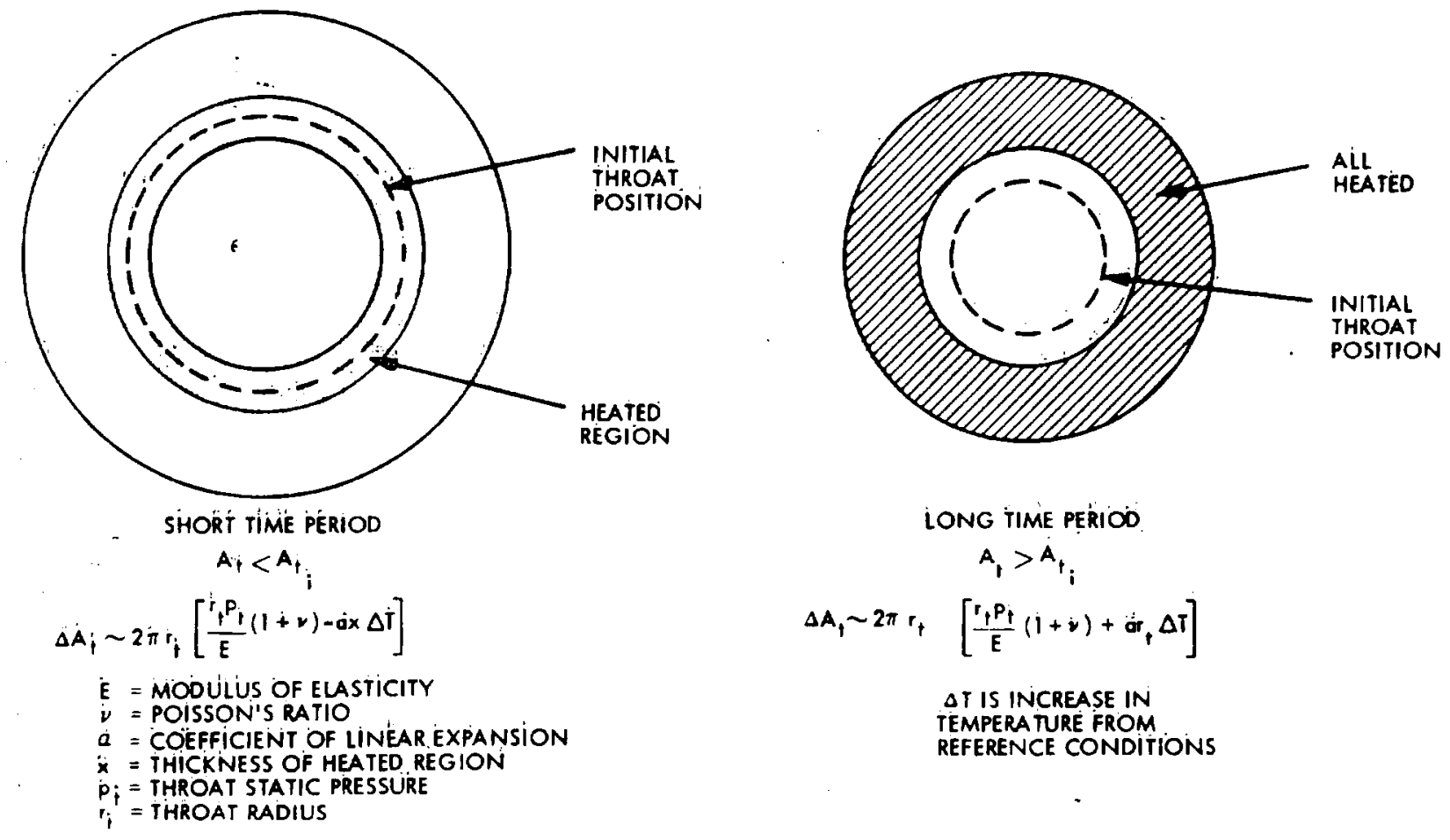

$\triangle T$ IS INCREASE IN

TEMPERATURE FROM

REFERENCE CONDITIOONS

\section{Figure 6-3. Throat Area Variation with Temperature (Reference 6-13)}

where $A_{t}$ is the throat area, $B_{c}$ is the proportionality constant in Newton's second law, $P_{c}$ is the chamber pressure, and $m$ is the mass flowrate.

4.3.4.2 Pulse Mode. The characteristic velocity for'a single pulse $(\underset{p}{(0)})$ is defined as:

$$
c_{p}=\frac{A_{t^{g}}}{\dot{m}_{p}} \int_{t_{0}}^{t_{f}} P_{c} d t
$$

Where $A_{t}$ is calculated as described in Paragraph $4.3 .3 .2, B_{c}$ is the proportionality constant in Newton's second law, $\dot{m}_{p}$ is the mass of propeliant expended during the pulse, $t_{0}$ is the time of valve signal oper, $t_{f}$ is the time at which the integration is terminated, and $P_{c}$ is the time-varying chamber pressure. 


\subsubsection{Thrust Coefficient}

The thrust coefficient is an indicator of nozzle performance and is often used as a correlation parameter between thrust and chamber pressure. It may be calculated as follows.

4.3.5.1 Steady State. The steady state thrust coefficient $\left(C_{f}\right)$ is defined as:

$$
C_{f}=\frac{F}{A_{t} P_{c}}
$$

where $F$ is the measured steady state thrust, $A_{t}$ is the calculated steady state throat area, and $P_{c}$ is the measured steady state chamber pressure. 4.3.5.2 Pulse. A thrust coefficient for a single pulse $\left(C_{f p}\right)$ may
be defined as:

$$
C_{f p}=\frac{I_{b i t}}{A_{t} \int_{t_{0}}^{t_{f}} P_{c} d t}
$$

where $I_{b i t}$ is the measured impulse bit, $A_{t}$ is the throat area, $t_{0}$ is the time of valve signal open, $t_{f}$ is the time at which the integral is terminated, and $P_{c}$ is the measured time-varying chamber pressure.

\subsubsection{Percent Ammonia Dissociation}

The performance of a monopropellant hydrazine reactor may be determined by examining the characteristic exhaust velocity, $c$. However, there is another single parameter unique to monopropellant hydrazine thrusters which is sufficient to completely specify reactor performance. This parameter pertains to the amount of armonia remaining in the decomposition products as the gases leave the catalyst bed and is termed percent ammonia dissociation.

The overall decomposition of hydrazine within a catalyst bed may be thought of as occurring in a two-step process. First, the hydrazine is decomposed exothermically according to: 


$$
\mathrm{N}_{2} \mathrm{H}_{4}-\frac{4}{3} \mathrm{NH}_{3}+\frac{1}{3} \mathrm{~N}_{2}
$$

which is followed by the slower, endothermic, catalytic dissoctation of the ammonia:

$$
\mathrm{NH}_{3}-\frac{1}{2} \mathrm{~N}_{2}+\frac{3}{2} \mathrm{H}_{2}
$$

While these two relations are not intended to represent the details of the overall decomposition mechanism, which is in fact much more complex, they are useful for relating the intitial and final chemical specles (Reference 6-15). Combining the two equations yields:

$$
\mathrm{N}_{2} \mathrm{H}_{4}-\frac{4}{3}(1-X) \mathrm{NH}_{3}+\frac{1}{3}(1+2 \mathrm{X}) \mathrm{N}_{2}+2 \mathrm{X} \mathrm{H} \mathrm{H}_{2}
$$

where $X$ is the percent of the originally formed ammonia which has dissociated into hydrogen and nitrogen. The reactions may be assumed to cease after the gases have left the catalyst bed, thus freezing the chemical composition of the gases and fixing the performance of the reactor.

If the mole fractions of the ammonia, hydrogen, and nitrogen are determined by extracting gas samples as described in Section $v$, the percent ammonia dissociation may readily be calculated from the above relation. In those instances where nitrogen has been used as a pressurant in contact with the hydrazine, the nitrogen-saturated propellant will yleld a larger nitrogen mole fraction in the decomposition products than would otherwise be expected. The recomended procedure is to determine percent ammonia dissociation from the ratio of the mole fraction of hydrogen $\left(y_{b}\right)$ to the mole fraction of ammonia $\left(y_{a}\right)$ :

$$
x=\frac{2\left(\frac{y_{h}}{y_{a}}\right)}{3+2\left(\frac{y_{h}}{y_{a}}\right)}
$$

\subsection{SUGGESTED REPORTING REQUIREMENTS}

5.1 REPORT OUTLINE

The reporting requirements outlined here represent the information which would ideally be included in a report on thruster performance. The 
intent is to provide a performance characterization of a given monopropellant engine and to include correlations for reconstruction of thrust or impulse from chamber pressure measurements. While it is suggested that manufacturers and users of monopropellant thrusters report performance according to the following outline, it is recognized that some programs may not be willing to pay for this level of documentation, while other projects will require a far more detalled reporting of performance than outlined here.

\section{Engine Hardware Description}

Schematic Diagram

Component Description, Parameters, Photographs, Drawings

Thorough Narrative Description

II. Test Facility Description

Overall System Schematic Diagrams, Drawings

Vacuum Facility Schematic Diagrams, Drawings

Test Stand Diagrans, Drawings

Instrumentation Schematic Diagrams

Instrumentation List

Thorough Narrative Description

III. Measurement Uncertainties Analysis

IV. Test Program Description

V. Data Reduction Techniques

Deviations From Recommended Practices

Data Corrections Applied

VI. Rocket Engine Performance Test Data

Steady State

Thrust vs Propellant Inlet Pressure

Vacuum Specific Impulse vs Propellant. Inlet Pressure 
Pulse

Impulse Bit vs Electrical Pulse Width, Propellant Inlet Pressure, Initial Catalyst Bed ${ }^{1}$ Temperature

Vacuum Specific Impulse vs Electrical Pulse Width, Propellant Inlet Pressure, Initial Catalyst Bed Temperature

Centroid vs Electrical Pulse Width, Propellant Inlet Pressure, Initial Catalyst Bed Temperature

Pulse Train

Impulse vs Electrical Pulse Width, Percent Duty Cycle, Propellant Inlet Pressure, Initial

Catalyst Bed Temperature

Vacuum Specific Impulse vs Electrical Pulse Width, Percent Duty Cycle, Propellant Inlet Pressure, Initial Catalyst Bed Temperature

Centroid vs Electrical Pulse Width, :Train Length, Percent Duty Cycle, Propellant Inlet Pressure, Initial Catalyst Bed Temperature

Pulse or Steady State Performance vs Accumulated Time on Thruster

VII. Performance Correlations

Steady State Thrust Coefficient vs Chamber Pressure

Pulse Thrust Coefficient vs Chamber Pressure Integral, Initial Catalyst Bed Temperature :

VIII. Response Parameters

IX. Other Terms As Specified in Test Program Description

5.2 ADDITIONAL REQUIREMENTS

The following additional notes are applicable to engine performance:

(1) Normalization. Normailized data shail not be reported.

(2) Standard Inlet Conditions. Correction of test data to standard inlet conditions shall not be performed. It is thus required that test conditions be carefuliy established prior to initiating a run sequence. 
(3) Pulse Mode Performance. Enough information should be shown on each plot of pulse mode performance to completely establish the run conditions. This information should include, at a minimum, the electrical pulse width, initial catalyst bed temperature, propellant inlet pressure, and propellant inlet temperature.

(4) Units. The recommended units for reporting thruster performance are SI units optionally followed by English engineering units in parentheses.

\subsection{GLOSSARY}

This glossary contains the terminology and nomenclature as introduced and used in this section. Heavy reliance has been placed upon the relevant Chemical Propulsion Information Agency work in monopropellant hydrazine technology (Reference 6-16) as well as other similar publications (References $6-17$ and $6-18$ ). In addition to the nomenclature introduced thus far, additional performance terminology has been extracted from Reference 6-16 and incorporated here for completeness.

\subsection{ASSIGNMENT OF SYMBOLS}

Another document (Reference 6-17) has outlined policies for the assigning of symbols to concepts. Some of the more relevant of these recommendations may be summarized as follows:

(1) Subscriots. The preferred order for subscripts is to indicate first the substance or function and then station, when double subscripts are used.

(2) Current vs Improved Symbols. Letter symbols already adopted in other American Standards and symbols generally used in the literature on rockets shall be retained wherever practicable. Preference will be given generally to the symbol of widest usage among several possible symbols. In specific cases where an improved symbol is indicated, it should resemble the symbol currently used in rocket propulsion. Improvement will consist of, in order of importance, (a) a symbol or concept consistent with usage in other fields as set forth in existing standards, (b) a technically more accurate concept, and (c) a simpler symbol.

(3) Fundamental vs Hardware Terminology. Principal symbols will be assigned to basic concepts only; relation to configuration or parts should be by subscript.

(4) Specific Definition of Concepts. A basic concept may have variations in definition. Therefore, only one primary symbol (and its alternates) will be identified with any one basic concept. Variations in definition of 
a concept may arise from (a) arbitrarily selected values used in the definition, or (b) differences in terminology describing the concept. These variations should be resolved by use of appropriate subscripts where necessary.

(5) Upper Case vs Lower Case. For primary symbols, lower case letters should be used for total quantities to the extent consistent with conventional employment in related fields and standards. For subscripts lower case usage is to be preferred (upper case should be employed only in established symbols or to avoid confusion).

\section{$6.2 \quad$ MODES OF OPERATION}

In addition to the above, the monopropellant community must often distinguish between different modes of engine operation. The following subscripts are suggested for delineating these operations:

Operating Mode

Steady state

Single pulse

Train of puls.es

Single pulse, rotational

Train of pulses, rotational

\section{Subscript}

none

$p$

$\mathrm{T}$

$\mathrm{R}$

RT

(1)

T $\quad$ '

\section{$6.3 \quad$ STATION}

The following subscripts are suggested for delineation among measurements made at various locations of a monopropellant rocket engine:

\section{Axial Location}

Inlet to thruster valve (feed)

Downstream of valve, upstream of injector exit (injector)

Downstream of injector, upstream of catalyst bed, within chamber

Downstream of catalyst bed at entrance to nozzle, within chamber

At nozzle throat

At nozzle exit

\section{Subscript}

f

i

$\mathrm{cu}$

c

$t$

e 


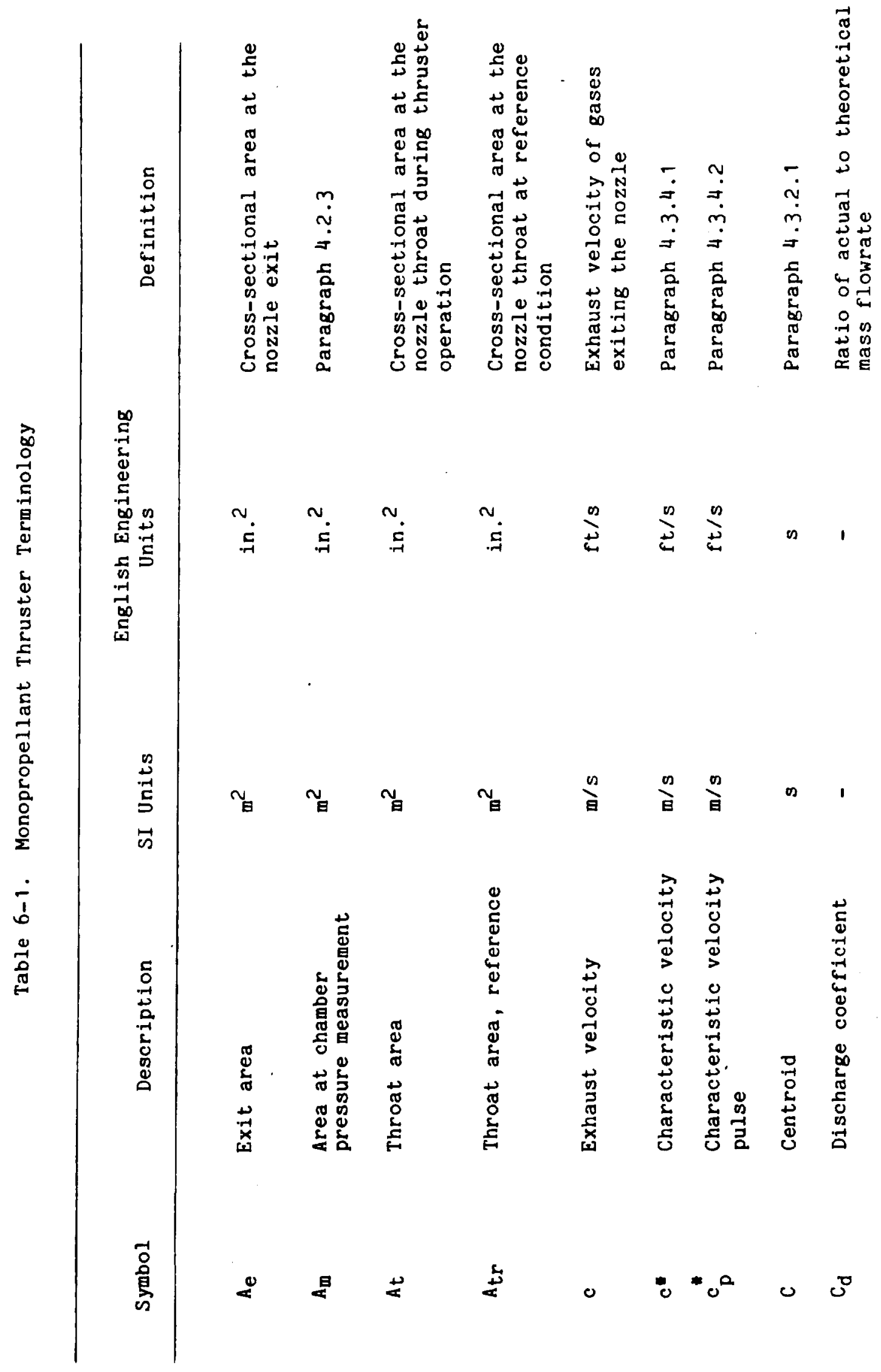




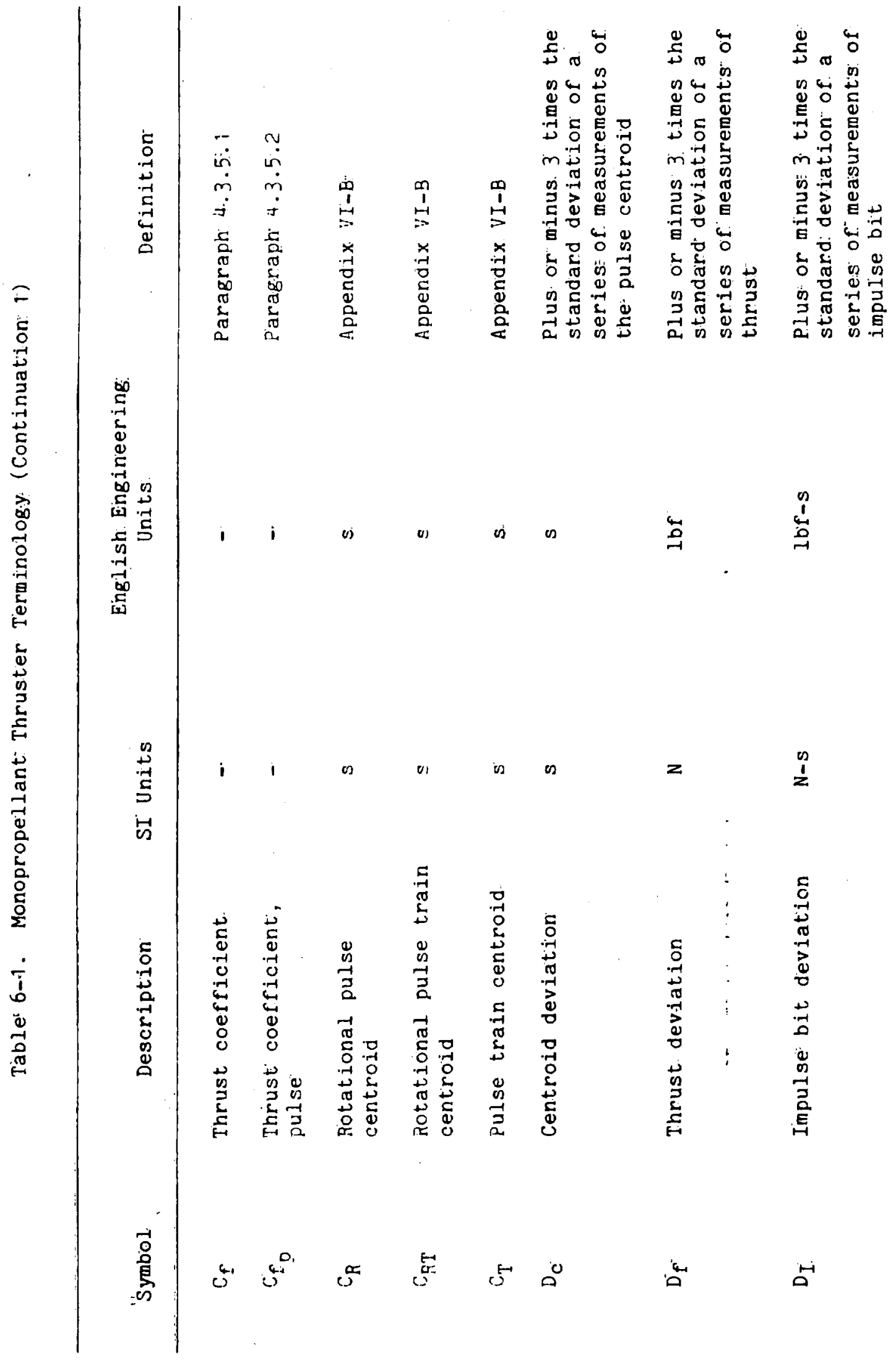




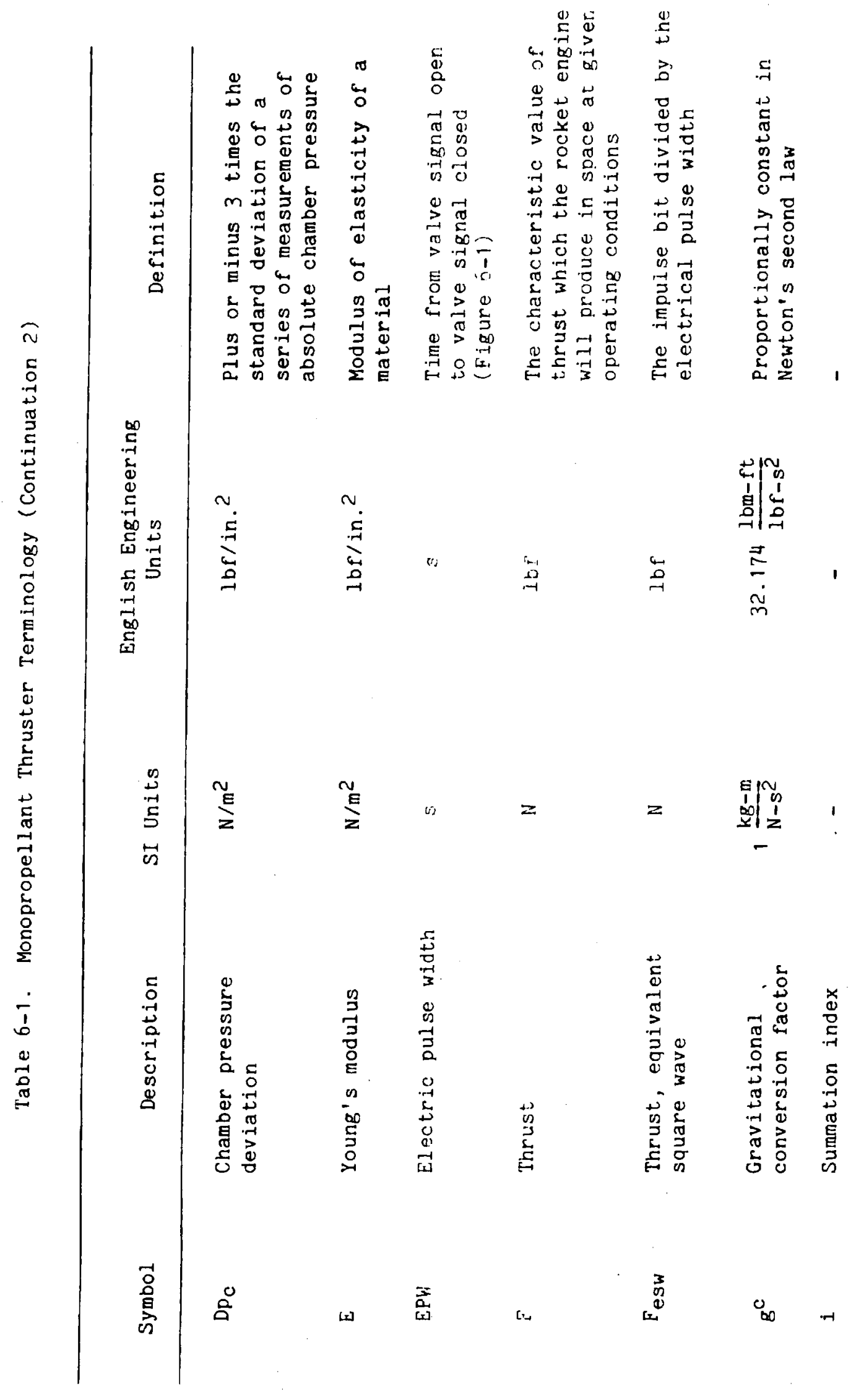




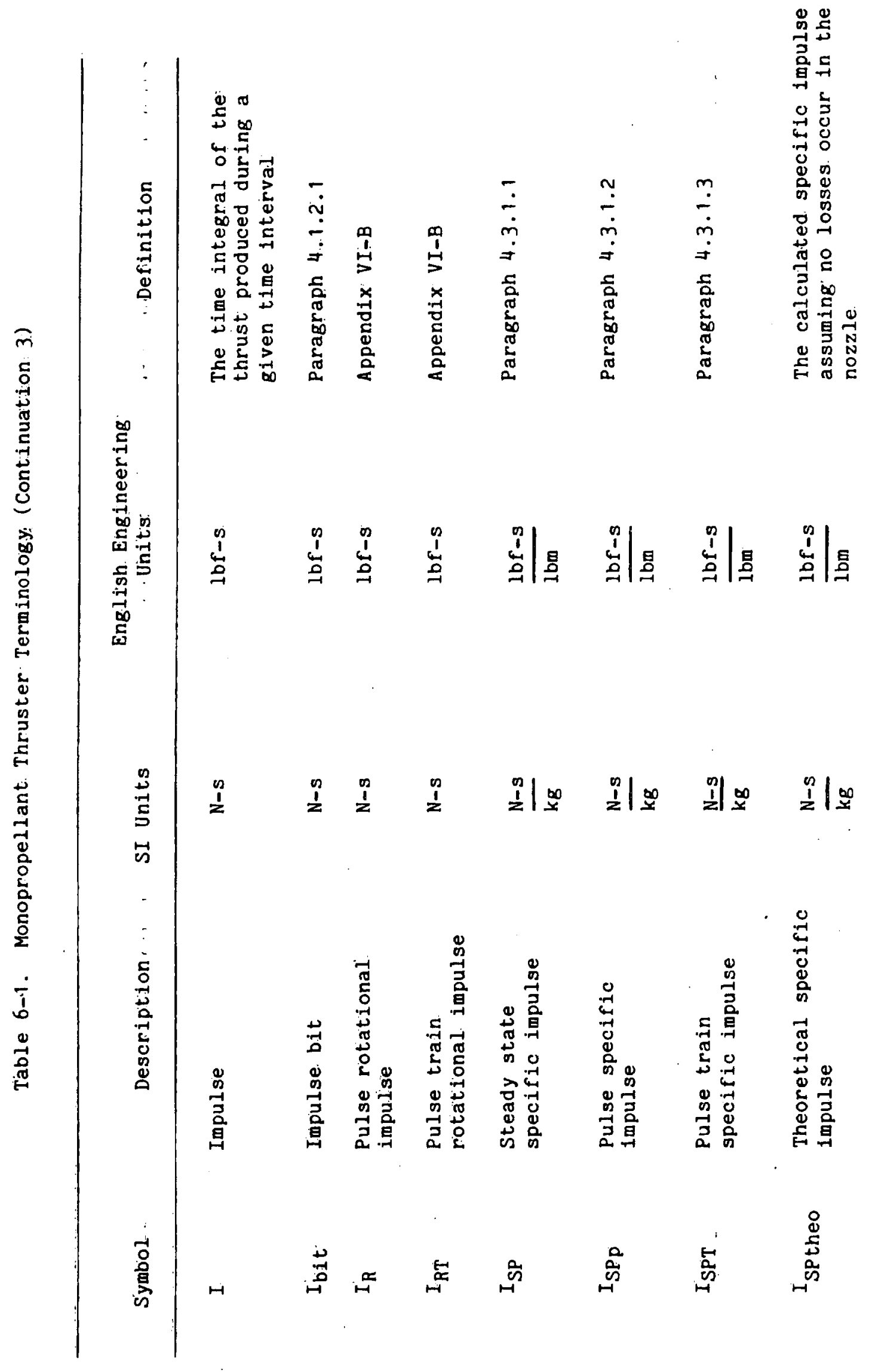




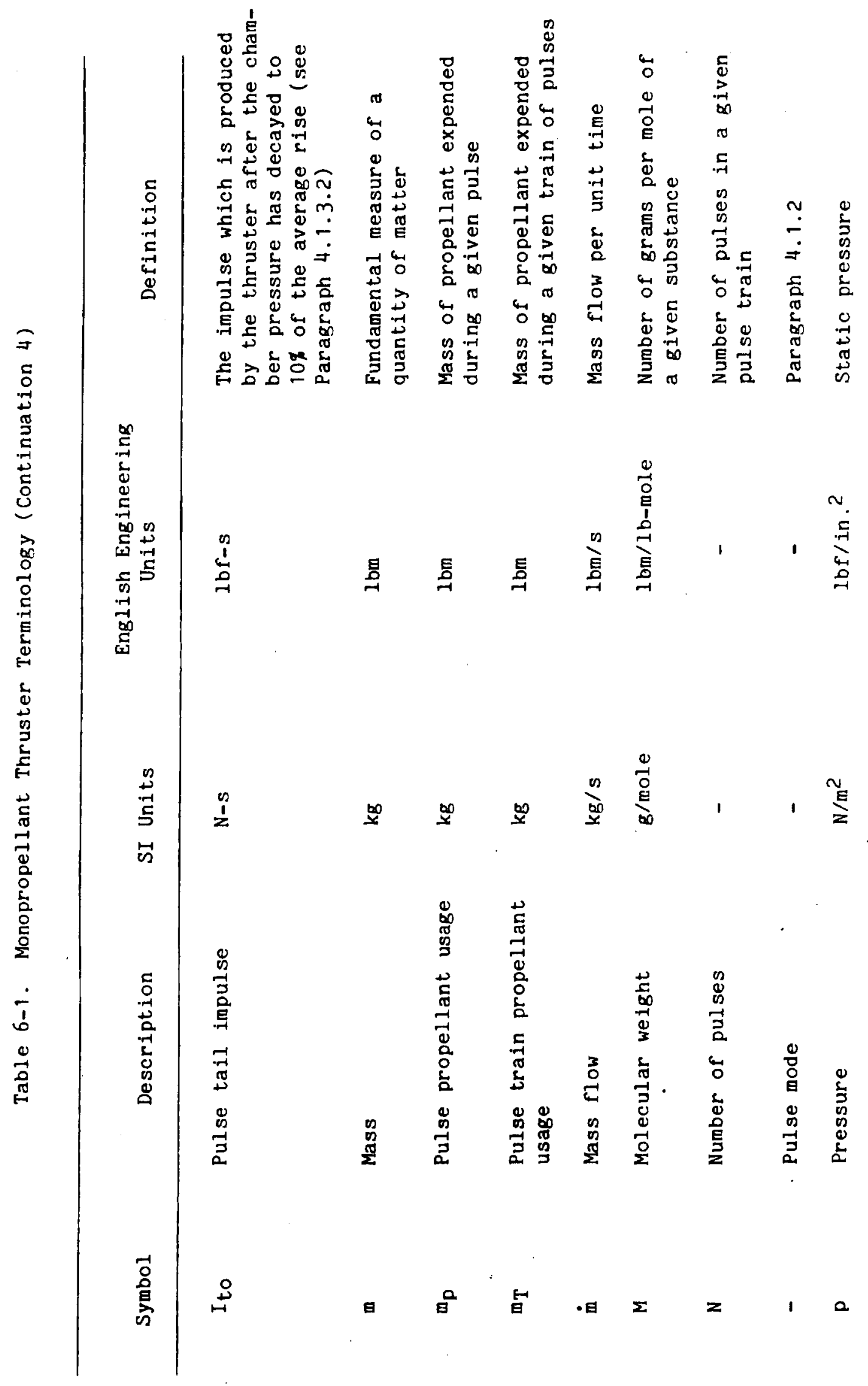




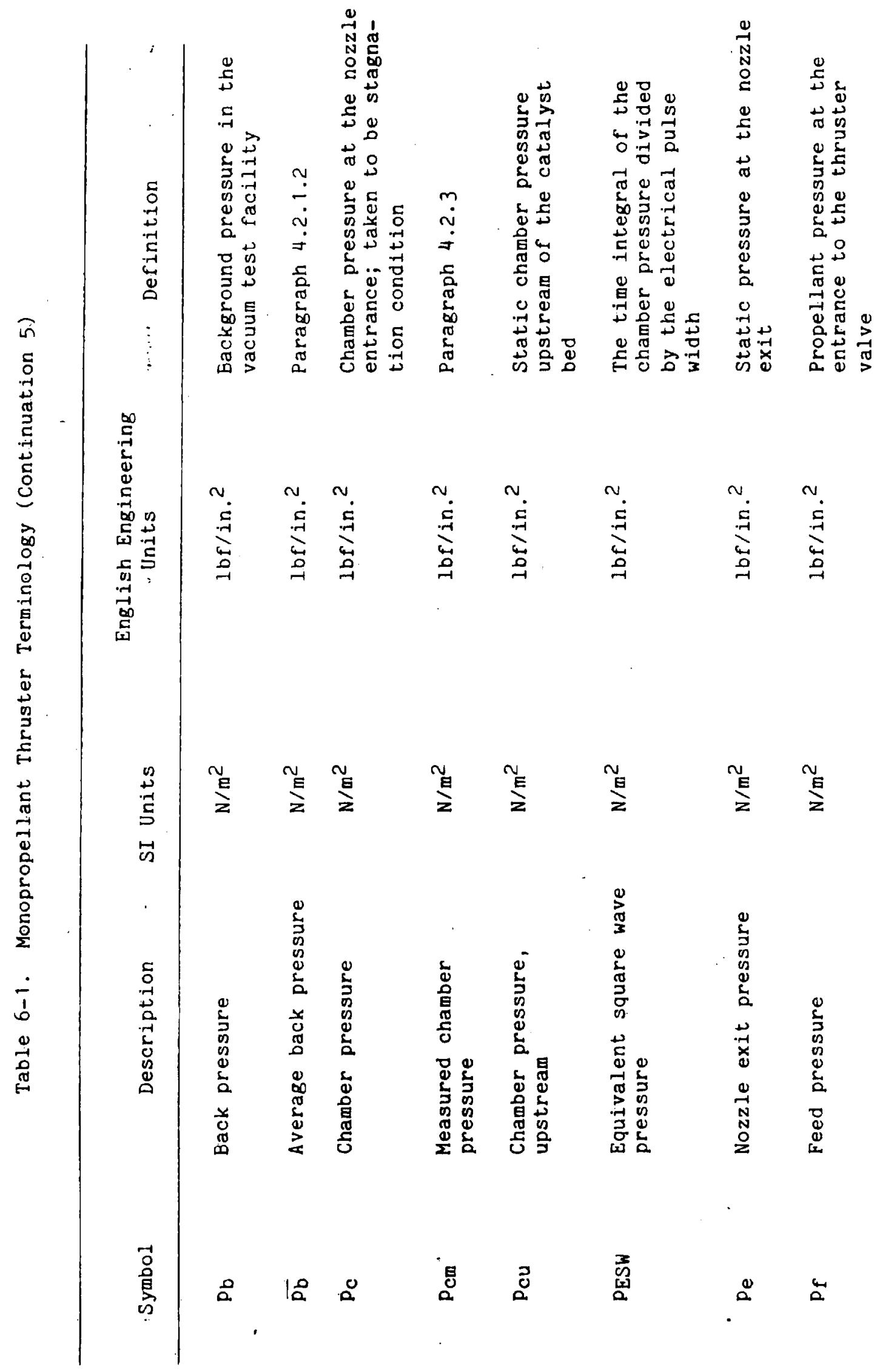




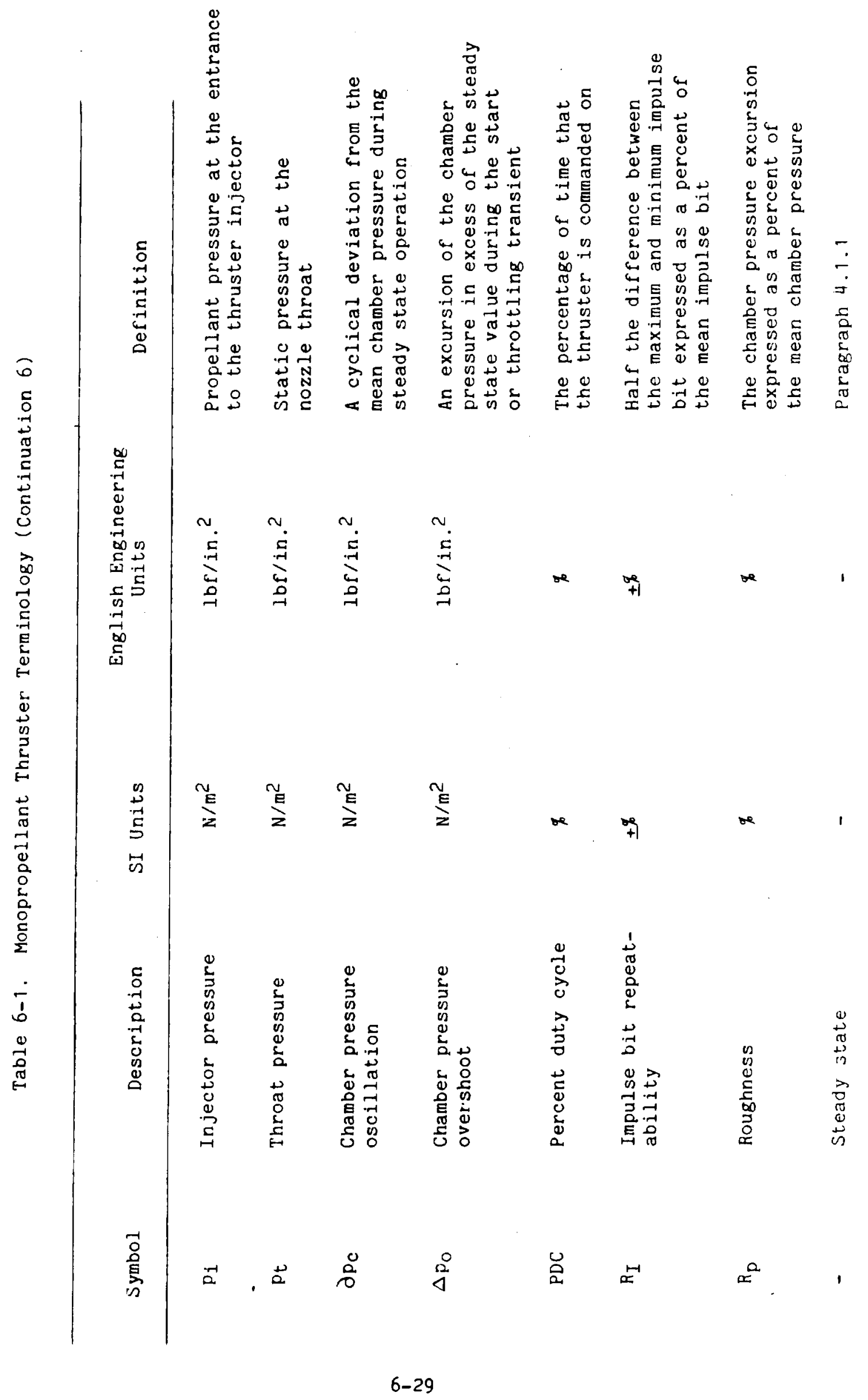




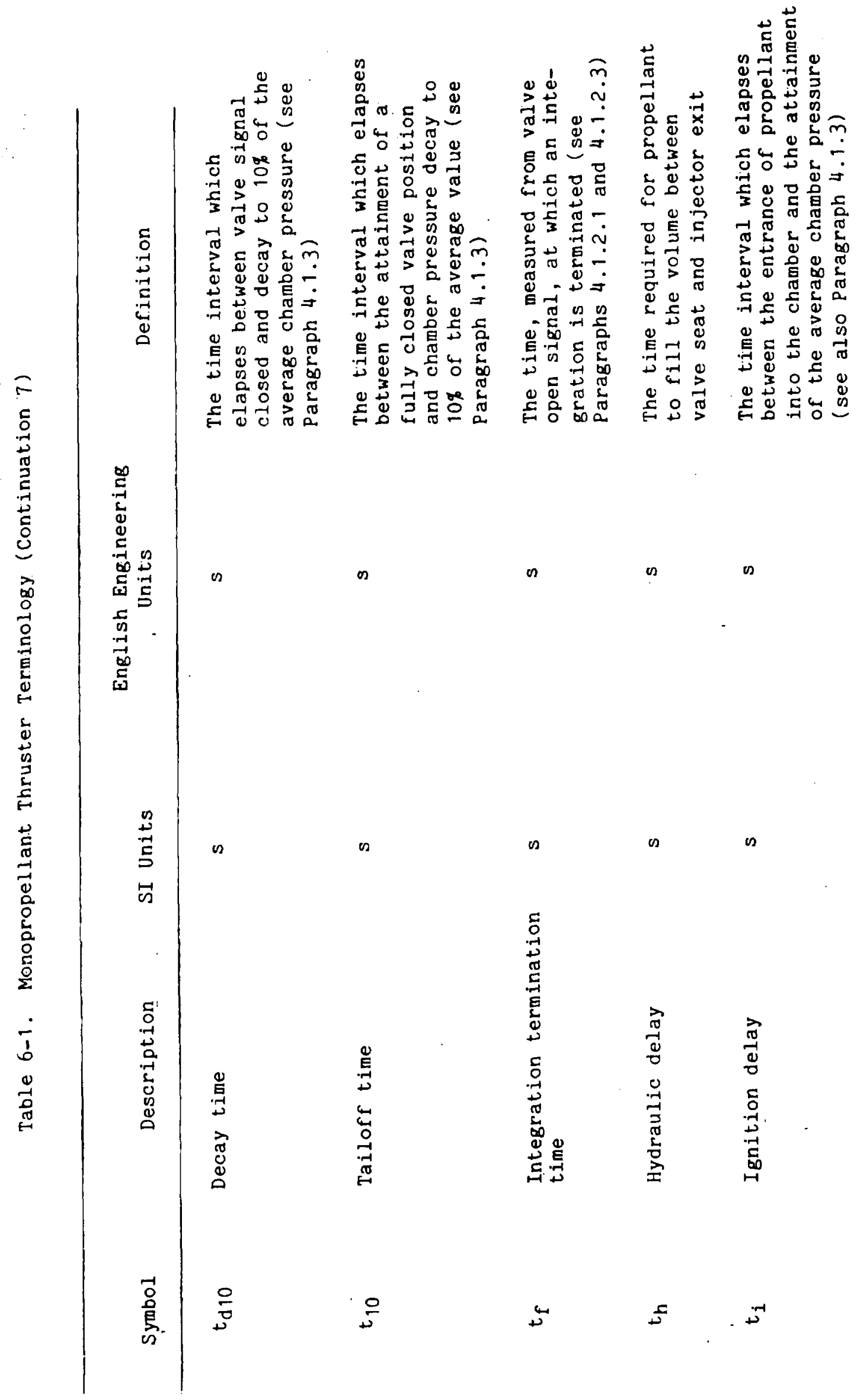




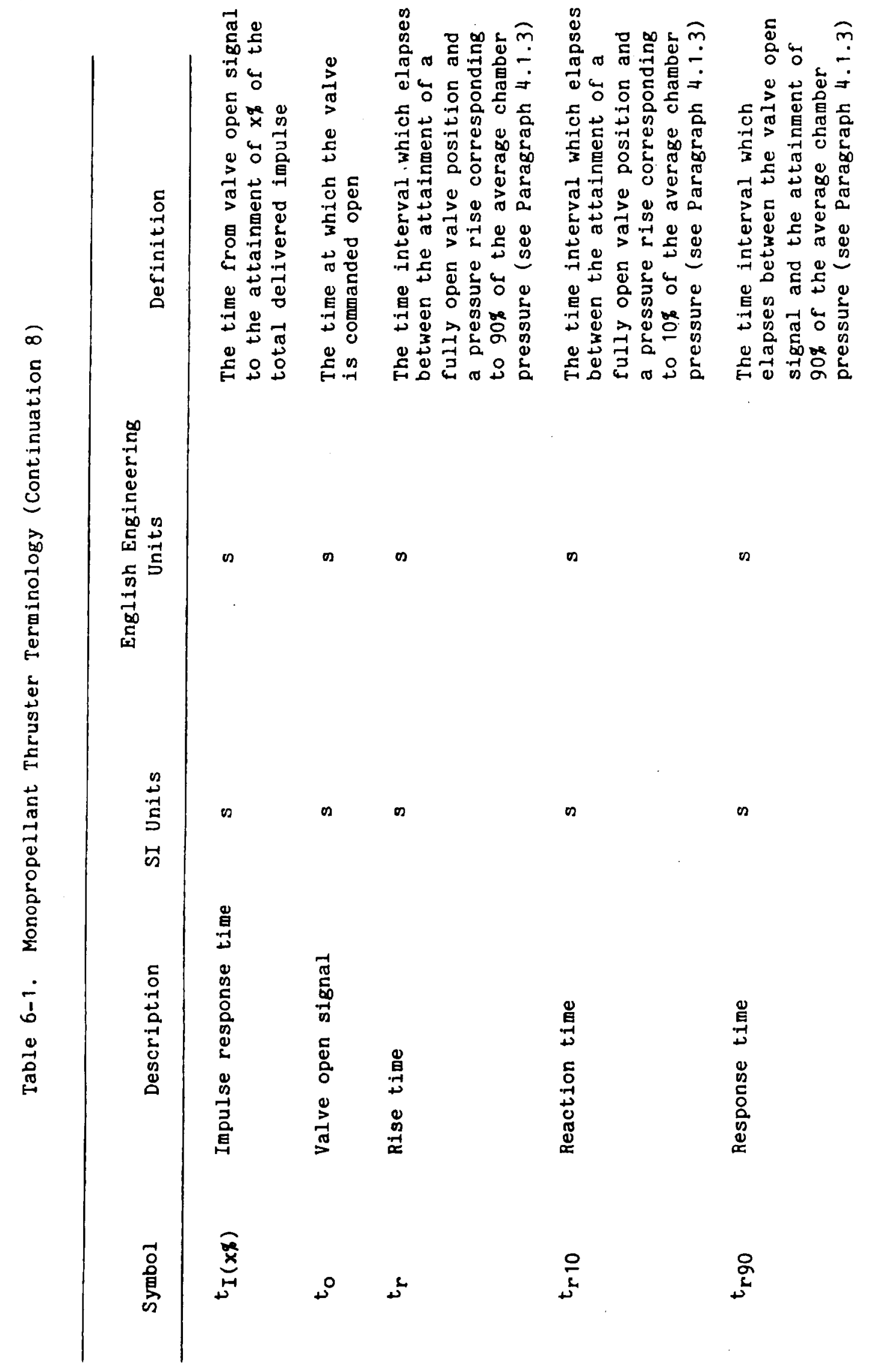




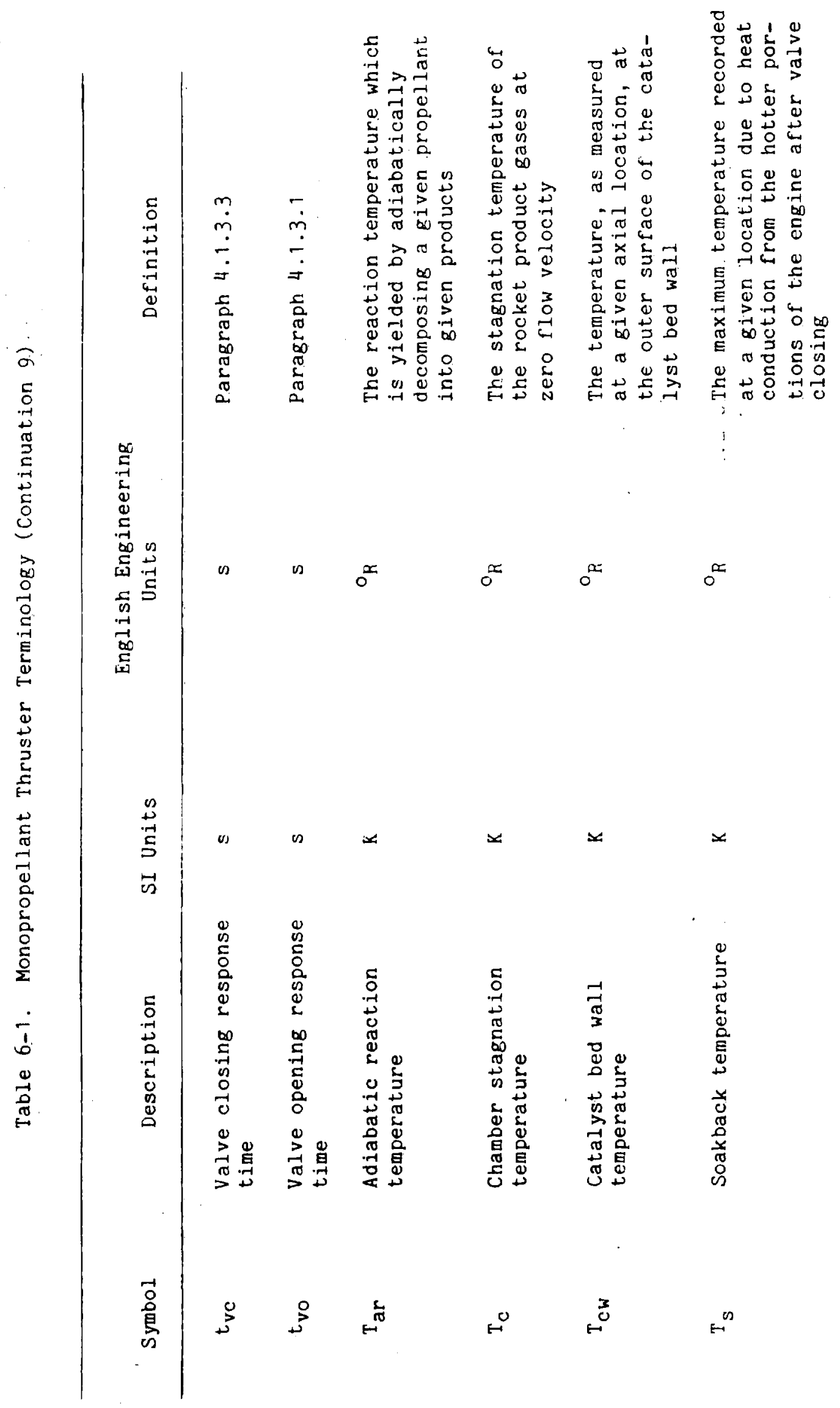




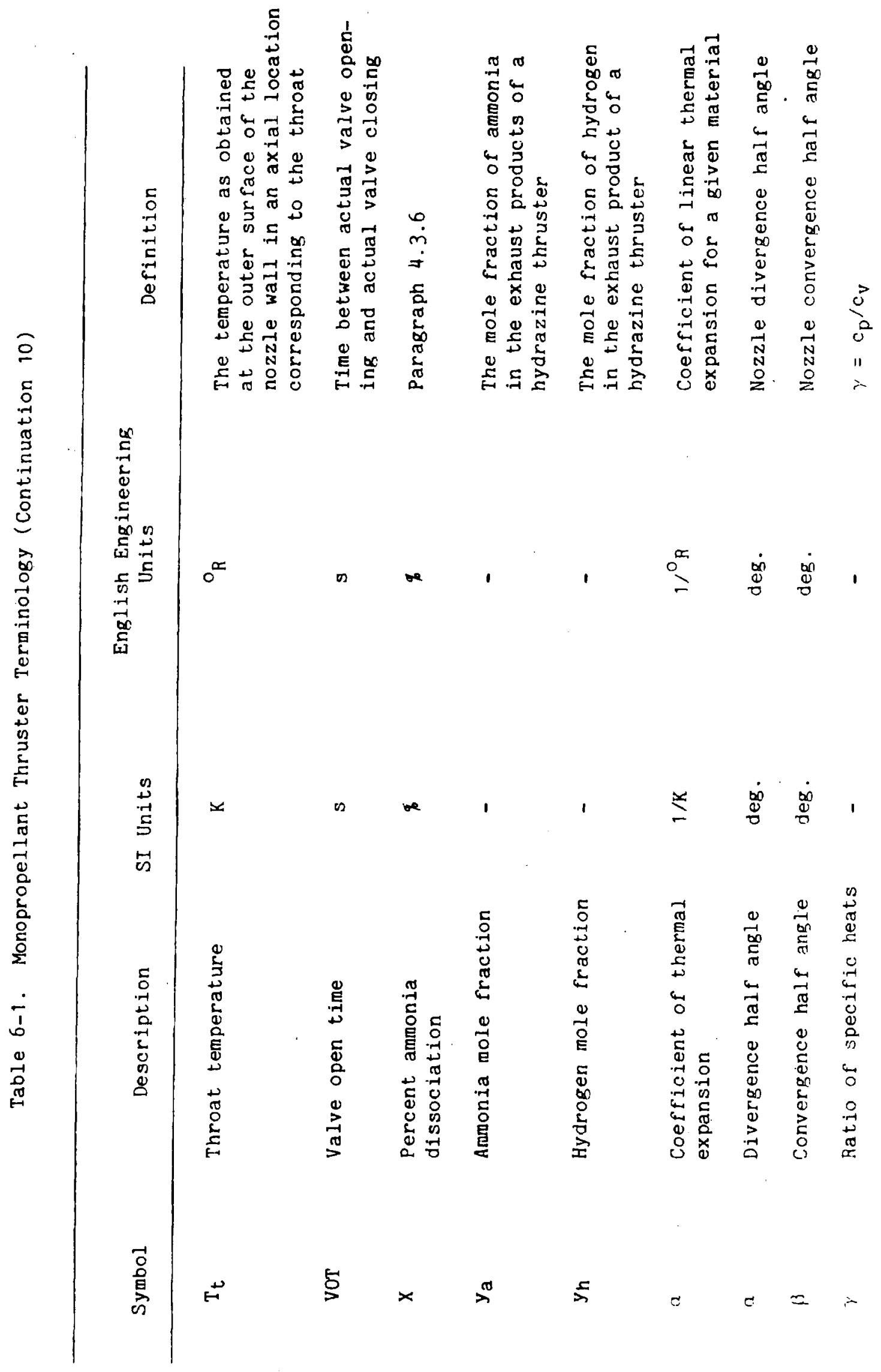




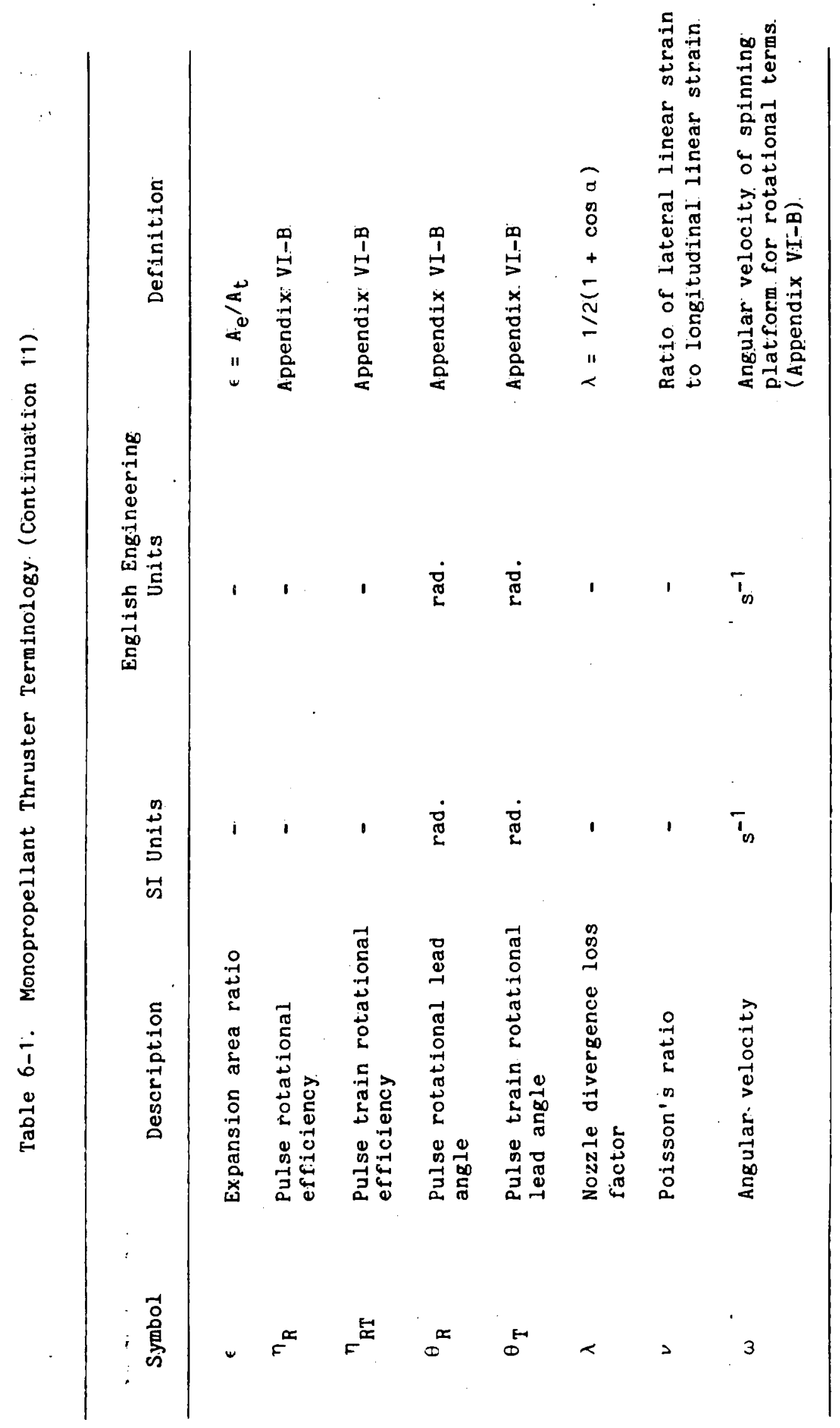




\subsection{REFERENCES}

6-1. Gardenshire, L. W., "Selecting Sample Rates," ISA Journal, pp. 59-64, April 1964 .

6-2. Conte, S. D., and de Boor, C., Elementary Numerical Analysis, McGraw-Hill Book Company, New York, 1972.

6-3. Hamming, R. W., Numerical Methods for Scientists and Engineers, MeGraw-Hill Book Company, 1973.

6-4. Mechtly, E. A., The International System of Units, Physical Constants and Conversion Factors, NASA SP-7012, 1969.

6-5. Green, L., "Flow Separation in Rocket Nozzles," ARS Journal, Vol. 23, pp. 34-35, 1953.

6-6. Page, R. H., "Flow Separation in Nozzles," Journal of the Aerospace Sciences, Vol. 29, pp. 110-111, January 1962.

6-7. Roscheke, E. J., and Massier, P. F., "Flow Separation in a Contour Nozzle," ARS Journal, pp. 1612-1613, October 1962.

6-8. Garrett, J. W., Simmons, M., and Gobbell, W. C., Exit Nozzle Flow Separation as Influenced by Nozzle Geometry. Fuel-oxidizer Ratio. and Pressure Level, AEDC-TR-67-122, Arnold Engineering Development Center, Tennessee, July 1967.

6-9. Rothe, D. E., Experimental Study of Viscous Low-Density Nozzle Flows, CAL Report AI-2590-A-2, Cornell Aeronautical Laboratory, June 1970 .

6-10. Rae, W. J., Final Report on a Study of Low-Density Nozzle Flows With Application to Microthrust Rockets, CAL Report AI-2590-A-1, Cornell Aeronautical Laboratory, December 1969.

6-11. Back, L. H., Massier, P.: F., and Cuffel, R. F., "Flow and Heat Transfer Measurements in Subsonic Air Flow Through a Contraction Section," Int. Journal of Heat and Mass 'Transfer, Vol. 12, pp. 1-13, 1969 .

6-12. Back, L. H., Cuffel, R. F., and Massier, P. F., "Influence of Contraction Section Shape and Inlet Flow Direction on Supersonic Nozzle Flow Performance," Journal of Spacecraft and Rockets, Vol. 9, No. 6, pp. 420-427, June 1972 .

6-13. JANNAF Rocket Engine Performance Test Data Acquisition and Interpretation Manual, CPIA Publication 245, Apr11 1975.

6-14. Arbit, H. A., and Clapp, S. D., Fluorine-Hydrogen Performance, Phase I, Part I: Analysis. Design, and Demonstration of High Performance Injectors for the Liouid Fluorine - Gaseous Hydrogen Propellant Combination, NASA CR-54978, Rocketdyne Research Department, pp. 135-137, July 1966. 
6-15. Price, T. W., and Evans, D. D., The Status of Monopropeliant Hydrazine Technology, JPL TR 32-1227, jet Propulsion Laboratory, Pasadena, California, February 1968.

6-16. Glossary, Monopropellant Hydrazine Engine Technology, JANNAF Monopropeliant Working Group, Chemical Propulsion Information Agency, March 1976.

6-17. Beltran, M. R., and Kosvic, T. C., Rocket Propulsion Nomenclature, CPIA Publication No. 131, January 1967.

6-18. American Standard Letter Symbols for Rocket Propulsion, Pubiication Y10.14-1959; American Society of Mechanical Engineers, 1960. 


\author{
APPENDIX VI-A \\ THEORETICAL PERFORMANCE OF MONOPROPELLANT HYDRAZINE
}

This appendix presents results from thermochemical performance calculations for the decomposition of hydrazine. Theoretical specific impulse and thrust coefficient are shown as functions of percent ammonia dissociation and nozzle expansion area ratio in Figures VI-A-1 and VI-A-2. Characteristic velocity and adiabatic reaction temperature as a function of ammonia dissociation are presented in Figure VI-A-3. The ratio of specific heats at chamber conditions and the molecular weight of the product gases are shown in Figure VI-A-4.

The values used in the generation of these figures were taken from Reference VI-A-1 and extended by assuming a constant gamma expansion from the last point given in Reference VI-A-1. The chemical composition of the product gases was assumed frozen at chamber conditions and any potential condensation of ammonia during the expansion was ignored. Specific impulse and thrust coefficient were calculated assuming zero divergence loss.

A stagnation pressure of $1030 \mathrm{kN} / \mathrm{m}^{2}$ ( $150 \mathrm{psi}$ ) was used for all results presented here. The effect on the calculated values of varying the pressure is quite small over the range of operating conditions ut1lized by most monopropellant hydrazine thrusters; however, tabular results at various stagnation pressures are presented in Reference VI-A- 1 .

\title{
REFERENCE
}

VI-A-1. Lee, D. H., Performance Calculations for Monopropellant Hydrazine and Monopropellant Hydrazine - Hydrazine Nitrate Mixtures, JPL TR 32-348, Jet Propulsion Laboratory, Pasadena, California, December 3, 1962. 


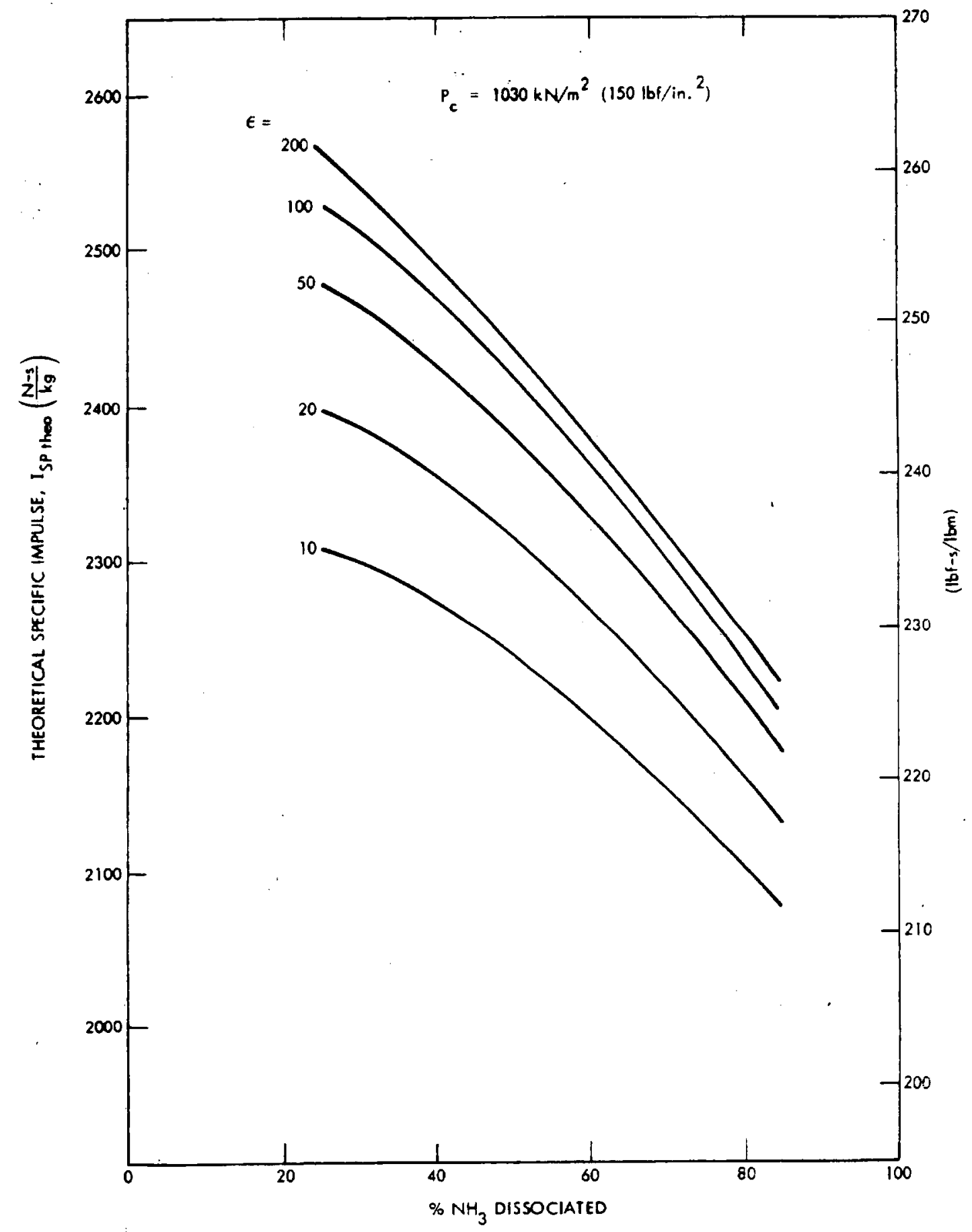

Figure VI-A-1. Theoretical Specific Impulse for Monopropellant Hydrazine 


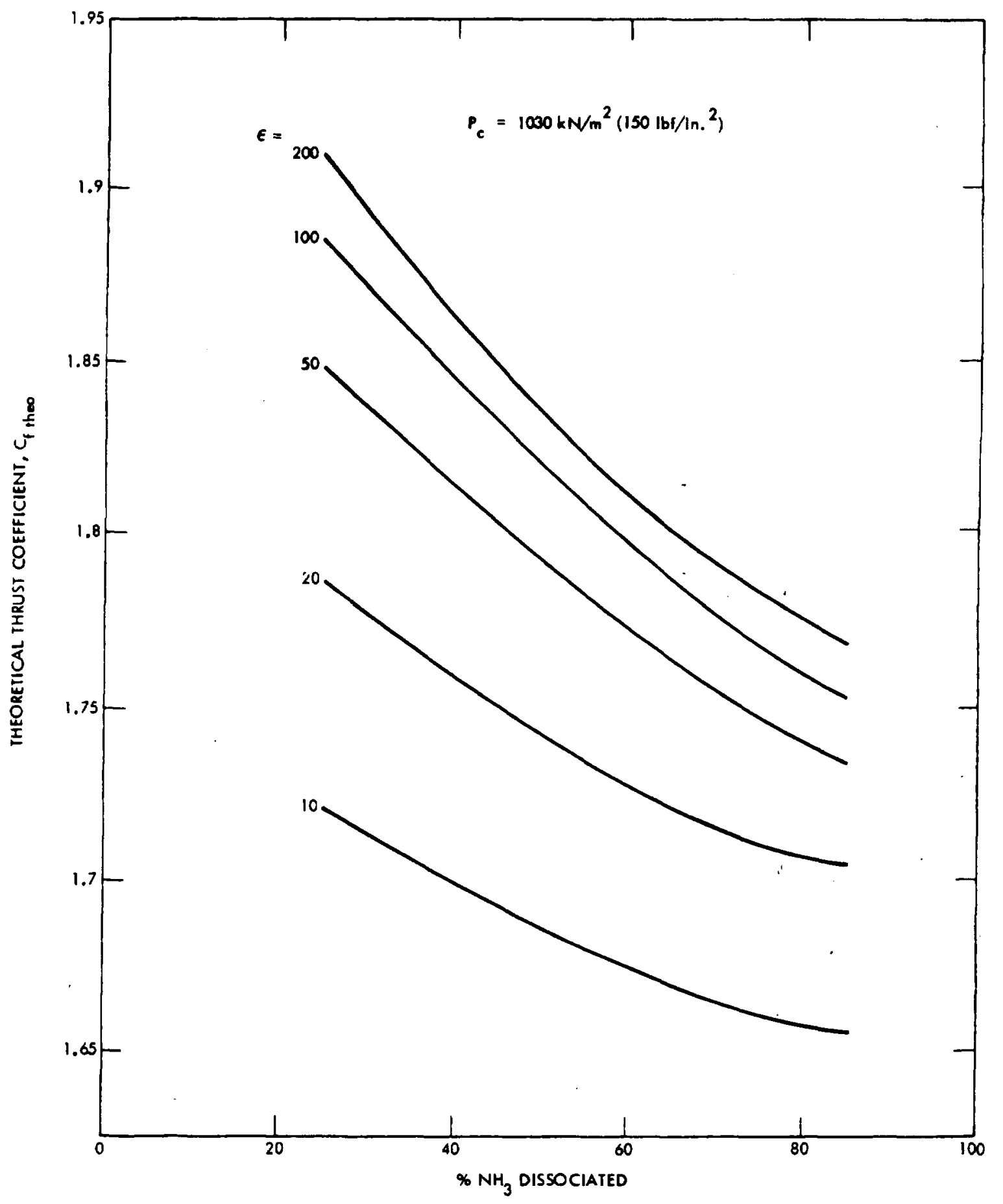

Figure VI-A-2. Theoret1cal Thrust Coefficlent for Monopropellant Hydrazine 


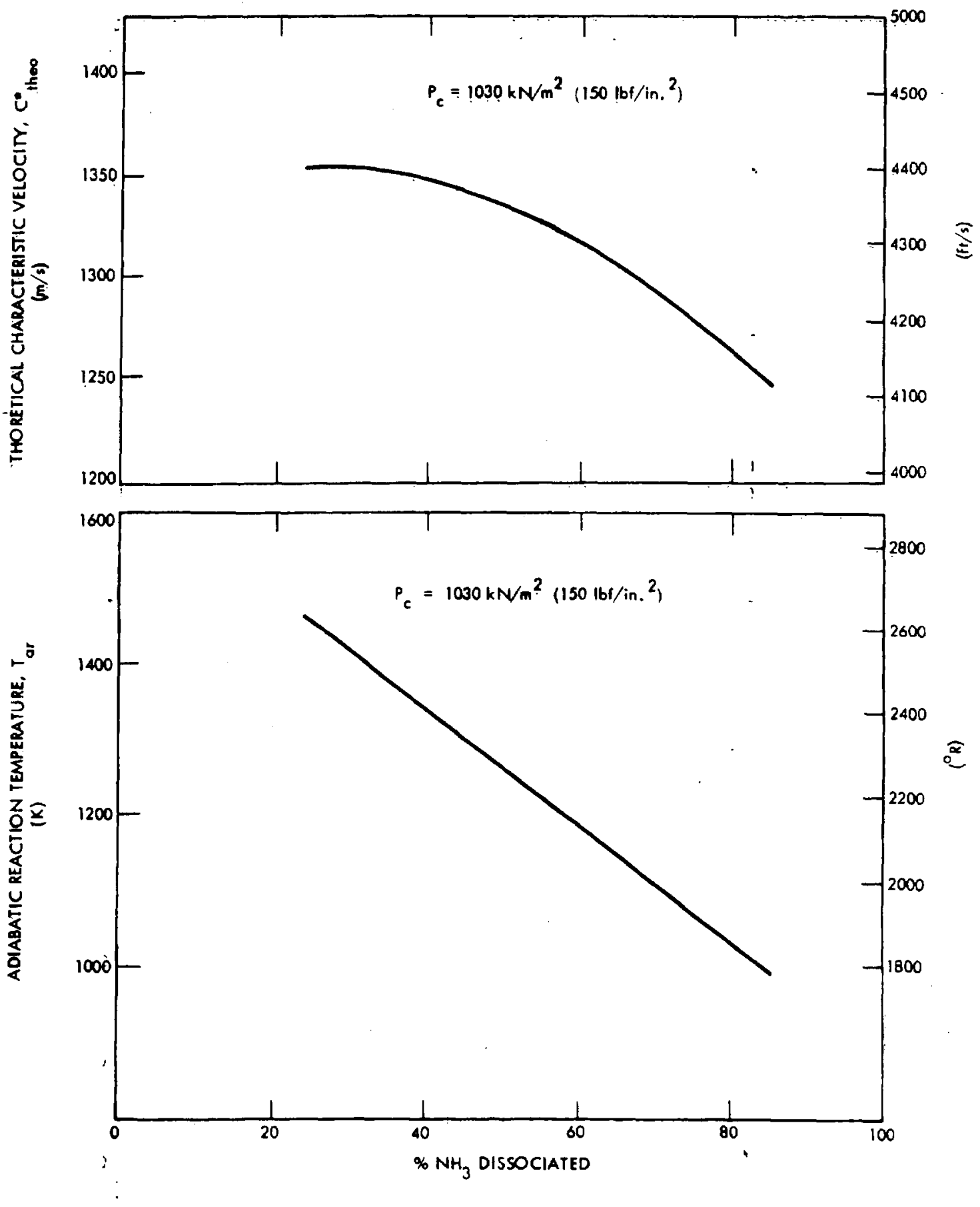

Figure VI-A-3. Theoretical Characteristic Velocity and Adiabatic Reaction Temperature for Monopropellant Hydrazine 

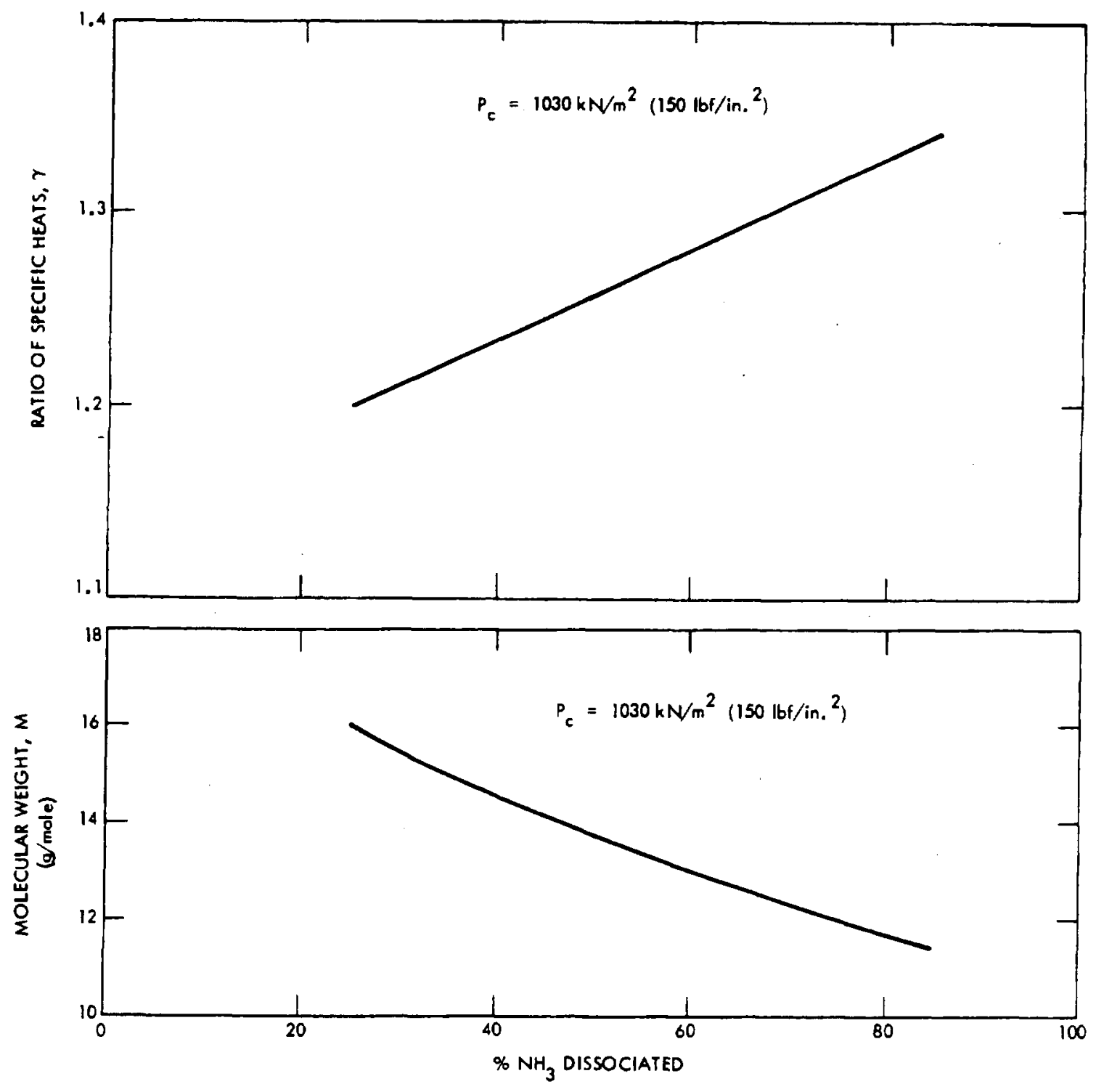

Figure VI-A-4. Ratio of Specific Heats and Molecular Weight of Product Gases at Chamber Conditions for Monopropellant Hydrazine 
Thrusters which are operated while firing in an outward radial direction from a spinning platform lose a portion of the total impulse due to the fact that the impulse is delivered over a finite angle (Figure $V 1-B-1$ ). The rotational terms which describe thruster operation in this situation are discussed below.

ROTATIONAL EFFICIENCY

Rotational efficiency is a measure of the efficiency with which impulse is delivered along a given radial direction from a platform which is spinning at a rotational angular velocity of $\omega \mathrm{rad} / \mathrm{s}$. It may be calculated for a single pulse $\left(\eta_{R}\right)$ and for a train of pulses $\left(\eta_{\mathrm{RT}}\right)$ as follows:

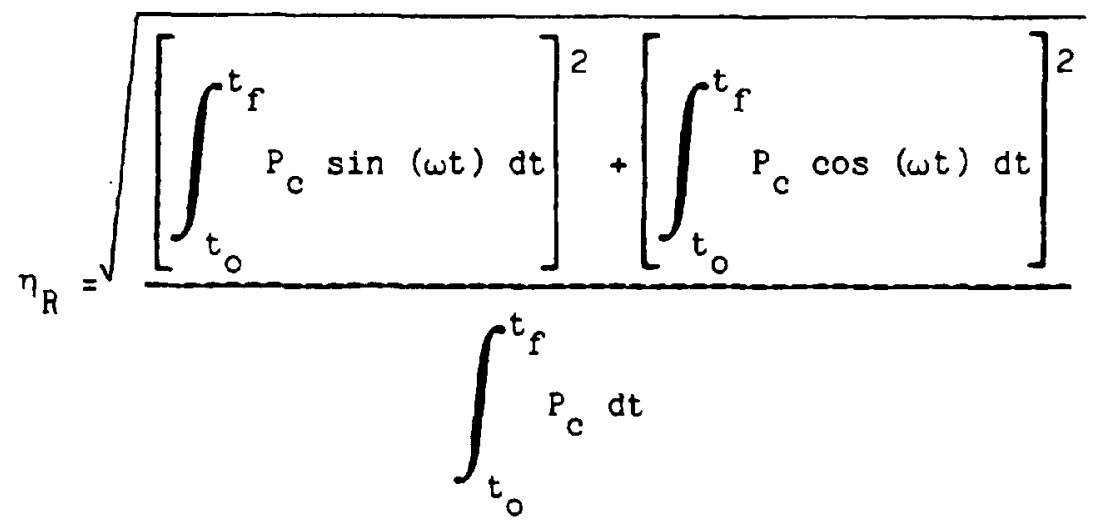

and

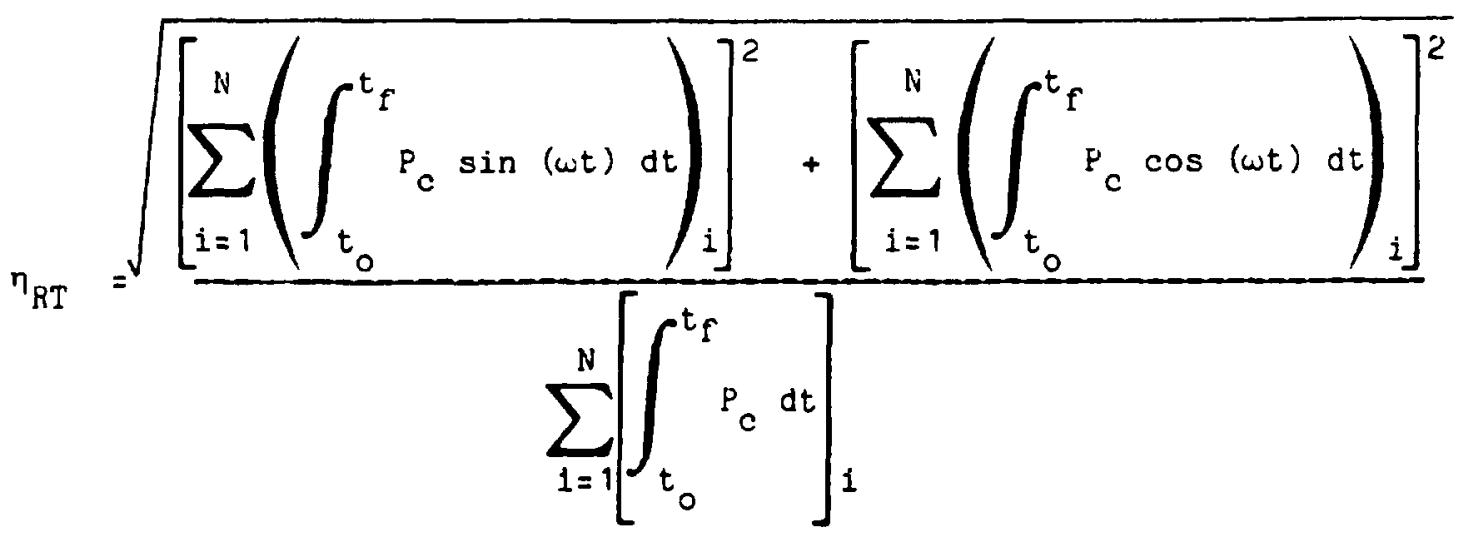

